\title{
Chemical Heterogeneity of Humic Substances and its Impact on Metal Complexation in Natural Waters
}

\author{
by
}

\section{Parthasarathi Chakraborty}

\author{
M. Tech \\ Cochin University of Science and Technology \\ India
}

A thesis submitted to the Faculty of Graduate Studies and Research

in partial fulfillment of the requirements for the degree of

Doctor of Philosophy

Department of Chemistry

Carleton University

Ottawa, Ontario

Canada

(C) copyright

2007, Parthasarathi Chakraborty 


$\begin{array}{ll}\begin{array}{l}\text { Library and } \\ \text { Archives Canada }\end{array} & \begin{array}{l}\text { Bibliothèque et } \\ \text { Archives Canada }\end{array} \\ \begin{array}{l}\text { Published Heritage } \\ \text { Branch }\end{array} & \begin{array}{l}\text { Direction du } \\ \text { Patrimoine de l'édition }\end{array} \\ \begin{array}{l}\text { 395 Wellington Street } \\ \text { Ottawa ON K1A ON4 }\end{array} & \begin{array}{l}\text { 395, rue Wellington } \\ \text { Ottawa ON K1A ON4 } \\ \text { Canada }\end{array}\end{array}$

Your file Votre référence ISBN: 978-0-494-33484-3 Our file Notre référence ISBN: 978-0-494-33484-3

NOTICE:

The author has granted a nonexclusive license allowing Library and Archives Canada to reproduce, publish, archive, preserve, conserve, communicate to the public by telecommunication or on the Internet, loan, distribute and sell theses worldwide, for commercial or noncommercial purposes, in microform, paper, electronic and/or any other formats.

The author retains copyright ownership and moral rights in this thesis. Neither the thesis nor substantial extracts from it may be printed or otherwise reproduced without the author's permission.
AVIS:

L'auteur a accordé une licence non exclusive permettant à la Bibliothèque et Archives Canada de reproduire, publier, archiver, sauvegarder, conserver, transmettre au public par télécommunication ou par l'Internet, prêter, distribuer et vendre des thèses partout dans le monde, à des fins commerciales ou autres, sur support microforme, papier, électronique et/ou autres formats.

L'auteur conserve la propriété du droit d'auteur et des droits moraux qui protège cette thèse. $\mathrm{Ni}$ la thèse ni des extraits substantiels de celle-ci ne doivent être imprimés ou autrement reproduits sans son autorisation.
In compliance with the Canadian

Privacy Act some supporting forms may have been removed from this thesis.

While these forms may be included in the document page count, their removal does not represent any loss of content from the thesis.
Conformément à la loi canadienne sur la protection de la vie privée, quelques formulaires secondaires ont été enlevés de cette thèse.

Bien que ces formulaires aient inclus dans la pagination, il n'y aura aucun contenu manquant.

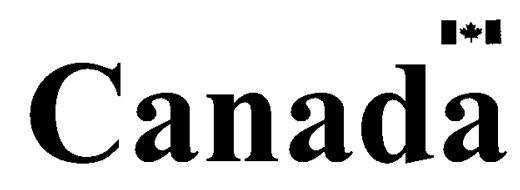




\begin{abstract}
The objective of this research was to achieve a better understanding of the effects of chemical heterogeneity of humic substances (HS) on their complexation of metals in natural waters. The apparent stability and lability of metal-HS complexes were found to be dependent on the metal loading and heterogeneity of the humic substance. Heterogeneity was found to play a crucial role in metal-DOC interactions and to control trace metals competitions with target metals in natural waters. Anodic Stripping Voltammetry with Hanging Mercury Drop Electrode was used to investigate the Differential Equilibrium Function (DEF) and the heterogeneity parameters of metal-HS complexes in natural waters. The heterogeneity of metal-HS complexes was also investigated by kinetic speciation of the metals. Dissociation rate coefficients of metalHS complexes were studied in order to determine the effects of heterogeneity of HS in metal-contaminated natural waters collected from Sudbury, Ontario. The kinetic speciation approach also revealed that the stability of metal-DOC complexes increased with the increase in heterogeneity of humic substances and with low metal loading (low $[\mathrm{M}] /[\mathrm{DOC}]$ mole ratio). It was found that HS had different heterogeneity for different metals because of the availability of different complexing sites to different metals. This study also included investigation of the nature of metal-DOC bonding, covalence and electrovalence and their strengths (stability constants) in model solutions and in natural waters. Competing Ligand Exchange Method (CLEM) along with Adsorptive Stripping Voltammetry (AdSV) or Graphite Furnace Atomic Absorption Spectrometry (GFAAS) were used to investigate the reaction kinetics. Diffusive Gradients in Thin films (DGT) technique was also used to investigate the physical heterogeneity of HS.
\end{abstract}




\section{ACKNOWLEDGEMENTS}

I express my sincere gratitude to my supervisor Prof. C. L. Chakrabarti, who not only served as my supervisor but also encouraged and challenged me throughout my academic program. I am indebted to him for his invaluable guidance. I should also like to express my gratitude to Prof. Herman P. van Leeuwen and Prof. Raewyn M. Town for their invaluable insight into different aspects of my graduate research and their comments and suggestions.

I also wish to thank the many graduate students and visiting scientists that have passed through Prof. Chakrabarti's laboratories during my stay. In particular, Jeff Guthrie and Cathy Murimboh deserve special mention for many helpful discussions on my research project. Jeff helped me learn the ropes during my first year as a graduate student at Carleton University. I express my sincere gratitude to John Murimboh, Ismail Al Fasfous, Rong Wang, Jiujiang Zhao, Yamini Gopalapillai, Tahir Yapici, Andrew Deng, Min Yang, Mark Pereira and Sheren Boca, for their scientific discussions. Additionally, I express my sincere gratitude to Vimal for her unconditional love and affections and making my stay possible in Canada.

Finally, I wish to express my most sincere gratitude to my family; especially to my parents, my brother and Sucharita for their unconditional love and their unbounded confidence in me through fair weather and foul. 


\section{Table of Contents}

Abstract......................................................... iii

Acknowledgements.......................................... iv

Table of Contents............................................ v $\mathrm{v}$

List of Figures................................................. viii

List of Tables........................................... xi

1 Introduction 1

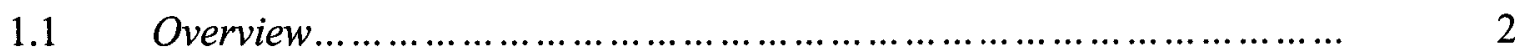

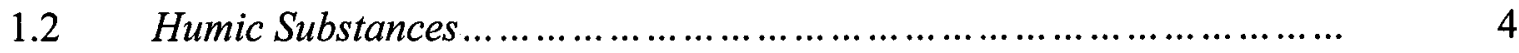

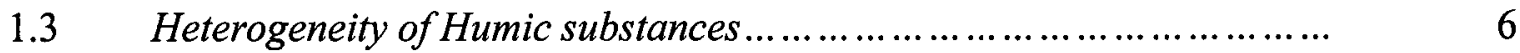

1.4 Interactions between Metal and Humic Substances............................

$1.5 \quad$ Interactions between metals and aquatic organisms.........................

$1.6 \quad$ Chemical Speciation ................................................................

$1.7 \quad$ Methods for determination of speciation parameters ..........................

$1.8 \quad$ Windermere Humic Aqueous Model VI (WHAM VI) .........................

Significance of mine and municipal effluent samples from Sudbury and

1.9 freshwater samples from Rouyn Noranda area for metal speciation study

$1.1 \quad$ Effect of metals in human health ..............................................

1.11 Hypothesis and Objectives.................................................. 21

1.13 Outline of the thesis......................................................... 22

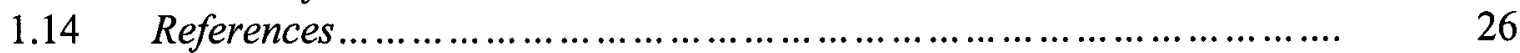

Kinetic speciation of $\mathrm{Ni}$ (II) bound to DOC in mine effluents

2 by Competing Ligand Exchange Method using AdCSV and GFAAS: $A$ validation of the kinetic model 31

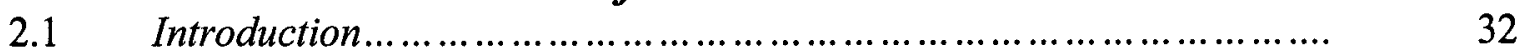

$2.2 \quad$ Kinetic Model ................................................................

2.3 Experimental............................................................ 36

2.3.1 Reagents and Chemicals..................................................

2.3.2 Analytical Methods.......................................................

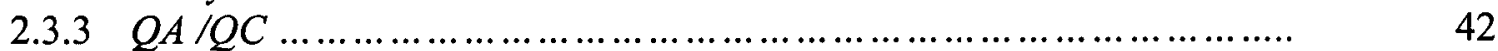

$2.4 \quad$ Sampling Sites.......................................................... 42

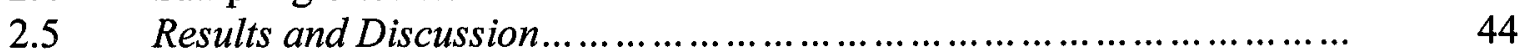

2.5.1 Kinetic speciation of nickel by CLEM/AdCSV.............................

2.5.2 Kinetic speciation of nickel by CLEM/GFAAS.............................. 52

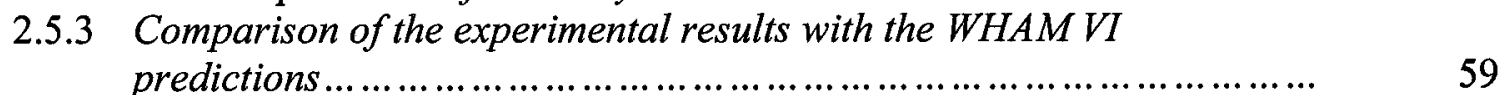

2.6 Conclusions 64

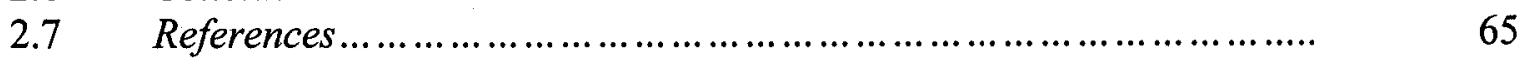

3 Chemical speciation of $\mathrm{Co}, \mathrm{Ni}, \mathrm{Cu}$, and $\mathrm{Zn}$ in mine effluents 


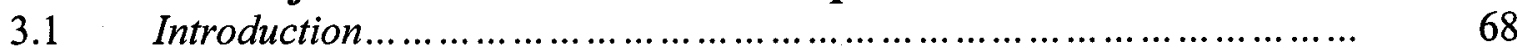

3.2 Experimental........................................................... 69

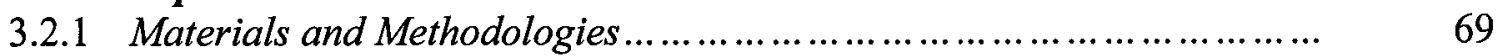

3.2.2 Instrumental and experimental conditions ..................................

3.3 Results and Discussion..................................................... 73

3.3.1 Effect of competition of major cation, $\mathrm{Ca}^{2+}$, on Ni and $\mathrm{Cu}$ binding by DOC in aqueous solutions..................................................... 90

3.3.2 Effect of heterogeneity of humic substances on metal speciation in mine effluents .................................................................... 98

3.3.3 Comparison of the experimental results with the WHAM VI predictions.... 100

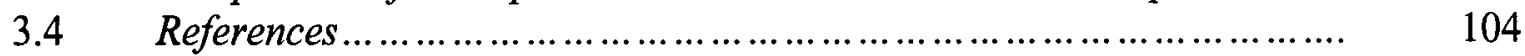

Determination of copper and nickel speciation in mine

4 aqueous effluents by Diffusive Gradient In Thin Film (DGT) technique

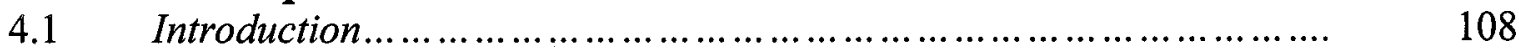

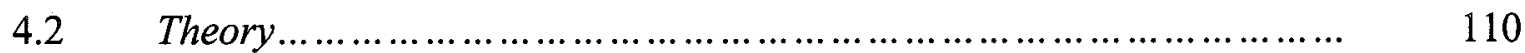

4.3 Experimental.............................................................. 112

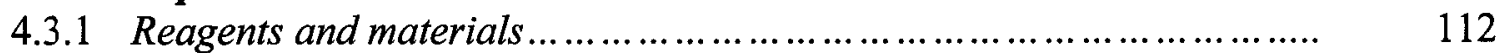

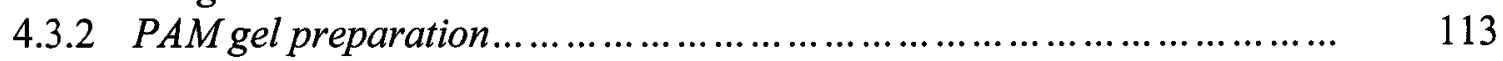

4.3.3 Chelex gel preparation ........................................................ 113

4.3.4 Materials and Methods ................................................... $\quad 114$

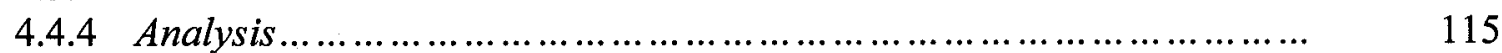

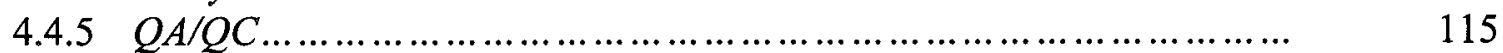

4.5 Results and Discussion...................................................... 116

4.6 Conclusions ........................................................ 132

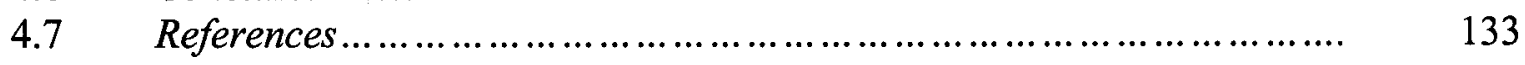

Simultaneous determination of speciation parameters of $\mathrm{Cu}, \quad 135$

$5 \quad \mathrm{~Pb}, \mathrm{Cd}$ and $\mathrm{Zn}$ in model solutions of Suwannee River Fulvic Acid by Scanned Stripping Voltammetry

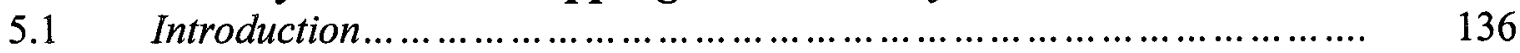

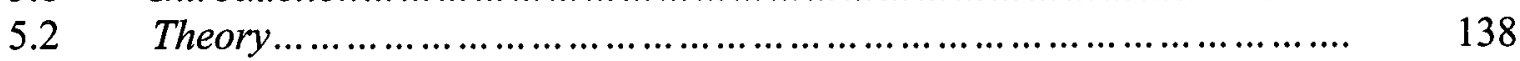

5.2.1 Scanned Stripping Voltammetry .............................................. 138

5.2.2 Differential Equilibrium Function (DEF) .................................... 140

5.2.3 Diffusion coefficients................................................................ 141

5.3 Experimental............................................................... 142

5.3.1 Materials and Methodology.................................................... $\quad 142$

5.3.2 Suwannee River Fulvic Acid Model Solutions ................................. 142

5.3.3 Reagents .......................................................................... 143

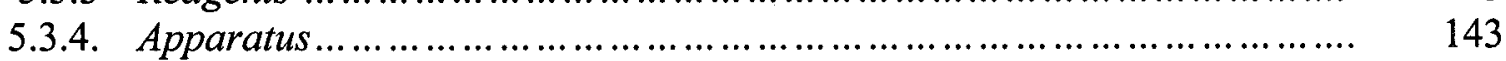

5.3.5 Electrochemical parameters................................................... 144

$5.4 \quad$ Results and Discussion ........................................................... 


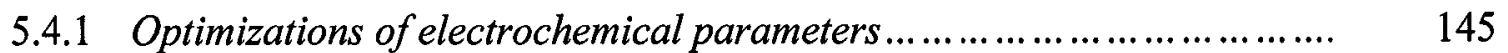

5.4 .2 Deposition time......................................................... 145

5.4 .3 Step potential ............................................................ 147

5.4 .4 Modulation amplitude....................................................... 148

5.4.5 Effect of formation of intermetallic compounds.......................... 150

5.4.6 Peak height versus peak area............................................. 153

5.5 Simultaneous determination of speciation parameters in -Suwannee River Fulvic Acid (SRFA) model solutions of these four metals............. 156

5.5.1 Speciation parameters of $\mathrm{Cu}$ in model solutions........................... 156

5.5.2 Speciation parameters of $\mathrm{Zn}$ in model solution........................... 160

5.5.3 Speciation parameters of Cd in model solution........................... 163

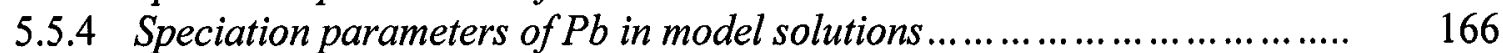

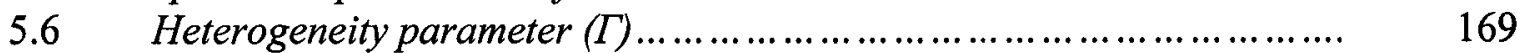

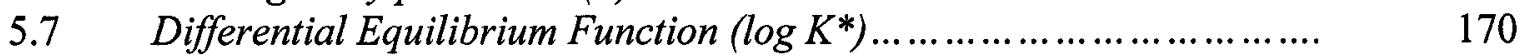

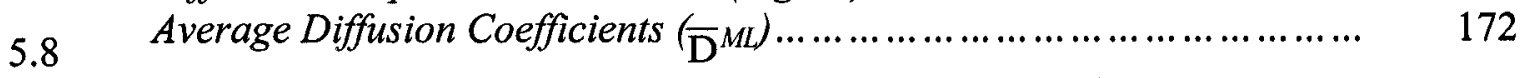

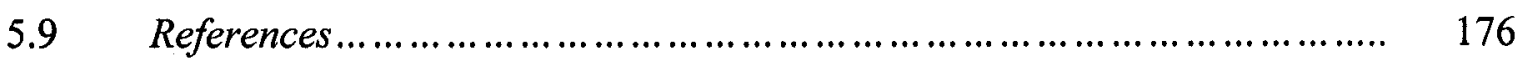

Complexation of Lead in Model Solutions of Suwannee River $\quad 180$

6 Fulvic Acid (SRFA): Heterogeneity and Effects of Competition by Copper, Zinc and Cadmium

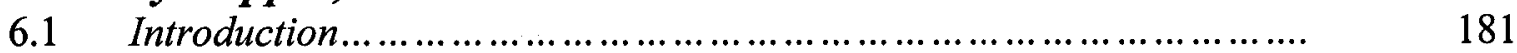

6.2 Experimental........................................................ 186

6.2.1 Materials and Methodology ............................................... 186

6.2.2 Model Solutions of Suwannee River Fulvic Acid............................ 186

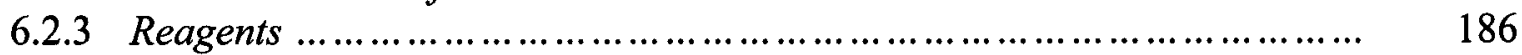

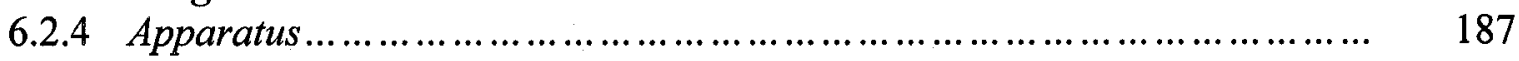

6.3 Results and Discussion...................................................... 188

6.3.1 Effect of varying concentrations of SRFA on Pb(II) complexations........ 188

6.3.2 Effect of Cu(II), Cd(II), and Zn(II) on Pb(II)-SRFA Complexation.......... 196

$6.4 \quad$ References.............................................................. 204

7 Conclusions $\quad 207$

$7.1 \quad$ Overall Conclusion................................................... 208 


\section{List of Figures}

Figure 1.1 Conceptual model of metal-organism interactions.................. 9

Figure 1.2 Conceptual diagram of the Biotic Ligand Model (BLM)............. 10

Figure 1.3 Two limiting cases for control of metal binding to transporters..... 11

Figure 2.1 Experimental set-up for kinetic experiments..................... 39

Figure 2.2 Map of the sampling area of Sudbury, Ontario and the mines investigated............ 43

Figure 2.3 The percentage of $\mathrm{Ni}(\mathrm{II})$ released $\left(i_{p} / i_{o}\right) \%$ from $\mathrm{Ni}(\mathrm{II})$-DOC complexesin mine effluent water samples, determined by CLEM/AdSV

Figure 2.4 The effect of dilution on speciation of Ni(II)-DOC complexes in Copper Cliff Mine Effluent, determined by CLEM/AdCSV

Figure 2.5 The percentage of Ni(II) released from Ni(II)-DOC complexes in mine effluent water samples, determined by

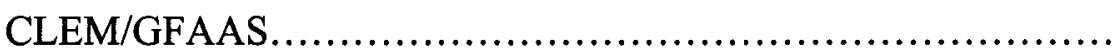

Figure 2.6 The effect of dilution on speciation of Ni(II)-DOC complexes in Copper Cliff Mine Effluent, determined by CLEM/GFAAS..........

Figure 2.7 The effect of nickel-to-DOC mole ratio on the fast dissociating component $\left(\% \mathrm{C}_{1}\right)$ of $\mathrm{Ni}(\mathrm{II})$-DOC complexes in mine effluent water samples.

Figure 2.8 Comparison of the pNi labile predicted by WHAM VI, with the measured concentrations of labile $\mathrm{Ni}(\mathrm{II})$-complexes in mine effluent.

Figure 3.1 Ligand exchange kinetics for Ni(II)-DOC complexes in the undiluted and the diluted effluent

Figure 3.2 Ligand exchange kinetics for $\mathrm{Co}$ (II)-DOC complexes in the undiluted and the diluted effluent.

Figure 3.3 Ligand exchange kinetics for $\mathrm{Cu}(\mathrm{II})$-DOC complexes in the undiluted and the diluted effluent.

Figure 3.4 Ligand exchange kinetics for $\mathrm{Zn}$ (II)-DOC complexes in the 
undiluted and the diluted effluent....................................

Figure 3.5 Effect of $\mathrm{Ca}^{2+}$ concentrations, on the $\%$ of $\mathrm{Ni}(\mathrm{II})$ release from $\mathrm{Ni}$ HA complexes in a model solution...

Figure 3.6 Effect of $\mathrm{Ca}^{2+}$ concentrations, on the \% of $\mathrm{Cu}(\mathrm{II})$ release from $\mathrm{Cu}$ HA complexes in a model solution.

Figure 3.7 Comparison of the WHAM VI predicted pMetal with the measured concentration of labile metal complexes in the undiluted $(100 \%)$ effluent sample collected from Copper Cliff mine, Sudbury, Canada.

Figure 3.8 Comparison of the WHAM VI predicted pMetal with the measured concentration of labile metal complexes in the diluted (45\%) effluent sample collected from Copper Cliff mine, Sudbury, Canada.

Figure 4.1 Representation of the concentration of free metal ion species in a DGT device and adjacent water during deployment.

Figure 4.2 Schematic representation of a section through the DGT assembly.

Figure 4.3 Plot of measured mass of $\mathrm{Cu}$ accumulated in the binding gel of DGT vs time (h) at $25^{\circ} \mathrm{C}$

Figure 4.4 Plot of measured mass of $\mathrm{Ni}$ accumulated in the binding gel of DGT vs time (h) at $25^{\circ} \mathrm{C}$

Figure 4.5 Plot of measured mass of $\mathrm{Cu}$ accumulated in the binding gel of DGT as a function of the thickness of the diffusive gel in the DGT device at $25^{\circ} \mathrm{C}$.

Figure 4.6 Plot of measured mass of $\mathrm{Ni}$ accumulated in the binding gel of DGT as a function of the thickness of the diffusive gel in the DGT device at $25^{\circ} \mathrm{C}$.

Figure 5.1 Effect of deposition time on peak currents ( $i_{p}$ ) of M(II)-SRFA complexes.

Figure 5.2 Effect of step potential on peak currents ( $\left.i_{p}\right)$ of M(II)-SRFA Complexes

Figure 5.3 Effect of modulation amplitude on peak currents $\left(i_{p}\right)$ of M(II)-SRFA 
complexes.

Figure 5.4 Effect of deposition time on peak currents ( $\mathrm{i}_{\mathrm{p}}$ ) of $\mathrm{Cu}(\mathrm{II})$ when intermetallic compounds are formed in a solution of metal mixture

Figure 5.5 Effect of deposition time on peak currents ( $\mathrm{i}_{\mathrm{p}}$ ) of $\mathrm{Zn}$ (II) intermetallic compounds are formed in a solution of metal mixture

Figure 5.6 Effect of deposition potential on the ratio of peak area and peak height.

Figure 5.7 Voltammogram of $\mathrm{Cu}(\mathrm{II}), \mathrm{Zn}(\mathrm{II}), \mathrm{Cd}(\mathrm{II})$ and $\mathrm{Pb}(\mathrm{II})$ under the experimentally optimized conditions

Figure 5.8 Effect of deposition potential on the release $\left(i_{p} / i_{0}\right)$ of metal from the $\mathrm{Cu}$ (II)-SRFA complex with the $\mathrm{Cu} / \mathrm{SRFA}$ mole ratio as a parameter.

Figure 5.9 Effect of deposition potential on the release $\left(i_{p} / i_{0}\right)$ of metal from the $\mathrm{Zn}$ (II)-SRFA complex with the $\mathrm{Zn} / \mathrm{SRFA}$ mole ratio as a parameter.

Figure 5.10 Effect of deposition potential on the release $\left(i_{p} / i_{o}\right)$ of metal from the $\mathrm{Cd}(\mathrm{II})$-SRFA complex with the $\mathrm{Cd} / \mathrm{SRFA}$ mole ratio as a parameter.

Figure 5.11 Effect of deposition potential on the release $\left(i_{p} / i_{o}\right)$ of metal from the $\mathrm{Pb}$ (II)-SRFA complex with the $\mathrm{Pb} / \mathrm{SRFA}$ mole ratio as a parameter

Figure 6.1 Typical pseudo-polarograms for $\mathrm{Pb}$ (II)-FA complexes in model

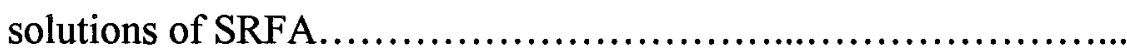

Figure 6.2 Differential equilibrium function of $\mathrm{Pb}(\mathrm{II})-\mathrm{SRFA}$ complexes in

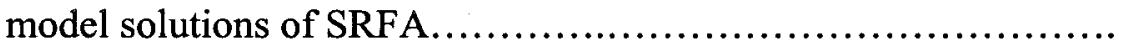

Figure 6.3 Competition effect of trace metals on the pseudo-polarographic waves of $\mathrm{Pb}(\mathrm{II})-\mathrm{SRFA}$ complexes in model solutions. 


\section{List of Tables}

Table 2.1 Optimized electrochemical parameters for the determination of kinetic speciation of nickel in Sudbury mining and municipal effluents by Square Wave Adsorptive Stripping Voltammetry ........

Table 2.2 Optimized Ashing and Atomization Temperatures for Determination of Nickel in Mine Effluents by Graphite Furnace Atomic Absorption Spectrometry

Table 2.3 Some chemical properties of the mine effluent water samples collected from Sudbury area, Ontario.

Table 2.4 Some important chemical properties of the mining and municipal effluent samples

Table 2.5 Kinetically distinguishable components of nickel speciation by CLEM/AdCSV.

Table 2.6 Kinetically distinguishable components of nickel speciation by CLEM/GFAAS.

Table 2.7 WHAM model predictions of the speciation of nickel and the measured concentrations of labile Ni(II)-DOC complexes in mine effluent water samples from the Sudbury area, Ontario.

Table 3.1 Characteristics of the undiluted (100\%) and the diluted (45\%) effluent

Table 3.2 Composition of the undiluted (100\%) and the diluted (45\%) effluent

Table 3.3 Change in the $[$ Metal]/[DOC] mole ratio on the dilution of the effluent with the tap water.

Table 3.4 Kinetically distinguishable components of $\mathrm{Co}-\mathrm{Ni}-\mathrm{Cu}$ - and $\mathrm{Zn}$ DOC complexes in the undiluted (100\%) effluent.................

Table 3.5 Kinetically distinguishable components of Co-, $\mathrm{Ni}-\mathrm{Cu}$ - and $\mathrm{Zn}-$ DOC complexes in the diluted (45\%) effluent..................... 87

Table 3.6 Effect of $\left[\mathrm{Ca}^{2+}\right]$ on the lability of Ni-HA complexes................ 93

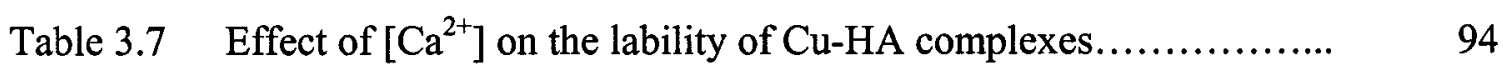


Table 4.1 Some chemical characteristics of undiluted (100\%) and diluted (45\%) effluent

Table 4.2 Chemical speciation of Cu-DOC complexes in diluted and in undiluted Copper Cliff Mine aqueous effluents obtained by DGT technique.

Table 4.3 Chemical speciation of Ni-DOC complexes in diluted and in undiluted Copper Cliff Mine aqueous effluents obtained by DGT technique

Table 4.4 Comparison of the labile metal fraction determined by DGT with the labile metal fraction determined by CLEM/AdCSV.

Table 5.1 Effect of decreasing mole ratios of $\mathrm{C}_{\mathrm{M}, \mathrm{T}} / \mathrm{C}_{\mathrm{SRFA}}$ on the Differential Equilibrium Functions, mean diffusion coefficients and heterogeneity of $\mathrm{Cu}$ (II)-SRFA complexes in model solutions of SRFA

Table 5.2 Effect of decreasing mole ratios of $\mathrm{C}_{\mathrm{M}, \mathrm{T}} / \mathrm{C}_{\mathrm{SRFA}}$ on the Differential Equilibrium Functions, mean diffusion coefficients and heterogeneity of $\mathrm{Zn}(\mathrm{II})-\mathrm{SRFA}$ complexes in model solutions of SRFA.

Table 5.3 Effect of decreasing mole ratios of $\mathrm{C}_{\mathrm{M}, \mathrm{T}} / \mathrm{C}_{\mathrm{SRFA}}$ on the Differential Equilibrium Functions, mean diffusion coefficients and heterogeneity of $\mathrm{Cd}(\mathrm{II})-\mathrm{SRFA}$ complexes in model solutions of SRFA.

Table 5.4 Effect of decreasing mole ratios of $\mathrm{C}_{\mathrm{M}, \mathrm{T}} / \mathrm{C}_{\mathrm{SRFA}}$ on the Differential Equilibrium Functions, mean diffusion coefficients and heterogeneity of $\mathrm{Pb}(\mathrm{II})-\mathrm{SRFA}$ complexes in model solutions of SRFA.

Table 5.5 Comparison of diffusion coefficients of free metal ions with the four different metals-SRFA complexes in model solutions of different mole ratios of $\mathrm{C}_{\mathrm{M}, \mathrm{T}} / \mathrm{C}_{\mathrm{SRFA}}$, determined simultaneously

Table 6.1 Effect of increasing concentration of SRFA on the Differential Equilibrium Functions, mean diffusion coefficients and lability 
$\left(\mathrm{i} / \mathrm{i}_{\mathrm{lim}}\right)$ of $\mathrm{Pb}(\mathrm{II})-\mathrm{FA}$ complexes in model solutions of Suwannee River Fulvic Acid................................................

Table 6.2 Differential equilibrium functions, mean diffusion coefficients, and normalized peak current $\left(\mathrm{i} / \mathrm{i}_{\mathrm{lim}}\right)$ of $\mathrm{Pb}(\mathrm{II})-\mathrm{SRFA}$ complexes in model solutions of SRFA in the presence of various competing metals $\mathrm{Cu}(\mathrm{II}), \mathrm{Zn}(\mathrm{II})$, and $\mathrm{Cd}(\mathrm{II})$ 
1

Introduction

Reproduced with permission of the copyright owner. Further reproduction prohibited without permission. 


\subsection{Overview}

Trace metals present as natural components in freshwaters are micronutrients for biota. Organisms require trace metals for catalysis of redox reactions, electron transport, structural functions in nucleic acid metabolism, and as cofactors for the activation of different enzymes [1]. The concentration of metals required for optimal development is species-specific, and the physico-chemical form of the metals is an important factor in determining whether the metals present in the surrounding environment are nutrients or toxicants.

In freshwaters, trace metals are present as different chemical species (chemical speciation). They can either be present in the free metal ion form or as complexed by inorganic ligands $\left(\mathrm{HCO}_{3}{ }^{-}, \mathrm{CO}_{3}{ }^{2-}, \mathrm{SO}_{4}{ }^{2-}, \mathrm{Cl}^{-}, \ldots\right)$ organic ligands (amino acids, fulvic acids, humic acids,...), or on particle surfaces (Fe-oxides, biological material,...). Most of these species are not directly taken up by the aquatic organisms and only a small fraction of the total metal concentration is bioavailable, and interacts with organisms. The bioavailability of the metal is controlled by the metal speciation [2- 5].

Laboratory studies suggest that growth and toxicity are mainly a function of the activity of the free metal ion, a postulate which inspired the development of the Free Ion Activity Model (FIAM) [3, 4]. The FIAM has been validated for a number of different metals ( $\mathrm{Cu}$, $\mathrm{Zn}, \mathrm{Mn}, \mathrm{Fe}, \mathrm{Cd}$ ), organisms, and for biological responses (growth, uptake, nutrient limitation, toxicity). However, under natural conditions, where natural organic ligands considerably modify the speciation of metals, there is a lack of knowledge about the chemical heterogeneity of humic substances and their interactions with trace metal ions in natural waters. The chemical heterogeneity of humic substances is related to the buffer intensity of the complexing system, which influences the capacity of natural waters to 
sustain life after metal pollution events. The effect of discharge of aqueous mine effluents to receiving waters (a major source of pollution of natural waters) has not been well studied. In addition, the effects of dilution of effluent by receiving waters on the speciation of trace metals are unknown. The growing awareness of strong dependence of the toxicity of heavy metals upon their chemical forms (chemical speciation) has led to an increasing interest in the qualitative and quantitative determination of specific metal species. Metal speciation has therefore become an important topic in environmental chemistry research.

The overall aim of this thesis is to provide relevant studies on the heterogeneity of humic substances and its effects on the coordination chemistry of trace metals in natural waters. The results of these studies should provide a better scientific understanding to water resource managers and decision makers, who will take into consideration also the chemical compositions of receiving waters, which will set limits on the amounts of metalcontamimated mine effluents allowable in a given system at a given time. 


\subsection{Humic Substances}

Humic substances which are natural organic matter (NOM), are major constituents of the oragnic matter in soil and natural waters. Humic substances arise by the microbial degradation of biomolecules (lipids, proteins, carbohydrates, lignin) dispersed in the environment after the death of living cells. They contribute to soil and water chemical and physical quality and are also precursors of some fossil fuels. They can also be found in peat, coal, many upland streams and in ocean water. Humic substances make up a large portion of the dark matter in humus and are complex colloidal supramolecular mixtures that have never been separated into pure components. Since the end of the 18 th century, humic substances have been designated as humic acid, fulvic acid or humin. These fractions are defined strictly on their solubility in either acid or alkali, which are operationally-defined classification, and impart no chemical information about the extracted materials. It is important to note, however, that no sharp division exists between humic acids, fulvic acids and humins. They are all part of an extremely heterogeneous supramolecular system and the differences between the subdivisions are due to variations in chemical composition, acidity, degree of hydrophobicity and self-associations of molecules. When humic substances are characterized, especially when functionality is studied, there is always the problem that one usually has to separate the huge number of different bioorganic molecules into homogenous fractions.

A modern structural description regards humic material as a supramolecular structure of relatively small bio-organic molecules (having molecular mass $<1000 \mathrm{Da}$ ) self-assembled mainly by weak dispersive forces such as van der Waals, $\pi-\pi$, and $\mathrm{CH}-\pi$ bonds into only 
apparently large molecular sizes. According to a new view of humic substances recently proposed by Sutton and Sposito [6], humic substances are collections of diverse, relatively low molecular mass components forming dynamic associations stabilized by hydrophobic interactions and hydrogen bonds. These associations are capable of organizing into micellar structures in suitable aqueous environment. A large fraction of humic substances are represented by hydrophobic compounds (long alkyl-chain alkanes, alkenes, fatty acids, sterols, terpenoids, and phenyl-alkyl residues of lignin degradation) which allow their self-association into supramolecular structures separated from the water medium and, thus, their long residence time in the natural environment. Humic substances are endowed with acidic functional groups, mainly carboxylic acids, which confer on these molecules the ability to chelate multivalent cations such as $\mathrm{Mg}^{2+}, \mathrm{Ca}^{2+}$, and $\mathrm{Fe}^{2+}$. This chelation of ions is an important role of humic acids with respect to living systems. By chelating the ions, they facilitate the uptake of these metal ions by several mechanisms: one of which is preventing their precipitation, another seems to be a direct and positive influence on their bioavailability. Heterogeneity of humic substances plays an important role in chelating these potentially toxic metals. Since heterogeneity is a major factor that obscures elucidation of molecular structures of humic substances, understanding chemical, structural, and molecular heterogeneity of humic substancess has long been a focus of environmental chemistry. 


\subsection{Heterogeneity of humic substances}

Heterogeneity of humic substances is both due to physical and chemical reasons: their heterogeneity results from the following three characteristic features:

1. Polyelectrolytic properties, due to the existence of a large number of dissociable functional groups per molecule;

2. Polyfunctionality, due to the fact that they possess within the same molecule many complexing site types with different intrinsic binding energies;

3. Very large size (compared to "simple ligands" such as inorganic anions or aminoacids), resulting in conformational changes and aggregate formation, with the possible concomitant sterical changes within the complexing sites.

For a simple ligand, heterogeneity is defined as unity, orHeterogeneity parameter $(\Gamma)=1$ (which means homogeneous). As the heterogeneity of a ligand increases, the value of $\Gamma$ decreases. For natural systems, $\Gamma$ values usually lie between 0.3 and 0.7 [7]. The same humic substance might have different heterogeneity for different metal ions for the following reasons:

1. Different complexing sites might be available to different metal ions.

2. The stabilities of the strongest and weakest sites titrated with the same metal might vary from metal to metal.

Heterogeneity of humic substances is dependent on $\mathrm{pH}$ and ionic strength, because of the availability of range of different binding sites at different $\mathrm{pH}$ and ionic strength [8]. Heterogeneity is related to the buffer intensity of the complexing system, which influences the capacity of natural waters to sustain life after metal pollution events. 


\subsection{Interactions between Metals and Humic Substances}

Dissolved Organic Carbon (DOC) is ubiquitous in the aquatic environment. In natural waters, $50-90 \%$ of the total DOC consists of humic substances [9]. Humic substances in natural waters bind with potentially toxic metals, preventing them from becoming bioavailable and making the aquatic environment life-sustaining for biota. Humic substances in freshwaters react with metals in various ways, one of which is preventing their precipitation, and another is controlling the speciation and transport of trace metals $[10-12]$

In general terms, humic substances can be described as supramolecular associations of aromatic and aliphatic residues carrying carboxyl, phenolic and alkoxy group, although sulphate, ester, alanine, semiquinones, phosphate ester, and other moieties have been proposed for some humic isolates. The major functional groups in humic substances are $\mathrm{COOH}$, phenolic-OH, and alcoholic-OH groups. It has been reported that in humic substances, $\sim 60-90 \%$ of the acid groups are carboxylic and the remainder are phenolic [13]. These acid groups are weak binding sites, which comprise between $90-99 \%$ of the total binding sites on humic substances and form weak metal-humate complexes. The remaining $\sim 1-10 \%$ of the total binding sites are strong binding sites, which from strong metal-humate complexes.

The extent of metal complexation to humic substances in natural waters can be close to $100 \%$ for very reactive metals such as copper [14]. However, the extent of metal complexation varies from metal to metal, and depends on the nature of the humic 
substances and on the competition of other trace metals with the target metal for the binding sites of humic substances [15-18].

Dissolved Organic Carbon (DOC), conctitutes about $40-80 \%$ of humic substances in natural waters, are used as surrogates of humic substances in study of interactions of humic substances with metals in natural waters.

In natural waters, complexation of trace metals by humic substances may be influenced by major cations [19] such as sodium, potassium, calcium and magnesium, which may be present at many orders of magnitude greater concentrations $\left(\sim 10^{-3} \mathrm{M}\right)$ than those of trace metal ions $\left(<10^{-8} \mathrm{M}\right)$; their much greater concentrations outweigh their weaker metalbinding ability. The literature contains several reports of experimental studies on the competition of major cations such as calcium and magnesium with trace metals such as copper and nickel for binding by humic substances [20-23]. Calcium has been reported to have no competitive effect on $\mathrm{Cu}(\mathrm{II})$-humate binding under the experimental conditions used by Morel and Hering [24]. They concluded that different binding sites on the humate ligand must be involved in the calcium and copper binding. It has been reported by Cao et al. [20] that calcium does have a measurable effect on the binding of trace metals such as $\mathrm{Cd}, \mathrm{Pb}$ and $\mathrm{Cu}$ by humic acid; the effect, however, is $\mathrm{pH}$-dependent. On the basis that calcium mainly forms outer-sphere complexes with ligands, Cao et al. [20] concluded that the effect of adding calcium may be an overall change in electrostatic interactions. However, small but measurable competitions between calcium and copper in fulvic acid titrations have been reported by Cabaniss and Shuman [21], and by Sunda and Hanson [25]. More recently, Mandal et al. [22], reported that calcium and magnesium 
strongly compete with $\mathrm{Ni}$ binding to fulvic acid. Guthrie et al. [23] have reported similar trends of humic acid at different $\mathrm{pH}$ values.

\subsection{Interactions between metals and aquatic organisms}

Interactions of trace metals with organisms are very complex and are not completely known. A conceptual model of metal-organism interactions [4] considered that internalization of a metal is divided in two steps. First, the metal present in the water, complexed or not, diffuses through the diffusive boundary layer to the cell and binds with the active sites of the cell membrane. Second, uptake of the metal by the cell occurs and the biological utilization of the metal or its accumulation in the cell follows [26, 27].

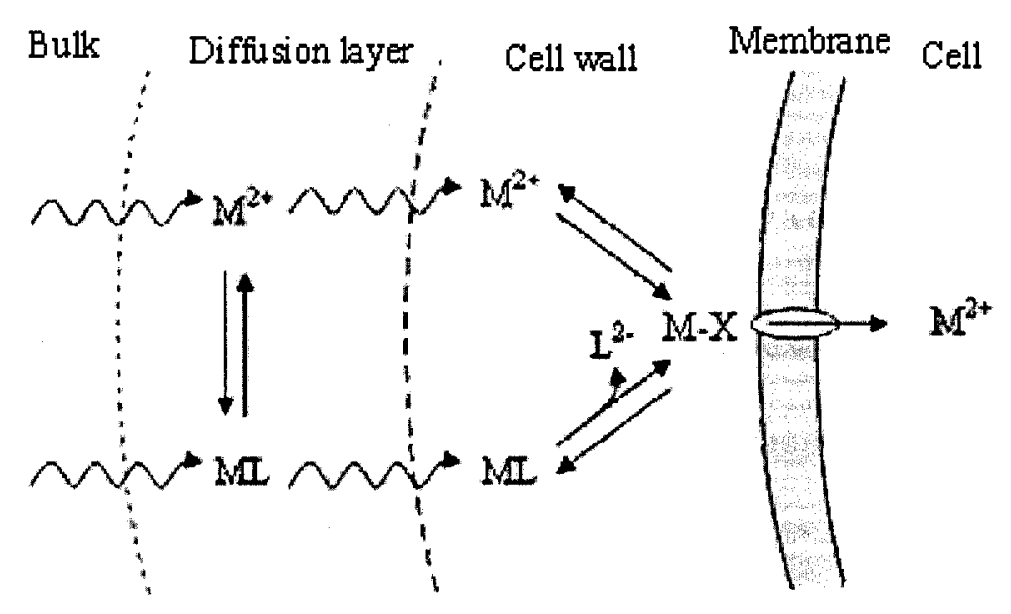

Figure 1.1: Conceptual model of metal-organism interactions (adapted from Campbell et al. 1995)

The Free Ion Activity Model (FIAM) was developed based on a convincing body of evidence that the free metal ion activity, not the total dissolved metal complexation, is the main factor influencing the bioavailability of the metal and its potential toxicity to aquatic organisms [3, 4]. Symptoms of intracelluar toxicity include ultrastructural 
deformities, and reductions in cell division rate, respiration, photosynthesis, mobility, electron transport activity and ATP production. The goal of the FIAM was to predict the bioavailability of a metal as function of its free metal ion activity in water. The formulation of FIAM and the assumptions underlying it have been critically reviewed by Campbell [4]. Considering the interaction of a free metal ion $\mathrm{M}^{2+}$ or a metal-ligand complex ML with the cell membrane forming a M-X-Cell complex (Figure 1.1), the concentration of the surface complex [M-X-Cell] is proportional to the free metal ion concentration and is independent of the metal species considered. Assuming that $[\mathrm{M}-\mathrm{X}-$ Cell] is proportional to the biological response, the $\mathrm{M}^{2+}$ concentration is the factor influencing the response of the organism. The metal transport across the cell membrane occurs through physiologically active sites [28-30].

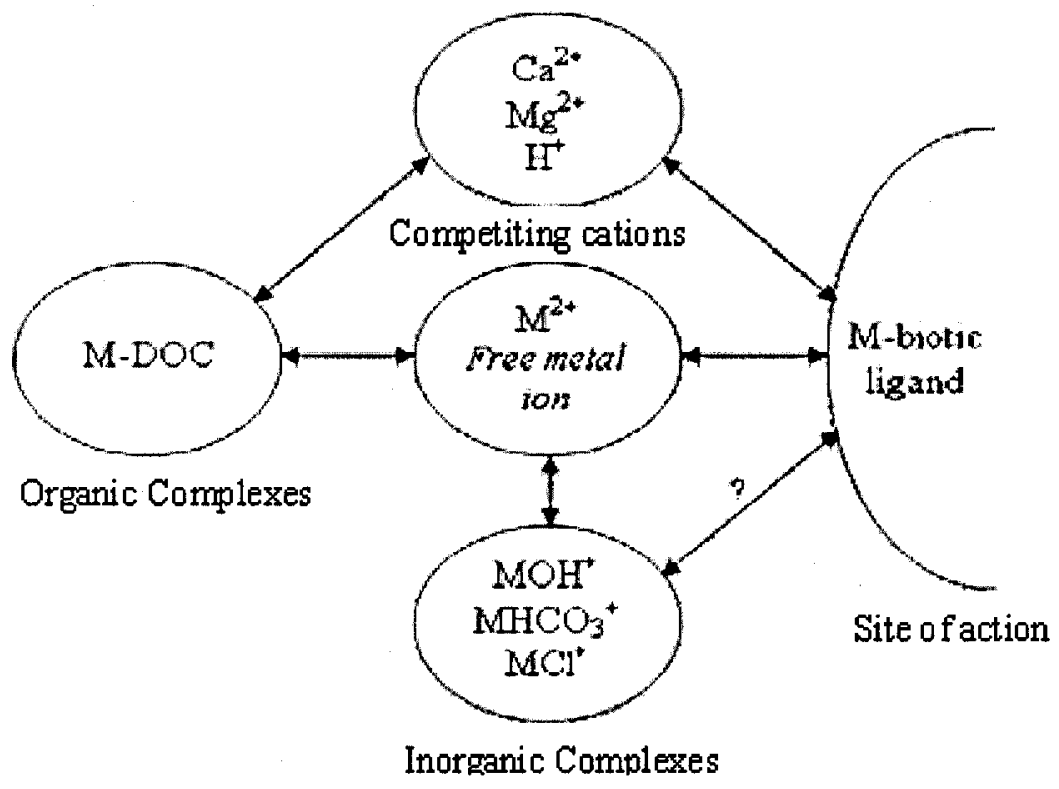

Figure 1.2: Conceptual diagram of the Biotic Ligand Model (BLM) (Adapted from Di Toro et al, 2001) 
The FIAM was developed based on results obtained in laboratory studies and was mostly focused on the metal speciation. However, the FIAM was not sufficiently focusing on the cell membrane and its interactions with the different components of water, which is essential for developing a precise model of bioavailability. In natural systems, the water chemistry is much more complex than in model system of synthetic media. Humic substances offer a large range of binding sites for dissolved metals and considerably influence metal speciation [31]. Furthermore, major metals interact with the cell membrane and influence the number of sites available for the trace metal to bind. Based on the FIAM and on its intellectual desecendent, Gill Surface Interaction Model (GSIM) [32], Biotic Ligand Model (BLM) was formulated, introducing the concept of biotic ligand.
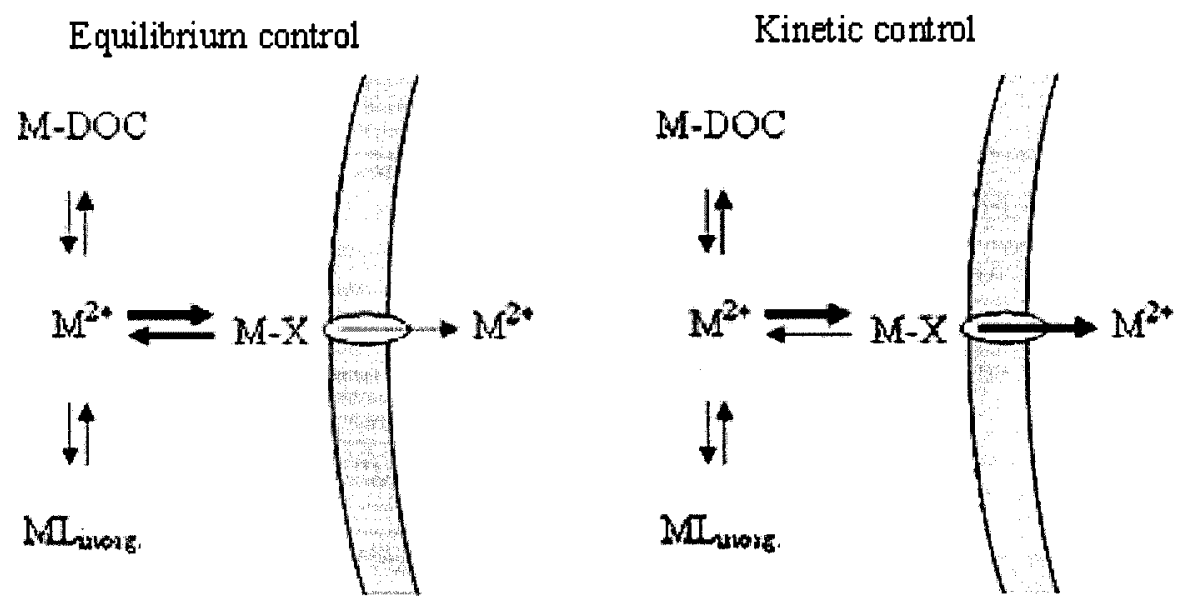

Figure 1.3: Two limiting cases for control of metal binding to transporters (Adapted from Hudson 1998) 
Biotic ligand corresponds to the site of action where the metal binds to the cell surface prior to its internalization and toxicity [33]. The BLM takes into consideration the competition between the biotic ligand and environmental ligands such as natural organic ligands (Figure 1.2). The formulation and the assumptions of the BLM are very similar to the FIAM, but the BLM considers competing cations and competing ligands [33, 30, 34]. The assumptions and limitations of the BLM were recently critically reviewed by Campbell et al. [34]. The case of the rate-limiting internalization is a critical point for the BLM. This model considers that there is no diffusion limitation from the bulk solution to the cell wall (Figure 1.1). The BLM assumes that the metal concentration at the cell wall is at chemical equilibrium with the biotic ligand. Two types of controls (Figure 1.3) are considered at the cell wall [29]. The first is "equilibrium control", in which rates of formation and dissociation of $\mathrm{M}-\mathrm{X}$-Cell with $\mathrm{M}^{2+}$ are equal and much greater than the biouptake rate. Internalization is then controlled by the equilibrium between metal bound to the biotic ligand and free metal ion concentration. The second is "kinetic control", in which the rates of formation and internalization are nearly equal and much larger than the dissociation rate. This situation implies that the metal bound to the biotic ligand is immediately internalized and that the biouptake is faster than the supply of free $\mathrm{M}^{2+}$ from the solution. The possibility of uptake rate limitation due to kinetic control was raised by Hudson in 1998 [29]. The limits of these models and the possibility of a diffusional limitation of the metal was treated theoretically in a study comparing the diffusion and uptake fluxes under different conditions [35]. It was shown that, in case of diffusion limitation, the biouptake was controlled by a labile form of the metal. 
It is well known that toxicity of elements in aquatic system depends upon their physicochemical forms. It is also well established that some metals (e.g., $\mathrm{Cr}, \mathrm{Mn}, \mathrm{Fe}, \mathrm{Co}, \mathrm{Cu}, \mathrm{Zn}$, Mo) and that metalloids (e.g., B, Si, Se) are essential for living organisms and that are necessary components of some proteins, playing important physiological function. Their excess, as well as deficiency, may have serious consequences for aquatic biota. Therefore, determination of the total content (concentration) of a selected element in the sample is not sufficient for estimation, for example, of its bioavailability and toxicity, for which the distribution of the element in various forms (i.e., its chemical speciation) is the determinant.

\subsection{Chemical speciation}

Chemical speciation: Definition of speciation term is not very clear. In the literature, it is used with different meanings, depending on the purpose and nature of the experimental work at hand. It is often used to denote detailed metal-species distribution in studies of synthetic or sufficiently simple solution, in which each metal species can be characterized.

The International Union for Pure and Applied Chemistry (IUPAC) has defined elemental speciation in chemistry as follows:

(i) Chemical Species. Chemical element: specific form of an element defined as to isotopic composition, electronic or oxidation state and/ or complex or molecular structure. 
(ii) Speciation analysis. Analytical chemistry: analytical activities of identifying and/or measuring the quantities of one or more individual chemical species in a sample.

(iii) Speciation of an element; speciation. Distribution of element amongst defined chemical species in a system.

When elemental speciation is not feasible, the term fractionation is used and is defined as follows.

(iv) Fractionation. Process of classification of an analytes or a group of analytes from a certain sample according to physical or chemical properties.

In complicated environmental samples it is most often used to denote the differentiation between groups of metal species (e.g., the whole of labile complexes, colloidal species, or complexes with natural organic matter), for which the determination of complete species distribution is not feasible. In such cases, different physicochemical forms of metal in aquatic environment can be described by several parameters, such as labile fraction, dissociation rate coefficient of M-DOC complexes, stability constant of M-DOC complexes, diffusion coefficient, and heterogeneity of humic substances. This thesis describes the importance of verifying the validity of these speciation parameters by employing different experimental techniques that can do speciation of metal complexes in natural waters. 


\subsection{Methods for determination of speciation parameters}

Determination of distinct chemical species, often referred to as speciation analysis, is now widely acknowledged to be of vital importance in environmental chemistry. Several methods are available to determine free metal ion concentrations in water. Because of the requirement of very low detection limits and extremely high analytical sensitivity for quantitative determination of very low concentrations of metals present in natural waters, only a few analytical techniques have the required analytical sensitivity and selectivity to be classified as capable.

To determine extremely low free metal ion concentrations, an indirect method, the competing ligand exchange (CLE) coupled with differential pulse anodic/cathodic stripping voltammetry/ Adsorptive Cathodic stripping voltammetry (DPASV/DPCSV/ AdCSV) is generally used [36-39]. It consists of the addition of a known ligand to sample of natural waters, followed by the determination of the labile metal concentrations, which allows the calculation of the free metal ion concentration by metal titration.

The Competing Ligand Exchange Method (CLEM) / Graphite Furnace Atomic Absorption Spectrometry (GFAAS) and CLEM / Adsorptive Cathodic Stripping Voltammetry (AdCSV) have the capability of quantitatively determining labile metals in natural waters. The literature contains some publications on speciation of trace metals by the Competing Ligand Exchange Method using other techniques, such as, Inductively Coupled Plasma Mass Spectrometry (ICP-MS), and Inductively Coupled Plasma Atomic Emission Spectroscopy (ICP-AES). These techniques are useful for studying the speciation chemistry of trace metals in unpolluted freshwaters having very low 
concentrations of metals and DOC [40-44]. However, published literature on studies of metal speciation in metal-polluted natural waters is scarce. Since GFAAS can tolerate much higher solid contents which eliminate sample dilution, it offers advantages [45] for polluted waters. CLEM/GFAAS has proved to be a powerful technique for highly metalpolluted aqueous effluents containing high ionic strength and high acidity.

AdCSV has many advantages over other applicable techniques. AdCSV using a Hanging Mercury Drop Electrode (HMDE) can detect very low concentrations of metals with high sensitivity and high precision in samples having a wide range of $\mathrm{pH}$ values [46]. However, for metal speciation in natural waters, AdCSV suffers from adsorption of dissolved organic carbon on the HMDE. Humic substances contain hydrophobic organic regions that are easily adsorbed on the surface of HMDE, which prevents metal ions from undergoing electrode reaction at the electrode surface, resulting in a decrease in peak current and erroneous results. Despite the above disadvantages, AdCSV is one of the most powerful techniques that is available for determination of the speciation parameters of metals in natural waters.

Another very useful and relatively new technique to investigate free metal ion and their weak metal complexes in aqueous systems is Diffusive Gradient in Thin-Film (DGT) technique. The DGT technique has two distinct advantages over traditional techniques in that it (1) preconcentrates the analyte in the binding phase, and (2) eliminates matrix effects [47]. The DGT is based on mass transport control of the metal species of interest from natural waters [48-50], soils [ 51], and sediment pore waters [52, 53], and makes use of two hydrogel layers. For metals, it is based on the diffusion of free (hydrated) 
metal ions and labile soluble metal complexes at a known rate through a diffusive hydrogel of known thickness, and successive immobilization of the metal cations on a chelating resin. DGT Technique measures only dissolved species with molecular sizes sufficiently smaller than the pore size of the hydrogel to allow them to diffuse freely through it, and which are sufficiently labile to bind on the resin's functional groups. The amount of metal immobilized on the resin is a measure of the concentration of available metal in the aqueous sample [54].

\subsection{Windermere Humic Aqueous Model (WHAM VI)}

Modelling chemical speciation is an important step in predicting metal speciation in freshwaters, especially in circumstances when direct measurement is difficult or prohibitively expensive. Many models such as MINTEQA2, GEOCHEM and more recently, the Windermere Humic Aqueous Model (WHAM), versions V and VI, and the Consistent Non-Ideal Competitive Adsorption (NICCA)-Donnan Model, have been used to model the metal speciation in freshwater systems. In modelling freshwaters for metal speciation, humic substances (HS), which are ubiquitous in the aquatic environment and which represent predominant fractions of the dissolved organic carbon (DOC), have played an important role as naturally-occurring organic complexants for binding metals. The most important constituents of HS are fulvic acid (FA) which is soluble in acids, and humic acid (HA) which is insoluble in acids. The earlier models, GEOCHEM and MINTEQA2, do not correctly describe the fulvic and humic acids, and are further hampered by their limited databases. The models that have been more widely used are WHAM, versions V and VI, and the NICCA-Donnan model. These models have been tested on numerous data sets that have been compiled by various authors. 
The NICCA-Donnan model, developed by Koopal et al., assumes a continuous distribution of binding sites and takes into account both the electrostatic effects of major cations such as $\mathrm{Ca}^{2+}$ and $\mathrm{H}^{+}$and the heterogeneous nature of the binding sites on HS. It has been applied to trace metals such as $\mathrm{Cu}, \mathrm{Cd}, \mathrm{Pb}$ and $\mathrm{Al}$. However, one serious drawback of the NICCA-Donnan model is that it assumes monodentate metal binding to $\mathrm{HS}$, which has led to problems when modelling $\mathrm{Cu}$. Lack of sufficient data sets has also made it difficult for the NICCA-Donnan model to model such metals as $\mathrm{Al}$ and $\mathrm{Pb}$ WHAM, developed by Tipping et al., is an equilibrium-based model that assumes discrete-site electrostatic binding. It draws on a number of sub-models which have been calibrated against literature data. Many studies using WHAM have been done with the objective of parameterizing the Model.

In WHAM version VI, fulvic and humic acids are pictured as rigid spheres of uniform size with ion-binding groups positioned on the surface. Proton dissociation is represented by postulating eight groups of different acid strengths; the four lowest $\mathrm{p} K \mathrm{~A}$ values (type A) consist mainly of carboxylic acid groups, while the remaining four (type B) have higher $\mathrm{p} K \mathrm{~A}$ values and consist mainly of phenolic acids. There are equal numbers of binding sites within each group, and the content of sites in each type B group is half that in type A groups. The regular assignment of proton binding sites allows for the representative creation of bidentate and tridentates metal binding sites. Metal ions and their first hydrolysis products compete with each other and with protons for the type A and type B groups.

In order to appraise the applicability of WHAM for freshwater samples, WHAM predictions need to be compared with measured concentrations. One important parameter 
to consider is the $\left[\mathrm{M}^{2+}\right]$, which has been reported to be a predictor of ecotoxicity. WHAM is able to predict $\left[\mathrm{M}^{2+}\right]$ given some easily determined input parameters such as $\mathrm{pH}$ and concentrations of total metals, dissolved anions and cations, and DOC. Accurate determination of $\left[\mathrm{M}^{2+}\right]$ in freshwaters is an important requirement for studying the interactions of metals with natural organic ligands in freshwaters. WHAM predictions are used as "checks" against the measured $\left[\mathrm{M}^{2+}\right]$.

\subsection{Significance of the mine and municipal effluent from Sudbury mining area for metal speciation studies}

Atmospheric deposition from smelting operations and discharge of mines and municipal effluents in Sudbury [ $400 \mathrm{~km}$ north of Toronto, ON, $\left(46^{\circ} 37^{\prime} \mathrm{N}, 80^{\circ} 48^{\prime} \mathrm{W}\right)$ ], Canada, has resulted in metal contamination of freshwater resources. Sudbury is known as the Nickel City because of its nickel and copper mines.

Sudbury's mineral wealth is shared by Inco Limited (founded 1902), and Falconbridge Limited (1928). Some of the original mines, such as Creighton Mine, are still producing today. Both companies built massive infrastructures to treat their ores, and for many years there were three smelter sites operating in the area - Inco Limited processed ore in Copper Cliff (still in operation), and Coniston, while Falconbridge Limited continues to treat its ores in the town of Falconbridge. Nickel, copper, cobalt, arsenic and other metals are always found as naturally-occurring elements in soils and in freshwaters, but several studies have reported elevated levels in some parts of the Sudbury Basin and freshwater resources, particularly in areas close to the historic smelting sites. The 
consensus is that over the years, smelting and refining activities have gradually increased these metal levels.

A significant fraction of the flow of many rivers consists of mine and municipal wastewater effluents. The discharge of large volume of mine and municipal effluents can result in the exposure of humans and aquatic organisms to a variety of different wastewater-derived contaminants including high concentrations of free metal ions and their labile complexes.

\subsection{Effect of metals on human health}

Mine effluents containing high metal concentrations when they are discharged into receiving stream of freshwaters may have adverse effects on fish and other aquatic organism in natural waters. Depending on the physicochemical forms of the metal, the metal accumulation in aquatic bioorganisms varies. Fish habitats are also exposed to these toxic metals and may face toxic effects. $\mathrm{Ni}, \mathrm{Cu}$ and $\mathrm{Pb}$ (metals of our interest) have adverse effect on human health, which is briefly discussed below.

Effects of copper on human health:

Long-term exposure to copper can cause irritation of the nose, mouth and eyes and it causes headaches, stomachaches, dizziness, vomiting and diarrhoea. Intentionally high uptakes of copper may cause liver and kidney damage and even death. There are scientific articles that indicate a link between long-term exposure to high concentrations of copper and a decline in intelligence of young adolescents. Whether this should be of concern is a topic for further investigation. 
Effects of nickel on human health:

In small quantities nickel is essential, but when the uptake is too high it can be a danger to human health. An uptake of too large quantities of nickel has the following consequences: higher chances of development of lung cancer, nose cancer, larynx cancer and prostate cancer, lung embolism, respiratory failure, birth defects, asthma and chronic bronchitis and heart disorders.

Health Risks of Lead Exposure

Short-term exposure to high levels of lead can cause vomiting, diarrhea, convulsions, coma or even death. Severe cases of lead poisoning are rare in Canada. However, even small amounts of lead can be harmful, especially to infants, young children and pregnant women.

\subsection{Hypothesis and Objectives}

The objective of this work is to test the hypothesis that stability and lability of metal complexes of humic substances in natural waters are determined by the [metal]/[ligand] mole ratio, and the heterogeneity of the humic substances. The hypothesis will be tested by investigating the chemical bonding of nickel and other $3 \mathrm{~d}$ transition metals with wellcharacterized fulvic and humic acids, separately, in the laboratory by using model solutions, and field samples of metal complexes of humic substances, including mining and metallurgical effluents from mining and municipal areas in Sudbury, Ontario. The investigations will include study the nature of their chemical bonds (covalence and electrovalence bond) and their strengths (stability constants) in model solutions and in natural waters. The hypothesis testing will involve further development and testing of the 
following metal speciation techniques: Competing Ligand Exchange Method (CLEM) / Adsorptive Stripping Voltammetry (AdSV); CLEM/ Graphite Furnace Atomic Absorption Spectrometry (GFAAS) and Diffusive Gradient in Thin Film (DGT) Technique in investigating chemical heterogeneity of humic substances in natural waters.

\subsection{Outline of the Thesis}

Chapter 2 attempts to validate the method used to determine the percentage of labile fraction of metal-DOC complexes and their dissociation rate coefficients in mine and municipal effluents by using two independent techniques, viz. CLEM/AdCSV and CLEM/GFAAS. These two methods were previously used in this laboratory and were applied to model solutions. However, application of CLEM to a complicated system like mine effluents which contain multimetal mixtures was not previously done and is essential for further applications. Experiments performed to confirm the applicability of CLEM in mine effluents are described. This work was published in Analytical and Bioanalytical Chemistry (Chakraborty et al., 2006) [55].

Chapter 3 explores the lability of DOC complexes of $\mathrm{Co}, \mathrm{Ni}, \mathrm{Cu}$, and $\mathrm{Zn}$ in the mining effluent, and investigates the effects of dilution of the effluent on the release of metals from the metal-DOC complexes. This study was done using CLEM/AdCSV on effluent samples from Copper Cliff Mine, Sudbury, Canada, using two samples of the effluents: one, undiluted (100\%) effluent, and the other, diluted (45\%) effluent. The dilution was done by Inco Limited with laboratory tap water in order to determine the effects of dilution on the metal complexes in the effluents when they were discharged into 
receiving streams of freshwaters. The concentration of $45 \%$ was selected by Inco Limited as an environmentally relevant concentration on the basis of rates of discharge into Junction Creek watershed and volume calculations.

This work also shows that changes in the ionic strength produces conformational changes along with aggregation and precipitation of the DOC. Changes in electrostatic interactions between the metal cations and the humate polyanions is also described. This work was published in Analytica Chimica Acta (Chakraborty \& Chakrabarti, 2006) [56].

Chapter 4 aims to evaluate the performance of the diffusive gradient in thin film technique for speciation of metals in mine effluent aqueous samples, collected from Copper Cliff Mine, Sudbury, Canada. The results of metal speciation in mine effluent sample obtained by the above technique were compared with the data obtained by using Competing Ligand Exchange Method (CLEM)/ Adsorptive Cathodic Stripping Voltammetry (AdCSV) presented in Chapter 3. Chapter 4 explores the lability of DOC complexes of nickel, copper, in mine aqueous effluents, and investigates the effects of dilution of the effluents with laboratory water on the lability of metal complexes. It was found that the percentages of labile fraction of copper in $100 \%$ and $45 \%$ effluent samples, as well as, labile fraction of nickel in $100 \%$ effluent, both determined by the above technique were lower than those determined by CLEM/AdCSV. Also, the percentage of labile fraction of total nickel in $45 \%$ of the aqueous effluent determined by the DGT technique did not agree with the electrochemical speciation results. Comparison of these two sets of speciation data suggest that $\mathrm{Cu}(\mathrm{II})$ in undiluted $100 \%$ and diluted $45 \%$ mine effluents formed small-sized and large-sized labile complexes. However, larger 
complexes cannot be determined by the DGT technique. Labile Ni(II) complexes in the $100 \%$ undiluted effluent had diffusion coefficients similar to that of nickel aqua complex, and hence, can be bioavailable. Speciation data by these two techniques are complementary and provide a more comprehensive picture and a better insight into the physical and chemical characteristics of the metal species than either the DGT technique or the metal-complex dissociation kinetics alone can do. This work has been submitted to Environmental Chemistry (Chakraborty et al., 2007), for publication [57].

Chapter 5 attempts quantitative determination of speciation parameters of trace metals: $\mathrm{Cu}, \mathrm{Zn}, \mathrm{Cd}$ and $\mathrm{Pb}$ in aqueous samples containing chemically heterogeneous humic substances simultaneously in a single run. Since chemical heterogeneity of humic substances plays an important role in the thermodynamics (metal complex stability) and kinetics (metal complex lability) of trace-metal competition by humic substances, Scanned Stripping Voltammetry that can reveal special, distinctive nature of metalcomplexation, has been used in this study. A comparison of heterogeneity parameters $(\Gamma)$ for $\mathrm{Zn}(\mathrm{II}), \mathrm{Cd}(\mathrm{II}), \mathrm{Pb}(\mathrm{II})$ and $\mathrm{Cu}(\mathrm{II})$ complexes in model solutions of Suwannee River Fulvic Acid (SRFA) shows that $\Gamma_{\mathrm{Cd}}>\Gamma_{\mathrm{Zn}}>\Gamma_{\mathrm{Pb}}>\Gamma_{\mathrm{Cu}}$, suggesting that SRFA behaves as a relatively homogeneous complexant for $\mathrm{Zn}(\mathrm{II})$ and $\mathrm{Cd}(\mathrm{II})$, whereas it behaves as a relatively heterogeneous complexant for $\mathrm{Pb}(\mathrm{II})$ and even more heterogeneous complexant for $\mathrm{Cu}$ (II) under the experimental conditions used. The order of Differential Equilibrium Function (DEF), $\log \mathrm{K}^{*}$ values at $\mathrm{pH} 5.00$ follow the sequence: $\log \mathrm{K}_{\mathrm{Cu}} *>\log \mathrm{K}_{\mathrm{Pb}} *>$ $\log \mathrm{K}_{\mathrm{Zn}}{ }^{*}>\log \mathrm{K}_{\mathrm{Cd}}$. These results are in good agreement with the literature values. Significant contribution of this work is the possibility of simultaneous determination of 
several metals in a sample in a single experiment, and hence, in a shorter time than taken by multiple experiments. This work was published in Analytical and Bioanalytical Chemistry (Chakraborty et al., 2007) [58].

Chapter 6 The apparent stability and lability of any target metal-HS complexes depend on the competition of the trace metal ions with the target metal for complexation with heterogeneous humic substances. Factors which control the trace metals competitions in natural water system are the stability of $\left(\log \mathrm{K}^{*}\right)$ of M-Humate complexes and the heterogeneity of the humic substances. In this chapter $\mathrm{Pb}$ (II)-SRFA complexation and the trace metal competition of $\mathrm{Cu}(\mathrm{II}), \mathrm{Zn}$ (II) and $\mathrm{Cd}$ (II) for the binding sites of SRFA in model solution were explored. Relatively few studies have considered the consequences of ligand heterogeneity on trace metal ions complexation by humic substances.

This work has been submitted to Analytical and Bioanalytical Chemistry (Chakraborty et al., 2007) [59].

Chapter 7 Presents an overall conclusion for the whole thesis. 


\subsection{References}

1. Lehninger, A.L., 1982. Principles of biochemistry. Worth, New York.

2. Luoma, S.N., 1983. Sci. Total Environ. 28: 1-22.

3. Morel, F.M.M. and Hering, J.G., 1993. Principles and applications of aquatic chemistry. Wiley, New York, 301 pp.

4. Campbell, P.G.C., 1995. Interactions between trace metals and aquatic organisms: A critique of the free-ion activity model. In: A. Tessier and D.R. Turner (Editors), Metal speciation and bioavailability in aquatic systems. IUPAC Series. John Wiley and Sons, Chichester, pp. 45-102.

5. Sunda, W.G. and Huntsman, S.A., 1998. Sci. Total Environ., 219(2-3): 165-181.

6. Sutton R, Sposito G, (2005) Environ Sci Technol 39: 9009-9015.

7. M. Filella, Raewyn M. Town (2001) Fres. Journal of Chemistry 370:4,413-418

8. Filella M, Buffle J, van Leeuwen H P, (1990), Anal. Chim. Acta, 232, 209.

9. Morel F M M, Hering J G (1993) Principles of Aquatic Chemistry, John Wiley, New York, USA p. 360.

10. Vermeer A W P, McCulloch J K, Van Riemsdijk W H, Koopal L K (1999) Environ Sci Technol 33: 3892-3897.

11. Langsto W J, Bryan G W, (1984) in: Complexation of Trace metals in Natural Waters; Kramer C J M, Duinker J C (Eds), Martinus Nijhoff/Dr. W. Junk Publishers: The Hague, The Netherlands, p 375.

12. Brown G K, Cabaniss S E, MacCarthy P, Leenheer JA (1999) Anal Chim Acta 402: 183-193. 
13. Morel F M M, Hering JG (1993) Principles and Applications of Aquatic Chemistry, John Wiley, New York, USA p. 377.

14. Francois M.M. Morel, Janet G.Hering, Principles and Applications of Aquatic Chemistry, New York; Wiley, 1993, p. 390.

15. Xue H B, Kistler D, Sigg L (1995) Limnol Oceanogr 40:1142-1152.

16. Mandal R, Salam M S A, Murimboh J, Hassan NM, Chakrabarti CL, Back MH, Gregoire D C, Scrhoeder W H (1999) Anal Chim Acta 395:323-334

17. Kinniburgh D C, Tipping E (2001) Environ Sci Technol 35:2049-2059.

18. Christl I, Kretzschmar R (2001) Environ Sci Technol 35:2505-2511.

19. Francois M.M. Morel, Janet G.Hering, Principles and Applications of Aquatic Chemistry, New York; Wiley, 1993, p. 379.

20. Cao, Y.; Conklin, M.; Betterton, E. Environ. Health Persp. 1995, 103, 29-32.

21. S.E. Cabaniss, M.S. Shuman, Geochim. Cosmochim. Acta 1988, 52, 185-193.

22. R. Mandal,, M. S. A Salam, J. Murimboh, N. M Hassan, C.L. Chakrabarti, M. H. Back, D. C. Gregoire, Environmental Science and Technology. 2000, 34(11), 2201-2208.

23. J. W. Guthrie, R. Mandal, M. S. A Salam, N. M. Hassan, J. Murimboh, C. L Chakrabarti, M. H. Back, D. C. Gregoire, Analytica Chimica Acta. 2003, 480(1), 157-169.

24. J G. Hering, F. M.M. Morel, Environ. Sci. Technol. 1988, 22, 1234-1237.

25. W. G. Sunda; P. J. Hanson. In chemical Modelling in Aqueous systems: speciation sorption, solubility and kinetics; Jenne, E. A.; Ed.; ACS symposium series 93; American Chemical Society: Washington, DC, 1979 
26. Tessier, A. and Turner, D.R., 1995. Metal speciation and bioavailability in aquatic systems. Wiley, Chichester, $679 \mathrm{pp}$.

27. Wilkinson, K.J., Slaveykova, V.I., Hassler, C.S. and Rossier, C., 2002. Chimia, 56(12): 681-684.

28. Simkiss, K. and Taylor, M.G., 1995. Transport of metals across membranes. In: A. Tessier and D.R. Turner (Editors), Metal speciation and bioavailability in aquatic systems. IUPAC Series, pp. 1-44.

29. Hudson, R.J.M., 1998. Sci. Total Environ, 219(2-3): 95-115.

30. Bell, R.A., Ogden, N. and Kramer, J.R., 2002. Comp. Biochem. Physiol. CToxicol. Pharmacol. 133(1-2): 175-188.

31. Buffle, J., 1984. Natural organic matter and metal-organic interactions in aquatic systems. In: H. Sigel (Editor), Metal ions in biological systems, Basel, pp. 165221.

32. Pagenkopf, G.K., 1983. Environ. Sci. Technol., 17(6): 342-347.

33. Di Toro, D.M., Allen, H.E., Bergman, H.L., Meyer, J.S., Paquin, P.R. and Santore, R.C., 2001. Environ. Toxicol. Chem., 20(10): 2383-2396.

34. Campbell, P.G.C., Errécalde, O., Fortin, C., Hiriart-Baer, V.P. and Vigneault, B., 2002.. Comp.Biochem. Physiol. C-Toxicol. Pharmacol, 133(1-2): 189-206.

35. van Leeuwen, H.P., 1999. Environ. Sci. Technol, 33: 3743-3748.

36. Donat, J.R. and van den Berg, C.M.G., 1992. Mar. Chem., 38(1-2): 69-90.

37. Xue, H. and Sigg, L., 1994. Anal. Chim. Acta, 284: 505-515.

38. Xue, H. and Sigg, L., 2002b. A review of competitive ligandexchange/voltammetric methods for speciation of trace metals in freshwater. In: 
M. Taillefert and T. Rozan (Editors), Environmental electrochemistry: Analysis of trace element biogeochemistry. ACS, Washington, DC, pp. 336-370.

39. Xue, H. and Sigg, L., 1993. Limnol. Oceanogr., 38(6): 1200-1213.

40. Haraldsson C, Lyven B, Pollak M, Skoog A (1993) Anal Chim Acta 284:327-336

41. Ammann, Adrian A (2002) Anal Bioanal Chem 372:448-452.

42. Heltai Gy, Percsich K, Fekete I, Barabas B, Jozsa T (2000) Microchemical Journal 67: 43-51.

43. Temminghoff E J M, Plette, ACC, Van Eck R, Van Riemsdijk W H (2000) Anal Chim Acta 417:149-157.

44. Sedykh E M, Starshinova N P, Bannykh L N, Ershova E, Yu, Venitsianov E.V (2000) Zhurnal Analiticheskoi Khimii 55:344-349.

45. Sturgeon R E (1997) Spectrochim Acta B 52:1451-1457.

46. Wang J (1994) Analytical Electrochemistry, VCH Publishers, p. 32.

47. Davison W, Zhang H, (2000) Ocean Sci. and Technol, 283-302.

48. Zhang H, Davison W, Knight B, McGrath S, (1998) Environ. Sci. Technol., 32(5), 704-710.

49. Zhang H, Davison W, Gadi R, Kobayashi T, (1998), Anal. Chim. Acta. 370(1), 29-38.

50. Dahlqvist R, Zhang H, Ingri J, Davison W, (2002), Anal. Chim. Acta, 460(2), 247-256.

51. Harper M P, Davison W, Zhang H, Tych W, (1998), Geochim. Cosmochim. Acta 62(16), 2757-2770. 
52. Zhang H, Davison W, Mortimer R J G, Krom M D, Hayes P J, Davies I M (2002) Sci. of the Total Environ, 296(1-3), 175-187.

53. Fones G R, Davison W, Hamilton-Taylor J, (2004) Continental Shelf Research, $24(13-14)$,

54. Davison W, Zhang H (1994), Nature 367, 546.

55. P. Chakraborty, Y. Gopalapillai, J. Murimboh, I. I. Fasfous and C. L. Chakrabarti, (2006), Anal. Bioanal. Chem. 386 (6), 1803-1813.

56. P. Chakraborty and C. L. Chakrabarti, (2006) Anal. Chim. Acta, 571, (2), 260-269

57. P. Chakraborty, J. J. Zhao, J. Murimboh, and C. L. Chakrabarti, (2007), Environ. Chem. Manuscript No. EN07034.

58. P. Chakraborty, I. I. Fasfous, J. Murimboh, and C. L. Chakrabarti, (2007), Anal. Bioanal. Chem. 388 (2), 463-474.

59. P. Chakraborty, I. I. Fasfous, J. Murimboh, and C. L. Chakrabarti, (2007), Anal. Bioanal. Chem. Manuscript No. ABC-00606-2007. 
Kinetic speciation of $\mathrm{Ni}$ (II) bound to DOC in mine aqueous effluents by Competing Ligand Exchange Method using AdCSV and GFAAS: A validation of the kinetic model 


\subsection{Introduction}

Laboratory method validation typically refers to the process of evaluating the performance of the test methodology. It is often necessary to determine the acceptability of the data generated in laboratory speciation analysis. The goal of this chapter is to provide evidence that the CLEM can be applied to complex mine aqueous effluents containing multimetal mixtures for metal speciation studies.

This chapter attempts to apply the method used to determine the labile fraction of metalDOC complexes and their dissociation rate coefficients in mine and municipal effluents by using two independent techniques, viz. CLEM/ AdCSV and CLEM/GFAAS. These two methods were previously used in this laboratory and were validated in model solutions [1] (less complex compared to mine effluents). However, application of CLEM in a complex system like mine effluents which contain multi-metal mixtures was not previously done and was essential for further applications. Experiments performed to confirm the applicability of CLEM in mine effluents are described.

Because of the requirement of very low detection limits and extremely high analytical sensitivity for quantitative determination of very low concentrations of metals present in natural waters, the CLEM / Graphite Furnace Atomic Absorption Spectrometry (GFAAS) and CLEM / Adsorptive Cathodic Stripping Voltammetry (AdCSV) were used to determine the applicability of CLEM.

In this work, the kinetic speciation of nickel in mining and municipal effluents (collected from Sudbury, Ontario) was studied by using two variants of CLEM: AdCSV using DMG as the competing ligand, and GFAAS using Chelex 100 as the competing ligand. 
Since the freshwater environment is often a non-equilibrium system, kinetic approaches to the chemical speciation of metals are required in addition to the usual equilibrium approaches [2-7] in order to obtain a more complete picture of trace metal speciation, which influences toxicity to biota in fresh waters.

This study includes undiluted mining and municipal effluents (aqueous) and diluted effluents (diluted with receiving freshwaters from the surrounding environment). The mixing (dilution) ratios and the receiving waters used for the dilution of the effluents ( $45 \%$ and $30 \%)$ were arbitrarily chosen, but were representative of the prevalent mining practices. The purpose of the above dilution was to mimic the natural waters that result from dilution of the mining and municipal effluents with receiving freshwaters so that this study would deal with the environmental realities that are of concern to the managers and regulators of water resources.

The aim of this work was to confirm the applicability of CLEM in mine and municipal aqueous effluent and to determine the effects of mixing of mining and municipal effluents from the Sudbury (Canada) nickel-bearing areas with receiving freshwaters on the nickel speciation in the resulting waters, using two independent techniques.

\subsection{The Kinetic Model}

The kinetic model proposed by Olson and Shuman $[8]$ was adapted $[9,10]$ to investigate the kinetic speciation of nickel in mining and municipal effluents. Consider a water sample of $n$ components, in which each component, $\mathrm{ML}_{i}$, exists in equilibrium with its dissociation products: the free metal ion (i.e. the metal aqua complex), $M$, and a naturally occurring, heterogeneous complexant, $\mathrm{L}_{i}$, such as humic acid (charges have been omitted 
for simplicity). The subscript, $i$, represents different binding sites on the naturallyoccurring heterogeneous complexant.

$$
\begin{aligned}
& \mathrm{ML}_{i \underset{\mathrm{k}_{\mathrm{f}, i}}{\stackrel{\mathrm{k}_{\mathrm{d}, i}}{\longrightarrow}} \mathrm{M}+\mathrm{L}_{i}} \mathrm{\text {(Slow) }} \\
& \mathrm{M}+\mathrm{P} \longrightarrow \mathrm{M}-\mathrm{P}
\end{aligned}
$$

where the formation and dissociation rate constants, $\mathrm{k}_{\mathrm{f}, i}$ and $\mathrm{k}_{\mathrm{d}, i}$, are coupled by the stability constant, $K=k_{f} / k_{d}$, through the principle of microscopic reversibility.

If each complex, $\mathrm{ML}_{i}$, dissociates simultaneously and independently (at a rate that depends on the nature of the functional group, its position on the macromolecule, and the residual charge), the concentration of the free metal ion, $c_{\mathrm{M}}$, and the total concentration of all complexes, $c_{\mathrm{ML}}$, at any time, $t$, is given by a summation of exponentials as shown in equations 3 and 4, respectively.

$$
\begin{aligned}
& c_{\mathrm{M}}(\mathrm{t})=\sum_{i=1}^{\mathrm{n}} c_{\mathrm{ML}}^{\circ} \cdot\left[1-\exp \left(-\mathrm{k}_{\mathrm{d}, i} \cdot t\right)\right] \\
& c_{\mathrm{ML}}(\mathrm{t})=\sum_{i=1}^{\mathrm{n}} c_{\mathrm{ML}}^{\circ} \cdot \exp \left(-\mathrm{k}_{\mathrm{d}, i} \cdot t\right)
\end{aligned}
$$

where $c_{\mathrm{ML}, i}^{\circ}$ is the initial concentration of $\mathrm{ML}_{i}$ and $c_{\mathrm{ML}, i}(t)$ is the concentration of $\mathrm{ML}_{i}$ at any time, $t$.

The model assumes that 1) the reactions are first-order and pseudo-first-order; 2) reaction (2) is much faster than reaction (1), so that reaction (1) is the rate-determining step, and the measured kinetics then represent the kinetics of the dissociation of the metal complex, $\mathrm{ML}_{i}$, 3) ML does not directly (i.e. without predissociation) react with the Chelex resin, 
and 4) the ratio between the concentrations of complexed metal and free metal is much larger than unity (i.e. $c_{\mathrm{ML}} / c_{\mathrm{M}}<1$ ).

Non-Linear Regression Analysis for Kinetic measurement.

Analyzing experimental data to obtain physical parameters is a crucial point in the kinetic speciation method. In this paper, data was fitted to the kinetic model by non-linear regression analysis using the Marquadt-Levenberg algorithm. The minimum number of parameters required to accurately fit the data was determined by finding the number of components in which the sum of square of the weighted residuals shown below achieved a minimum value.

Sum of squares of the weighted residuals $=\sum\left[\frac{\mathrm{C}(\mathrm{t})-\mathrm{C}_{\mathrm{T}}(\mathrm{t})}{\mathrm{C}(\mathrm{t})^{1 / 2}}\right]^{2}$

where, $\mathrm{C}(\mathrm{t})$ is the experimental value and $\mathrm{C}_{\mathrm{T}}(\mathrm{t})$ is the calculated value using the parameters obtained from the regression analysis.

For a polyfunctional, complexant such as fulvic acid, the number of components is not a simple issue. The small number of components with specific rate constants may not accurately describe the chemistry of the binding sites of the fulvic acid. A binding site may have a range of binding energy because of the heterogeneous nature of fulvic acid. This in turn will lead to a distribution of values for the dissociation rate constants for the complexes. Nevertheless, the specific rate constants may represent an average value for a group of complexes on a particular site. 


\subsection{Experimental}

\subsubsection{Reagents and Chemicals}

Ultrapure water of resistivity $18.2 \mathrm{M} \Omega / \mathrm{cm}$ was obtained direct from a Nanopure Diamond water purification system (Barnstead, USA) fitted with an organic purification column to remove organic matter. Stock solutions of $10 \mu \mathrm{g} / \mathrm{mL}$ each of $\mathrm{Ni}(\mathrm{II})$ and $\mathrm{Cu}$ (II) were prepared by dilution of $1000 \mu \mathrm{g} / \mathrm{mL}$ stock solutions (ICP grade, SCP Science) with ultrapure water, acidified to contain 1\% (v/v) ultrapure nitric acid (Baseline grade, Seastar). Working standards were prepared by serial dilution with ultrapure water. Ultrapure nitric acid (Baseline, Seastar Chemicals) $1 \%(\mathrm{v} / \mathrm{v})$ was added to all standard solutions to prevent metal loss by adsorption on the container walls. A stock solution of 0.1 M DMG (Fisher Scientific) was prepared by dissolving an appropriate mass of solid DMG powder in methanol (Spectro grade, Caledon). Analytical grade (minimum 99\% pure) Chelex 100 resin (Bio-Rad, 100-200 mesh, sodium form) was prepared by washing it with $150 \mathrm{~mL}$ of ultrapure water. All containers used in this work were pre-cleaned by soaking in $10 \% \mathrm{HNO}_{3}$ (AR grade) for one week at room temperature, followed by a fivetime rinse with ultrapure water. Finally, they were soaked in ultrapure water until they were used.

\subsubsection{Analytical Methods}

For the kinetic study by CLEM/AdCSV, an Autolab PGSTAT30 (Eco Chemie), controlled by a personal computer and equipped with a Metrohm 663 VA stand was used. The working electrode was a Hanging Mercury Drop Electrode (HMDE), the reference electrode an $\mathrm{Ag} / \mathrm{AgCl}$ electrode in a glass tube filled with $3 \mathrm{M} \mathrm{KCl}$, and the counter 
electrode a Pt wire (Metrohm). The test solutions (of the effluent samples and the model solutions) were purged for $10 \mathrm{~min}$. with ultrahigh purity nitrogen gas. The competing ligand in large excess (500-fold greater than the metal) was added to the test solution just prior to the start of the kinetic experiment. Experimental conditions viz. deposition potential, deposition time, step potential and frequency were optimized as shown in Table 2.1.

A Perkin-Elmer 4100ZL Zeeman graphite furnace atomic absorption spectrometer (GFAAS) Zeeman background correction, equipped with an AS-40 autosampler, and an HGA-600 graphite furnace was used for the kinetic study by CLEM/GFAAS. The transversely heated graphite tubes (Perkin-Elmer) were pyrolytically-coated, and were equipped with integrated L'vov platforms. The signal was measured in the peak area mode. Each completed determination was followed by a 2-s clean-up cycle of the graphite tube at $2400^{\circ} \mathrm{C}$. During the drying, ashing and clean-up cycles, the internal argon gas was passed through the furnace at $300 \mathrm{~mL} / \mathrm{min}$, but the gas flow was interrupted during the atomization step. The instrumental parameters: drying temperature, ashing temperature and atomization temperature are presented in Table 2.2. The signal was measured in peak area mode. Concentrations were determined by external calibration. Every fifth sample analyzed was a blank. All measurements were done in quadruplicate. The variation between each replicate samples was less than $5 \%$ and the daily variation was less than $5 \%$. The GFAAS was equipped with a Teflon Reactor, described below in Figure 2.1. Two and a half grams $(1 \% \mathrm{w} / \mathrm{v})$ of Chelex 100 was added to $250 \mathrm{~mL}$ of the sample solution in a cylindrical Teflon Reactor ( $500 \mathrm{~mL}$ volume). The sample solution was stirred continuously with a Teflon-coated stirring bar, and was filtered with an online 
$0.40 \mu \mathrm{m}$ polycarbonate membrane filter (Corning) to separate the Chelex 100 resin. Aliquots of the filtrate were collected in $1.5-\mathrm{mL}$ sample cups (VWR) using a peristaltic pump. The changes in the $\mathrm{pH}$ of the test solutions between the beginning and the end of the experiment were found to be $< \pm 0.5 \mathrm{pH}$ units. 


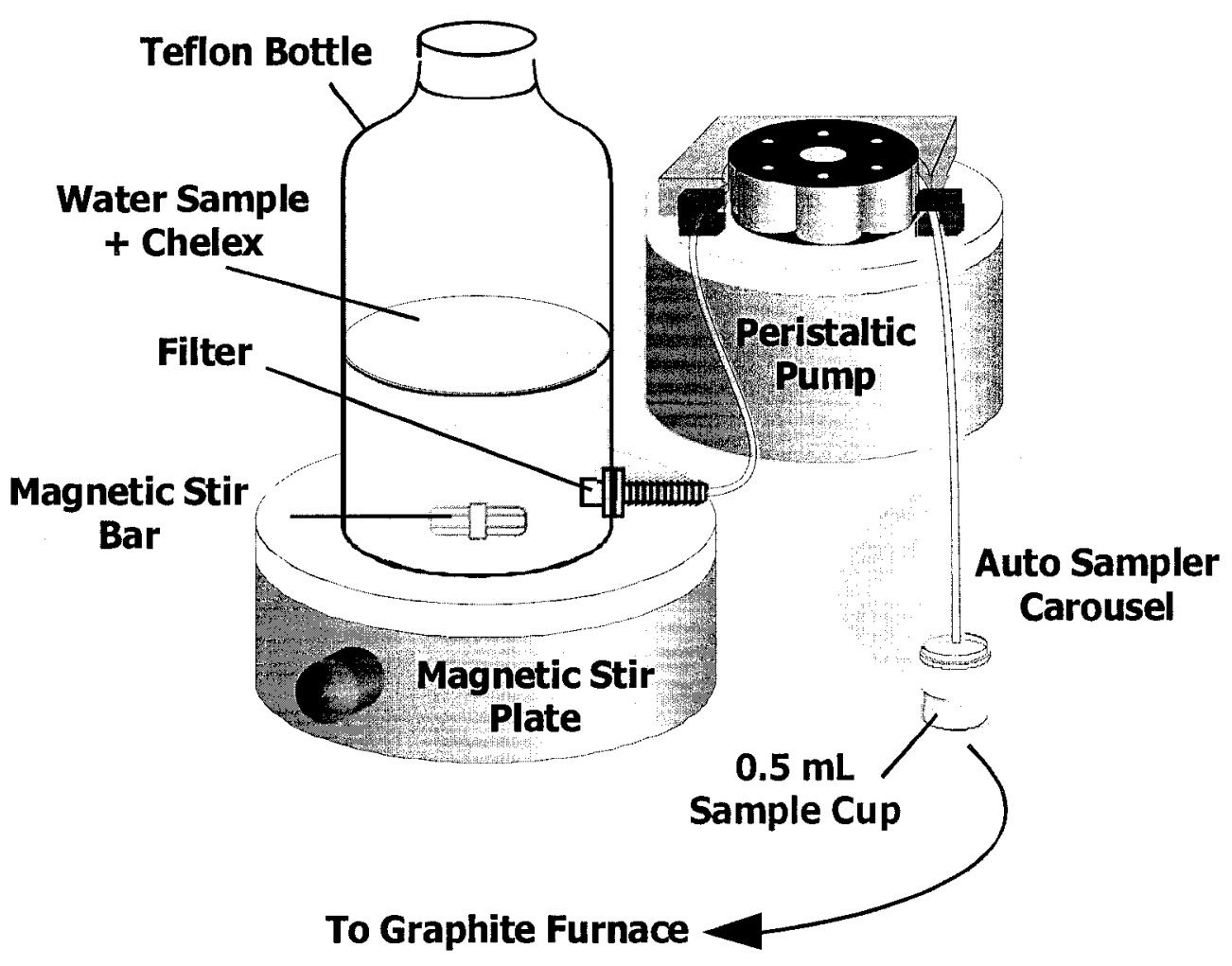

Figure 2.1 Experimental set-up for kinetic experiments. 
Table 2.1. Optimized electrochemical parameters for the determination of kinetic speciation of nickel in Sudbury mining and municipal effluents by Square Wave Adsorptive Stripping Voltammetry using DMG as a competing ligand

\begin{tabular}{cc}
\hline Pretreatment & 500 \\
\hline Purge Time (s) & 0 \\
Conditioning Potential (V) & 0 \\
Duration (s) & -0.6 \\
Deposition Potential (V) & 45 \\
Duration (s) & 15 \\
Equilibration Time (s) & \\
Measurement & 10 \\
Frequency (Hz) & \\
Potential & -1.2 \\
Initial Potential (V) & 0.005 \\
End Potential (V) & \\
Step Potential (V) & \\
\hline
\end{tabular}


Table 2.2. Optimized Ashing and Atomization Temperatures for Determination of Nickel in Mine Aqueous Effluents by Graphite Furnace Atomic Absorption Spectrometry.

\begin{tabular}{ccccccc}
\hline Step & $\begin{array}{c}\text { Step } \\
\text { Description }\end{array}$ & $\begin{array}{c}\text { Temp } \\
\left({ }^{\circ} \mathbf{C}\right)\end{array}$ & $\begin{array}{c}\text { Ramp } \\
\text { Time (s) }\end{array}$ & $\begin{array}{c}\text { Hold } \\
\text { Time (s) }\end{array}$ & $\begin{array}{c}\text { Internal } \\
\text { Flow }\end{array}$ & $\begin{array}{c}\text { Gas-Flow } \\
\text { Type }\end{array}$ \\
\hline $\mathbf{1}$ & Initial Drying & 110 & 1 & 30 & 250 & Normal \\
$\mathbf{2}$ & Final Drying & 130 & 15 & 30 & 250 & Normal \\
$\mathbf{3}$ & Ashing & 1100 & 10 & 20 & 250 & Normal \\
$\mathbf{4}$ & Atomization & 2300 & 0 & 5 & 0 & Normal \\
$\mathbf{5}$ & Cleanout & 2400 & 1 & 3 & 250 & Normal \\
\hline
\end{tabular}




\subsection{3 $Q A / Q C$}

Quality control for metal analyses included repeated injections and periodic (one per hour in every two-hour operation of the equipment) analysis of the Certified Reference Standard, NIST 1640. A prior set of samples was reanalyzed if the measured value differed from the certificate value by $>10 \%$. The relative standard deviation among replicate determinations was typically $\leq 5 \%$.

\subsection{Sampling Sites}

Mine effluent samples were collected in October 2005 from several sampling sites in the Sudbury area (Figure 2.2); Sudbury municipal effluents were also collected at the same time. The effluent samples were from Copper Cliff Mine, Crean Hill Mine, Garson Mine and the receiving water samples were collected from the Vermillion River. A $0.45 \mu \mathrm{m}$ membrane filter (CN-6 Metricel, $47 \mathrm{~mm}$ diameter, 150 $\mu \mathrm{m}$ thickness, Gelman Sciences, Inc) was used to separate particulates from dissolved species in the water samples in this study. This filter is made of mixed cellulose esters and has the advantage of providing filtrates having low blanks for the metals. 

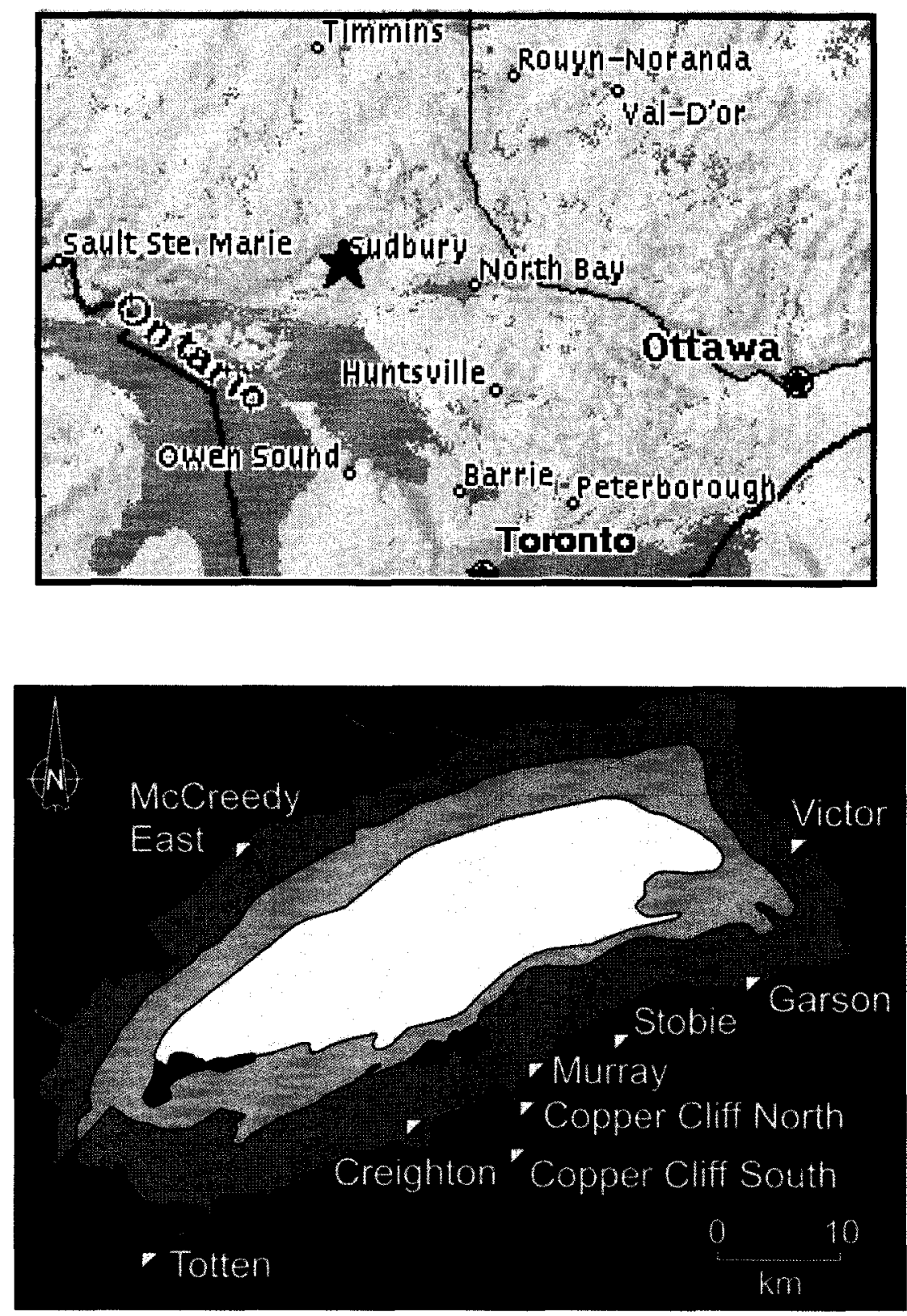

Figure 2.2 Map of the sampling area of Sudbury, Ontario and the mines investigated 


\subsection{Results and Discussion}

The concentrations of nickel, DOC, and other chemical properties of the samples are presented in Table 2.3. Higher concentrations of dissolved nickel were observed in Copper Cliff Mine effluent, Crean Hill Mine effluent and Sudbury Municipal effluent compared with Garson Mine effluent and Vermillion River water. However, the dissolved concentrations of nickel do not represent the bioavailable nickel species because $\mathrm{DOC}$ can complex nickel, thereby reducing the concentration of the $\mathrm{Ni}^{2+}$ free metal ion [11]. Since water quality depends on the presence of potentially toxic metal species, which is strongly influenced by interactions of nickel with DOC, it is necessary to study the interactions of nickel with DOC in natural waters.

The binding capacity and affinity for metal binding is dependent on the number and type of ligands, on their position in the structure of the complexants, on the metal/binding sites ratio, $\mathrm{pH}$, ionic strength and other factors [12]. Humic substances, which are ubiquitous in the aquatic environment, are known to posses strong binding sites accounting for $\sim 1$ $10 \%$ of the total sites and weak binding sites accounting for $\sim 90-99 \%$ of the total sites [13]. A relatively high concentration of DOC was found in Sudbury Municipal effluent $(23.22 \mathrm{mg} / \mathrm{L})$, whereas Garson Mine effluent had the lowest concentration of DOC (2.9 $\mathrm{mg} / \mathrm{L}$ ). The Ni/DOC ratios for each sample are presented in Table 2.4. The nickel-toDOC ratio usually determines the distribution of metal among the kinetically distinguishable components of the complexes. However, the above situation is even more complicated for mine and municipal effluents as a result of the competition of trace metal ions with nickel for the same binding sites of DOC, the screening effect of major cations, and the different binding capacities of DOC from different sources. 
Table 2.3. Some chemical properties of the mine aqueous effluent water samples collected from Sudbury area, Ontario.

\begin{tabular}{|c|c|c|c|c|c|c|c|}
\hline & $\begin{array}{l}\text { Vermillion River } \\
\text { Water (VRW) }\end{array}$ & $\begin{array}{r}\text { Copper Cliff Mine } \\
\text { Effluent (CCME) }\end{array}$ & $\begin{array}{l}\begin{array}{l}\text { Garson Mine Effluent } \\
\text { (GME) }\end{array} \\
\end{array}$ & $\begin{array}{l}\text { Crean Hill Mine } \\
\text { Effluent (CHME) }\end{array}$ & $\begin{array}{l}\text { Sudbury Municipal } \\
\text { Effluent (SME) }\end{array}$ & Mixture 1 & Mixture 2 \\
\hline pH & 6.7 & 7.6 & 7.9 & 7.5 & 6.5 & 7.0 & 7.10 \\
\hline Conductivity (mS/m) & 20.1 & 359.0 & 255.0 & 26.9 & 76.3 & 157.1 & 179.2 \\
\hline $\operatorname{DOC}(\mathrm{mg} / \mathrm{L})^{\mathrm{a}}$ & 9.90 & 6.32 & 2.90 & 3.37 & 23.21 & 7.12 & 5.04 \\
\hline \multicolumn{8}{|l|}{$[\mathbf{M}]^{b}$} \\
\hline $\begin{array}{l}\mathrm{Ni} \\
\mathrm{Zn} \\
\mathrm{Cd} \\
\mathrm{Cu} \\
\mathrm{Al} \\
\mathrm{Co} \\
\mathrm{Pb} \\
\mathrm{Mn}\end{array}$ & $\begin{array}{l}7.2 \times 10^{-7} \\
2.8 \times 10^{-7} \\
8.9 \times 10^{-11} \\
2.0 \times 10^{-7} \\
2.6 \times 10^{-6} \\
\text { detectable } \\
2.1 \times 10^{-9} \\
4.7 \times 10^{-8}\end{array}$ & $\begin{array}{l}1.7 \times 10^{-6} \\
9.9 \times 10^{-7} \\
1.8 \times 10^{-9} \\
2.3 \times 10^{-6} \\
1.4 \times 10^{-6} \\
2.9 \times 10^{-8} \\
2.7 \times 10^{-9} \\
6.2 \times 10^{-8}\end{array}$ & $\begin{array}{l}7.7 \times 10^{-7} \\
4.8 \times 10^{-7} \\
6.0 \times 10^{-11} \\
1.8 \times 10^{-7} \\
1.7 \times 10^{-6} \\
\text { detectable } \\
3.6 \times 10^{-9} \\
3.9 \times 10^{-8}\end{array}$ & $\begin{array}{l}1.7 \times 10^{-6} \\
2.4 \times 10^{-7} \\
3.6 \times 10^{-10} \\
8.9 \times 10^{-8} \\
6.7 \times 10^{-7} \\
1.4 \times 10^{-8} \\
3.3 \times 10^{-9} \\
1.9 \times 10^{-7}\end{array}$ & $\begin{array}{l}1.3 \times 10^{-6} \\
1.4 \times 10^{-6} \\
6.1 \times 10^{-10} \\
3.2 \times 10^{-7} \\
1.8 \times 10^{-6} \\
5.7 \times 10^{-9} \\
2.9 \times 10^{-9} \\
5.2 \times 10^{-8}\end{array}$ & $\begin{array}{l}1.3 \times 10^{-6} \\
8.3 \times 10^{-7} \\
8.3 \times 10^{-10} \\
8.8 \times 10^{-7} \\
1.9 \times 10^{-6} \\
8.4 \times 10^{-9} \\
2.4 \times 10^{-9} \\
5.4 \times 10^{-8}\end{array}$ & $\begin{array}{r}1.2 \times 10^{-6} \\
6.0 \times 10^{-7} \\
8.8 \times 10^{-10} \\
1.2 \times 10^{-6} \\
2.1 \times 10^{-6} \\
8.3 \times 10^{-9} \\
2.4 \times 10^{-9} \\
5.4 \times 10^{-8}\end{array}$ \\
\hline \multicolumn{8}{|l|}{ Major Cations (M) ${ }^{c}$} \\
\hline $\begin{array}{l}\mathrm{Mg} \\
\mathrm{Ca} \\
\mathrm{Na} \\
\mathrm{K}\end{array}$ & $\begin{array}{l}8.3 \times 10^{-4} \\
4.7 \times 10^{-4} \\
2.0 \times 10^{-4} \\
7.8 \times 10^{-3}\end{array}$ & $\begin{array}{l}1.0 \times 10^{-3} \\
7.8 \times 10^{-3} \\
6.6 \times 10^{-3} \\
7.1 \times 10^{-3}\end{array}$ & $\begin{array}{c}1.2 \times 10^{-3} \\
3.9 \times 10^{-3} \\
10.2 \times 10^{-3} \\
5.6 \times 10^{-3}\end{array}$ & $\begin{array}{c}\mathrm{ND} \\
8.1 \times 10^{-4} \\
1.6 \times 10^{-4} \\
4.5 \times 10^{-5}\end{array}$ & $\begin{array}{l}8.8 \times 10^{-4} \\
8.4 \times 10^{-4} \\
5.4 \times 10^{-3} \\
7.4 \times 10^{-3}\end{array}$ & $\begin{array}{l}1.1 \times 10^{-3} \\
4.3 \times 10^{-3} \\
5.1 \times 10^{-3} \\
1.2 \times 10^{-2}\end{array}$ & $\begin{array}{l}1.0 \times 10^{-3} \\
5.8 \times 10^{-3} \\
4.2 \times 10^{-4} \\
4.0 \times 10^{-3}\end{array}$ \\
\hline \multicolumn{8}{|l|}{ Major Anions $(\mathbf{M})^{d}$} \\
\hline $\begin{array}{l}\mathrm{F} \\
\mathrm{Cl} \\
\mathrm{NO}_{3} \\
\mathrm{SO}_{4} \\
\end{array}$ & $\begin{array}{c}5.6 \times 10^{-5} \\
2.7 \times 10^{-4} \\
\mathrm{ND} \\
2.2 \times 10^{-4} \\
\end{array}$ & $\begin{array}{l}3.1 \times 10^{-4} \\
2.4 \times 10^{-3} \\
8.6 \times 10^{-5} \\
2.1 \times 10^{-2} \\
\end{array}$ & $\begin{array}{l}4.3 \times 10^{-4} \\
8.1 \times 10^{-3} \\
5.2 \times 10^{-4} \\
7.4 \times 10^{-3} \\
\end{array}$ & $\begin{array}{l}1.2 \times 10^{-5} \\
7.1 \times 10^{-5} \\
1.1 \times 10^{-5} \\
7.1 \times 10^{-4} \\
\end{array}$ & $\begin{array}{l}\cdots \\
-- \\
--- \\
\end{array}$ & $\begin{array}{c}4.5 \times 10^{-4} \\
7.5 \times 10^{-4} \\
\mathrm{ND} \\
8.4 \times 10^{-3} \\
\end{array}$ & $\begin{array}{l}4.6 \times 10^{-4} \\
1.3 \times 10^{-3} \\
3.3 \times 10^{-4} \\
5.4 \times 10^{-3} \\
\end{array}$ \\
\hline
\end{tabular}

${ }^{\mathbf{a}}$ Determined by Shimadzu Total Organic Carbon Analyzer, Model TOC-VCSH; ${ }^{\mathbf{b}}$ Determined by ICP-MS; ${ }^{\mathbf{c}}$ Determined by Thermo Jarrel Ash IRIS Radial Inductively Coupled Plasma Optical Emission Spectrometer (ICP-OES); ${ }^{\mathbf{d}}$ Determined by Dionex Series $4000 \mathrm{i}$ Ion Chromatograph; Mixture 1: 45\% CCME + 55\% VRW; Mixture 2: 30\% CCME + 30\% VRW + 40\% SME. ND: could not be determined; ---: not enough samples to do the analysis. 
Table 2.4. Some important chemical properties of the mining and municipal aqueous effluent samples

\begin{tabular}{|c|c|c|c|c|c|}
\hline Sample & pH & $\begin{array}{c}\text { Conductivity } \\
(m S / m)\end{array}$ & $\begin{array}{l}\mathbf{N i}]_{\text {Total }} \\
(\mathbf{M})\end{array}$ & $\begin{array}{c}\text { DOC } \\
(\mathrm{mg} / \mathrm{L})\end{array}$ & $\begin{array}{c}{[\mathrm{Ni}]_{\text {Total }} /[\mathbf{D O C}]} \\
(\mathrm{M} \text { in } \mathrm{mg} / \mathrm{L}) \\
\end{array}$ \\
\hline $\begin{array}{c}\text { Vermillion River Water } \\
\text { (VRW) }\end{array}$ & 6.7 & 20.1 & $7.2 \times 10^{-7}$ & 9.90 & 0.015 \\
\hline $\begin{array}{c}\text { Copper Cliff Mine Effluent } \\
\text { (CCME) }\end{array}$ & 7.6 & 359.0 & $1.7 \times 10^{-6}$ & 6.32 & 0.053 \\
\hline $\begin{array}{c}\text { Garson Mine Effluent } \\
\text { (GME) }\end{array}$ & 7.9 & 257.0 & $7.7 \times 10^{-7}$ & 2.90 & 0.053 \\
\hline $\begin{array}{l}\text { Crean Hill Mine Effluent } \\
\text { (CHME) }\end{array}$ & 7.5 & 255.0 & $1.7 \times 10^{-6}$ & 3.37 & 0.096 \\
\hline $\begin{array}{l}\text { Sudbury Municipal Effluent } \\
\text { (SME) }\end{array}$ & 6.5 & 76.3 & $1.3 \times 10^{-6}$ & 23.22 & 0.011 \\
\hline Mixture 1 & 7.1 & 179.2 & $1.2 \times 10^{-6}$ & 5.04 & 0.046 \\
\hline Mixture 2 & 7.0 & 157.1 & $1.3 \times 10^{-6}$ & 7.12 & 0.032 \\
\hline
\end{tabular}

Mixture 1: 45\% CCME + 55\% VRW.

Mixture 2: $30 \%$ CCME + 30\% VRW + 40\% SME. 


\subsubsection{Kinetic speciation of nickel by CLEM/AdCSV}

The kinetic data from the undiluted and diluted samples are presented in Figs. 2.3 and 2.4, respectively. The signal in CLEM/AdCSV was measured in the peak height mode. The relative concentration of free nickel released during the reaction is given by the quotient $i_{\mathrm{p}} / i_{\mathrm{o}}$, where $i_{p}$ represents the current observed with the sample, and $i_{o}$ represents the current observed for a reference solution of nickel with no complexation. Each curve in Figs. 2.3 and 2.4 shows two distinguishable features: a quickly rising section that represents the rapid dissociation of weak Ni(II)-DOC complexes, weak inorganic complexes and free $\mathrm{Ni}^{2+}$ ion, and a very slowly rising section that lies almost parallel to $\mathrm{x}$-axis, which can be attributed to strong $\mathrm{Ni}(\mathrm{II})$ DOC complexes. The data in Figs. 2.3 and 2.4 were fitted to the Kinetic Model (Eq. 3) by non-linear regression analysis using Marquardt-Levenberg algorithm. The results are presented in Table 2.5. Although these data were fitted to a simplified equation, it is necessary to note that the systems are complex. The first part of all curves in Fig. 2.3 is almost indistinguishable from one another, suggesting that it represents dissociation of nickel complexes having very similar dissociation rate constants; probably, they are all metal complexes of low thermodynamic stability and are labile. The highest \% of nickel released (ip/io \%) from Ni(II)-DOC complexes was observed in Crean Hill Mine effluent, followed by Copper Cliff Mine effluent, and Vermillion River water. The lowest fraction of nickel released was observed in Garson Mine effluent. Figure 2.3 shows that in Crean Hill Mine effluent, $86 \%$ of total dissolved nickel is labile, and $76.2 \%$ of total nickel in Copper Cliff Mine effluent is 


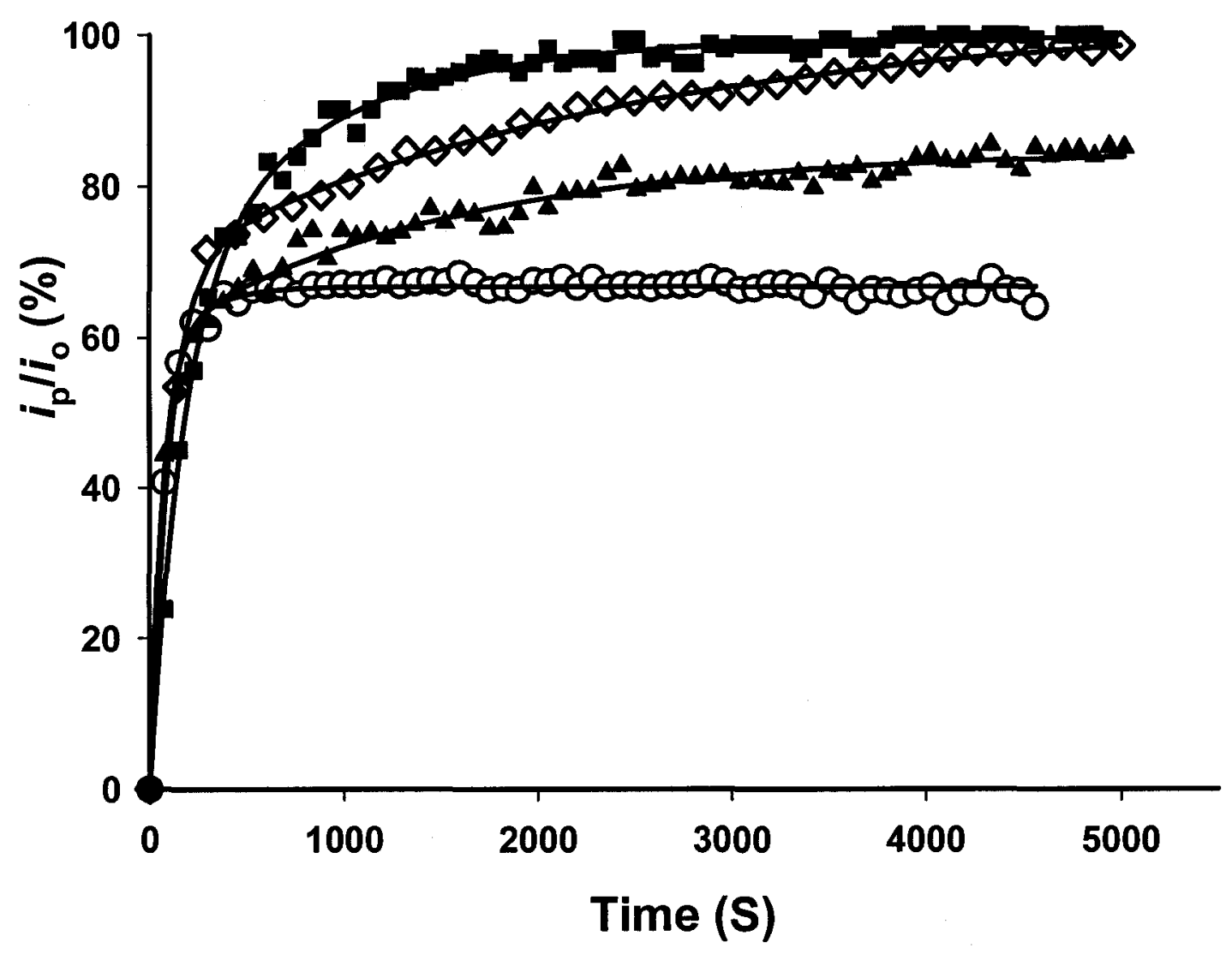

Figure 2.3 The percentage of $\mathrm{Ni}(\mathrm{II})$ released $\left(i_{\mathrm{p}} / i_{o}\right) \%$ from $\mathrm{Ni}(\mathrm{II})$-DOC complexes in mine aqueous effluent water samples, determined by CLEM/AdSV. DMG was the competing ligand. ( $\square$, Crean Hill Mine effluent; $(\diamond)$, Copper Cliff Mine effluent; ( $\mathbf{\Delta}$ ), Vermillion River water; (O), Garson Mine effluent. Solid lines represent non-linear curve fitting. 


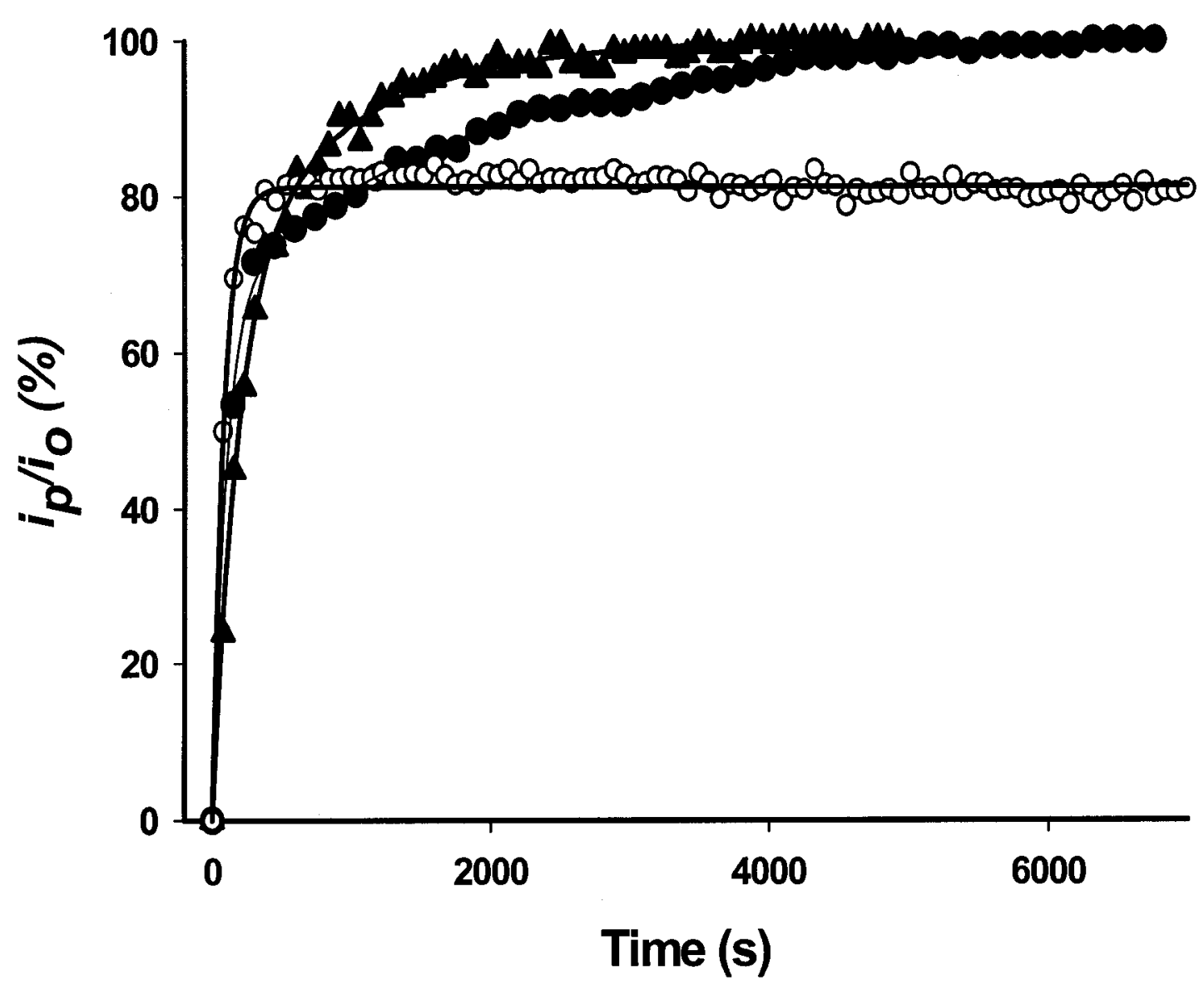

Figure 2.4 The effect of dilution on the percentage of Ni(II) released $\left(i_{\mathrm{p}} / i_{o}\right) \%$ from Ni(II)-DOC complexes in Copper Cliff Mine aqueous Effluent, determined by CLEM/AdSV. DMG was the competing ligand. (•), 100\% Copper Cliff Mine effluent; (o), Mixture of 45\% Copper Cliff Mine effluent and 55\% Vermillion River water sample; ( $\boldsymbol{\Delta}), 30 \%$ Copper Cliff Mine effluent, $30 \%$ Vermillion River water and $40 \%$ Sudbury Municipal effluent. Solid lines represent non-linear curve fitting. 
Table 2.5. Kinetically distinguishable components of nickel speciation by CLEM/AdSV using DMG as the competing ligand.

\begin{tabular}{|c|c|c|c|c|}
\hline Samples & $\mathrm{C}_{1}(\%)$ & $\mathrm{C}_{2}(\%)$ & $k_{1}\left(\times 10^{-3}\right), s^{-1}$ & $\mathbf{k}_{2}\left(\times 10^{-5}\right), \mathrm{s}^{-1}$ \\
\hline $\begin{array}{c}\text { Vermillion River Water } \\
\text { (VRW) }\end{array}$ & $69.0 \pm 2.0$ & $30.6 \pm 1.2$ & $10.2 \pm 0.5$ & $1.0 \pm 0.5$ \\
\hline $\begin{array}{l}\text { Copper Cliff Mine Effluent } \\
\text { (CCME) }\end{array}$ & $75.2 \pm 2.5$ & $24.8 \pm 2.6$ & $10.3 \pm 0.6$ & $5.1 \pm 0.5$ \\
\hline $\begin{array}{c}\text { Garson Mine Effluent } \\
\text { (GME) }\end{array}$ & $66.6 \pm 2.6$ & $33.4 \pm 1.1$ & $1.2 \pm 0.4$ & $8.6 \pm 0.5$ \\
\hline $\begin{array}{l}\text { Crean Hill Mine Effluent } \\
\text { (CHME) }\end{array}$ & $86.0 \pm 2.7$ & $14.1 \pm 1.8$ & $5.7 \pm 0.4$ & $1.2 \pm 0.4$ \\
\hline $\begin{array}{l}\text { Sudbury Municipal Effluent } \\
\text { (SME) }\end{array}$ & -- & --- & --- & --- \\
\hline Mixture 1 & $75.9 \pm 3.0$ & $23.9 \pm 2.2$ & $3.5 \pm 0.2$ & $1.1 \pm 0.2$ \\
\hline \multicolumn{4}{|l|}{ Mixture 2} & $1.0 \pm 0.1$ \\
\hline
\end{tabular}

Mixture 1: $45 \%$ CCME + 55\% VRW.

Mixture 2: $30 \%$ CCME + 30\% VRW + 40\% SME.

--- could not be determined by CLEM/AdSV because of adsorption of organics on the electrode. 
labile. Vermillion River water, which has almost the same concentration of dissolved nickel as Garson Mine aqueous effluent shows similar $i_{p} / i_{o} \%$ ( $66.0 \%$ vs $69.0 \%$ ). The dissolved concentrations of nickel in Crean Hill Mine aqueous effluent ( $\mathrm{pH}$ 7.5) and in Copper Cliff Mine effluent ( $\mathrm{pH}$ 7.6) were similar. The increase in release of nickel from Ni(II)-DOC complexes in Crean Hill Mine effluent was probably due to higher nickel-to-DOC ratio (Table 2.4). The dissociation rate constant of the fastest component (labile) in Copper Cliff Mine effluent $\left(\mathrm{k}_{\mathrm{d} 1}\right)$ was found to be $1.03 \times 10^{-2} \mathrm{~s}^{-}$ ${ }^{1}$, suggesting that it probably represents the $\mathrm{Ni}^{2+}$ free metal ion [i.e. $\mathrm{Ni}\left(\mathrm{H}_{2} \mathrm{O}\right)_{6}{ }^{2+}$ ] and other labile nickel species. Lavigne et al. [14] reported, $\mathrm{Ni}\left(\mathrm{H}_{2} \mathrm{O}\right)_{6}{ }^{2+}$ species with a rate constant of $0.62 \mathrm{~s}^{-1}$. Garson Mine effluent containing the lowest nickel-to-DOC ratio of all the samples of mining and municipal effluents released the lowest percentage of nickel from $\mathrm{Ni}(\mathrm{II})$-DOC complexes among all the samples. The fastest component, $c_{l}$, with the dissociation rate constant $\left(\mathrm{k}_{\mathrm{d} 1}\right)$ for $\mathrm{Ni}(\mathrm{II})-\mathrm{DOC}$ complexes in Garson Mine effluent was found to be $1.2 \times 10^{-3} \mathrm{~s}^{-1}$. The data for the kinetic speciation of nickel in Sudbury Municipal effluent is not available because it contained very high concentration of DOC, which probably resulted in the adsorption of DOC on the surface of the hanging mercury drop electrode and prevented its proper functioning.

The $\mathrm{pH}$ was found to have a strong effect on the extent of binding as is the case for any weak acid ligand whose apparent affinity for a metal would increase with $\mathrm{pH}$. This effect is exacerbated by the increase in coulombic attraction of the metal ion to the binding sites as the humic acid (a major part of DOC) becomes deprotonated [15] at higher pH. Similarly, even though Vermillion River water is rich with DOC the 
lower $\mathrm{pH}$ in Vermillion River water ( $\mathrm{pH}$ 6.7), has probably resulted in weaker nickel species by reducing the degree of deprotonation of the DOC.

Copper Cliff Mine effluent was diluted with Vermillion River water as follows: $45 \%$ (v/v) Copper Cliff Mine effluent with 55\% (v/v) of Vermillion River water. The dilution of the effluent did not affect the relative concentration of nickel released but affected the dissociation rate constants. The dissociation rate constant $\left(k_{d 1}\right)$ of the fastest component $\left(c_{1}\right)$ in the diluted effluent sample was found to be lower than that of the fastest component $\left(c_{1}\right)$ of Ni-DOC complexes in the undiluted Copper Cliff Mine effluent (Table 2.5 and Fig. 2.4). The results of the analysis of the diluted sample containing 30\% (v/v) of Copper Cliff Mine effluent, 30\% (v/v) of Sudbury Municipal effluent and 40\% (v/v) Vermillion River water, showed that the nickel released from $\mathrm{Ni}$ (II)-DOC complexes was $91.1 \%$ (Table 2.5 and Fig. 2.4). Such a high value of nickel released from $\mathrm{Ni}(\mathrm{II})-\mathrm{DOC}$ complexes in the effluents on mixing with receiving freshwaters (Vermillion River water) would constrain the choice of receiving waters for mixing with polluted natural waters, and may present problems for managers and regulators of freshwater resources in the choice for freshwaters for mixing with metal-contaminated mining, industrial and municipal effluents.

\subsubsection{Kinetic speciation of nickel by CLEM/GFAAS}

Kinetic data for the speciation of nickel in undiluted and diluted effluents by CLEM/GFAAS are presented in Figs. 2.5 and 2.6, respectively. The relative concentration of nickel was plotted as a function of time. The data in Figs. 2.5 and 2.6 were fitted to the kinetic model (Eq. 4) by nonlinear regression analysis to obtain the 
relative concentration of each kinetically distinguishable component and their associated dissociation rate constants. Two kinetically distinguishable components were observed in each of the curves in Figs. 2.5 and 2.6. The steeply rising section at the beginning of each curve $\left(k_{d 1} \sim 10^{-3} \mathrm{~s}^{-1}\right)$ in Figs. 2.5 and 2.6 can be attributed to uptake of the $\mathrm{Ni}^{2+}$ free metal ion and/or rapidly dissociating inorganic complexes of nickel, and rapidly dissociating organic complexes of nickel (repeated). The rate constant for the uptake of $\mathrm{Ni}^{2+}$ aqua complex by Chelex 100, was reported to be $(4 \pm$ 2) $\times 10^{-2} \mathrm{~s}^{-1}$ by Sekaly et al. [16]. The results suggest that complexes with dissociation rate constants $>10^{-2} \mathrm{~s}^{-1}$ cannot be experimentally differentiated from the metal aqua complex using the CLEM/GFAAS technique.

In Figs. 2.5 and 2.6, the fastest dissociation kinetics was observed in Crean Hill Mine effluent as found by using CLEM/AdCSV, and the slowest dissociation kinetics was observed in Sudbury Municipal effluent, which was rich in DOC. The kinetic speciation of Ni(II)-DOC complexes in this sample could not be determined by CLEM/AdCSV because of adsorption of organics on the HMDE. However, CLEM/GFAAS is free from this adsorption interference and could determine the kinetic speciation of nickel in the Sudbury Municipal effluent and had advantages over CLEM/AdCSV in this respect. The low nickel-to-DOC ratio in Sudbury Municipal effluent was responsible for the slowest dissociation kinetics of Ni(II)-DOC complexes (Fig. 2.5). For the Sudbury Municipal effluent which contained relatively high concentrations of DOC (Table 2.4), the 


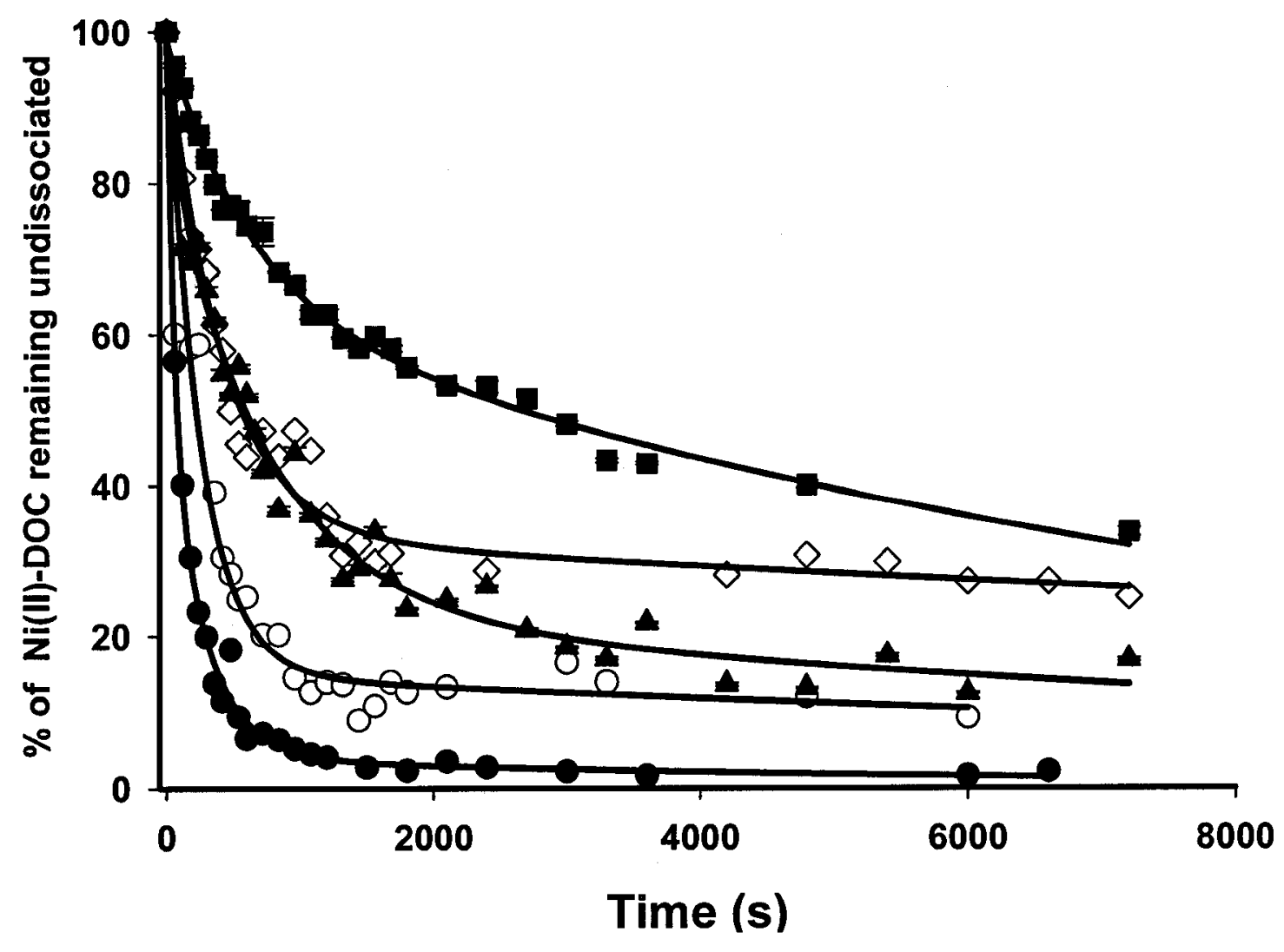

Figure 2.5 The percentage of $\mathrm{Ni}(\mathrm{II})$ released from $\mathrm{Ni}(\mathrm{II})-\mathrm{DOC}$ complexes in mine effluent aqueous samples, determined by CLEM/GFAAS. Chelex 100 was the competing ligand. $(\varpi)$, Sudbury Municipal effluent; $(\diamond)$, Garson Mine effluent; ( $\mathbf{\Delta}$ ), Copper Cliff Mine effluent; $(O)$, Vermillion River water; $(\bullet)$, Crean Hill Mine effluent. Solid lines represent non-linear curve fitting. 


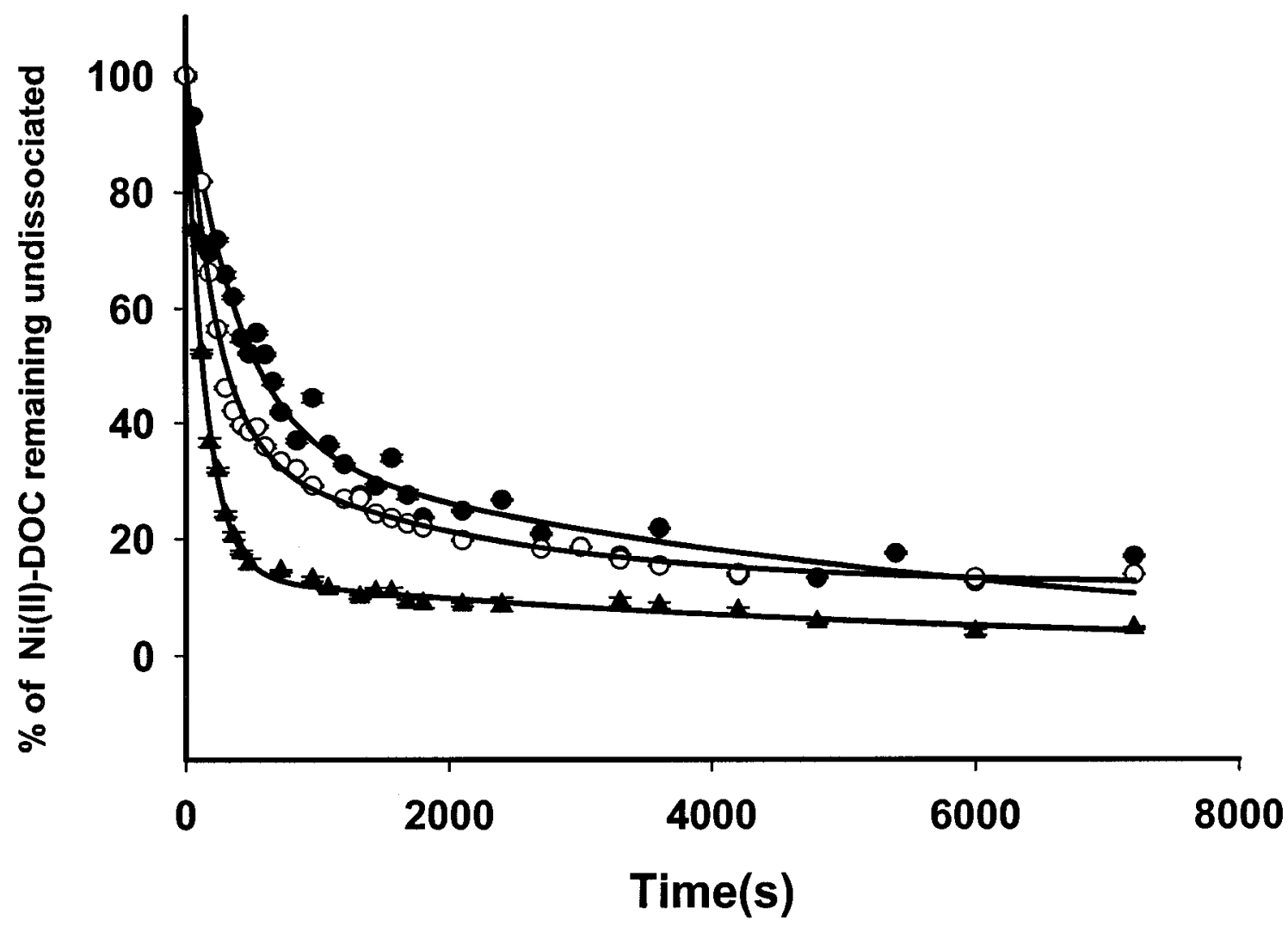

Figure 2.6 The effect of dilution on the percentage of Ni(II) released from Ni(II)DOC complexes in Copper Cliff Mine Aqueous Effluent, determined by CLEM/GFAAS. Chelex-100 was the competing ligand. (•), 100\% Copper Cliff Mine effluent; (o), Mixture of 45\% Copper Cliff Mine effluent and $55 \%$ Vermillion River water sample; ( $\mathbf{\Delta})$, Mixture of $30 \%$ Copper Cliff Mine effluent, $30 \%$ Vermillion River water and $40 \%$ Sudbury Municipal effluent. Solid lines represent non-linear curve fitting. 
Table 2.6. Kinetically distinguishable components of nickel speciation by CLEM/GFAAS using Chelex 100 as the competing ligand

\begin{tabular}{ccccc}
\hline Samples & $\mathbf{C}_{\mathbf{1}}(\mathbf{\%})$ & $\mathbf{C}_{\mathbf{2}}(\%)$ & $\mathbf{k}_{\mathbf{1}}\left(\times 10^{-\mathbf{3}}\right), \mathbf{s}^{-1}$ & $\mathbf{k}_{\mathbf{2}}\left(\times 10^{-5}\right), \mathbf{s}^{-1}$ \\
\hline $\begin{array}{c}\text { Vermillion River Water } \\
\text { (VRW) }\end{array}$ & $83.3 \pm 3.1$ & $17.0 \pm 4.0$ & $3.9 \pm 0.1$ & $5.7 \pm 0.5$ \\
$\begin{array}{c}\text { Copper Cliff Mine Effluent } \\
\text { (CCME) }\end{array}$ & $76.2 \pm 2.5$ & $23.8 \pm 2.6$ & $2.4 \pm 0.3$ & $2.2 \pm 0.4$ \\
$\begin{array}{c}\text { Garson Mine Effluent } \\
\text { (GME) }\end{array}$ & $67.5 \pm 2.6$ & $33.4 \pm 1.1$ & $2.5 \pm 0.6$ & $3.5 \pm 0.2$ \\
$\begin{array}{c}\text { Crean Hill Mine Effluent } \\
\text { (CHME) }\end{array}$ & $89.5 \pm 2.7$ & $10.2 \pm 1.5$ & $12.6 \pm 0.2$ & $1.9 \pm 0.1$ \\
$\begin{array}{c}\text { Sudbury Municipal Effluent } \\
\text { (SME) }\end{array}$ & $34.9 \pm 1.7$ & $65.3 \pm 1.5$ & $1.6 \pm 0.1$ & $10.0 \pm 0.3$ \\
$\begin{array}{l}\text { Mixture 1 } \\
\text { Mixture 2 }\end{array}$ & $75.9 \pm 2.0$ & $24.0 \pm 2.2$ & $3.6 \pm 0.4$ & $2.0 \pm 0.1$ \\
\hline
\end{tabular}

Mixture 1: $45 \%$ CCME $+55 \%$ VRW

Mixture 2: $30 \% \mathrm{CCME}+30 \% \mathrm{VRW}+40 \% \mathrm{SME}$. 
nickel-to-DOC ratio was so low as to make Ni(II)-DOC complexes less labile - the fastest components was about one-third of the total nickel concentration, which was in marked contrast with the other effluent samples (Table 2.6).

Copper Cliff Mine aqueous effluent (45\%) was diluted with Vermillion River water as mentioned earlier. In CLEM/GFAAS, it was found that the dilution (45\%) of the effluent did not affect the percentage of nickel metal released from $\mathrm{Ni}(\mathrm{II})-\mathrm{DOC}$ complexes but affected the dissociation rate constant of Ni(II)-DOC complexes - an increase in the relative concentration of nickel released from $\mathrm{Ni}(\mathrm{II})-\mathrm{DOC}$ complexes was observed for the sample of Copper Cliff Mine effluent (30\%), diluted with Sudbury Municipal effluent (30\%) and Vermillion River water (40\%).

Kinetic speciation data obtained by using CLEM/GFAAS showed good agreement with those obtained by using CLEM/AdCSV (Tables 5 and 6). Both the techniques showed that the relative concentration of the fast component $\left(c_{1}\right)$ increased with increasing nickel-to-DOC ratio. Figure 2.7 showed that the fast component $\left(c_{1}\right)$ increased asymptotically with the nickel-to-DOC ratio; with increasing ratios, the slope of growth decreased and tended to reach a constant value as the ratio reached 0.01 . The fastest components $\left(c_{1}\right)$ did not increase beyond this value even with further increase in the nickel-to-DOC ratio. The results indicate a progressive increase in the dissociation rate constants with increasing metal-to-DOC ratio, suggesting that the observed dissociation rate constants are associated with progressively weaker sites as the metal loading of the system is increased. A unique property of DOC is that their metal binding properties change with the degree of metal loading of the system [17]. The progressive increase in the observed dissociation rate constants with increasing 
metal-to-DOC ratio arises from the chemical and physical heterogeneity [18] of DOC. The results suggest that DOC has a wide range of sites with closely spaced binding energies, the cooperative metal-binding activity of which enable metals to be buffered over a large concentration range, spanning several orders of magnitude, with only gradual changes in free metal ion concentration [18]. The results are in agreement with the trend in complexation capacity observed by Town and Filella [19] for the speciation of $\mathrm{Cu}(\mathrm{II}), \mathrm{Zn}(\mathrm{II}), \mathrm{Cd}(\mathrm{II})$ and $\mathrm{Pb}$ (II) collected from a large data set of published literature on natural waters. A corollary of the above observation is that the sample which has an unusually large concentration of DOC compared with other samples, such as, Sudbury Municipal effluent sample, which has $23.22 \mathrm{mg} / \mathrm{L}$ of DOC (Table 2.4), and hence, the lowest nickel-to-DOC ratio, is predicted to have the largest component of the slowly labile Ni(II)-DOC complex and the smallest component of $\left(c_{1}=34.9 \pm 1.7 \%\right)$, which was the smallest $\mathrm{C}_{1} \%$ in Table 2.6, agrees with this prediction.

The first steep rising parts of all the curves obtained by using CLEM/AdCSV (Figs. 2.3 and 2.4) are indistinguishable, whereas the data obtained by using CLEM/GFAAS (Figs. 2.5 and 2.6) the first part of each curve is separated from each other. This was probably due to the shorter signal-measurement time in CLEM/AdCSV than in CLEM/GFAAS. Another probable explanation is considering humic substances as water-swollen gels, with functional groups for cation binding, both outside and inside of the cavernous gels. In interpreting their metal-complex formation and dissociation, their aggregational and conformational equilibria and diffusion of metal ions inside the cavern need be considered. 
In CLEM/AdCSV, it is likely that immediately after the dissociation of Ni-DOC bond inside the cavernous gel, DMG (liquid) can easily go inside the cavernous gel of humic acid and bind with $\mathrm{Ni}^{2+}$ ion. $\mathrm{Ni}(\mathrm{DMG})_{2}$ complexes can then easily diffuse out from the cavern. As a result, CLEM/AdCSV can measure the faster dissociation coefficient of Ni-DOC complexes. However, in CLEM/GFAAS, Chelex-100 (solid sphere), the competing ligand, can not go inside the cavernous gel and the formation of $\mathrm{Ni}-\mathrm{Chelex}$ bond depends on the dissociation of $\mathrm{Ni}-\mathrm{DOC}$ bond and followed by diffusion of the $\mathrm{Ni}^{2+}$ ion inside the cavernous gel of DOC. As a combined effect of the above two results, indistinguishable steeply rising curves were observed for all the samples by using CLEM/AdCSV (Figs. 2.3 and 2.4) and distinguishable rapidly falling curves obtained for the same samples by using CLEM/GFAAS (Figs. 2.5 and 2.6).

It seems from the data presented in Tables 5 and 6 that CLEM/AdCSV is suitable for relatively fast kinetics. CLEM/AdCSV and CLEM/GFAAS are equally suitable for slow kinetics. However, the two techniques are complementary to each other because of their different analytical windows.

\subsubsection{Comparison of the experimental results with the WHAM VI predictions}

The Windermere Humic Aqueous Model VI (WHAM VI), developed by Tipping [2023], is a thermodynamic equilibrium-based model that assumes discrete-site electrostatic binding. WHAM VI is able to predict free metal ion concentrations given some easily determined input parameters such as $\mathrm{pH}$ and concentrations of total metals, dissolved anions and cations, and DOC (Table 2.3). Accurate determination 
of free metal ion concentrations in freshwaters is necessary for studying the interactions of metals with DOC in freshwaters. Figure 2.8 presents a comparison of the experimentally measured results with the WHAM VI predictions for nickel in the undiluted and the diluted effluent and in freshwater samples. It is important to note that for the metal speciation, CLEM/AdCSV and CLEM/GFAAS give an analytical signal which represents the sum of the free plus labile $\mathrm{Ni}^{2+}$ species, whereas the WHAM-VI predicted values represent the free nickel ion concentration. Figure 2.8 shows that the free nickel ion and inorganic nickel complexes concentrations predicted by WHAM VI agree reasonably well with the measured concentrations of the sum of the labile complexes of the nickel. The dashed line represents 1:1 line. One problem in modelling by WHAM is that it requires an input datum for the concentration of "active" DOC, [24-30] i.e. the concentration of DOC that behaves like isolated, fulvic acid, and is actively involved in the binding of metals. This is an important parameter since it determines the number of binding sites available to the metals. Since the value of the "active" concentration of DOC, although critical, was not known, the effluent sample was modelled using four different active DOC concentrations: $50,60,75$, and $80 \%$ of the DOC as "active" to determine the "active" DOC concentration that best fitted the measured labile nickel ion concentrations.

The WHAM VI model with $75 \%$ active DOC concentrations fits well with the experimental results of $\mathrm{Ni}(\mathrm{II})$ complexes (Table 2.7); however, for Sudbury Municipal effluent, the WHAM VI model with $75 \%$ active DOC concentration predicted lower values than the measured values of the labile fraction of nickel. 


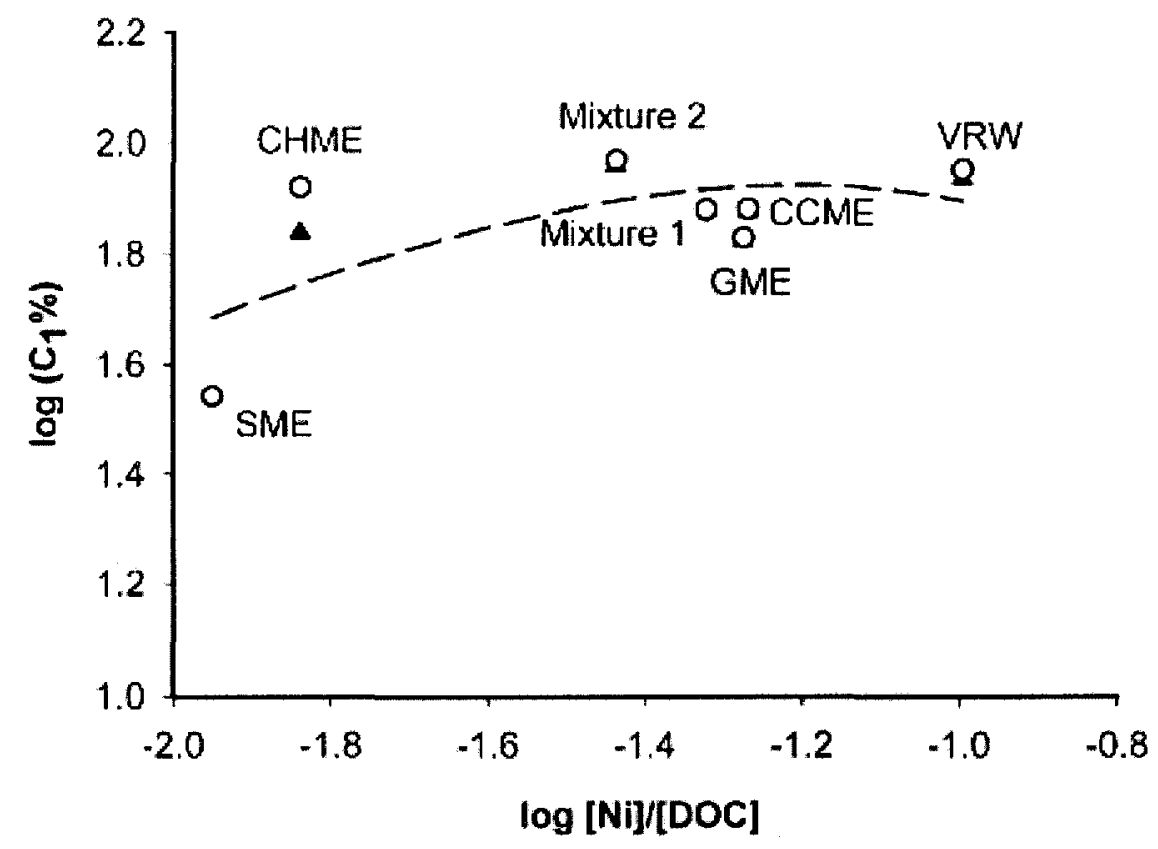

Figure 2.7 The effect of nickel-to-DOC mole ratio on the fast dissociating component $\left(\% \mathrm{C}_{1}\right)$ of $\mathrm{Ni}(\mathrm{II})-\mathrm{DOC}$ complexes in mine effluent water samples collected from the Sudbury area, Ontario, Canada. (o), $\% \mathrm{C}_{1}$ determined by CLEM/GFAAS. Chelex-100 was the competing ligand; ( $\mathbf{\Delta}), \% \mathrm{C}_{1}$ determined by CLEM/AdSV. DMG was the competing ligand. VRW: Vermillion River water; CCME: Copper Cliff Mine effluent; GME: Garson Mine effluent; CHME: Crean Hill Mine effluent; SME: Sudbury Municipal effluent; Mixture 1: 45\% CCME + 55\% VRW; Mixture 2: 30\% CCME + 30\% VRW + 40\% SME. 


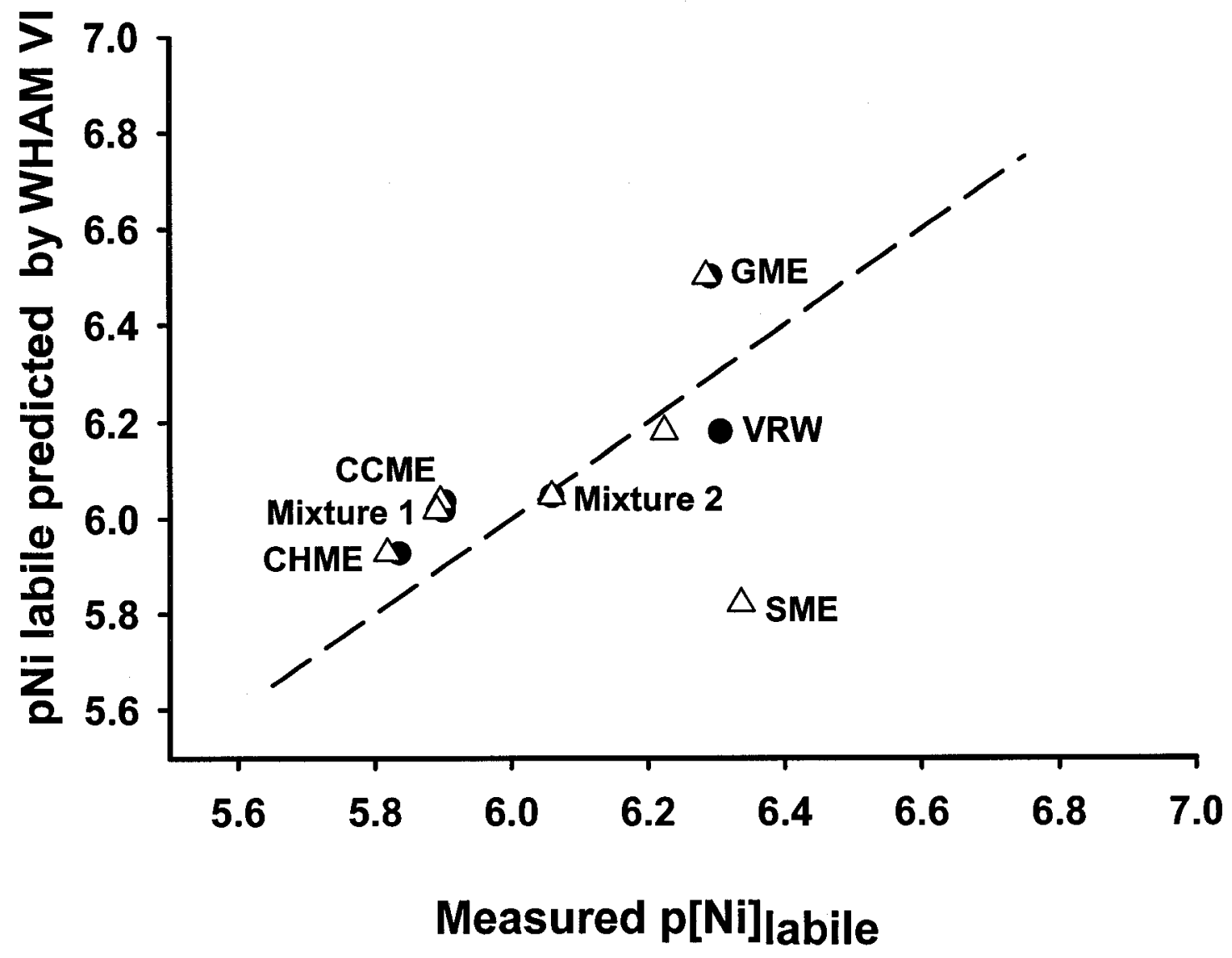

Figure 2.8 Comparison of the pNi labile predicted by WHAM VI, with the measured concentrations of labile $\mathrm{Ni}(\mathrm{II})$-complexes in mine effluent water samples collected from the Sudbury area, Ontario, Canada. (---) 1:1 line. WHAM VI predictions based on $75 \%$ of the DOC as a 'active'. $(\bullet)$, Free metal ion plus labile metal complexes measured by CLEM/AdSV, DMG was the competing ligand; $(\Delta)$, Free metal ion plus labile metal complexes measured by CLEM/GFAAS. Chelex-100 was the competing ligand. VRW: Vermillion River water; CCME: Copper Cliff Mine effluent; GME: Garson Mine effluent; CHME: Crean Hill Mine effluent; SME: Sudbury Municipal effluent; Mixture 1: 45\% CCME + 55\%VRW; Mixture 2: 30\% CCME+ 30\% VRW + 40\% SME. 
Table 2.7. WHAM model predictions of the speciation of nickel in mine effluent water samples based on $75 \%$ of the DOC as "active", and the measured concentrations of labile $\mathrm{Ni}(\mathrm{II})-\mathrm{DOC}$ complexes in mine effluent water samples collected from the Sudbury area, Ontario.

\begin{tabular}{lcccc}
\hline Sample & ${ }^{\mathrm{a}}[\mathrm{Ni}]_{\mathrm{t}}(\mathrm{M})$ & $\begin{array}{c}\text { WHAM VI } \\
\text { predictions } \\
(\mathbf{M})\end{array}$ & $\begin{array}{c}\text { Measured } \\
\text { concentration of labile } \\
\text { Ni(II)-DOC } \\
\text { complexes by CLEM/ } \\
\text { AdCSV } \\
(\mathbf{M})\end{array}$ & $\begin{array}{c}\text { Measured } \\
\text { concentration } \\
\text { of labile Ni(II)- } \\
\text { DOC complexes by } \\
\text { CLEM/GFAAS } \\
(\mathrm{M})\end{array}$ \\
\hline VRW & $7.2 \times 10^{-7}$ & $6.59 \times 10^{-7}$ & $4.97 \times 10^{-7}$ & $6.00 \times 10^{-7}$ \\
CCME & $1.7 \times 10^{-6}$ & $9.18 \times 10^{-7}$ & $1.28 \times 10^{-6}$ & $1.29 \times 10^{-6}$ \\
GME & $7.7 \times 10^{-7}$ & $3.16 \times 10^{-7}$ & $5.13 \times 10^{-7}$ & $5.20 \times 10^{-7}$ \\
CHME & $1.7 \times 10^{-6}$ & $1.18 \times 10^{-6}$ & $1.46 \times 10^{-6}$ & $1.52 \times 10^{-6}$ \\
SME & $1.3 \times 10^{-6}$ & $1.51 \times 10^{-6}$ & $-\cdots$ & $4.54 \times 10^{-7}$ \\
Mixture 1 & $1.3 \times 10^{-6}$ & $9.59 \times 10^{-7}$ & $1.19 \times 10^{-6}$ & $1.21 \times 10^{-6}$ \\
Mixture 2 & $1.2 \times 10^{-6}$ & $8.96 \times 10^{-7}$ & $9.11 \times 10^{-7}$ & $9.11 \times 10^{-7}$ \\
\hline
\end{tabular}

${ }^{\mathrm{a}}[\mathrm{Ni}]_{\mathfrak{t}}$ is total dissolved nickel, determined by ICP-MS.

${ }^{\mathrm{b}}$ Determined by Shimadzu Total Organic Carbon Analyzer, Model TOC-VCSH.

VRW: Vermillion River Water; CCME: Copper Cliff Mine Effluent; GME: Garson

Mine Effluent ;

CHME: Crean Hill Mine Effluent; SME: Sudbury Municipal Effluent;

Mixture 1: 45\% CCME + 55\% VRW;

Mixture 2: 30\% CCME+ 30\% VRW + 40\% SME. 
This may be due to the presence of anthropogenic organic matter, probably having different characteristics than humic substances used in the calibration of the WHAM. However, reasons for the differences between the WHAM VI predictions and the measured values of $\mathrm{p}(\mathrm{Ni}$ labile $)$ are not known. The wider wider application of such a simple model as WHAM to independent data may be an unreasonable expectation; also, artefacts associated with differences in analytical methods, or, experimental design may all be sources of differences.

\subsection{Conclusions}

The results presented in this chapter showed that CLEM/AdCSV is suitable to determine dissociation rate coefficient of M-DOC complexes with fast kinetics. CLEM/AdCSV and CLEM/GFAAS are equally suitable for slow kinetics. In natural waters, reaction kinetics of metal ions and heterogeneous complexants vary widely. CLEM/AdCSV which is suitable for the determination of fastest dissociation rate coefficients of M-DOC complexes was used for further studies. 


\subsection{References}

1. Guthrie J W, Mandal R, Salam M S, Hassan N M, Murimboh J, Chakrabarti C L, Back M H, Gregoire D C (2003) Anal Chim Acta 480:157-169.

2. Vermeer A W P, McCulloch J K, Van Riemsdijk W H, Koopal L K (1999) Environ Sci Technol 33: 3892-3897.

3. Langsto W J, Bryan G W, (1984) in: Complexation of Trace metals in Natural Waters; Kramer C J M, Duinker J C (Eds), Martinus Nijhoff/Dr. W. Junk Publishers: The Hague, The Netherlands, p 375.

4. Brown G K, Cabaniss S E, MacCarthy P, Leenheer JA (1999) Anal Chim Acta 402: 183-193.

5. Sutton R, Sposito G, (2005) Environ Sci Technol 39: 9009-9015.

6. Morel F M M, Hering JG (1993) Principles and Applications of Aquatic Chemistry, John Wiley, New York, USA p. 377.

7. Morel F M M, Hering JG (1993) Principles and Applications of Aquatic Chemistry, John Wiley, New York, USA p. 362.

8. Olson D L, Shuman MS (1985) Geochim Cosmochim Acta 49: 1371-1375.

9. Mandal R, Salam M S A, Murimboh J, Hassan NM, Chakrabarti CL, Back MH, Gregoire D C, Scrhoeder W H (1999) Anal Chim Acta 395:323-334

10. Chakrabarti C L, Back M H, Gregoire D C, Schroeder W H (1994) Anal Chim Acta 293:95-108.

11. Campbell P G C (1995) in Metal Speciation and Bioavailability in Aquatic Systems, John Wiley, New York, p.45. 
12. Guthrie J W, Mandal R, Salam M S, Hassan N M, Murimboh J, Chakrabarti C L, Back M H, Gregoire D C (2003) Anal Chim Acta 480:157-169.

13. Buffle J, Altmann R S, Fillela M (1990) Anal Chim Acta 232:225-237.

14. Lavigne J A, Langford C H, Mark M K S (1987) Anal Chem 59: 2616-2620.

15. Morel F M M (1993) Principles of Aquatic Chemistry, John Wiley, p. 388.

16. Sekaly A L R. Ph.D Thesis, Carleton University, Ottawa, Canada 2001.

17. Filella, M.; Buffle, J.; van Leeuwen, H. P. Anal. Chim. Acta 1990, 232, 209-232.

18. Buffle, J. Altmann, R. S.; Filella, M.; Tessier, A.; Geochim. Cosmochim. Acta $1990,54,1535-1553$.

19. Town, R. M.; Filella, M. Limnol. Oceanogr. 2000, 45, 1341-1357.

20. Tipping E (1994) Comp Geosci 20: 973.

21. Tipping E (1998) Aquatic Geochem 4:3.

22. Tipping E (1993) Colloids Surf A 73: 117.

23. Tipping E, Hurley M A (1992) Geochim Cosmochim Acta 56:3627.

24. Dwane GC, Tipping E (1998), Environ Int 24: 609-616.

25. Cabaniss SE, Shuman MS (1988) Geochim Cosmochim Acta 52:185-193

26. Bryan SE, Tipping E, Hamilton-Taylor J (2002) Comp Biochem Physiol C $133: 37-49$.

27. Nolan A L, Mclaughlin M J, Mason S D (2003) Environ Sci Technol 37:90-98

28. Tipping E, Lofts S, Lawlor A J (1998) Sci. Tot. Environ: 210-211: 63-77.

29. Lofts S, Tipping E (2000) Sci Tot Environ 251-252: 381-399

30. Tipping E, Rey-Castro C, Bryan S E, Hamilton-Taylor J (2002) Geochim Cosmochim Acta 66: 3211-3224. 
3

Chemical speciation of $\mathrm{Co}, \mathrm{Ni}, \mathrm{Cu}$, and $\mathrm{Zn}$ in mine aqueous effluents and the effect of effluent dilution on the release of the above metals from their metal-DOC complexes 


\subsection{Introduction}

Pollutant metals which may be present at relatively high concentrations in effluents from mines are potential hazards in the freshwater environment when it mixes with fresh waters. The bioavailability and toxicity of a metal-humate complex depends on its chemical speciation; hence, chemical speciation of trace metal is important in determining water quality. Interactions of trace metals with heterogeneous humic substance, which is ubiquitous in fresh waters, play an important role in trace metal transport, fate and bioavailability. Since freshwater environment is often a nonequilibrium system, kinetic approaches to the chemical speciation of metals are required in addition to the usual equilibrium approaches [1-6] in order to obtain a more complete picture of trace metal speciation, which influences toxicity to biota in fresh waters. In this chapter, kinetic speciation of $\mathrm{Co}, \mathrm{Ni}, \mathrm{Cu}$, and $\mathrm{Zn}$ was done by using CLEM/AdCSV. This was found to be more sensitive technique (Chapter 2).

In natural waters, complexation of trace metals by chemically heterogeneous humic substances may be influenced by heterogeneity of humic substances, metal loading and major cations [7]: sodium, potassium, calcium and magnesium, which may be present at many orders of magnitude greater concentrations $\left(\sim 10^{-3} \mathrm{M}\right)$ than those of trace metal ions $\left(<10^{-8} \mathrm{M}\right)$; their much greater concentrations outweigh their weaker metal-binding ability. It is well known that Copper Cliff Mine Effluent is treated by conventional hydroxide precipitation, lime addition, settling and subsequent $\mathrm{pH}$ adjustment prior to discharge and contain high concentration of major cations. In order to understand metal speciation in Copper Cliff Mine aqueous effluents, it is 
essential to know the effect of major cations on metal- HS complexation which has been discussed in Chapter 1.

The aim of this work was to study the speciation of $\mathrm{Co}$ (II), $\mathrm{Ni}$ (II), $\mathrm{Cu}$ (II) and $\mathrm{Zn}$ (II) in mining effluents and the effects of dilution of the effluents with water on the speciation of the metal-DOC complexes and the influence of the electronic configuration of $3 \mathrm{~d}$ transition metals, $\mathrm{Co}, \mathrm{Ni}, \mathrm{Cu}$ and $\mathrm{Zn}$, on the lability of their metal(II)-DOC complexes.

\subsection{Experimental section}

\subsubsection{Materials and Methodologies.}

For CLEM/AdCSV, a stock solution of 0.1 M DMG (Fischer Scientific) was prepared by dissolving an appropriate mass of pure dimethylglyoxime (DMG) in methanol (Caledon, spectro grade). A stock solution of 8-hydroxyquinoline (8-HQ) 0.1 (M) stock solution was prepared by dissolving an appropriate mass of pure 8-HQ in water containing a few drops of hydrochloric acid. A stock solution of ammonium 1pyrrolidinedithiocarbamate (APDC) $0.1 \mathrm{M}$ was prepared by dissolving appropriate mass of pure APDC (J.T. Baker Chemical Co. Phillipsburg, NJ) in $\sim 0.1 \% \mathrm{NH}_{3}$ aqueous solution. All competing ligands were added to ensure a large excess (at least 500-fold excess) over corresponding metal concentration. Metal standards were prepared from the inductively- coupled plasma mass spectrometry high-purity metal standards (SCP science, Montreal, Canada), $1000 \mathrm{mg} / \mathrm{L}$ for $\mathrm{Co}, \mathrm{Ni}, \mathrm{Cu}$ and $\mathrm{Zn}$, and $10000 \mathrm{mg} / \mathrm{L}$ for $\mathrm{Ca}$. These standards were used to prepare by serial dilution with 
ultrapure water, standard solutions of the above metals in ultrapure water, to which 1\% (V/V) ultrapure nitric acid (Baseline, Seastar Chemicals) was added to prevent metal loss by adsorption on the container walls. Ultrapure water of resistivity 18.2 $\mathrm{M} \Omega-\mathrm{cm}$, obtained from a Barnstead water system, was used to prepare all test solutions just prior to the kinetic run.

The soil humic acid (HA) was supplied by Dr. Les Evans (University of Guelph, Guelph, ON), who purified and characterized the HA according to the procedure recommended by the International Humic Substances Society [8].

All containers made of Teflon were pre-cleaned and filled with ultrapure water, following the procedure described by Chakrabarti et al. [9]. The water-filled containers were stored till they were used. The water in the containers was changed every week with ultrapure water of resistivity $18.2 \mathrm{M} \Omega$-cm.

Two aqueous effluent samples, supplied by Copper Cliff Mine in Sudbury, Ontario, Canada, were used: one was undiluted effluent (100\% effluent) and the other was diluted with the laboratory tap water so that it contained $45 \%$ of the original effluent ( $45 \%$ effluent); henceforth, the two effluent samples will be identified simply as the undiluted and the diluted effluent, respectively. The laboratory tap water used by Copper Cliff Mine to dilute the $100 \%$ effluent (to $45 \%$ effluent) contained $2 \mathrm{mg} / \mathrm{L}$ DOC. The DOC was determined with OI Analytical Model 1010TOC Analyzer. The metals (total dissolved concentrations) were determined by inductively-coupled plasma mass spectrometry using Perkin-Elmer Elan 6000 ICP-MS and by ICP-OES and the anions were determined by ion chromatography. 


\subsubsection{Instrumental and experimental conditions}

For the kinetic study by CLEM/AdCSV, an Autolab-PGSTAT (EcoChemie), controlled by a personal computer and equipped with a Metrohm 663 VA stand was used. The working electrode was a Hanging Mercury Drop Electrode (HMDE); the reference electrode an $\mathrm{Ag} / \mathrm{AgCl}$ electrode in a glass tube filled with $3 \mathrm{M} \mathrm{KCl}$; the counter electrode a Pt wire (Metrohm). All test solutions (the effluent samples and the model solutions) were purged for 10 minutes with ultra-high-purity nitrogen gas prior to the kinetic run. A competing ligand in large excess (500 fold) of the target metal concentration was added to the test solutions just prior to the starting of the kinetic run.

\section{Experimental conditions for $\mathrm{Ni}$}

The experimental procedure described in an earlier paper [10] from this laboratory was adapted for the kinetic analysis of $\mathrm{Ni}$ in the effluent samples. Dimethylglyoxime (DMG) was selected as the competing ligand for Ni [11]. Immediately after adding a large excess of DMG to the test solution, a potential of $-0.6 \mathrm{~V}$ was applied to the HMDE to start a $60 \mathrm{~s}$ accumulation step by adsorption of Ni-DMG, using square wave form at $100 \mathrm{~Hz}$, with a step potential of $5 \mathrm{mV} / \mathrm{s}$ and amplitude of $20 \mathrm{mV}$. The voltammogram of $\mathrm{Ni}$ was recorded by scanning from -0.6 to $-1.3 \mathrm{~V}$.

\section{Experimental conditions for Co}

The experimental procedure described in an earlier paper (same as $\mathrm{Ni}$ ) [10] from this laboratory was adapted for the kinetic analysis of Co in the effluent samples. DMG was selected as the competing ligand for Co [12]. Immediately after adding a large excess of DMG to the test solution, a potential of $-0.6 \mathrm{~V}$ was applied to the HMDE to 
start a $60 \mathrm{~s}$ accumulation step by adsorption of Co, using square wave form at $100 \mathrm{~Hz}$, with a step potential of $6.9 \mathrm{mV} / \mathrm{s}$ and amplitude of $40 \mathrm{mV}$. The voltammogram for Co was recorded by scanning from -0.6 to $-0.9 \mathrm{~V}$.

\section{Experimental conditions for $\mathrm{Cu}$}

The experimental procedure described in an earlier paper (same as for Ni) [10] was adapted for the kinetic analysis of $\mathrm{Cu}$ in the effluent samples. 8-hydroxyquinoline (8HQ) was selected as the competing ligand for $\mathrm{Cu}$ [13]. Immediately after adding an excess of 8-HQ to the test solution, a potential of $-0.2 \mathrm{~V}$ was applied to the HMDE to start a $10 \mathrm{~s}$ accumulation step by adsorption of $\mathrm{Cu}-8 \mathrm{HQ}$, using square wave form at $100 \mathrm{~Hz}$, with a step potential of $70 \mathrm{mV} / \mathrm{s}$ and amplitude of $10 \mathrm{mV}$. The voltammogram of $\mathrm{Cu}$ was recorded by scanning from -0.20 to $-0.75 \mathrm{~V}$.

\section{Experimental conditions for $\mathbf{Z n}$}

The experimental procedure described in an earlier paper (same as $\mathrm{Ni)}$ [10] was adopted for the kinetic analysis of $\mathrm{Zn}$ in the effluent sample. Ammonium 1pyrrolidinedithiocarbamate (APDC) was selected as the competing ligand for $\mathrm{Zn}$ [14]. Immediately after adding a large excess of APDC to the test solution, a potential of $0.3 \mathrm{~V}$ was applied to the HMDE to start a $60 \mathrm{~s}$ accumulation step by adsorption of $\mathrm{Zn}$ APDC complex, using square wave form at $50 \mathrm{~Hz}$, with a step potential of $4.5 \mathrm{mV} / \mathrm{s}$ and amplitude of $2.5 \mathrm{mV}$. The voltagram for $\mathrm{Zn}$ was recorded by scanning from -0.8 to $-1.2 \mathrm{~V}$. 


\subsection{Results and Discussion}

Humic substances, which are predominant components of DOC in freshwaters, are usually present as polymeric colloidal materials, as water-swollen gels, with functional groups for cation binding, both outside and inside of the cavernous gels. In interpreting their metal-complex formation and dissociation, their aggregational and conformational equilibria must be considered. As Langford et al. [15] have eloquently pointed out, one of the consequences of humic substances' water-swollen gelstructure, with binding groups both on the outer surface of the gel and inside the cavernous gel, is that thermodynamically equivalent binding sites may seem to be kinetically different because of the transport limitation for the metals-binding inside the cavernous gel. With this constraint in the interpretation of results, the following interpretation is presented.

Tables 3.1-3.3 present important characteristics and properties of the two samples of mine effluents. In Table 3.3, the metal/DOC mole ratio was calculated by assuming an average value of the ligand (DOC) of $\sim 5 \mathrm{mM} / \mathrm{g}$. The percentage of metal released from the metal-DOC complexes in the effluent samples was investigated by considering the organically-bound and inorganically-bound metal complexes. In view of the anions listed in Table 3.2, inorganically-bound metals may be considered labile. 
Table. 3.1. Characteristics of the undiluted (100\%) and the diluted (45\%) effluent*

\begin{tabular}{ccc}
\hline Properties & $\begin{array}{c}\text { Undiluted } \\
(\mathbf{1 0 0 \% )} \text { effluent }\end{array}$ & $\begin{array}{c}\text { Diluted } \\
\mathbf{( 4 5 \% )} \text { effluent }\end{array}$ \\
\hline $\mathrm{pH}$ & $7.3 \pm 0.05$ & $7.2 \pm 0.05$ \\
Conductivity (mS) & $300 \pm 3.0$ & $165 \pm 3.0$ \\
Colour & Colourless & Colourless \\
Smell & Pungent smell & Pungent smell \\
\hline
\end{tabular}

* The $\mathrm{pH}$ and conductivity were measured by an Accumet $20 \mathrm{pH} /$ conductivity meter (Fischer Scientific). 
Table 3.2. Composition of the undiluted (100\%) and the diluted (45\%) effluent

\begin{tabular}{ccc}
\hline Analyte & $\begin{array}{c}\text { Concentrations in 100\% } \\
\text { effluent }\end{array}$ & $\begin{array}{c}\text { Concentrations in } \\
\mathbf{4 5 \%} \text { effluent }\end{array}$ \\
\hline$[\mathrm{DOC}](\mathrm{mg} / \mathrm{L})$ & 6.12 & 3.25 \\
{$[\mathrm{DIC}](\mathrm{mg} / \mathrm{L})$} & 1.73 & 11.23 \\
{$[\mathrm{Co}](\mathrm{M})$} & $2.14 \times 10^{-7}$ & $1.04 \times 10^{-7}$ \\
{$[\mathrm{Ni}](\mathrm{M})$} & $2.41 \times 10^{-6}$ & $1.05 \times 10^{-6}$ \\
{$[\mathrm{Cu}](\mathrm{M})$} & $3.81 \times 10^{-6}$ & $1.74 \times 10^{-6}$ \\
{$[\mathrm{Zn}](\mathrm{M})$} & $3.58 \times 10^{-7}$ & $2.58 \times 10^{-7}$ \\
{$[\mathrm{Cd}](\mathrm{M})$} & $3.65 \times 10^{-8}$ & $2.58 \times 10^{-8}$ \\
{$[\mathrm{Na}](\mathrm{M})$} & $4.35 \times 10^{-3}$ & $2.17 \times 10^{-3}$ \\
{$[\mathrm{Fe}](\mathrm{M})$} & $5.9 \times 10^{-7}$ & $2.6 \times 10^{-7}$ \\
{$[\mathrm{Al}](\mathrm{M})$} & $5.97 \times 10^{-6}$ & $2.99 \times 10^{-6}$ \\
{$[\mathrm{Ca}](\mathrm{M})$} & $1.37 \times 10^{-2}$ & $6.87 \times 10^{-3}$ \\
{$[\mathrm{~K}](\mathrm{M})$} & $8.95 \times 10^{-4}$ & $4.48 \times 10^{-4}$ \\
{$[\mathrm{Mg}](\mathrm{M})$} & $1.23 \times 10^{-3}$ & $6.16 \times 10^{-4}$ \\
{$\left[\mathrm{SO}_{4}\right]^{2-}(\mathrm{M})$} & $2.08 \times 10^{-2}$ & $1.04 \times 10^{-2}$ \\
{$[\mathrm{Cl}]^{-}(\mathrm{M})$} & $2.5 \times 10^{-3}$ & $1.3 \times 10^{-3}$ \\
{$[\mathrm{NO}]^{-}(\mathrm{M})$} & $1.94 \times 10^{-4}$ & $4.9 \times 10^{-5}$ \\
\hline
\end{tabular}

DOC $=$ Dissolved Organic Carbon;

$\mathrm{DIC}=$ Dissolved Inorganic Carbon

DOC was measured with OI Analytical Model 1010TOC Analyzer.

The metals (total concentrations) were determined by Inductively-Coupled Plasma Mass Spectrometry by Perkin-Elmer Elan 6000 ICP-MS and Inductively Coupled Optical Emission Spectroscopy

The anions were determined by ion chromatography (DIONEX). 
Table 3.3. Change in the $[$ Metal $] /[D O C]$ mole ratio on the effect of dilution of the effluent with the laboratory tap water.In the absence of measured value, a typical value of $5 \mathrm{mM} / \mathrm{g}$. of the DOC is assumed.

[Metal]/[DOC] mole ratio

\begin{tabular}{|c|c|c|c|}
\hline Metal & Undiluted $(100 \%)$ effluent & Diluted & $(45 \%)$ effluent \\
\hline $\mathrm{Co}$ & 0.007 & & 0.006 \\
\hline $\mathrm{Ni}$ & 0.078 & & 0.065 \\
\hline $\mathrm{Cu}$ & 0.125 & & 0.107 \\
\hline $\mathrm{Zn}$ & 0.012 & & 0.016 \\
\hline
\end{tabular}


In discussing the results of ligand exchange kinetics, binding of metals by DOC, (which is mostly humic substances, and is ubiquitous in the freshwater environment) must be taken into account. As stated earlier, humic substances have been reported to possess strong binding sites accounting for $\sim 1-10 \%$ of the total sites (e.g. $-\mathrm{N}$ and $-\mathrm{S}$ containing complexing functional groups) and weak binding sites accounting for $\sim 90$ $99 \%$ of the total sites (e.g. carboxylate and phenolate functional groups) [16]. Metals vary widely in their affinity for specific binding to humic substances; for example, the affinity for specific binding of $\mathrm{Cu}$ to DOC is very strong, whereas the affinity for specific binding of zinc to DOC is weak [16]. Natural waters are systems which are typically far removed from coordination equilibrium and are characterized by slow kinetics, and hence, delayed equilibration. In order to study a target trace metal's competition with other trace metals in freshwaters, chemical equilibrium is sometimes assumed for simplified treatment of the metal-DOC interactions. For more realistic treatment of the metal-DOC reactions, it must be kept in mind that the metals first form complexes that are kinetically favourable. Subsequent reequilibration requires a metal and ligand double-exchange reaction, that is, both a ligand exchange in which the ligand having stronger binding sites replaces the ligand having weaker binding sites, and a metal exchange in which the stronger-binding metal replaces the weaker-binding metal, to form a strong metal-ligand complex at chemical equilibrium. [17]. Hence, speciation dynamics of metal-humic complexation reactions require adoption of a dynamic approach, combining both kinetic and equilibrium speciation in order to provide a more complete and realistic description of metal speciation in natural waters. 
In interpreting relative labilities of these metal-DOC complexes, the following should be considered as a general guiding principle: The absolute concentrations of dissolved metals are controlling factors in determining the metal-DOC stability constants; the $[$ metal $] /[\mathrm{DOC}]$ mole ratios are contributing factors in determining the metal that binds to the strong sites $(<10 \%)$, forming strong metal-DOC complexes, the remaining metal binds to the weak sites $(>90 \%)$, forming weak metal-DOC complexes. For DOC, the absolute concentrations must be calculated on the basis of its metal-binding functional groups. The stability constants of the metal-DOC complexes determine the concentrations of free metal ions at chemical equilibrium. This relatively simple picture is compounded by numerous other trace metals competing with the target trace metal, and by the competition of major cations, $\mathrm{Ca}^{2+}$ and $\mathrm{Mg}^{2+}$, which may be present in concentrations, that are several orders of magnitude larger than those of the target trace metal, especially in freshwaters with limestone and dolomitic bedrocks. Also, large concentrations of these major cations are sometimes present in freshwaters because of their widespread use by mining and metal industry, which use calcium and magnesium salts for neutralizing strong acids used in metal refining, and also by agricultural industry for neutralizing acidic agricultural lands. Added to the above complexities of freshwaters are numerous other naturally-occurring complexants, e.g. polysaccharides, proteins, which all compete with DOC for binding of the trace metals. Conformational changes resulting from electrostatic interactions among the various functional groups on a single molecule of DOC may make the coordination properties of the DOC molecule highly dependent on the extent of cation binding and on the ionic strength of the medium. In 
addition, the coordination equilibrium of 3-d transition metals which are reported to produce potentially toxic free metal ions, are typically slow. Also metal speciation dynamics involve metal and ligand exchange reactions, which are typically slow. The consequence of the above complexities is that the results presented in this study should be treated only as indicative, not definitive. In light of the above observation, the agreement with the WHAM predictions (presented later) should be regarded as reinforcing confidence in the WHAM modeling.

The results of ligand exchange kinetics in the undiluted and the diluted effluent are presented in Figs 1-4, which show the \% of metal released from M-DOC complexes $\left(i_{p} / i_{0} \%\right)$ of the samples as a function of time in the kinetic run, where, $i_{P}$ and $i_{o}$ are the current for the complex system and the reference current under conditions of no complexation, respectively. Figure 3.1 shows that the dilution resulted in a drastic decrease in the $\%$ of $\mathrm{Ni}$ released from the Ni species. In the undiluted effluent, the $\%$ of $\mathrm{Ni}$ released from the Ni-species rapidly increased to attain a maximum of $40 \%$, which thereafter remained unchanged; whereas, in the diluted effluent, the $\%$ of $\mathrm{Ni}$ released from $\mathrm{Ni}(\mathrm{II})$ complexes rapidly attained a maximum value of about $1.5 \%$, which thereafter remained unchanged. Figure 3.2 shows that the dilution of the effluent resulted in a drastic decrease in the $\%$ of Co released from the Co(II)-DOC complexes similar to that of $\mathrm{Ni}(\mathrm{II})$-DOC complexes. However, the undiluted effluent presented a somewhat different picture of the $\%$ of Co released from the $\mathrm{Co}(\mathrm{II})$ complexes as a function of time in the kinetic run. Initially, the $\%$ of Co released from the $\mathrm{Co}(\mathrm{II})$-species in the undiluted effluent increased rapidly for a short time; thereafter, the increase slowed down and became more gradual as a function of time 
in the kinetic run. However, unlike the $\mathrm{Ni}(\mathrm{II})$-DOC curve in Fig. 3.1, the Co(II)-DOC curve in Fig. 3.2 continued to rise gradually but slowly with time untill the released Co attained the value of about $55 \%$ at $3500 \mathrm{~s}$; it continued to maintain the same trend beyond this time (not shown). Figure 3.3 shows that the dilution slightly decreased the \% of released $\mathrm{Cu}$ from the $\mathrm{Cu}(\mathrm{II})$ complexes in the undiluted effluent compared to the diluted effluent. However, it is noteworthy that initially over a very short time period, both the curves for the undiluted $(100 \%)$ and the diluted $(45 \%)$ effluent sample rose rapidly, almost vertically, to values of about $75 \%$ and $70 \%$ respectively, which remained unchanged right up to the end of the measurement time of $1800 \mathrm{~s}$.

Figure 3.4 shows the kinetic curves for $\mathrm{Zn}(\mathrm{II})-\mathrm{DOC}$ complexes. The $\mathrm{Zn}$ released from the $\mathrm{Zn}(\mathrm{II})$-species in the undiluted effluent very slowly attained a value of nearly $55 \%$ at the end of the measurement time $1200 \mathrm{~s}$, whereas the curve for the diluted effluent initially followed a very similar trend to that of the undiluted effluent and then rose very slowly and gradually untill $\mathrm{Zn}$ released from the $\mathrm{Zn}$-species attained a value of $25 \%$ at the end of the measurement time of $1200 \mathrm{~s}$. It may be useful to point out that the rest of the unreleased, tightly-bound metal is considered as "non-labile" on the time scale of the present experiments.

The results of kinetic speciation presented in Figs. 3.1-3.4 can be described in terms of the kinetically distinguishable components and their rate coefficients for the dissociation of metal-DOC complexes, as presented in Tables 3.4 and 3.5. The uncertainty (shown as \pm values in Tables 3.4 and 3.5) represents variations in the experimental data at $95.5 \%$ confidence interval of four replicates. Some remarkable 
features of Tables 3.4 and 3.5 are presented below. The results for $\mathrm{Cu}$ speciation set $\mathrm{Cu}$ apart from the other three metals as having the fastest component, $\mathrm{C}_{l}$, predominant in both the undiluted and the diluted effluent. On the other hand, $\mathrm{Zn}$ is distinguishable from the other three metals in having the slowest component, $\mathrm{C}_{3}$, predominant in both the undiluted and the diluted effluent. A general explanation for the above difference is probably the fact that among the above four metals, $\mathrm{Cu}$ has the strongest and $\mathrm{Zn}$ has the weakest affinity for binding by DOC [18]. Of the four metals, Co has the largest fraction as the inert component $\left(\mathrm{C}_{3}\right)$ in both the undiluted and diluted effluents. This is probably the result of the absolute Co concentration being very low and the $[\mathrm{Co}] /[\mathrm{DOC}]$ has the lowest $[$ metal $] /[\mathrm{DOC}]$ mole ratio of the four [metal]/ $[\mathrm{DOC}]$ mole ratios (see Table 3.3 ). The $[\mathrm{Zn}] /[\mathrm{DOC}]$ mole ratio is roughly double of the $[\mathrm{Co}] /[\mathrm{DOC}]$ mole ratio in both effluents; and the percentage of $\mathrm{Zn}$ as the inert component $\left(\mathrm{C}_{3}\right)$ is much lower than those of $\mathrm{Co}$ and Ni. As explained earlier, in the simplified treatment of the metal-DOC complexation, the coordination equilibrium is dominated by the metal's affinity for specific binding as distinct from electrostatic binding. The main factors that determine the composition of the sample at chemical equilibrium is the absolute concentration of the metal. The affinity of $\mathrm{Ni}$ and $\mathrm{Co}$ for specific binding to $\mathrm{DOC}$ is stronger than that of $\mathrm{Zn}$; the stronger affinity for specific binding means formation of more stable $\mathrm{Ni}$ - and $\mathrm{Co}-\mathrm{DOC}$ complexes, i.e., less labile than the $\mathrm{Zn}-\mathrm{DOC}$ complexes. 


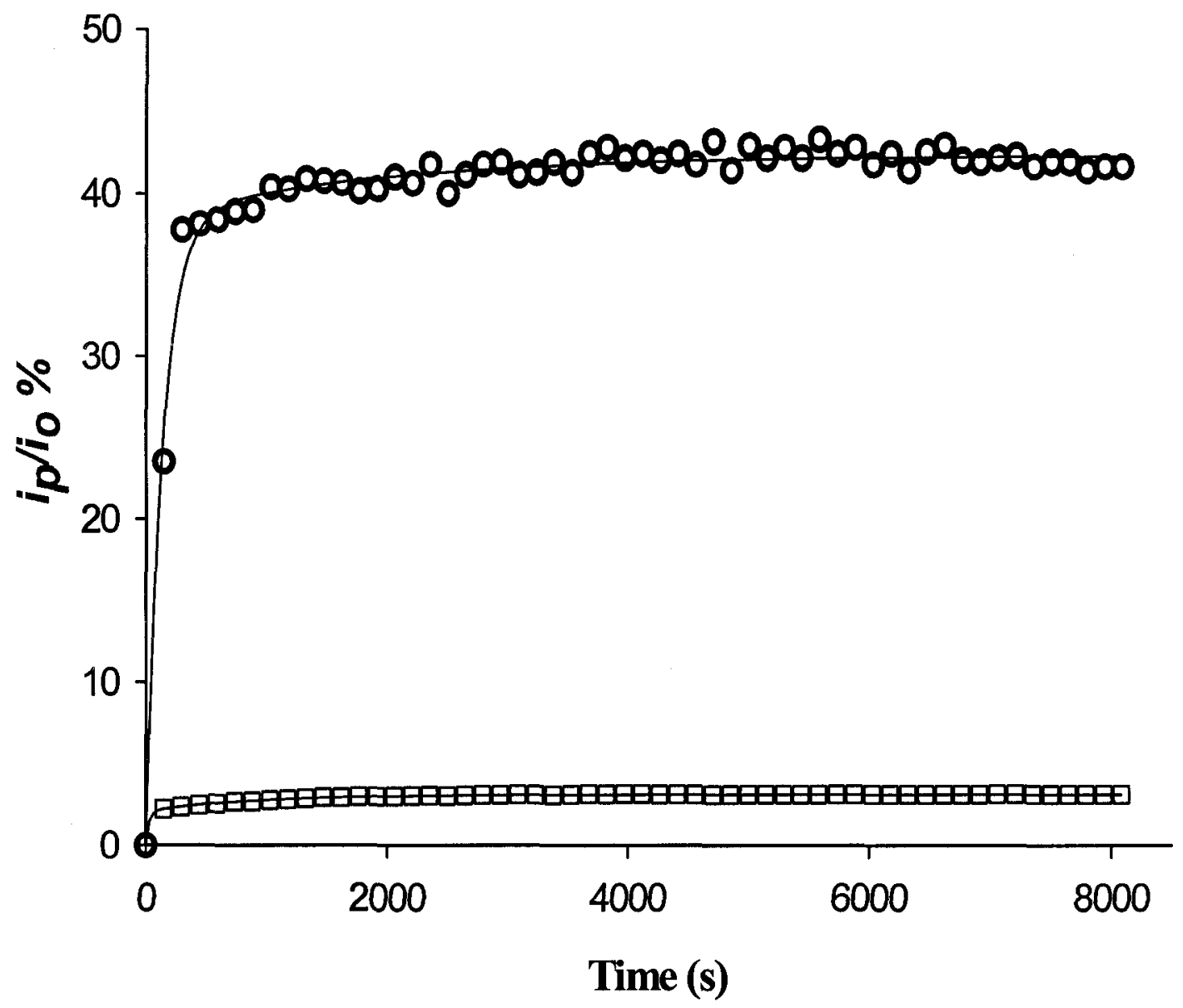

Figure 3.1. Ligand exchange kinetics for Ni(II)-DOC complexes in the undiluted (o) and the diluted effluent $(\square)$ at $\mathrm{pH}, 7.3 \pm 0.05$ and $7.2 \pm 0.05$, respectively, using DMG as a competing ligand. 


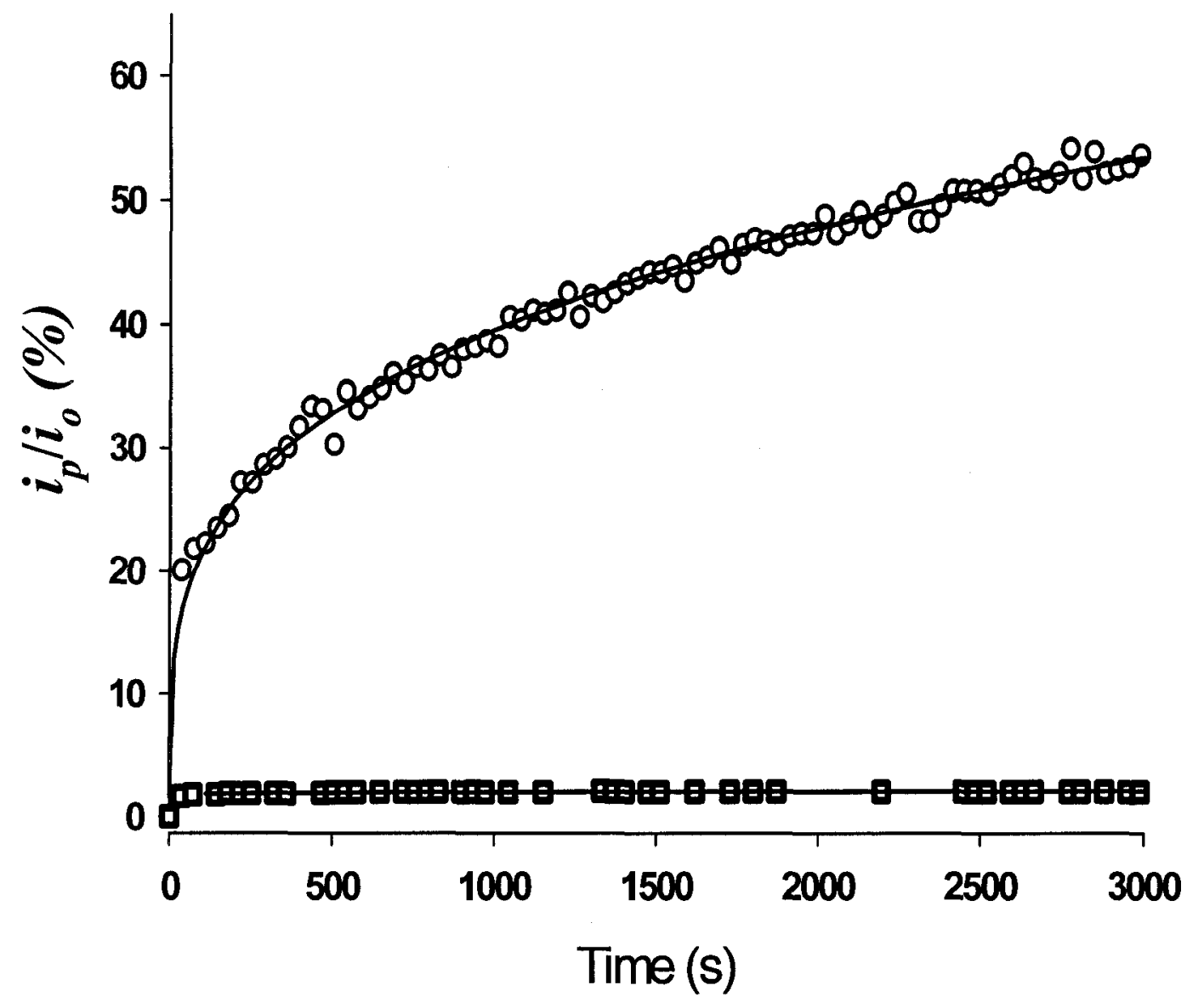

Figure 3.2 Ligand exchange kinetics for Co(II)-DOC complexes in the undiluted (o) and the diluted effluent $(\square)$ at $\mathrm{pH}, 7.3 \pm 0.05$ and $7.2 \pm 0.05$, respectively, using DMG as a competing ligand 


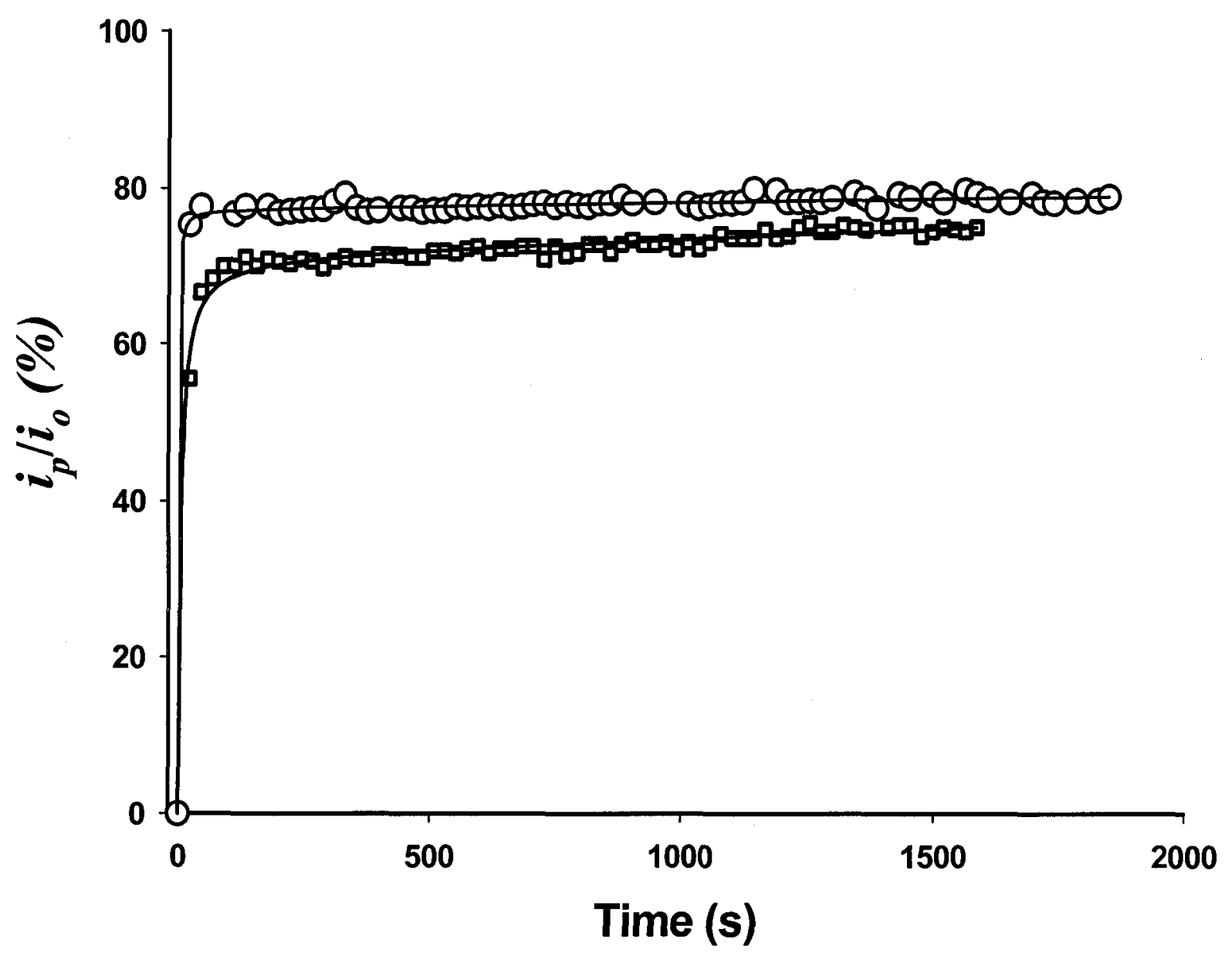

Figure 3.3 Ligand exchange kinetics for $\mathrm{Cu}(\mathrm{II})-\mathrm{DOC}$ complexes in the undiluted (0) and the diluted effluent $(\square)$ at $\mathrm{pH}, 7.3 \pm 0.05$ and $7.2 \pm 0.05$, respectively, using $8-\mathrm{HQ}$ as a competing ligand. 


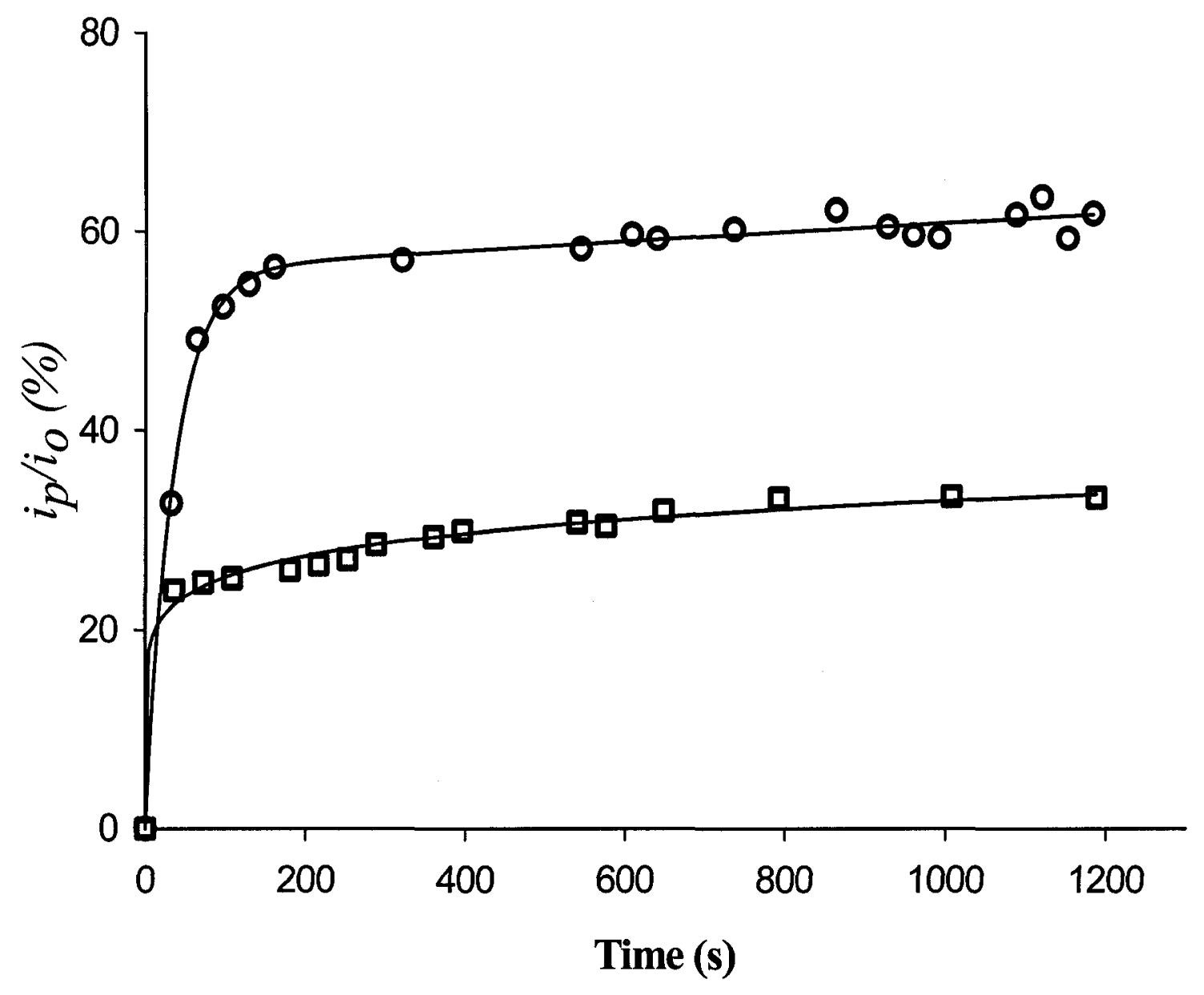

Figure 3.4 Ligand exchange kinetics for $\mathrm{Zn}(\mathrm{II})-\mathrm{DOC}$ complexes in the undiluted (0) and the diluted effluent $(\square)$ at $\mathrm{pH}, 7.3 \pm 0.05$ and $7.2 \pm 0.05$, respectively, using APDC as a competing ligand. 
Table 3.4. Kinetically distinguishable components of $\mathrm{Co}-$, Ni-, $\mathrm{Cu}-$ and $\mathrm{Zn}-\mathrm{DOC}$ complexes in the undiluted (100\%) effluent using CLEM in conjunction with AdCSV; at $\mathrm{pH} 7.20 \pm 0.05$, ionic strength $0.01 \mathrm{M}$; temperature $25 \pm 2{ }^{\circ} \mathrm{C}$.

\begin{tabular}{cccccccc}
\hline \multicolumn{6}{c}{ Kinetically distinguishable components of M(II)-DOC complexes } \\
\hline Metal & $\mathbf{C}_{\mathbf{1}}(\boldsymbol{\%})$ & $\mathbf{k}_{\mathbf{d} \mathbf{1}} \times \mathbf{1 0}^{\mathbf{1}}\left(\mathbf{s}^{-\mathbf{1}}\right)$ & $\mathbf{C}_{\mathbf{2}}(\mathbf{\%})$ & $\mathbf{k}_{\mathbf{d} \mathbf{2}} \times \mathbf{1 0}^{\mathbf{2}}\left(\mathbf{s}^{-\mathbf{1}}\right)$ & $\mathbf{C}_{\mathbf{3}}(\%)$ & $\mathbf{k}_{\mathbf{d} \mathbf{3}}\left(\mathbf{s}^{-1}\right)$ \\
\hline $\mathrm{Co}$ & $15.0 \pm 0.7$ & $0.22 \pm 0.01$ & $17.0 \pm 0.8$ & $0.51 \pm 0.01$ & $69.0 \pm 0.6$ & $(1 \pm 0) \times 10^{-5}$ \\
$\mathrm{Ni}$ & $38.5 \pm 0.1$ & $0.07 \pm 0.01$ & $3.9 \pm 0.1$ & $0.06 \pm 0.01$ & $57.7 \pm 0.1$ & $<10^{-6}$ \\
$\mathrm{Cu}$ & $53.5 \pm 0.6$ & $1.79 \pm 0.01$ & $16.3 \pm 0.7$ & $2.0 \pm 0.10$ & $30.0 \pm 0.5$ & $<10^{-6}$ \\
$\mathrm{Zn}$ & $36.5 \pm .6 .0$ & $0.56 \pm 0.01$ & $21.3 \pm 1.0$ & $0.97 \pm 0.04$ & $41.3 \pm 1.0$ & $(1 \pm 0.1) \times 10^{-4}$ \\
\hline
\end{tabular}


Table 3.5. Kinetically distinguishable components of $\mathrm{Co}-, \mathrm{Ni}-, \mathrm{Cu}-$ and $\mathrm{Zn}-\mathrm{DOC}$ complexes in the diluted (45\%) effluent using CLEM in conjunction with AdCSV. at pH $7.20 \pm 0.05$; ionic strength $0.01 \mathrm{M}$; Temperature $25 \pm 2{ }^{\circ} \mathrm{C}$.

\begin{tabular}{ccccccc}
\hline \multicolumn{6}{c}{ Kinetically distinguishable components of M(II)-DOC complexes } \\
\hline Metal & $\mathbf{C}_{\mathbf{1}}(\%)$ & $\mathbf{k}_{\mathrm{d} 1} \times \mathbf{1 0}^{\mathbf{1}}\left(\mathbf{s}^{-\mathbf{1}}\right)$ & $\mathbf{C}_{\mathbf{2}}(\%)$ & $\mathbf{k}_{\mathrm{d} \mathbf{2}} \times 10^{\mathbf{3}}\left(\mathbf{s}^{-1}\right)$ & $\mathbf{C}_{\mathbf{3}}(\%)$ & $\mathbf{k}_{\mathrm{d} 3}\left(\mathbf{s}^{-1}\right)$ \\
\hline $\mathrm{Co}$ & $1.6 \pm 0.1$ & $2.3 \pm 0.10$ & $0.5 \pm 0.1$ & $4.5 \pm 0.1$ & $98.0 \pm 0.1$ & $<10^{-6}$ \\
$\mathrm{Ni}$ & $1.5 \pm 0.5$ & $0.04 \pm 0.01$ & $1.5 \pm 0.5$ & $0.3 \pm 0.1$ & $97.0 \pm 0.1$ & $<10^{-6}$ \\
$\mathrm{Cu}$ & $62.0 \pm 1.0$ & $2.4 \pm 0.20$ & $11.5 \pm 5.0$ & $0.5 \pm 0.1$ & $26.7 \pm 1.0$ & $<10^{-6}$ \\
$\mathrm{Zn}$ & $18.5 \pm .0 .5$ & $0.22 \pm 0.01$ & $13.0 \pm 1.4$ & $4.3 \pm 0.1$ & $68.5 \pm 0.7$ & $<10^{-6}$ \\
\hline
\end{tabular}


In order to explain the effect of dilution on the lability of metal-DOC complexes, one needs to consider whether or not the dilution has made any change in the [metal]/[DOC] mole ratio. Table 3.3 show that the dilution has not appreciably changed any of the $[$ metal] $][\mathrm{DOC}]$ mole ratio other than that of zinc; the $[\mathrm{Zn}] /[\mathrm{DOC}]$ mole ratio has increased probably because of the presence of zinc in the laboratory tap water used for dilution. The metal-DOC bond energy is the sum total chemical free energy of the metal to functional groups of DOC and coulombic free energy of interactions between all the negative charges on the DOC polyanions and all other charges in the samples solution - the polyelectrolyte effect [19]. The coulombic forces (electrostatic interactions) are effective over relatively large distances and affect the free energies of ions even in dilute solutions (e.g. fresh waters). The chemical free energy of interactions-short-range, covalent bonding- is augmented by long-range coulombic interactions emanating from all the neighbouring, nonreacting negative sites of the DOC. This polyelectrolyte effect can strengthen greatly the binding of metal ions by humate polyanions in freshwaters.

Figures 3.1 and 3.2 (for $\mathrm{Ni}$ and $\mathrm{Co}$, respectively) show more drastic decrease in the \% of labile metal complexes than Figs. 3.3 and 3.4 (for $\mathrm{Cu}$ and $\mathrm{Zn}$, respectively), resulting from dilution of the effluents. What is the cause of the drastic decrease in the $\%$ of labile $\mathrm{Ni}(\mathrm{II})$ and $\mathrm{Co}(\mathrm{II})$ complexes, and the much lower decrease in the $\%$ of labile $\mathrm{Cu}(\mathrm{II})$ complexes in the diluted effluent? The answer lies in the large difference in the concentrations of $\mathrm{Ca}^{2+}$ ions in the undiluted and diluted effluents: $1.37 \times 10^{-2} \mathrm{M}$ $[\mathrm{Ca}]_{\text {Total }}$ in the undiluted effluent, and $6.87 \times 10^{-3} \mathrm{M}$ in the diluted effluent (Table 3.2) and the nature of the metal-DOC binding. The large decrease in the $[\mathrm{Ca}]_{\text {Total }}$ 
concentration which probably represents $\left[\mathrm{Ca}^{2+}\right]$ concentration in the diluted effluent resulted in a large decrease in the screening of coulombic interactions between the $\mathrm{Ni}^{2+}$ and $\mathrm{Co}^{2+}$ cations and the humate polyanions, thereby increasing the free energy of coulombic interactions in the metal-DOC bonding. This increased the strength of the Ni-DOC and Co-DOC binding, which resulted in the observed decrease in the release of $\mathrm{Ni}$ and $\mathrm{Co}$; the similarity in the decrease in the release of $\mathrm{Ni}$ and $\mathrm{Co}$ is a reflection of the similarity in the electronic configurations of $\mathrm{Ni}$ (II) and $\mathrm{Co}(\mathrm{II})$. Another probable answer lies in the change in the conformational properties of DOC, resulting from dilution of the $100 \%$ effluent sample. The dilution of $100 \%$ effluent decreases the conductivity, i.e., the ionic strength in the diluted $45 \%$ effluent. The ionic strength is an important determinant of the electrostatic interactions of charged species in the solution. The affinity of $\mathrm{Cu}(\mathrm{II})$ for specific binding (chemical free energy of interactions) to DOC is much greater than those of the other three metals. The much greater strength of the covalent bonding in the $\mathrm{Cu}-\mathrm{DOC}$ complex meant that the electrostatic interactions component of the Cu-DOC bond energy, and hence, the effect of screening of coulombic interactions between the $\mathrm{Cu}^{2+}$ cations and the negative charges on the humate polyanions are unimportant in the $\mathrm{Cu}-\mathrm{DOC}$ bond energy. The above explanation based on the effect of a massive excess of $\mathrm{Ca}^{2+}$ ions on the release of $\mathrm{Ni}$ and $\mathrm{Cu}$ from the $\mathrm{Ni}-\mathrm{DOC}$ and $\mathrm{Cu}-\mathrm{DOC}$ complexes in the effluents was confirmed by the following experiment using model solutions. The effect of dilution of Copper Cliff Mine effluent sample with the laboratory tap water was compared with the effect of dilution of the same effluent with Vermillion River water, which has been reported in the previous chapter. The comparison shows that 
the dilution with the laboratory tap water produced a mixture containing kinetically different nickel species than that produced by dilution with Vermillion River water.

\subsubsection{Effect of competition of major cation, $\mathrm{Ca}^{2+}$, on $\mathrm{Ni}$ and $\mathrm{Cu}$ binding by DOC in aqueous solutions}

Figures 3.5 and 3.6 and Tables 3.6 and 3.7 present the effects of a large excess of $\mathrm{Ca}^{2+}(\sim \mathrm{mM})$ compared to the $[\mathrm{Ni}]$ concentration $(\sim 100 \mathrm{nM})$ on the release of the target metals, $\mathrm{Ni}$ from the Ni-DOC complexes (Fig. 3.5 and Table 3.6), and $\mathrm{Cu}$ from the $\mathrm{Cu}(\mathrm{II})-\mathrm{DOC}$ complexes (Fig. 3.6 and Table 3.7), in model solutions containing $\mathrm{Ca}^{2+}$ and $\mathrm{Ni}^{2+}$ (in Fig. 5 and Table 3.6), and $\mathrm{Ca}^{2+}$ and $\mathrm{Cu}^{2+}$ (in Fig. 3.6 and Table 3.7). The $\left[\mathrm{Ca}^{2+}\right]$ concentrations were about 4 orders of magnitudes (see Table 3.2 ) in excess of those of $\mathrm{Ni}^{2+}$ or $\mathrm{Cu}^{2+}$, which were present at concentrations of one-tenth of a $\mu \mathrm{M}$. In Fig. 3.6, the $\mathrm{Ca}^{2+}$ ions added to the $\mathrm{Cu}^{2+}$ test solution was $1 \mathrm{mM}$; any higher concentrations of $\mathrm{Ca}^{2+}$ resulted in aggregation of the DOC, forming precipitates. Langford et al. [20] have reported on the aggregation of DOC by high concentrations of electrolytes. Jacques Buffle [21] has reported that aggregation of DOC increases with increasing electrolyte concentrations. Such aggregation of DOC occurs whenever its concentration is considerable, and the ionic strength of the medium is high. Also, as Figs. 3.5 and 3.6 show, the amount of electrolytes (e.g. $\mathrm{Ca}^{2+}$ in Fig. 3.5) required for aggregation of the DOC to occur is dependent on the nature of metal that binds to DOC; probably, a metal that binds strongly with DOC, such as $\mathrm{Cu}(\mathrm{II})$, requires much less electrolyte for the aggregation to occur than $\mathrm{Ni}$ (II) which binds much less strongly to DOC. The difference between the concentration level of $\mathrm{Ca}^{2+}$ that can be added to the Ni(II)-HA and to the $\mathrm{Cu}(\mathrm{II})-\mathrm{HA}$ (10 $\mathrm{mM}$ and $1 \mathrm{mM}$, 


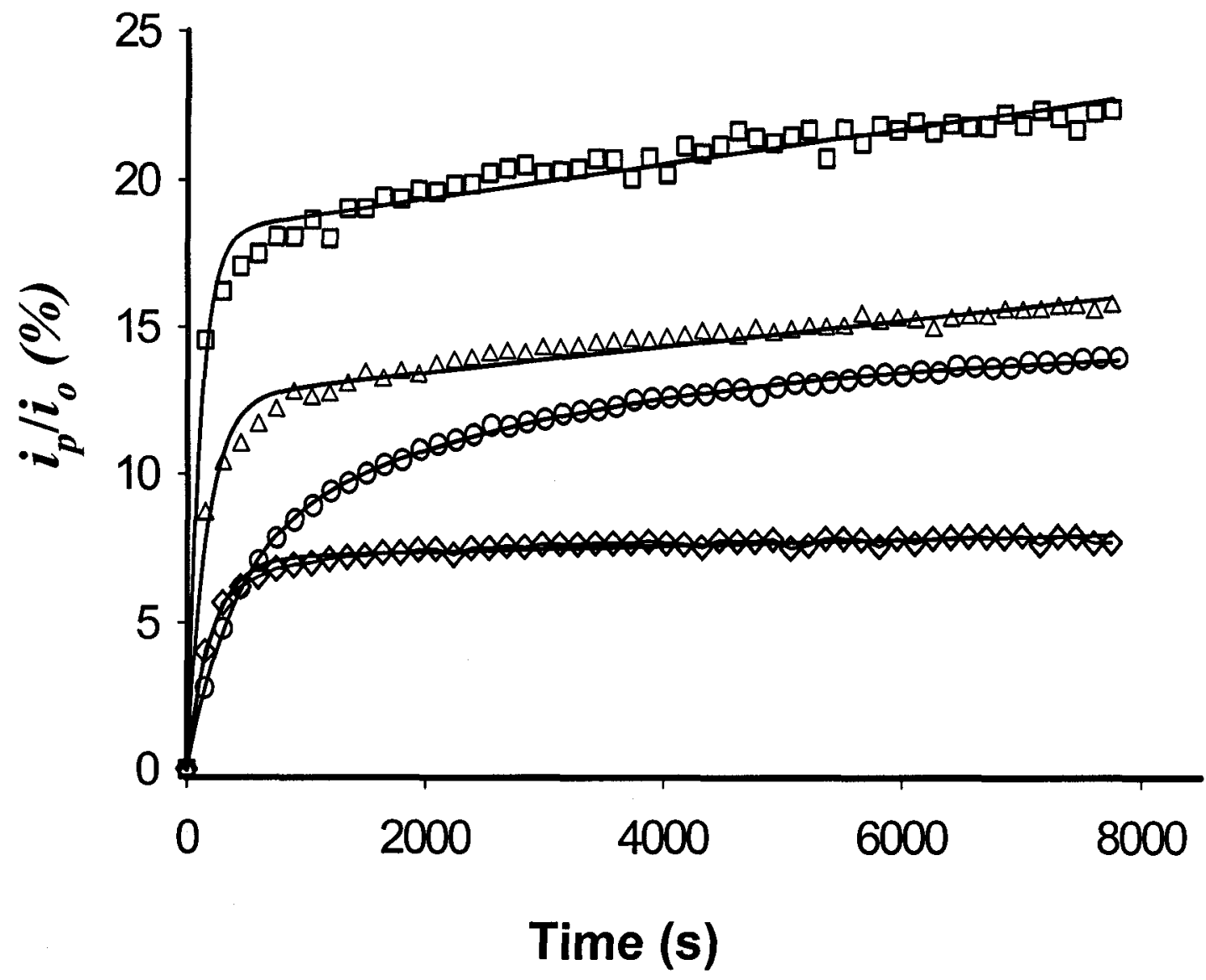

Figure 3.5 Effect of $\mathrm{Ca}^{2+}$ concentrations, $(\square)\left[\mathrm{Ca}^{2+}\right]=10 \mathrm{mM},(\Delta)\left[\mathrm{Ca}^{2+}\right]=1 \mathrm{mM}$, (o) $\left[\mathrm{Ca}^{2+}\right]=0.01 \mathrm{mM},(\diamond)\left[\mathrm{Ca}^{2+}\right]=0 \mathrm{mM}$ on the lability of Ni-HA complexes in a model solution of $[\mathrm{Ni}] /[\mathrm{HA}]=0.001$, at $\mathrm{pH} \quad 7.00 \pm 0.05$, ionic strength $0.01 \mathrm{M}$; temperature $25 \pm 2{ }^{\circ} \mathrm{C}$. 


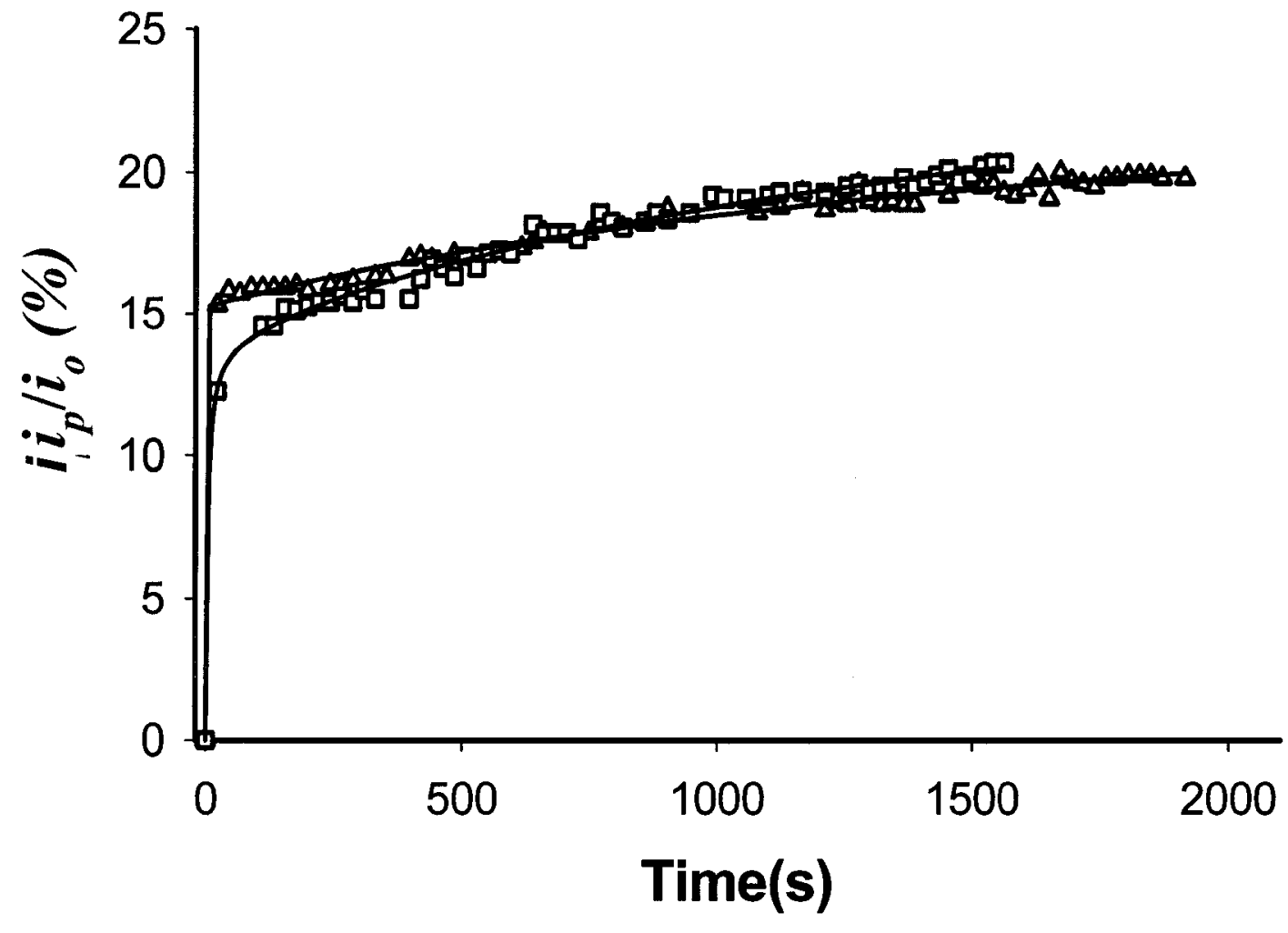

Figure 3.6 Effect of $\mathrm{Ca}^{2+}$ ion concentration, $(\square)\left[\mathrm{Ca}^{2+}\right]=0 \mathrm{mM},(\Delta)\left[\mathrm{Ca}^{2+}\right]=1 \mathrm{mM}$ on the lability of $\mathrm{Cu}-\mathrm{HA}$ complexes in a model solution of $[\mathrm{Cu}] /[\mathrm{HA}]$ $=0.001$, at $\mathrm{pH} 7.00 \pm 0.05$; ionic strength $0.01 \mathrm{M}$; temperature $25 \pm 2{ }^{\circ} \mathrm{C}$. 
Table 3. 6. Effect of $\left[\mathrm{Ca}^{2+}\right]$ on the lability of Ni-HA complexes; model solution, [Ni]/[HA] $=0.001$ at $\mathrm{pH} 7.00 \pm 0.05$, ionic strength $0.01 \mathrm{M}$; temperature $25 \pm 2{ }^{\circ} \mathrm{C}$.

Kinetically distinguishable components of Ni-HA complexes

\begin{tabular}{ccccc}
\hline $\begin{array}{c}{[\mathbf{C a}]} \\
(\mathbf{m M})\end{array}$ & $\mathbf{C}_{\mathbf{1}}(\mathbf{\%})$ & $\mathbf{k}_{\mathbf{d} 1} \times \mathbf{1 0}^{\mathbf{3}}\left(\mathbf{s}^{-1}\right)$ & $\mathbf{C}_{\mathbf{2}}(\mathbf{\%})$ & $\mathbf{k}_{\mathbf{d} 2}\left(\mathbf{s}^{-\mathbf{1}}\right)$ \\
\hline 0.0 & $7.0 \pm 2.8$ & $0.5 \pm 0.1$ & $93.0 \pm 10.0$ & $<10^{-6}$ \\
0.1 & $10.5 \pm 3.4$ & $1.7 \pm 0.1$ & $90.0 \pm 2.2$ & $<10^{-6}$ \\
1.0 & $12.5 \pm 7.0$ & $6.1 \pm 0.1$ & $87.5 \pm 2.2$ & $<10^{-6}$ \\
10.0 & $18.0 \pm 8.0$ & $9.4 \pm 1.0$ & $82.0 \pm 13.0$ & $<10^{-6}$ \\
\hline
\end{tabular}


Table 3.7. Effect of $\left[\mathrm{Ca}^{2+}\right]$ on the lability of $\mathrm{Cu}-\mathrm{HA}$ complexes; model solution; $[\mathrm{Cu}] /[\mathrm{HA}]=0.001$; at $\mathrm{pH} 7.00 \pm 0.05$; ionic strength $0.01 \mathrm{M}$; temperature $25 \pm 2{ }^{\circ} \mathrm{C}$.

Kinetically distinguishable components of $\mathrm{Cu}-\mathrm{HA}$ complexes

\begin{tabular}{lcccc}
\hline $\begin{array}{c}{[\mathbf{C a}]} \\
(\mathbf{m M})\end{array}$ & $\mathbf{C}_{\mathbf{1}}(\mathbf{\%})$ & $\mathbf{k}_{\mathrm{d} 1} \times \mathbf{1 0}^{\mathbf{3}}\left(\mathbf{s}^{-\mathbf{1}}\right)$ & $\mathbf{C}_{2}(\mathbf{\%})$ & $\mathbf{k}_{\mathrm{d} 2}\left(\mathbf{s}^{-\mathbf{1}}\right)$ \\
\hline 0.0 & $15.0 \pm 8.0$ & $0.79 \pm 0.14$ & $85.0 \pm 12.0$ & $<10^{-6}$ \\
1.0 & $15.0 \pm 8.0$ & $1.50 \pm 0.40$ & $84.0 \pm 18.0$ & $<10^{-6}$ \\
\hline
\end{tabular}


respectively) is possibly an indication that $\mathrm{Cu}(\mathrm{II})-\mathrm{HA}$ is more hydrophobic than $\mathrm{Ni}(\mathrm{II})-\mathrm{HA}$, and hence, requires less electrolyte for coagulation and precipitation. In Fig. 3.5 and Table 3.6, increasing concentrations of $\left[\mathrm{Ca}^{2+}\right]$ from $0.1 \mathrm{mM}$ to $10 \mathrm{mM}$, added to a model solution of $10^{-7} \mathrm{M}[\mathrm{Ni}]$ containing $\mathrm{HA}$ to give a mole ratio of $[\mathrm{Ni}] /[\mathrm{HA}]=0.001$, i.e. a very low $[\mathrm{Ni}] /[\mathrm{DOC}]$ mole ratio, resulted in an increased release of $\mathrm{Ni}$ from the $\mathrm{Ni}(\mathrm{II})-\mathrm{DOC}$ complexes. The amount of $\mathrm{Ni}$ released increased gradually from about $6 \%$ for zero $\left[\mathrm{Ca}^{2+}\right]$, to a maximum of about $22 \%$ for $\left[\mathrm{Ca}^{2+}\right]=10$ $\mathrm{mM}$ over the measurement time $7500 \mathrm{~s}$.

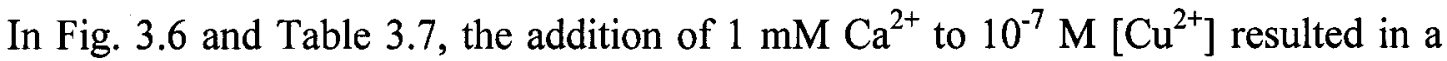
small but rapid increase in the amount of $\mathrm{Cu}$ released from the $\mathrm{Cu}(\mathrm{II})-\mathrm{DOC}$ complexes immediately on the addition of the $\mathrm{Ca}^{2+}$ to the $\left[\mathrm{Cu}^{2+}\right]$ test solution, from $\sim 12 \%$ for $\left[\mathrm{Ca}^{2+}=0 \mathrm{M}\right]$ to $\sim 16 \%$ for $\left[\mathrm{Ca}^{2+}=1 \mathrm{mM}\right]$. The elevated curve (compared to the curve with no $\left.\mathrm{Ca}^{2+}\right)$ retained the slightly higher release of $\mathrm{Cu}(\sim 16 \%)$ and continued to show the same trend of slow increase in the release of $\mathrm{Cu}$ up to the end of the measurement time $\sim 1900 \mathrm{~s}$.

The numerical values for the kinetic speciation of the four metals in the undiluted effluent sample are presented in Table 3.4, which shows that $53.5 \%$ of the [Cu(II)] and $38.5 \%$ of $[\mathrm{Ni}(\mathrm{II})]$ and $36.5 \%$ of $[\mathrm{Zn}(\mathrm{II})]$ were labile, whereas only $14.4 \%$ of the $[\mathrm{Co}(\mathrm{II})]$ was labile.

It is important to note that in Tables 3.4 and 3.5, the results of the kinetic speciation by CLEM/AdCSV yield rate coefficients which do not represent a single metal species, such as the free metal ion; rather they represent a cluster of metal species having very similar rate coefficients; for example, labile metal species comprising 
free metal ions and other rapidly-dissociating metal species-the cluster of metal species is labeled 'labile complexes'.

The large decrease in the conductivity of the diluted effluent sample (see Table 3.1) meant a great decrease in the ionic strength of the sample, and hence, a corresponding decrease in the electrostatic interactions of the charges in the sample solution. The results were decreased electrostatic repulsion between the negatively charged ligand sites on the humate polyanions and increased attractions among the negatively charged sites and the positively charged metal ions and $\mathrm{H}^{+}$ions. The experimental results show that decrease in the ionic strength caused by dilution of the effluent correlated with decrease in the release of metal from the metal-DOC complexes, probably because an increase in electrostatic attractions between the metal ions and the DOC polyanion caused by a decrease in the screening of electrostatic charges might have caused conformational changes in the polymeric, humic (DOC) colloid, resulting in changes in the bond-strength of Ni(II)-DOC and Co(II)-DOC complexes.

In chemical equilibrium, the $[\mathrm{M}] /[\mathrm{DOC}]$ ratio and the competitions among the metals affect the release of metal from metal-DOC complexes. In the undiluted effluent, the $[\mathrm{M}] /[\mathrm{DOC}]$ mole ratio follows the order: $\mathrm{Cu}>\mathrm{Ni}>\mathrm{Zn}>\mathrm{Co}$; this order parallels the order of lability of the $[\mathrm{M}]-\mathrm{DOC}$ complexes: $\mathrm{Cu}>\mathrm{Ni} .>\mathrm{Zn}>\mathrm{Co}$. This trend is expected on the basis of metal-binding by humic substances (the main component of DOC in freshwaters). Figure 3.3 and Tables 3.4 and 3.5 show that, among the kinetically distinguishable components of the metal complexes, the labile fraction of $\mathrm{Cu}(\mathrm{II})$ was the largest both in the undiluted and the diluted effluent. This 
was probably due to the absolute concentration of dissolved copper being the highest among the four metals, which, for the fixed concentration of DOC made the [Cu] /[DOC] mole ratio the highest among them, probably resulting in a greater fraction of the $\mathrm{Cu}(\mathrm{II})$-DOC complexes being labile. The unusual resistance to change in the release of $\mathrm{Cu}$ from the $\mathrm{Cu}-\mathrm{DOC}$ complexes (compared to the DOC complexes of $\mathrm{Ni}(\mathrm{II}), \mathrm{Co}(\mathrm{II})$ and $\mathrm{Zn}(\mathrm{II})$ shown in Figs. 3.3 and 3.6), can be explained in terms of formation and dissociation of the metal-DOC coordination complexes.

The formation and dissociation of these 3-d transition metals can be considered in terms of Ligand Field Stabilization Energy (LFSE) for the complexes in going from the octahedral coordination to the square-pyramidal transition state, which is favorable for $\mathrm{Cu}(\mathrm{II}) \mathrm{d}^{9}$ configuration, but unfavourable for $\mathrm{Co}(\mathrm{II}) \mathrm{d}^{7}$, and $\mathrm{Ni}$ (II) $\mathrm{d}^{8}$ configurations; $\mathrm{Zn}$ (II) $\mathrm{d}^{10}$ can have no LFSE. LFSE calculations indicate a large loss in LFSE for $\mathrm{Ni}\left(\mathrm{d}^{8}\right)$ complexes in going from six- to either five- or seven-coordinate species. For both dissociative and associative pathways, this configuration experiences a ligand field contribution to the Ligand Field Activation Energy. Hence $\mathrm{Ni}\left(\mathrm{d}^{8}\right)$ configuration is kinetically inert $[22]$. The other metals, e.g., $\mathrm{Co}\left(\mathrm{d}^{7}\right), \mathrm{Cu}\left(\mathrm{d}^{9}\right)$ lose little, and $\mathrm{Zn}\left(\mathrm{d}^{10}\right)$ with no LFSE result in more labile complexes than Ni. The $\mathrm{Cu}(\mathrm{II}) \mathrm{d}^{9}$ octahedral complexes, because of the added stabilization provided by the tetragonal distortion of the octahedral $\mathrm{Cu}$ (II) complex due to Jahn-Teller effect, results in shortening (and hence, strengthening) of the four equatorial bonds and lengthening (and hence, weakening) of the two axial bonds, making the $\mathrm{Cu}(\mathrm{II})$ tetragonally distorted complex at once the more stable (thermodynamically) at the four equatorial bonds and the more labile (kinetically) at the two axial bonds. 


\subsubsection{Effect of heterogeneity of humic substances on metal speciation in mine}

\section{effluents}

It is well known that continuous distributions of reaction sites are present in humic substances. The distribution of these reaction sites (with respect to their bonding strength) are expressed in terms of chemical heterogeneity. It was first reported theoretically by H.P. van Leeuwen [23] that heterogeneity of humic substances play a dominant role in reaction kinetics of metal in aqueous environment. Fillela and Town [24] reported that the heterogeneity of metal-NOM complexes extends also to the distribution of kinetic dissociation rate constants. The wide distribution of dissociation rate coefficient of a metal-DOC complex indicates more heterogeneity of humic substances for the particular metal.

Tables 3.3 and 3.4 show that the distribution of dissociation rate coefficient is highest for $\mathrm{Cu}$ followed by $\mathrm{Ni}$, $\mathrm{Co}$ and $\mathrm{Zn}$. Depending upon the distribution of dissociation rate coefficient of M-DOC complexes, it can be assumed that humic substances in mine effluent behave more heterogeneously with $\mathrm{Cu}$ followed by $\mathrm{Ni}, \mathrm{Co}$ and $\mathrm{Zn}$. The heterogeneity parameter follows the following order.

$\Gamma_{\mathrm{Cu}}<\Gamma_{\mathrm{Ni}}<\Gamma_{\mathrm{Co}_{0}}<\Gamma_{\mathrm{Zn}}$

However, in the diluted $45 \%$ effluent the heterogeneity follow the following order $\Gamma_{\mathrm{Cu}}<\Gamma_{\mathrm{Co}}<\Gamma_{\mathrm{Ni}}<\Gamma_{\mathrm{Zn}}$

The reasons for this anomaly of $\Gamma_{\mathrm{Co}}$ and $\Gamma_{\mathrm{Ni}}$ are unknown.

It is important to note that the results of the kinetic speciation by CLEM/AdCSV yields rate coefficients which do not represent a singular metal species, such as, free metal ion; rather they represent a cluster of metal species having very similar rate 
coefficients. Secondly, the analytical window for CLEM is simply the time from the start of the experiment to the time that has been arbitrarily chosen to terminate the experiment. However, the measurement of rapid kinetics is limited by experimental conditions such as the deposition time, equilibration time and the stripping rate (approximately $60 \mathrm{~s}$ between each data point). As a consequence, the upper limit of experimentally measurable rate coefficients is approximately $10^{-2} \mathrm{~s}^{-1}$. For a total reaction time of approximately $2 \mathrm{~h}$, this represents an analytical window of measurable rate coefficients of $10^{-2}-10^{-6} \mathrm{~s}^{-1}$ for this technique. The relative order of heterogeneity of humic substances in mine effluents for these metals follow the same trend as found by other scientists. As expected from the data, the stability of metalDOC complexes (percentage of inert complexes) increases with the increase of heterogeneity (i.e. low value of $\Gamma$ ) and with low metal loading (low $[\mathrm{M}] /[\mathrm{DOC}]$ mole ratio) as found for Co. 


\subsubsection{Comparison of the experimental results with the WHAM VI predictions}

Figure 7 presents a comparison of the experimentally measured results with the WHAM VI prediction for the four metals in the undiluted effluent. It is important to note that for the metal speciation, CLEM/AdCSV [10, 25-30] gives an analytical signal which represents the total concentration of all labile complexes including free $\left[\mathrm{M}^{2+}\right]$. CLEM/AdCSV yields kinetically distinguishable components of the metal (II)DOC complexes and their dissociation rate coefficients. The percent labile fraction is multiplied by the total metal concentration of the sample, yielding a concentration value that represents the labile complexes. The measured value therefore represents the sum of the weak metal complexes, whereas the WHAM-VI predicted values represent the free metal ions and weak inorganic complexes. Figure 3.7 shows that the free metal ion and inorganic metal complexes concentrations predicted by WHAM VI compare reasonably well with the measured concentration of the sum of the labile complexes of the metal. The (----) line represent 1:1 line. One major problem in modelling by WHAM is that it requires an input datum for the concentration of "active" DOC, i.e. the concentration of DOC that behaves like isolated, purified HS and is actively involved in the binding of metals. This is the most important parameter since it determines the number of binding sites available to the metals. Since the value of the "active" concentration of DOC, although critical, was not known, the effluent sample was modelled using five different active DOC concentrations: $40,50,60,67$, and $80 \%$ of the $\mathrm{DOC}$ as "active" [31-37] to determine the "active" DOC concentration that best fitted the measured labile-metal-ion concentrations. 


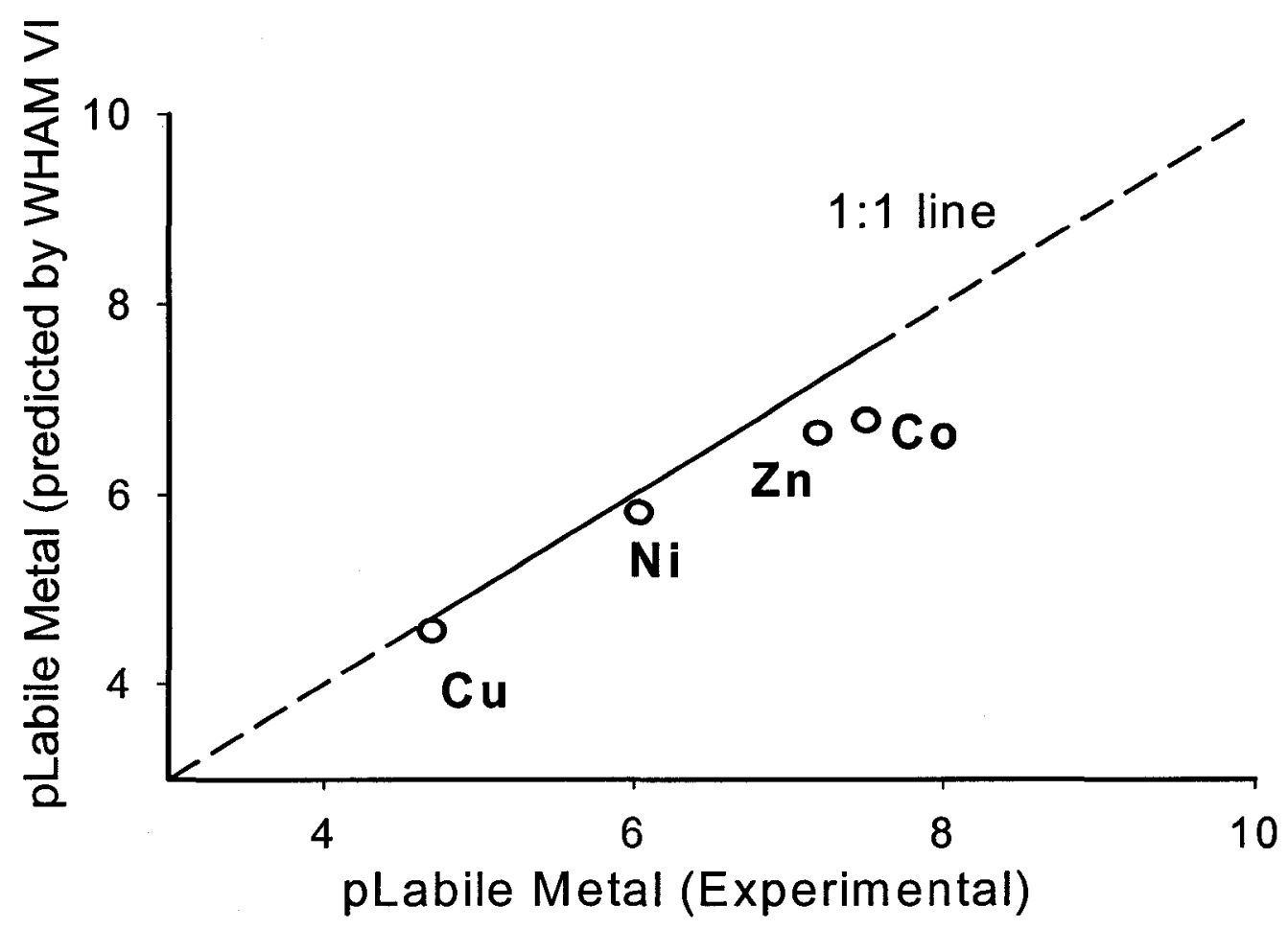

Figure 3.7 Comparison of the WHAM VI predicted $\mathrm{p}^{\text {Labile Metal }}$ with the measured concentration $\mathrm{p}^{\text {Labile Metal (Experimental) }}$ of labile metal complexes in the undiluted (100\%) effluent sample collected from Copper Cliff Mine, Sudbury, Canada,; the effluent sample was modeled using $67 \%$ as active DOC. 


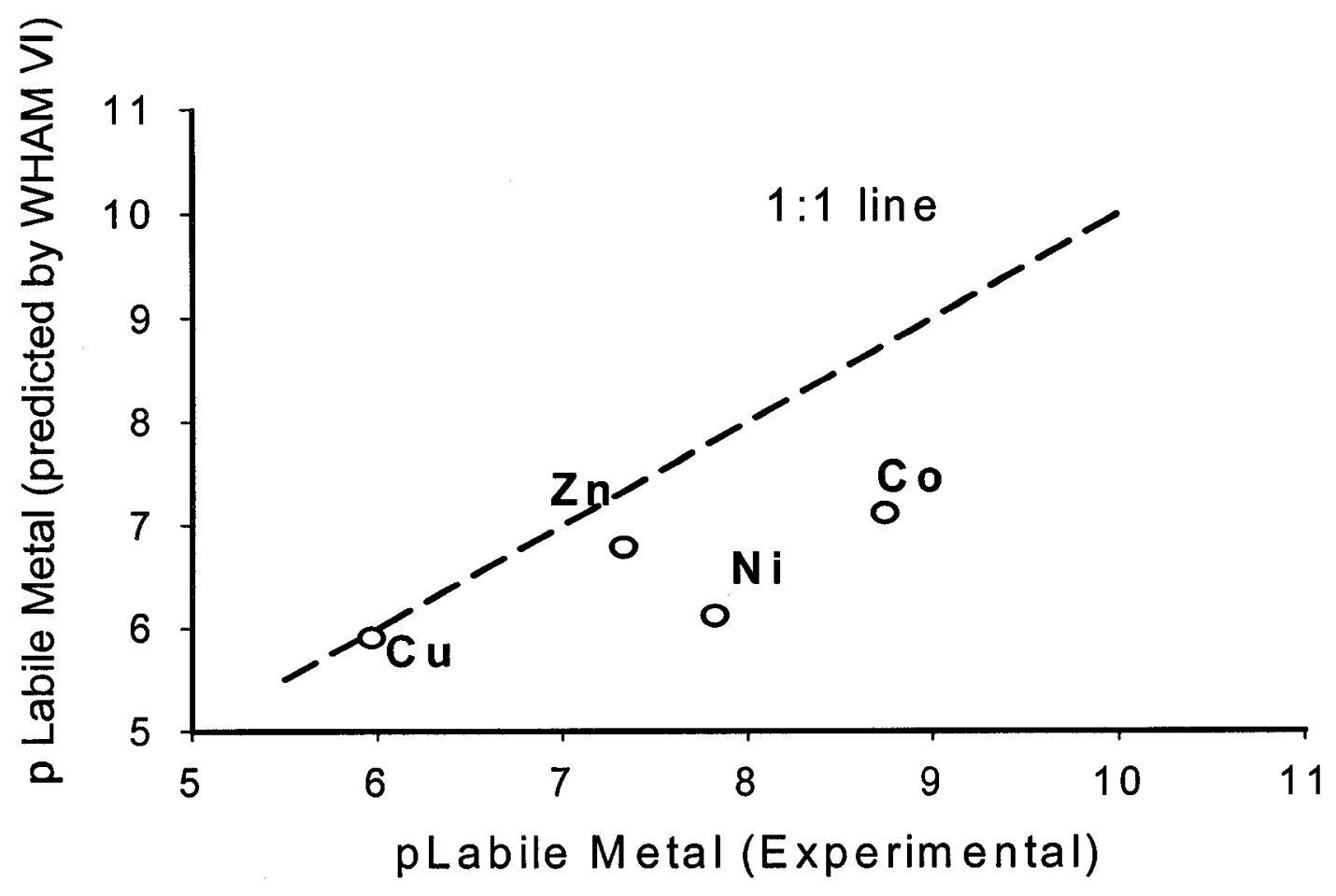

Figure 3.8. Comparison of the WHAM VI predicted $\mathrm{p}^{\text {Labile Metal }}$ with the measured concentration $\mathrm{p}^{\text {Labile Metal (experimental) }}$ of labile metal complexes in the diluted (45\%) effluent sample collected from Copper Cliff Mine, Sudbury, Canada, the effluent sample was modeled using $67 \%$ as active DOC. 
The WHAM VI model with $67 \%$ active DOC concentrations fits well with the experimental results of $\mathrm{Cu}$ (II), $\mathrm{Ni}$ (II) and $\mathrm{Zn}$ (II) complexes; however, for $\mathrm{Co}$ (II), the WHAM VI model with $67 \%$ active DOC concentration predicts higher than the measured value. The experimentally measured values of these four metals in the diluted effluent also compare reasonably well with the prediction of WHAM VI, using $67 \%$ active DOC concentration, as shown in Fig. 3.8. The measured values of the $\%$ of metal released from the $\mathrm{Cu}$ (II)-DOC and $\mathrm{Zn}$ (II)-DOC complexes agree very well with the WHAM VI predictions. However, for the Ni (II)-DOC and Co (II)-DOC complexes, WHAM VI predicts higher free metal ion concentrations.

Comparison of Figs 3.7 and 3.8 brings out minor differences in their deviation from the 1:1 line, which may not be statistically significant. The decrease in ionic strength on dilution of the $100 \%$ effluent probably caused a conformational change, resulting in unfolding of the polymeric random coil of DOC into a flexible linear polymer with more accessible binding sites, not accounted for in WHAM VI. One major limitation of WHAM VI is that conformational changes in DOC have not been provided for in the formulation of WHAM VI. The significance of this work is that it throws light into hitherto unknown effects of dilution of mine effluents containing $\mathrm{Ni}, \mathrm{Co}, \mathrm{Zn}$, and $\mathrm{Cu}$. The above finding will provide managers and decision-makers of water resources with a better scientific understanding for decision-making, taking into consideration the new constraints on the chemical compositions of receiving waters for mine effluents imposed by the above metals. 


\subsection{References:}

1. J G. Hering, F. M.M. Morel, Environ. Sci. Technol. 1988, 22, 1234-1237.

2. J.A. Larsson, H.L. Pardue, Anal. Chim. Acta, 224, 1989, 289.

3. D.L. Olson, M.S. Shuman, Anal. Chem. 55, 1983..

4. D.L. Olson, M.S. Shuman, Geochim. Cosmochim. Acta, 49, 1985, 1371

5. I. Schechter, Anal. Chem. 63, 1991, 1303.

6. C. H. Langford, R.L. Cook, Analyst. 120, 1995, 591.

7. Francois M.M. Morel, Janet G.Hering, Principles and Applications of Aquatic Chemistry, New york; Wiley, 1993, p. 379

8. K. A. Bolton, S. Sjoberg, L.J. Evans, Soil. Sci. Soc. American Journal, 60, 1996, 1064.

9. C.L. Chakrabarti, Y. Lu, Cheng, J., M.H. Back, W.H. Schroeder, Anal. Chim. Acta, 267, 1993, 47-64.

10. M. Lam, J. Murimboh, N. M. Hassan, C. L. Chakrabarti, Anal. Chim. Acta $4021999,195$.

11. R. Mandal,, M. S. A Salam, J. Murimboh, N. M Hassan, C.L. Chakrabarti, M. H. Back, D. C. Gregoire, Environmental Science and Technology. 2000, 34(11), 2201-2208..

12. M. A. Saito, J.W. Moffett, Marine Chemistry 75(1-2), (2001), 49-68.

13. F. Garay, V. Solis, M. Lovric, Journal of Electroanalytical Chemistry, 478(1,2), (1999), 17-24. 
14. Constant M. Van den Berg, Adri G. A Merks, Egbert K. Duursma, Estuarine, Coastal and Shelf Science 24(6), (1987), 785-97.

15. C.H. Langford and D.W. Gutzmann, Anal.Chim.Acta. 256, (1992), 183.

16. J. Buffle, R.S. Altmann, M. Fillela, Anal. Chim. Acta. 232 (1990), 225-237.

17. Francois M.M. Morel, Janet G.Hering, Principles and Applications of Aquatic Chemistry, New york; Wiley, 1993, p. 404

18. Francois M.M. Morel, Janet G.Hering, Principles and Applications of Aquatic Chemistry, New york; Wiley, 1993, p. 390

19. Francois M.M. Morel, Janet G.Hering, Principles and Applications of Aquatic Chemistry, New york; Wiley, 1993, p. 381.

20. C.H. Langford, D.S. Gamble, A.W. Underdown and S. Lee, Aquatic and Terrestrial Humic Materials, Ann Arbor Science, 1983, p. 222-224.

21. J. Buffle, Complexation Reactions In Aquatic System-An Analytica Approach, Ellis Horwood Ltd. 1990, p. 185.

22. B. Douglas,; D. McDaniel,; J. Alexander, Concept and Model of Inorganic Chemistry; Third edition ; Wiley, New York, 1994, p-489.

23. Herman van Leeuwen, Journal of Electroanalytical Chemistry

24. M Fillela, RM Town, 2001, Fresenius Journal Anal Chemistry 370, 413-418.

25. V. Celo, J. Murimboh, M. S.A. Salam, C. L. Chakrabarti, Environ. Sci. Technol. 35, 2001, 1084.

26. F S.E. Cabaniss, Environ. Sci. Technol. 24, 1990, 583.

27. J. A. Lavigne, C. H. Langford, M.K.S. Mark, Anal. Chem. 59, 1987, 2616 
28. A.L.R. Sekaly, R. Mandal, N.M. Hassan, J. Murimboh, C.L. Chakrabarti, M.H. Back, D.C. Gregoire, W.H. Schroeder, Anal. Chim. Acta 402, 1999, 211.

29. R. Mandal, A.L.R. Sekaly, C.L. Chakrabarti, M.H. Back, D.C. Gregoire, W.H. Schroeder. Anal. Chim. Acta 395. 1999, 309.

30. J.C.M. De Wit, Proton and Metal Binding to Humic Substances, Doctoral Thesis, Wageningen Agriculture University, The Netherlands, 1992, pp. 1013

31. G.C. Dwane, E.Tipping, Environ. Int., Volume: 24, (1998), p. 609

32. S.E. Cabaniss, M.S.Shuman, Geochim. Cosmochim. Acta, Volume: 52, (1988), p. 185

33. S.E.Bryan, E.Tipping, J.Hamilton-Taylor, Comp. Biochem. Physiol. C: Pharmacol. Toxicol., Volume: 133, (2002), pp. 37-49

34. A.L. Nolan, M.J.Mclaughlin, S.D.Mason, Environ. Sci. Technol., Volume: 37, (2003), p. 90

35. E.Tipping, S.Lofts, A.J. Lawlor, Sci. Tot. Environ., Volume: 210-211, (1998), p. 63

36. S. Lofts, E.Tipping, Sci. Tot. Environ., Volume: 251-252, (2000), p. 381

37. E.Tipping, C.Rey-Castro, S.E. Bryan, J. Hamilton-Taylor, Geochim. Cosmochim. Acta, Volume: 66, (2002), p. 3211 


\section{4}

Determination of copper and nickel speciation in mine aqueous effluents by the Diffusive Gradient In Thin Film (DGT) technique 


\subsection{Introduction}

This chapter explores the speciation of nickel and copper in aqueous effluents from mining operations by using the Diffusive Gradients In a Thin-Films (DGT) Technique [1], and investigates the effect of dilution of the aqueous effluent on the release of metals from metal-DOC complexes.

The DGT technique is a relatively new technique to investigate free metal ion and their weak metal complexes in aqueous systems. The DGT technique has two distinct advantages over traditional techniques in that it (1) preconcentrates the analyte in the binding phase, and (2) eliminates matrix effects [2]. This technique is based on mass transport control of the metal species of interest in natural waters [3-5], soils [3, 4 and 6], and sediment pore waters [7, 8], and makes use of two hydrogel layers. For metals, it is based on the diffusion of free (hydrated) metal ions and labile soluble metal complexes at a known rate through a diffusive hydrogel of known thickness, and successive immobilization of the metal cations on a chelating resin. The DGT technique measures only dissolved species with molecular sizes sufficiently smaller than the pore size of the hydrogel to allow them to diffuse freely through it, and which are sufficiently labile to bind on the functional groups of the binding resin. The amount of metal immobilized on the resin is a measure of the concentration of available metal in the aqueous system [9].

Different kinds of binding resins have been used as a binding gel layer in the DGT technique; the most popular resin is Chelex-100. Iminodiacetic acid has also been found to be an excellent material to make binding gel for divalent and trivalent metal ions. Chelex 100 is a robust and tolerant resin; it functions best for most metals in the 
$\mathrm{pH}$ range of 5-9. In most applications of DGT, Chelex 100 has been used. This paper evaluates the performance of the DGT technique for the determination of metal speciation in a complex mine aqueous effluent. Chelex-100 resin was used as a binding gel for copper and nickel. The selectivity of Chelex resin for metal cations is the same as that of iminodiacetic acid. The selectivity factor of Chelex resin for copper and nickel when present with zinc are 126 and 4.40 [10]; these numbers are quantitative measures of the affinity that Chelex resin has for copper and nickel ions compared to its affinity for zinc ion. The high selectivity of Chelex resin for copper and nickel relative to zinc is the reason for our use of Chelex rein as a binding layer in this project. It has been reported previously that the DGT technique proved to be efficient to measure integrated values of labile metal concentration especially, when short-time variations of the concentration are of great interest..

As a first step toward the monitoring of labile metals in metal-impacted waters using the DGT technique, this study focuses on copper and nickel fractionation in the presence of other ligands. The purpose is to explore complexation reactions between metals and heterogeneous complexants in the mine effluent. The results obtained by the DGT technique are compared with the data presented in chapter 3. As a matter of fact, only few studies attempted to measure and compare labile fraction of $\mathrm{Ni}$ and $\mathrm{Cu}$ in mine effluent simultaneously with DGT device [11]. 
The aim of this work was to study the chemical speciation of $\mathrm{Ni}$ (II) and $\mathrm{Cu}$ (II) in the mining effluent by using DGT technique and to evaluate the effectiveness of DGT as a speciation technique for complex mine effluents.

\subsection{Theory:}

DGT's theoretical basis is diffusion of metals in a hydrogel and sorption properties of a metal-binding resin [1-2]. Diffusional transport of metals in solution to a cationexchange resin occurs through a hydrogel layer. The underlying binding layer is traditionally a Chelex-100 resin-impregnated hydrogel layer. Free metal ion and labile complexes which dissociate very fast in freshwaters diffuse through the diffusional layer and bind to the binding layer (Figure 4.1).

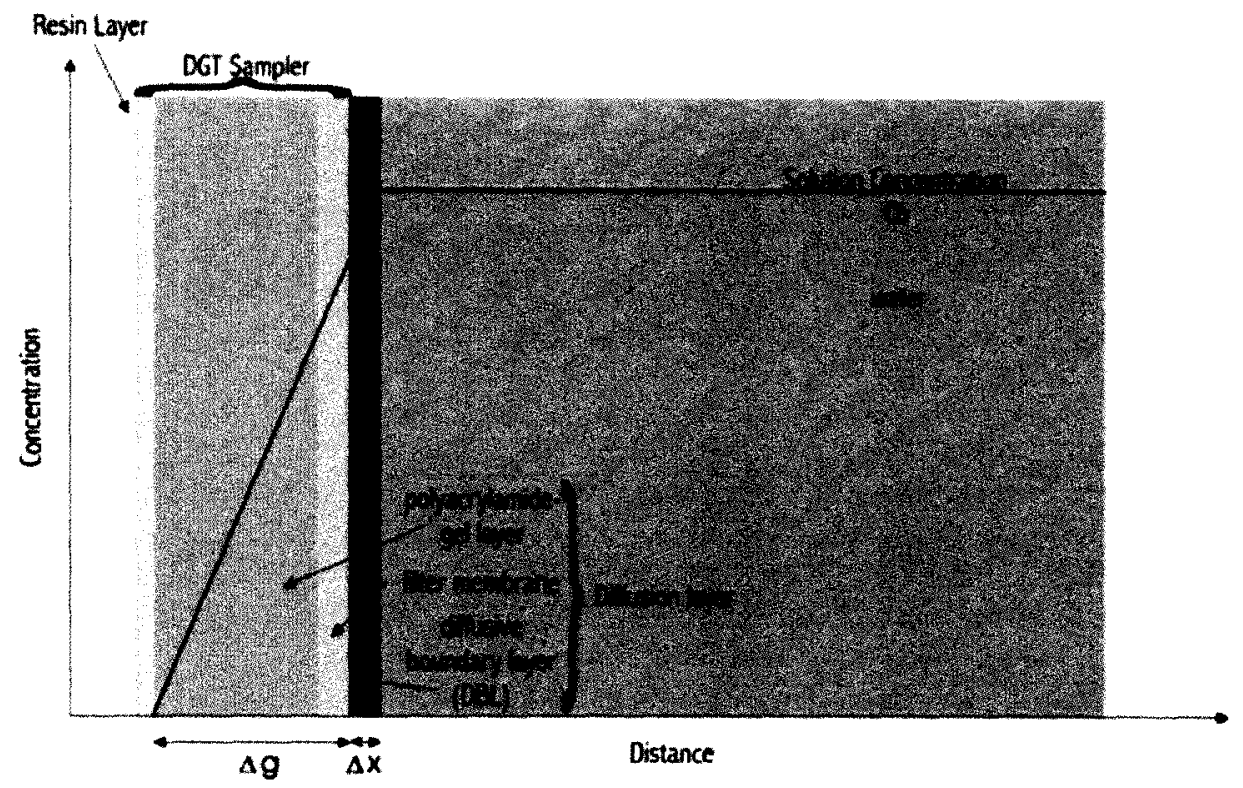

Figure 4.1 Representation of the concentration of free metal ion species in a DGT device and adjacent water during deployment (adapted from INAP 2002) 
The concentration of the DGT labile fraction of metal $\left(C_{b}\right)$ in natural waters, i.e. species that are diffusible through a diffusion layer having certain pore size and reactive to the binding resin, can be estimated by measuring the mass of a metal $(M)$ accumulated in the binding resin for a certain deployment time $(t)$, after elution in an acidic solution using the DGT equation developed by Zhang et al. [1]:

$$
\mathrm{C}_{b}=\frac{\mathrm{M} \Delta \mathrm{g}}{\mathrm{D} \mathrm{tA}}
$$

where $\Delta g$ is the thickness of the diffusive gel, $D$ the diffusion coefficient $\left(\mathrm{m}^{2} \mathrm{~s}^{-1}\right)$ of the free metal ion in the diffusive gel, and $A$ is the area of the DGT device exposed to the solution. The Diffusive Boundary Layer (DBL) thickness can be calculated by using equation 3 [1]. In this equation, $\delta$ is the DBL thickness.

$$
\frac{1}{M}=\frac{\Delta g}{D C_{b} t A}+\frac{\delta}{D C_{b} t A}
$$

However, equation 2 has two unknowns $\left(\mathrm{C}_{\mathrm{b}}\right.$ and $\left.\delta\right)$; thus in order to solve for both the variables, a second equation is required and it has been developed through deployment of an additional DGT device having a different diffusive gel layer thickness $\left(\Delta \mathrm{g}^{\prime}\right.$ and $\left.\Delta \mathrm{g}^{\prime \prime}\right)$; the DBL thickness can be calculated by equation 3 [1].

$$
\delta=\frac{\left(\mathrm{M} \Delta \mathrm{g}^{\prime}\right)\left(\Delta \mathrm{g}^{\prime}\right)-\left(\mathrm{M} \Delta \mathrm{g}^{\prime \prime}\right)\left(\Delta \mathrm{g}^{\prime \prime}\right)}{\left(\mathrm{M} \Delta \mathrm{g}^{\prime}-\mathrm{M} \Delta \mathrm{g}^{\prime}\right)}
$$

$\mathrm{M}_{\Delta \mathrm{g}^{\prime}}$ and $\mathrm{M}_{\Delta \mathrm{g}^{\prime \prime}}$ are the measured mass of the analyte metal in the binding gel of DGT device having a diffusive gel thickness of $\Delta \mathrm{g}^{\prime}$ and $\Delta \mathrm{g}^{\prime \prime}$, respectively. The DGT-labile concentrations have been calculated according to the DGT equation 1. The DGT-labile fraction of metal ions $(\Psi)$ is defined as 


$$
\psi=\frac{\text { DGT labile metal ion concentraion }}{\text { Total metal concentration }}
$$

\subsection{Experimental}

\subsubsection{Reagents and material}

Polyacrylamide (PAM) hydrogel diffusion layers, Chelex 100 impregnated binding phases and plastic DGT holders were purchased from DGT Research Ltd. (UK). DGT samplers were assembled based on procedures as described below [2]

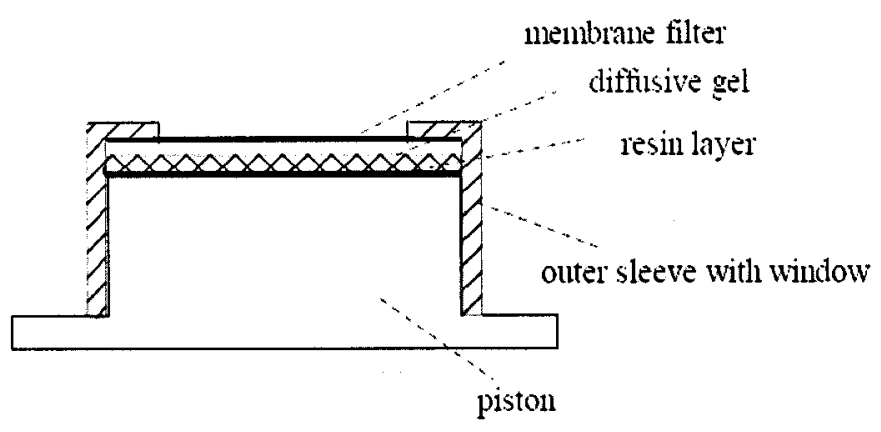

Figure 4.2 Schematic representation of a section through the DGT assembly.

A plastic base piston ( $2.5 \mathrm{~cm}$ diameter) was loaded with resin gel, diffusive gel and filter and the plastic top securely push fit over it to leave a $2.0 \mathrm{~cm}$ diameter window. $0.45 \mu \mathrm{m}$ pore-size cellulose acetate filter (Advantec MFS, USA) used as a covering membrane. PAM gel and Chelex gel were prepared by the following procedures [1]. Schematic representation of a section through the DGT assembly is presented in Figure 4.2. 


\subsubsection{PAM gel preparation}

PAM hydrogel containing $15 \%$ by volume acrylamide and $0.3 \%$ by volume Acryaide agarose cross-linker was used throughout this work as the diffusive gel layer. For $10 \mathrm{~mL}$ of gel solution, $70 \mu \mathrm{L}$ of freshly prepared ammonium persulphate initiator $(10 \%)$ and $20 \mu \mathrm{L}$ of TEMED catalyst were added. The solution was immediately cast between two glass plates separated by plastic spacers and allowed to set at temperature of $40 \pm 5^{\circ} \mathrm{C}$. The thicknesses of the PAM gels were $0.040,0.080$ and $0.120 \mathrm{~cm}$. The gels were cut into $2.5 \mathrm{~cm}$ diameter discs before use.

\subsubsection{Chelex gel preparation}

The binding resin gel consisted of $2 \mathrm{~g}$ of ion-exchange resin Chelex-100 (Na form, 100-200 wet mesh) in $10 \mathrm{~mL}$ of gel solution. Less ammonium persulphate and TEMED were used to prolong the setting process and allow the resin to settle by gravity to one side of the gel as a plane of approximately close-packed beads.

The following aqueous effluent sample supplied by Copper Cliff mine in Sudbury, Ontario, Canada, were used: one was undiluted aqueous effluent (100\%); the other was diluted with the laboratory tap water so that it contained $45 \%$ of the original aqueous effluent ( $45 \%$ effluent); henceforth, these two aqueous effluent samples will be identified simply as the $100 \%$ and the $45 \%$ effluent, respectively. Temperature, $\mathrm{pH}$ and conductivity were measured immediately after the samples were received at the laboratory using Accumet $\mathrm{pH}$ meter, manufactured by Fisher Scientific, Model 20. The $\mathrm{pH}$ meter was calibrated prior to the measurement, and the data were collected for at least $30 \mathrm{~min}$. The $\mathrm{pH}$ was measured to $\pm 0.01 \mathrm{pH}$ unit. The laboratory tap water 
used by Copper Cliff Mine to dilute the $100 \%$ aqueous effluent to $45 \%$ aqueous effluent contained $2 \mathrm{mg} / \mathrm{L}$ DOC.

\subsubsection{Materials and Methods}

Standard commercially available DGT devices consisting of a simple, tight-fitting piston design with a $2 \mathrm{~cm}$ diameter window were used for all measurements. The DOC was measured with OI Analytical model 1010 TOC Analyzer. The metals (total dissolved concentrations) were determined by Inductively Coupled Plasma Mass Spectrometry using Perkin-Elmer Elan 6000 ICP-MS or, ICP-OES (already mentioned); the anions were determined by ion chromatography. Concentrated nitric acid (Optima Fisher Scientific) was used for all acidification. The acid and sodium hydroxide (Fisher Scientific) were used to adjust the solution $\mathrm{pH}$. All experiments were carried out in Teflon containers. A Perkin-Elmer AAnalyst 600 Graphite Furnace Atomic Absorption Spectrometer (GFAAS) with Zeeman Background Correction, equipped with an $\mathrm{AS} 800$ autosampler, was used for the determination of $\mathrm{Ni}$ and $\mathrm{Cu}$ concentrations. The transversely-heated graphite tubes (Perkin-Elmer) were pyrolytically-coated, and were equipped with integrated L'vov platforms. The signal was measured in the peak area mode. Each completed determination was followed by a 2-s clean-up cycle of the graphite tube at $2400^{\circ} \mathrm{C}$. During the drying, ashing and clean-up cycles, the internal argon gas was passed through the furnace at 300 $\mathrm{mL} / \mathrm{min}$, but the gas flow was interrupted during the atomization step. 


\subsubsection{Analysis}

After deployment, the Chelex 100-gel layers were cautiously removed from the DGT devices and placed in $1.5 \mathrm{~mL}$ vials. $1 \mathrm{~mL}$ of ultrapure nitric acid was then added, and the test samples were left for 1 day to leach out all bound metals from the resin into the nitric acid. A Perkin-Elmer Graphite Furnace Atomic Absorption Spectrometer (Analyst 600) was used to determine the concentration of metals in the eluent test samples, from which the accumulated metal was calculated. Total concentrations of major cations and trace metals in acidified filtered samples were determined by Inductively Coupled Plasma-Atomic Emission Spectrometry or Inductively Coupled Plasma-Mass Spectrometry (ICP-MS). The Competing Ligand Exchange Method in conjunction with Adsorptive Cathodic Stripping Voltammetry was used for determining the speciation of nickel and copper using the optimized experimental conditions for the speciation of copper and nickel in mine aqueous effluents which have been discussed in previous chapter.

\subsection{5 $Q A / Q C$}

Quality control for metal analyses included repeated injections and periodic analysis of the Certified Reference Standard, NIST 1640. A prior set of sample was reanalyzed if the measured value differed from the certified value by $>10 \%$. The relative standard deviation of replicate determination was typically $\leq 5 \%$. The concentration was determined using analytical calibration curve. Every fifth sample analyzed was a blank. All measurements were done in quadruplicate. 


\subsection{Results and Discussion}

The $\mathrm{pH}$ of undiluted $100 \%$ and diluted $45 \%$ effluent samples were measured immediately after filtration of the sample through $0.45 \mu \mathrm{m}$ Gelman filters and found to be $7.30 \pm 0.05$ and $7.20 \pm 0.05$, respectively. The conductivity of undiluted $100 \%$ and diluted $45 \%$ effluent samples were measured immediately after filtration and found to be $300 \pm 3 \mathrm{mS}$ and $165 \pm 3 \mathrm{mS}$, respectively. A series of experiments were performed using gel assemblies (DGT unit) to test Eq. 1. This set of experiment was important to check the applicability of the DGT device for the very complex mine effluent samples. When gel assemblies with fixed exposure surface area $\left(3.14 \mathrm{~cm}^{2}\right)$ and diffusive gel layer thickness were exposed to the effluent samples with continuous stirring for different times, the measured mass of copper and nickel increased linearly with time (Figs. 4.3 and 4.4). Gel assemblies with different diffusive gel thicknesses were also exposed to effluent samples for a fixed time. The measured mass of copper and nickel were inversely proportional to the diffusion layer thickness. These observations nicely agree with the theoretical predictions (Figs. 4.5 and 4.6). The results confirm the principle and mechanism of the DGT technique and allow Eq. 1 to be used for calculating the bulk concentrations of labile copper and nickel in Copper Cliff Mine aqueous effluent samples. To determine the thickness of the diffusive boundary layer (DBL) at the surface of the DGT devices, a set of the DGT devices with two different gel layers thicknesses $(0.4$ and $0.8 \mathrm{~mm})$ of APA gel were deployed in triplicate. The thickness of the DBL was calculated using Eq. 3, and was found to be $0.074 \mathrm{~mm}$. Total dissolved concentrations of nickel, copper, DOC and 
all other properties of the samples have already been reported in Chapter 3. In this chapter, a few important data are summarized in Table 4.1. The dissolved concentrations of nickel and copper in 100\% Copper Cliff mine aqueous effluents were 141.2 and $241.9 \mu \mathrm{g} / \mathrm{L}$. The concentration of DOC in $100 \%$ mine effluent was found to be $6.1 \mathrm{mg} / \mathrm{L}$. The metal speciation data for $\mathrm{Ni}$ and $\mathrm{Cu}$ in $100 \%$ Copper Cliff mine effluent samples by the DGT technique are presented in Tables 4.2 and 4.3. It was found that $81.3 \pm 3.9 \mu \mathrm{g} / \mathrm{L}$ of labile Cu (DGT labile) was present in the $100 \%$ mine aqueous effluent sample. These results were obtained by using a DGT with a diffusive gel of $0.04 \mathrm{~cm}$ thickness (Table 4.2). 
Table.4.1. Some chemical characteristics of the undiluted (100\%) and the diluted $(45 \%)$ effluent.

\begin{tabular}{|c|c|c|}
\hline Properties & $\begin{array}{c}\text { Undiluted } \\
(100 \%) \text { effluent }\end{array}$ & $\begin{array}{c}\text { Diluted } \\
(45 \%) \text { effluent }\end{array}$ \\
\hline $\mathrm{pH}$ & $7.3 \pm 0.05$ & $7.2 \pm 0.05$ \\
\hline Conductivity (mS) & $300 \pm 3.0$ & $165 \pm 3.0$ \\
\hline Colour & Colourless & Colourless \\
\hline Smell & Pungent smell & Pungent smell \\
\hline Analyte & $\begin{array}{c}\text { Concentrations in } 100 \% \\
\text { effluent }\end{array}$ & $\begin{array}{c}\text { Concentrations in } 45 \% \\
\text { effluent }\end{array}$ \\
\hline$[\mathrm{DOC}](\mathrm{mg} / \mathrm{L})$ & 6.12 & 3.25 \\
\hline$[\mathrm{DIC}](\mathrm{mg} / \mathrm{L})$ & 1.73 & 11.23 \\
\hline$[\mathrm{Co}](\mathrm{M})$ & $2.14 \times 10^{-7}$ & $1.04 \times 10^{-7}$ \\
\hline$[\mathrm{Ni}](\mathrm{M})$ & $2.41 \times 10^{-6}$ & $1.05 \times 10^{-6}$ \\
\hline$[\mathrm{Cu}](\mathrm{M})$ & $3.81 \times 10^{-6}$ & $1.74 \times 10^{-6}$ \\
\hline$[\mathrm{Zn}](\mathrm{M})$ & $3.58 \times 10^{-7}$ & $2.58 \times 10^{-7}$ \\
\hline$[\mathrm{Cd}](\mathrm{M})$ & $3.65 \times 10^{-8}$ & $2.58 \times 10^{-8}$ \\
\hline$[\mathrm{Na}](\mathrm{M})$ & $4.35 \times 10^{-3}$ & $2.17 \times 10^{-3}$ \\
\hline$[\mathrm{Fe}](\mathrm{M})$ & $5.9 \times 10^{-7}$ & $2.6 \times 10^{-7}$ \\
\hline$[\mathrm{Al}](\mathrm{M})$ & $5.97 \times 10^{-6}$ & $2.99 \times 10^{-6}$ \\
\hline$[\mathrm{Ca}](\mathrm{M})$ & $1.37 \times 10^{-2}$ & $6.87 \times 10^{-3}$ \\
\hline$[\mathrm{K}](\mathrm{M})$ & $8.95 \times 10^{-4}$ & $4.48 \times 10^{-4}$ \\
\hline$[\mathrm{Mg}](\mathrm{M})$ & $1.23 \times 10^{-3}$ & $6.16 \times 10^{-4}$ \\
\hline$\left[\mathrm{SO}_{4}\right]^{2-}(\mathrm{M})$ & $2.08 \times 10^{-2}$ & $1.04 \times 10^{-2}$ \\
\hline$[\mathrm{Cl}]^{-}(\mathrm{M})$ & $2.5 \times 10^{-3}$ & $1.3 \times 10^{-3}$ \\
\hline$\left[\mathrm{NO}_{3}\right]^{-}(\mathrm{M})$ & $1.94 \times 10^{-4}$ & $4.9 \times 10^{-5}$ \\
\hline
\end{tabular}

$\mathrm{pH}$ and conductivity were measured by an Accumet $20 \mathrm{pH} /$ conductivity meter from Fischer Scientific. DOC $=$ Dissolved Organic Carbon; DIC $=$ Dissolved Inorganic Carbon;DOC was measured with an OI Analytical Model 1010TOC Analyzer.The metals (total dissolved concentrations) were determined by Inductively-coupled plasma mass spectrometry by Perkin-Elmer Elan 6000 ICP-MS and Inductively Coupled Optical Emission Spectroscopy. The anions were determined by ion chromatography. 


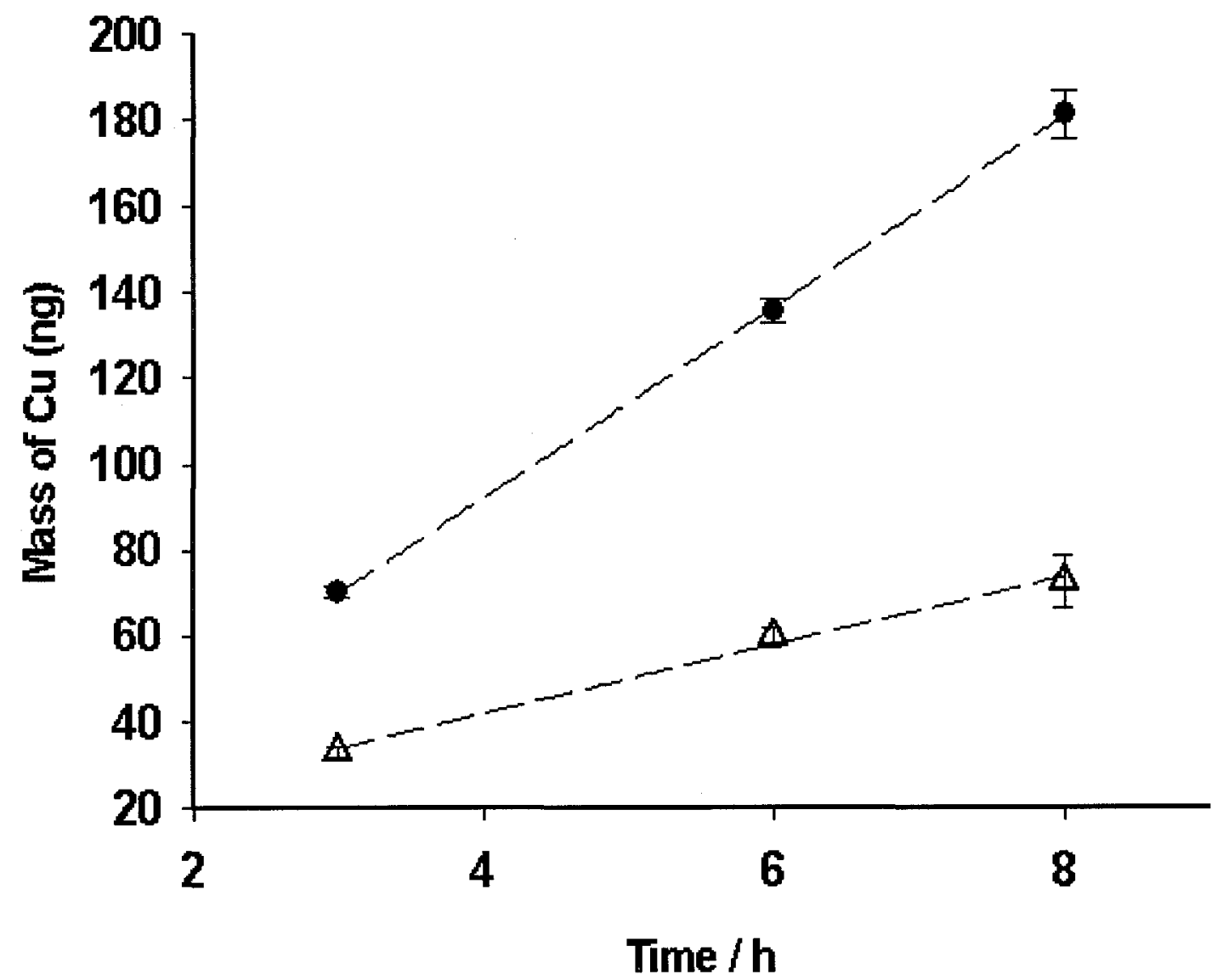

Figure 4.3: Plot of measured mass of $\mathrm{Cu}$ accumulated in the binding gel of DGT vs time (h) at $25^{\circ} \mathrm{C}$. (•) $100 \%$ Copper Cliff Mine effluent; $(\Delta) 45 \%$ Copper Cliff Mine effluent. 


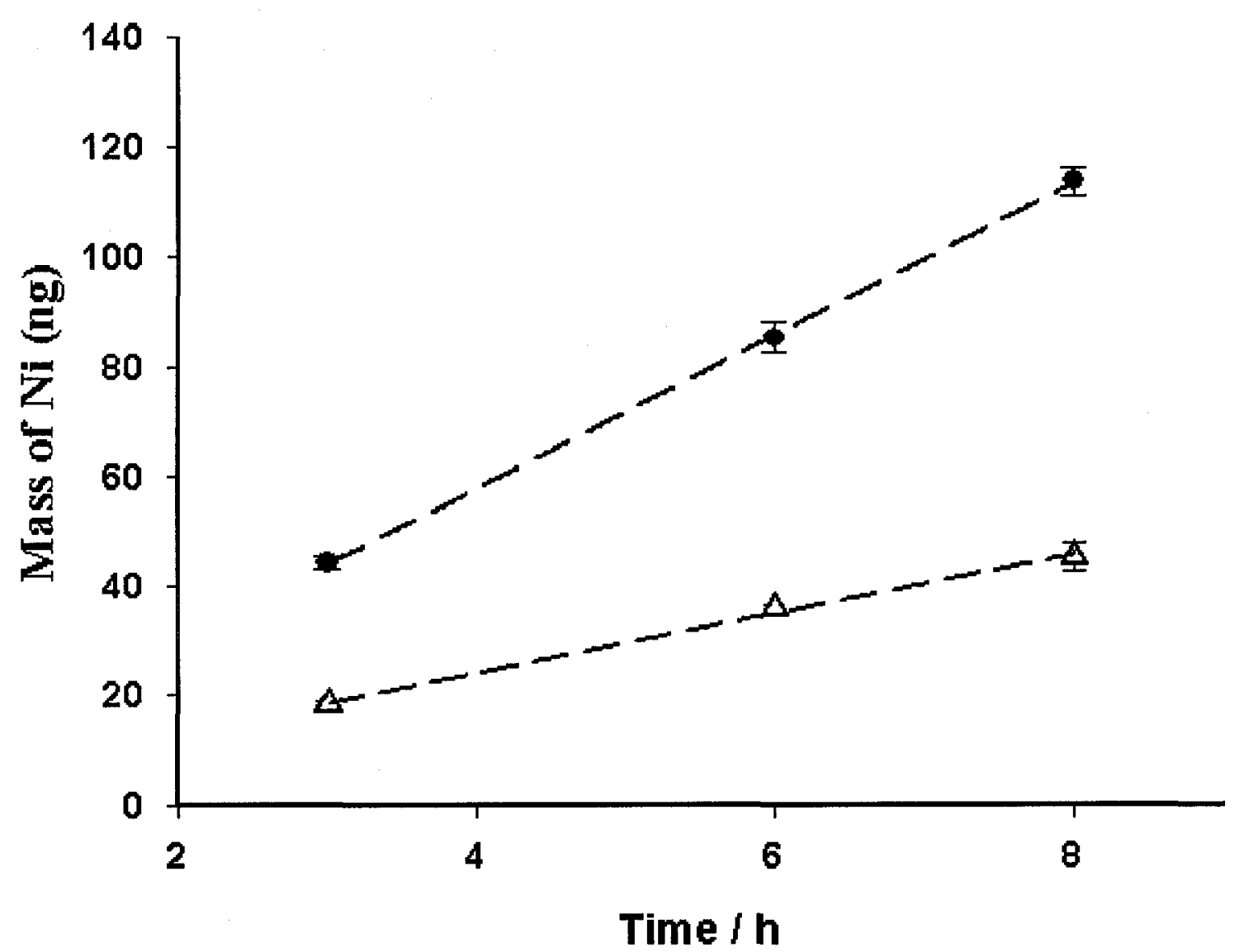

Figure 4.4 : Plot of measured mass of Ni accumulated in the binding gel of DGT vs time (h) at $25^{\circ} \mathrm{C} .(\bullet) 100 \%$ Copper Cliff Mine effluent; $(\Delta) 45 \%$ Copper Cliff Mine effluent. 


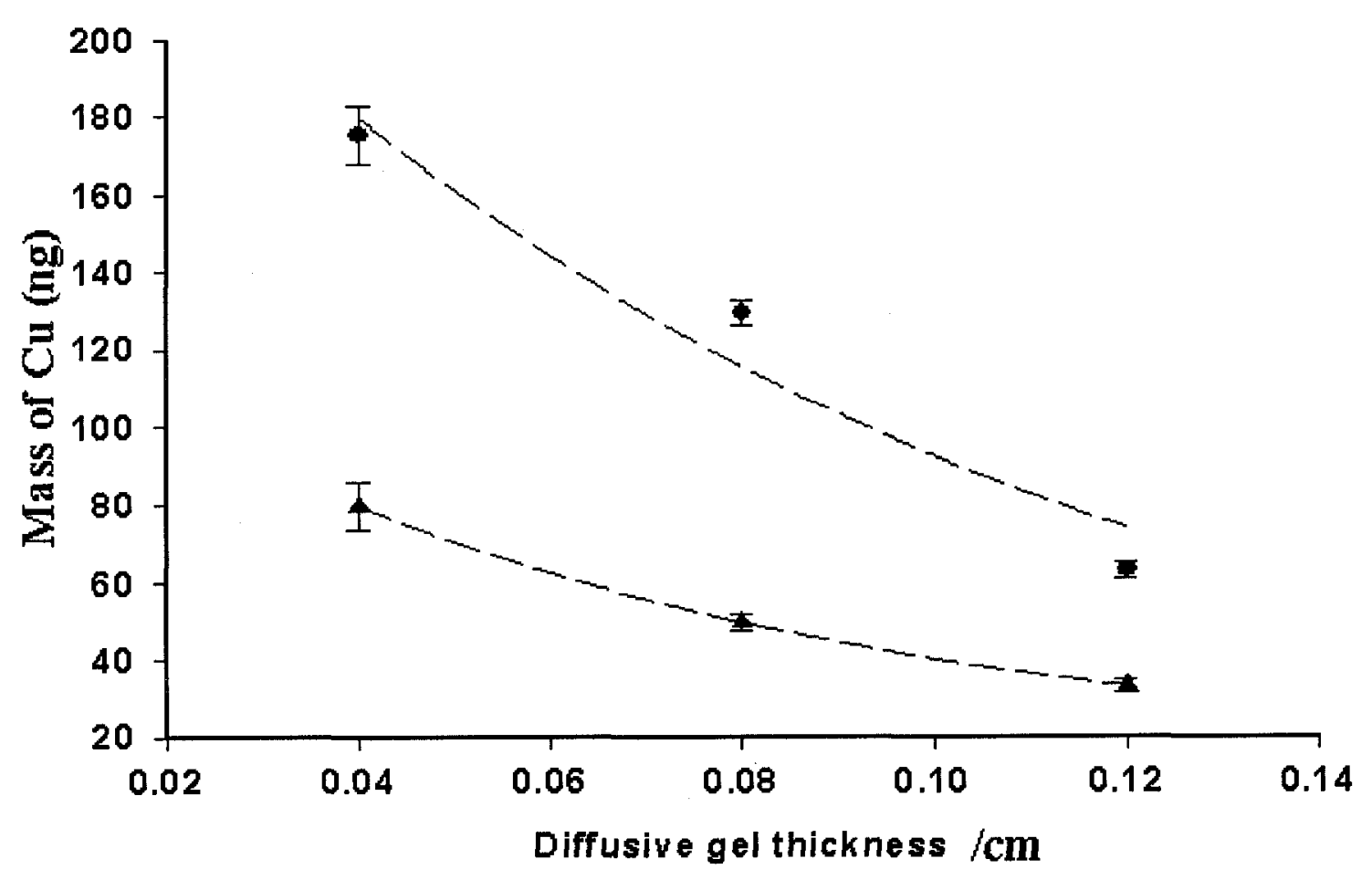

Figure 4.5: Plot of measured mass of $\mathrm{Cu}$ accumulated in the binding gel of DGT as a function of the thickness of the diffusive gel in the DGT device at $25^{\circ} \mathrm{C} .(\bullet) 100 \%$ Copper Cliff Mine effluent; $(\Delta)$ 45\% Copper Cliff Mine effluent. 


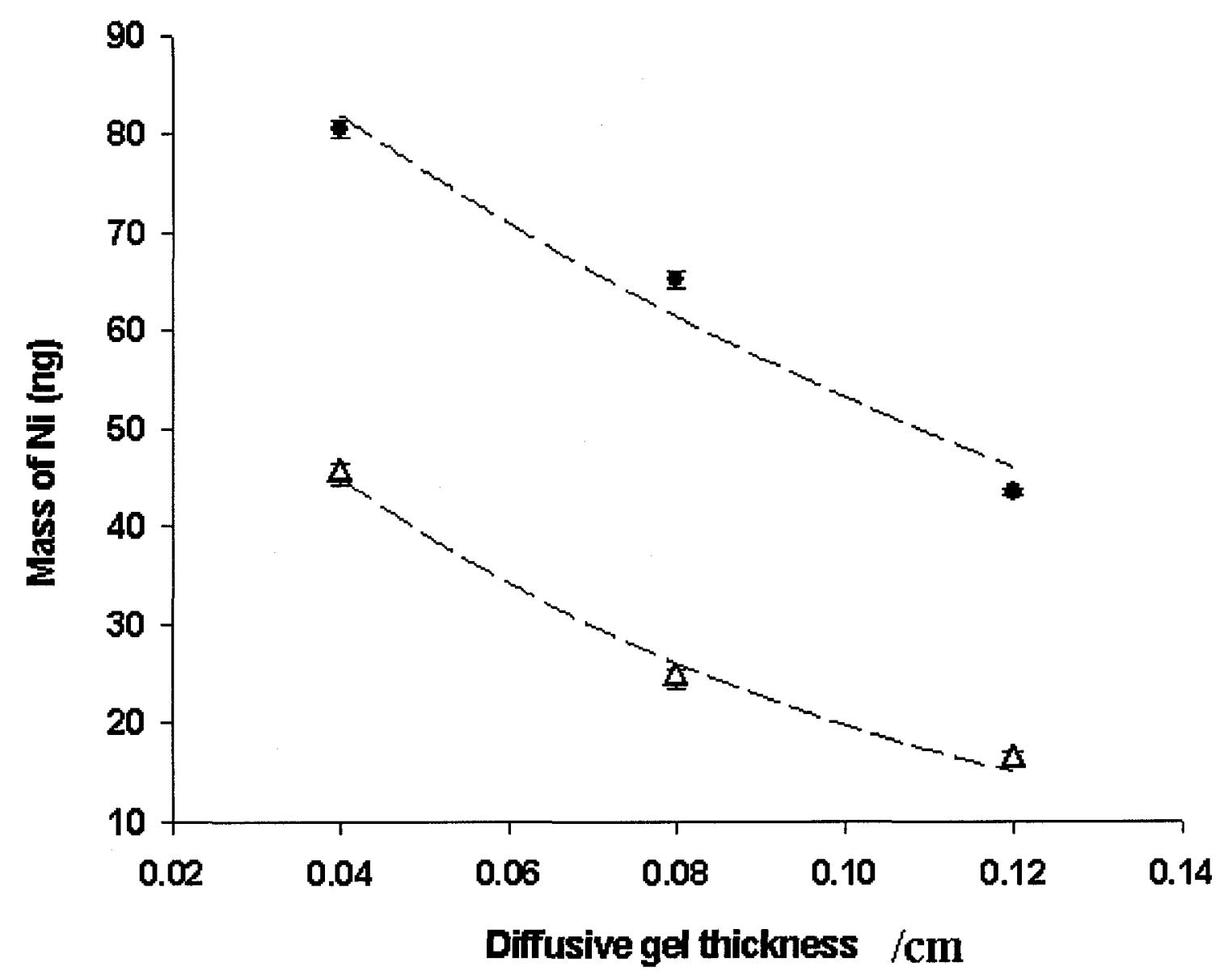

Figure 4.6: Plot of measured mass of $\mathrm{Ni}$ accumulated in the binding gel of DGT as a function of the thickness of the diffusive gel in the DGT device at $25^{\circ} \mathrm{C}$. (•) $100 \%$ Copper Cliff Mine effluent; $(\Delta) 45 \%$ Copper Cliff Mine effluent. 
The concentration of labile $\mathrm{Cu}$ in the diluted $45 \%$ aqueous effluent was found to be $38.2 \pm 3.9 \mu \mathrm{g} / \mathrm{L}$ by calculation using Eq 1 . This decrease in the concentration of labile copper complexes (DGT labile) was due to the decrease in the total copper concentration in the diluted $45 \%$ mine effluent sample. The total copper concentration in $45 \%$ mine aqueous effluent was $110.5 \mu \mathrm{g} / \mathrm{L}$. However, the labile fractions of copper in $100 \%$ and $45 \%$ aqueous effluents were found to be very close to each other, and there was no significant change in the percentage of labile fraction of total copper (Table 4.4). The similarity in the percentage of labile fraction of copper in $100 \%$ and $45 \%$ mine aqueous effluent was probably due to the similar $\mathrm{Cu}(\mathrm{II})$ to $\mathrm{DOC}$ mole ratio. A set of data is presented in Table 4.2 for labile copper concentration in $100 \%$ and $45 \%$ mine effluent samples by using DGT devices with diffusive gel of different thicknesses $(\Delta \mathrm{g})$. Labile copper concentration in $100 \%$ and $45 \%$ mine aqueous effluent samples were determined by DGT devices with diffusive gel of different thickness $(\Delta \mathrm{g})$, and similar bulk concentrations were found (Table 4.2). It was found that $58.0 \pm 2.9 \mu \mathrm{g} / \mathrm{L}$ of labile nickel (DGT labile) was present in the $100 \%$ mine aqueous effluent sample. The concentration of DGT labile nickel in diluted $45 \%$ aqueous effluent was found to be $23.5 \pm 0.1 \mu \mathrm{g} / \mathrm{L}$. These results were obtained by using a DGT with a diffusion layer of $0.04 \mathrm{~cm}$ thickness (Table 4.3). The concentration of total labile nickel complexes (DGT labile) in 100\% mine effluent and $45 \%$ effluent was determined by using the DGT technique with diffusive gel layer with different thicknesses. All these data are presented in Table 4.3. 
Table 4.2. Chemical speciation of $\mathrm{Cu}-\mathrm{DOC}$ complexes in diluted and in undiluted Copper Cliff Mine aqueous effluents obtained by DGT technique.

\begin{tabular}{ccc}
\hline$\Delta \mathrm{g}(\mathrm{cm})$ & $\begin{array}{c}\mathrm{DGT}_{\text {Labile Cu in 100\% Effluent }}(\mu \mathrm{g} / \mathrm{L}) \\
0.04\end{array}$ & $\mathrm{DGT}_{\text {Labile Cu in 45\% Effluent }}(\mu \mathrm{g} / \mathrm{L})$ \\
0.08 & $81.3 \pm 3.9$ & $38.2 \pm 3.9$ \\
0.12 & $82.5 \pm 2.4$ & $40.6 \pm 1.7$ \\
& $82.4 \pm 1.3$ & $39.1 \pm 2.4$ \\
\hline
\end{tabular}


Table 4.3. Chemical speciation of Ni-DOC complexes in diluted and in undiluted Copper Cliff Mine aqueous effluents obtained by DGT technique.

\begin{tabular}{ccc}
\hline$\Delta \mathrm{g}(\mathrm{cm})$ & $\begin{array}{c}\mathrm{DGT}_{\text {Labile Ni in 100\% Effluent }}(\mu \mathrm{g} / \mathrm{L}) \\
0.04\end{array}$ & $\begin{array}{c}\mathrm{DGT}_{\text {Labile Ni in } 45 \% \text { Effluent }}(\mu \mathrm{g} / \mathrm{L}) \\
0.08\end{array}$ \\
\hline & $57.9 \pm 2.9$ & $23.5 \pm 1.0$ \\
0.12 & $58.1 \pm 1.5$ & $24.1 \pm 0.1$ \\
& $55.0 \pm 1.7$ & $21.2 \pm 2.0$ \\
\hline
\end{tabular}


Total labile concentration of nickel complexes in both the effluent samples determined by DGT devices with different diffusive gel thickness $(\Delta \mathrm{g})$ are in good agreement with each other.

The labile fraction of nickel in $100 \%$ and $45 \%$ aqueous effluent remained almost unchanged and there was no significant change in the $\%$ of labile fraction of nickel after the dilution of the effluent sample (Table 4.4). Similar percentages of labile fraction for nickel in $100 \%$ and $45 \%$ mine aqueous effluent was probably due to the similar $\mathrm{Ni}(\mathrm{II})$ to DOC mole ratio. The dilution of effluent sample showed that there was no significant change in the percentage of labile fraction of both copper and nickel. Data presented in the previous chapter of the same samples by using Competing Ligand Exchange Method (CLEM) in conjunction with Adsorptive Cathodic Stripping Voltammetry (AdCSV) showed that there was also no significant change in the percentage of labile fraction of copper in the undiluted and diluted effluent sample. However, a drastic decrease in the percentage of labile fraction of nickel was observed after dilution (Table 4.4) by CLEM/AdCSV using dimethylglyoxime (DMG) as a competing ligand. As discussed in the previous chapter, the large decrease in the $[\mathrm{Ca}]_{\text {Total }}$ concentration which probably represents $\left[\mathrm{Ca}^{2+}\right]$ concentrations in the diluted effluent resulted in a large decrease in the screening of coulombic interactions between the $\mathrm{Ni}^{2+}$ cations and the humate polyanions, thereby increasing the free energy of coulombic interactions in the metal-DOC bonding. This increased the strength of the Ni-DOC binding, which resulted in the observed decrease in the percentage release of Ni. Secondly, the change in the conformational properties of DOC, resulting from the dilution of the 
$100 \%$ effluent sample, may be due to decrease in the ionic strength in the diluted effluent sample. However, the percentage of labile fraction of the total nickel in the $45 \%$ effluent sample determined by DGT technique does not agree well with the previous explanation. There was no significant change in the percentage of labile fraction (DGT labile) of total nickel in diluted $45 \%$ effluent sample. The labile fraction (L) is expressed by Eq. 5, and has been determined by electrochemical techniques.

$$
L=\frac{i_{p}}{i_{o}} \times 100
$$

where, $i_{P}$ and $i_{o}$ are the current for the complex system and the reference current under conditions of no complexation, respectively, which means $i_{p} / i_{o}$ represents the fraction of the total metal released by the metal-complex. Adsorption of surface active species on the HMDE can prevent metal from undergoing electrochemical reactions on the HMDE and can reduce $i_{p}$ and hence, decrease the labile fraction (L). Table 4.4 shows that the percentage of labile fraction for nickel in $100 \%$ and $45 \%$ effluent samples, as determined by CLEM/AdCSV, were radically different, with the $45 \%$ mine effluent giving much smaller values than those of the $100 \%$ mine effluent, whereas the percentage of DGT labile fractions for the $100 \%$ and $45 \%$ mine effluent gave nearly equal results. For explanation, it is necessary to understand both the measurement techniques. Before the results are compared, it is essential to emphasize the basic difference between these two measurement techniques.

DGT measures a flux which is used to calculate an average concentration over the deployment period, and the discrimination of metal species in the gel is based on size, lability and mobility (diffusion). A gel pore size of $\sim 5 \mathrm{~nm}$ permits free metal ions, 
inorganic metal complexes and small organic metal complexes to diffuse, whereas particles of larger size and large colloids are excluded. Since the complex must dissociate in the hydrogel to be measured, only metal complexes with sufficiently rapid dissociation rates will form metals to be retained by the resin. Kinetically inert species are thus excluded.

However, in CLEM/AdCSV, the electrochemical response depends on the dissociation of M-DOC bond in the sample solution and diffusion of M-AL complex $(\mathrm{AL}=$ Added Ligand), through the diffusive boundary layer to the electrode, which is constant at a constant deposition potential, $\mathrm{pH}$ and ionic strength. In calculating the DGT labile fraction of metal, the diffusion coefficient of free metal ion was used to calculate the percentage of the metal ions and the labile metal complexes having diffusion rate coefficient similar to the metal aqua complex. However, in CLEM/AdCSV, all labile metal complexes were included in the process. Secondly, the measurement process by the DGT devices occurs via exclusion of species larger than the pore size of the diffusive medium. As a result, there is a probability of excluding large but weak metal complexes in the DGT technique The percentage of labile fraction of copper determined by CLEM/AdCSV was higher than the percentage of labile fraction of copper determined by the DGT device both in $100 \%$ and $45 \%$ Copper Cliff Mine effluents (Table 4.3). This indicates the existence of high-molecular-weight labile copper species both in the $100 \%$ and $45 \%$ Copper Cliff Mine effluents. Fractions of labile copper complexes were small enough to pass through the diffusive gel of the DGT device. It is also well known that metal complexes of humic substances have diffusion coefficient substantially lower than the 
free metal ion [12]. Since the diffusion coefficient for free ions was used in this study, the DGT labile concentrations were probably underestimated, contributing to the difference measured by the two methods. It has been reported by Scaly et al. that complexation by simple organic ligands such as nitrilotriacetic acid (NTA) or diglycolic acid (DGA) lower the diffusion coefficient of trace metal in the gel by approximate $25 \%[13,14]$. If we use this reduced diffusion coefficient for copper and assume that $100 \%$ copper of the concentration measured with DGT is complexed with simple organic ligands the results are different from those obtained by CLEM/AdCSV. 
Table 4.4. Comparison of the labile metal fraction determined by DGT with the labile metal fraction determined by CLEM/AdCSV.

\begin{tabular}{cccc}
\hline Metals & $\begin{array}{c}\text { Effluent aqueous } \\
\text { samples }\end{array}$ & $\begin{array}{c}\text { Percentage (\%) of labile } \\
\text { fraction of the total } \\
\text { metal, determined by } \\
\text { CLEM/AdCSV }\left(i_{p} / i_{o} \%\right)\end{array}$ & $\begin{array}{c}\text { Percentage (\%) } \\
\text { of DGT labile } \\
\text { metal fraction of } \\
\text { total metal }(\psi)\end{array}$ \\
\hline \multirow{2}{*}{$\mathrm{Cu}$} & $100 \%$ Mine Effluent & $53.5 \pm 0.6$ & $33.9 \pm 1.2$ \\
& $45 \%$ Mine Effluent & $62.0 \pm 1.0$ & $35.6 \pm 0.5$ \\
\hline \multirow{2}{*}{$\mathrm{Ni}$} & $100 \%$ Mine Effluent & $38.5 \pm 0.1$ & $41.0 \pm 1.5$ \\
& $45 \%$ Mine Effluent & $1.5 \pm 0.5$ & $38.2 \pm 1.0$ \\
\hline
\end{tabular}


Table 4.4 suggests that copper in both $100 \%$ and $45 \%$ effluent samples formed larger $\mathrm{Cu}(\mathrm{II})$-HS complexes having slow diffusion rate coefficients, and labile $\mathrm{Cu}(\mathrm{II})-\mathrm{HS}$ complexes larger than the pore size of the diffusive gel could not cross the diffusive gel membrane in the DGT device. However, the percentages of labile nickel complexes determined by both techniques in the 100\% Copper Cliff Mine effluents were in very good agreement with each other. These results suggesting the presence of small labile nickel complexes which diffused through the pore size of the diffusive gel. It was reported by Hassan et al. [15] that labile Ni complexes in Copper Cliff Mine effluent were a mixture of nickel aqua complex and/ or small very weak organic and inorganic complexes. Fillela et al. [16] have also reported that the greatest proportions of dissolved trace metals are in the low molecular weight fraction.

The measured DGT labile fractions of nickel in the 100\% Copper Cliff Mine aqueous effluents using the diffusion coefficient of free nickel ion are in good agreement with the results obtained by CLEM/AdCSV. This probably indicates that labile nickel complexes in the $100 \%$ Copper Cliff Mine effluent have a diffusion coefficient similar to that of free nickel ion and labile nickel complexes in the 100\% Copper Cliff effluent are small in size.

The WHAM predictions for nickel ion and its inorganic complexes in the $100 \%$ effluent are in very good agreement with CLEM/AdCSV [17] results. However, in the $45 \%$ aqueous effluent, the percentage of labile nickel species determined by CLEM/AdCSV is much lower than that of labile Ni given by the DGT. We have no explanation for this difference. WHAM predictions agree with the labile $\mathrm{Ni}$ concentration determined by the DGT technique. 


\subsection{Conclusions:}

Comparison of these two sets of speciation data tell us that $\mathrm{Cu}$ (II) in the undiluted $100 \%$ and the diluted $45 \%$ mine effluents formed small-sized and large-sized labile complexes. The smaller $\mathrm{Cu}(\mathrm{II})$ labile complexes were determined by DGT technique; however, larger complexes were not determined by the DGT technique. Labile Ni(II) complexes in the $100 \%$ undiluted effluent had diffusion coefficients similar to that of nickel aqua complex, and hence, could be bioavailable. Speciation data by these two techniques were complementary and provided a more comprehensive picture and a better insight into the physical and chemical characteristics of the metal species than either the DGT technique or the complex dissociation kinetics alone could do. 


\subsection{References:}

1 Zhang H., Davison W. (1995) Analytical Chemistry, 67(19), 3391-400.

2 Davison W, Zhang H, (2000) Ocean Sci. and Technol, 283-302.

3 Zhang H, Davison W, Knight B, McGrath S, (1998) Environ. Sci. Technol,, 32(5), 704-710.

4 Zhang H, Davison W, Gadi R, Kobayashi T, (1998), Anal. Chim. Acta. 370(1), 29-38.

5 Dahlqvist R, Zhang H, Ingri J, Davison W, (2002), Anal. Chim. Acta, 460(2), $247-256$.

6 Harper M P, Davison W, Zhang H, Tych W, (1998), Geochim. Cosmochim. Acta 62(16), 2757-2770.

7 Zhang H, Davison W, Mortimer R J G, Krom M D, Hayes P J, Davies I M (2002) Sci. of the Total Environ, 296(1-3), 175-187.

8 Fones G R, Davison W, Hamilton-Taylor J, (2004) Continental Shelf Research, 24 (13-14),

9 Davison W, Zhang H (1994), Nature 367, 546-

10 Instruction manual by Bio Rad., Chelex 100 and chelex 20 chelating ion exchange Resin.

11 Sebastian Mylen

12 Zhang H, Davison W (2000) Anal Chem, 72, 4447-

13 Scally S, Davison W, Zhang H (2006) Anal Chim Acta 558, 222-

14 Unsworth E R., Warnken K W., Zhang H, Davison W, Black F, Buffle J, Cao J, Cleven R, Galceran J, Gunkel P, Kalis E, Kistler D, van Leeuwen H P., 
Martin M, Noël S, Nur Y, Odzak N, Puy J, van Riemsdijk W, Sigg L, Temminghoff E, Tercier-Waeber, Mary-Lou Toepperwien S, Town R M., Weng L and Hanbin Xue (2006) Environ. Sci. Technol., 40(6), 1942-1949.

15 Hassan N M, Murimboh J D, Sekaly A L R, Mandal R, Chakrabarti C L, Gregoire D C, (2006) Anal Bioanal Chem 384: 1558-1566

16 Town R M, Filella M (2002) Rev Environ Sci Biotechnol 1:277-297

17 Chakraborty P., Chakrabarti C. L. (2006), Anal. Chim. Acta 571(2), 260269. 


\section{5}

Simultaneous determination of speciation parameters of $\mathrm{Cu}, \mathrm{Pb}, \mathrm{Cd}$ and $\mathrm{Zn}$ in model solutions of Suwannee River Fulvic Acid by Scanned Stripping Voltammetry 


\subsection{Introduction:}

There is an increased need for rapid determination of speciation parameters of several trace metals in sample solutions with a single measurement in various fields like environmental and industrial metal pollution control. The literature contains number of publications on the multielement analysis of trace metals concentrations by various techniques, such as Inductively Coupled Plasma Mass Spectrometry (ICP-MS) [1-5], Inductively Coupled Plasma Atomic Emission Spectrometry (ICP-AES) [6-9], Graphite Furnace Atomic Absorption Spectrometry (GFAAS) [10-13], and Anodic Stripping Voltammetry (ASV) [14-18]. However, it is generally recognized total metal concentrations in freshwaters do not reflect the water quality, and that the specific physicochemical forms (i.e. chemical speciation) rather than the total metal concentrations determine their reactivity, transport and fate in the natural environment. Ecotoxicity of a metal is generally correlated with metal speciation and not with the total metal concentration. Humic substances which are ubiquitous in the aquatic environment are structurally complex macromolecules. In general terms, their structures can be described as assemblies of covalently linked aromatic and aliphatic residues carrying carboxyl, phenolic and alkoxy group, although sulphate, ester, alanine, semiquinones, phosphate ester, and other moieties have been proposed for some humic isolates. The major functional groups in humic substances are $-\mathrm{COOH}$, phenolic-OH, and alcoholic $\mathrm{OH}$ groups. Functional groups of humic substances in natural waters bind potentially toxic metals, preventing them from being bioavailable, thereby making the aquatic environment livable for biota. Humic substances react with metals in various ways, one of which is complex-formation, preventing their 
precipitation. In the dissolved state, humic substances control speciation and transport of trace metals in natural waters [19-21].

Reports on simultaneous determination of speciation parameters of trace metals are scarce [22-24]. ICP-MS, ICP-AES are very useful techniques for simultaneous determination of speciation chemistry of trace metals only in uncontaminated freshwaters having very low concentrations of dissolved metals and DOC [25-29].

Eletrochemical stripping analysis is an extremely sensitive technique for determining trace metals [30-31]. Since the metals can be preconcentrated into mercury electrode by factors of $100-1000$, detection limits are improved by $2-3$ orders of magnitude compared to metal concentrations in original samples. Four to six metals can be determined simultaneously in various matrices at concentration levels down to $10^{-10} \mathrm{M}$, utilizing relatively inexpensive electrochemical stripping instrumentation.

Electrochemical stripping techniques have the ability to differentiate between different physicochemical forms (chemical speciation) of metals. Also, their high sensitivity enables direct (i.e. without external preconcentration) determination of trace metals in natural waters with minimum sample treatment so that chemical equilibrium in the bulk solution is not perceptibly disturbed. However, for metal speciation in natural waters, ASV suffers from the problem of adsorption of dissolved organic carbon on the Hanging Mercury Drop Electrode (HMDE) used in ASV. Hydrophobic organic part of humic substances are easily adsorbed on the surface of HMDE, thereby preventing metal ions from undergoing electrode reaction at the electrode surface and resulting in a decrease in peak current and in erroneous signals. 
Also, intermetallic compound-formation of different trace metals may lead to erroneous results. However, these disadvantages can be minimized by optimizing the electrochemical and experimental parameters.

Simultaneous determination of chemical speciation of trace metals in natural waters is a difficult challenge, requiring quantitative, simultaneous determination of concentrations of multimetals and their speciation parameters. The objective of this paper is to investigate the advantages and limitations of simultaneous determination of speciation parameters of $\mathrm{Cu}, \mathrm{Zn}, \mathrm{Cd}$ and $\mathrm{Pb}$ in model solutions of Suwannee River Fulvic Acid (SRFA) using pseudopolarography. It is necessary to start with model solution of SRFA as a preliminary step to invstigation of fulvics in their metalcomplexation in natural waters.

Scanned Stripping Voltammetry (SSV) involves a series of ASV cycles that are plotted as a function of the deposition potential, producing an s-shaped, polarogramlike curve, known as pseudopolarogram, which reflects thermodynamic and kinetic properties of metal complexes in aqueous media. In this work, all speciation parameters and complexing properties of trace metals are represented by Differential Equilibrium Functions [32].

\subsection{Theory}

\subsubsection{Scanned Stripping Voltammetry (SSV)}

The voltammetric current-potential curve was used to determine speciation parameters by using the following equation, which was developed by Filella et al. [34]. 


$$
E=E_{o}+\frac{R T}{n F} \ln \left[\frac{1}{A^{1 / \Gamma} C_{L, T}}\left(\frac{C_{M, T}}{C_{L, T}}\right)^{(1-\Gamma) / \Gamma}\left(\frac{D_{R}}{D_{M L}}\right)^{1 / 2}\right]+\frac{R T}{n F} \ln \left[\frac{\left(1-i / i_{\lim }\right)^{1 / \Gamma}}{i / i_{\lim }}\right]
$$

where $E_{0}$ is the standard potential (V) of the redox couple, $R$ is the universal gas constant $\left(8.314 \mathrm{~J} \mathrm{~K}^{-1} \mathrm{~mol}^{-1}\right), \mathrm{T}$ is the absolute temperature in kelvin $(\mathrm{K}), \mathrm{n}$ is the number of electrons involved in the redox reaction, F is Faraday constant $(96,485 \mathrm{C}$ $\left.\mathrm{mol}^{-1}\right), \mathrm{D}_{\mathrm{R}}$ is the diffusion coefficient of reduced form of $\mathrm{M}$ in mercury, $\mathrm{D}_{\mathrm{ML}}$ is the diffusion coefficient of $\mathrm{ML}$ in the solution, $\mathrm{i}_{\mathrm{lim}}$ is the diffusion-limited current, and $\mathrm{i}$ is the measured current. $\mathrm{A}$ is Freundlich constant; $\mathrm{c}_{\mathrm{M}, \mathrm{T}}$ and $\mathrm{c}_{\mathrm{L}, \mathrm{T}}$ are the concentrations of $\mathrm{M}$ and $\mathrm{L}$, respectively, in the bulk solution. $\Gamma$ is degree of heterogeneity of the system and is independent of experimental conditions. $\Gamma$ is related to the complexation buffer intensity of the system and to the range of $\log \mathrm{K}^{*}$ (where $K^{*}$ is the Differential Equilibrium Parameter) in which the heterogeneous complexant is effective. The smaller the $\Gamma$, the larger is the range. This equation is based on the following assumptions: (a) free $M$ is reversively reduced into $\mathrm{M}^{0}$; all complexes are labile at the electrode surface; $[M]_{b}>>[M]$ (i.e. $[M]_{b}=C_{M}$ ) where, $[M]_{b}$ is the concentration of metal bound to DOC and $[\mathrm{M}]$ is the total metal concentration in the sample; the Freundlich adsorption isotherm is followed; and there is no adsorption of complex or complexant at the electrode surface.

The meaning of $\Gamma$ and its constancy make it a very important parameter for describing the properties of heterogeneous complexant such as humic substances, especially for interpretation of voltammetric signals. The advantage of equation 1 is that the 
heterogeneous properties of the complexant (i.e., $\Gamma$ ) is explicitly considered. The parameter can be directly calculated from the polarograms by using Eq. 1 .

\subsubsection{Differential Equilibrium Function (DEF)}

The Differential Equilibrium Function (DEF) was first introduced by Gamble and Langford, [33, 34] and was further developed by Filella et al. [32] to describe thermodynamic stability of metal complexes of naturally-occurring, heterogeneous complexants, such as humic and fulvic acids. Following Filella et al. [32], the DEF is expressed as:

$$
\log \theta=\Gamma \log \mathrm{K}_{\circ}^{*}-\Gamma \log \mathrm{K}^{*}
$$

where $K^{*}$ is the Differential Equilibrium Parameter, and $\theta$ is the degree of occupation of sites. $K_{0}{ }^{*}$ is a constant and has no special significance other than the fact that it is the value of $K^{*}$ when all the sites are fully occupied (i.e. when $\theta=1$ ).

The constant, $K_{0}{ }^{*}$, was determined from the shift of the polarographic wave relative to the pseudopolarogram of the metal aqua complex using equations 3 [35] and 4 [32].

$$
\ln \alpha=\frac{n F}{R T}\left(E_{1 / 2}-E_{1 / 2}^{L}\right)+\ln \left(\frac{i_{\lim }}{i_{\lim }^{L}}\right)
$$

where $E_{l / 2}$ is the half-wave potential in the absence of ligand, $E_{1 / 2}^{L}$ is the half-wave potential in the presence of ligand, $i_{l i m}$ is the limiting current in the absence of ligand, $i_{\mathrm{lim}}^{\mathrm{L}}$ is the limiting current in the presence of ligand, and $\alpha$ (the degree of complexation) which is related to $K_{0}^{*}$ by equation (4) 


$$
\alpha=c_{L, T} \frac{K^{*} \Gamma}{1-\Gamma}\left(\frac{c_{L, T}}{c_{L, M}}\right)^{(1-\Gamma) / \Gamma}
$$

Since Differential Equilibrium Function explicitly accounts for $\theta$ (the degree of occupation of sites by the metal), $K_{0} *$ is relatively independent of the experimental conditions. However, determination of $\Gamma$ and $K_{0}{ }^{*}$ still may be influenced by the limitations of ASV used in determining them.

\subsubsection{Diffusion Coefficients}

In ASV, the limiting current, $i_{\text {lim }}$, at a constant potential, $\mathrm{E}$, on a spherical stationary electrode is given by [36]:

$$
i_{\lim }=n F A D c_{M, T}\left(1 / \delta+1 / r_{o}\right)
$$

where $\mathrm{D}$ is the diffusion coefficient of the metal complexes in aqueous solution, $\mathrm{A}$ is the electrode surface area exposed to the analyte, $\delta$ is the diffusion layer thickness, and $r_{0}$ is the radius of the electrode; all other terms have been defined previously. For large electrodes (marcroelectodes), $1 / r_{0}<1 / \delta$, so that $i_{\text {lim }}$ is primarily dependent on $\delta$, which itself depends on the hydrodynamic conditions [36]:

$$
i_{\text {lim }}=\frac{n F A D c_{M, T}}{\delta}
$$

In the case of reproducible stirring by a magnetic stirrer [37]:

$$
\delta=g \sqrt{D / \omega}
$$

where $\omega$ is the rotation rate of the stirrer, and $\mathrm{g}$ is a constant that depends on the cell geometry. Substituting equation 7 in equation 6 , one gets:

$$
i_{\lim }=\frac{n F A D^{1 / 2} c_{M, T} \omega^{1 / 2}}{g}
$$


In heterogeneous systems gives a mean diffusion coefficient, $\overline{\mathrm{D}}$, which is a weighted average of $D_{M}$ and $D_{M L}[38]$ :

$$
\overline{\mathrm{D}}=\frac{\mathrm{D}_{\mathrm{M}} \mathrm{c}_{\mathrm{M}}+\mathrm{D}_{\mathrm{ML}} \mathrm{c}_{\mathrm{ML}}}{\mathrm{c}_{\mathrm{M}, \mathrm{T}}}
$$

Where $\mathrm{D}_{\mathrm{M}}$ and $\mathrm{D}_{\mathrm{ML}}$ are the diffusion coefficient of the metal and of the complex (the latter is assumed to be equal to the diffusion coefficient of the ligand), respectively; $c_{M}, c_{M L}$ and $c_{M, T}$ are the free, complexed and total bulk metal concentrations, respectively.

\subsection{Experimental}

\subsubsection{Materials and Methodology}

Suwannee River Fulvic Acid (SRFA)

Suwannee River Fulvic Acid (SRFA, (Catalogue. No. 1S101F) was obtained from International Humic Substances Society (IHSS, USA) [39]. The concentration of carboxylic and phenolic groups in SRFA has been reported to be 11.44 and 2.91 mmol g${ }^{-1}$, respectively [39]. The molar concentration of FA considered in this chapter is related to the concentration of carboxylic groups.

\subsubsection{Suwannee River Fulvic Acid Model Solutions}

Three model solutions (to be henceforth called 'test solutions') were prepared in ultrapure water containing various concentrations of SRFA $\left(1 \times 10^{-3} \mathrm{~mol} . \mathrm{L}^{-1}, 5 \times 10^{-4}\right.$ mol. $\mathrm{L}^{-1}$ and $\left.5 \times 10^{-5} \mathrm{~mol} . \mathrm{L}^{-1}\right)$ and equal-molar concentrations of $\mathrm{Cu}(\mathrm{II}), \mathrm{Zn}(\mathrm{II}), \mathrm{Cd}(\mathrm{II})$ and $\mathrm{Pb}(\mathrm{II})$; the concentration of each of metal was $5 \times 10^{-7} \mathrm{~mol} . \mathrm{L}^{-1}$. The $\mathrm{pH}$ of the test 
solutions was adjusted to $5.0 \pm 0.1$ using $\mathrm{HAc} / \mathrm{NaAc}$ buffer. The test solutions were left 60 hours in a dark place for equilibration before analysis.

\subsubsection{Reagents}

Standard solutions (1000 $\mathrm{mg} \mathrm{L}^{-1}$ ) of $\mathrm{Cu}(\mathrm{II}), \mathrm{Zn}(\mathrm{II}), \mathrm{Cd}(\mathrm{II})$ and $\mathrm{Pb}$ (II) were purchased from SCP Science, Montreal, Canada. Ultrapure water of resistivity $18.2 \mathrm{M} \Omega-\mathrm{cm}$ was obtained from a Milli-Q-Plus water purification system (Millipore Corporation). A 2 mol L $\mathrm{L}^{-1}$ stock solution of sodium acetate was prepared by dissolving an appropriate quantity of sodium acetate trihydrate (ACS grade/BDH) in ultrapure water. A stock solution of $2 \mathrm{~mol} \mathrm{~L}^{-1}$ potassium nitrate (supporting electrolyte) was prepared by dissolving potassium nitrate (Analar, BDH) in ultrapure water. The sodium acetate solution was then purified of metals by electrolysis at $-1.5 \mathrm{~V}$ vs. $\mathrm{E}_{\mathrm{SCE}}$ for a minimum of $48 \mathrm{~h}$. immediately prior to its use. While the electrolysis was continued the sodium acetate aqueous solution was drained from the electrolysis cell in order to make sure that the impurity metals removed by electrolysis did not go back into the sodium acetate solution upon the termination of electrolysis. A $2 \mathrm{~mol} \mathrm{~L}^{-1}$ stock solution of acetic acid was prepared by diluting glacial acetic acid (ACS grade/Anachemia) with ultrapure water.

\subsubsection{Apparatus}

Voltammetric measurements were made with a computer-controlled Autolab PGSTAT30 potentiostat/galvanostat (Eco Chemie BV, The Netherlands), equipped with a Metrohm 663 VA stand (Metrohm, Switzerland). The working electrode was a static mercury drop electrode (Metrohm, Switzerland). The reference electrode was a 
$\mathrm{Ag} / \mathrm{AgCl}$ electrode in a glass tube filled with $3 \mathrm{~mol} \mathrm{~L}^{-1} \mathrm{KCl}$ and fitted with a porous Vycor tip (Bioanalytical Systems, Inc., USA). The counter electrode was made of a platinum rod (Metrohm, Switzerland). Analysis of voltammetric peaks was done using the General Purpose Electrochemical Software v4.8 (Eco Chemie BV, The Netherlands). The data were transferred to a computer and saved for processing.

\subsubsection{Electrochemical parameters}

Every test solution was purged with pure nitrogen gas for $10 \mathrm{~min}$ immediately prior to analysis. The following optimized operating conditions were used: deposition time 40 $\mathrm{s}$, equilibration time $15 \mathrm{~s}$, initial potential $-1.2 \mathrm{~V}$, end potential $+0.1 \mathrm{~V}$, step potential $5 \mathrm{mV}$, modulation amplitude $15 \mathrm{mV}$, modulation time $50 \mathrm{~ms}$, interval time $500 \mathrm{~ms}$. The deposition time was chosen to avoid surface saturation effects during the stripping step. The pseudopolarograms were constructed by plotting the peak-height current versus the deposition potential. The experimental data were fitted to equation 2 using a commercial software program, NLREG v5.2 [40]. 


\subsection{Results and discussion:}

To determine the speciation parameters of four different metals simultaneously and accurately by using ASV, optimization of the following experimental parameters was done as follows.

\subsubsection{Optimizations of electrochemical parameters:}

\subsubsection{Deposition time:}

In simultaneous determination, the effect of deposition time on the stripping peak currents of $\mathrm{Cu}, \mathrm{Zn}, \mathrm{Cd}$ and $\mathrm{Pb}$ over the deposition time range of $40 \mathrm{~s}$ to $300 \mathrm{~s}$ was investigated. The plots of stripping peaks current of all the metals as a function of deposition time are shown in Fig. 5.1, which shows that at a given applied potential, the peaks currents are dependent on the deposition time.

The time required for accumulation of the metal ion onto the electrode depends on the concentration of the metal ion, less time being required for higher concentrations. An increase in the stripping peak current with accumulation time was observed for all the four metals. The dependence of the peak current on the accumulation time is limited by several factors, e.g. the saturation of the electrode, intermetallic compound formation and adsorption of humic substances on the electrode, resulting in the current reaching a plateau at high accumulation time, as shown in Fig. 5.1. A deposition time of $40 \mathrm{~s}$ was used for all these metals as it combines good sensitivity with relatively short analysis time and less interference. 


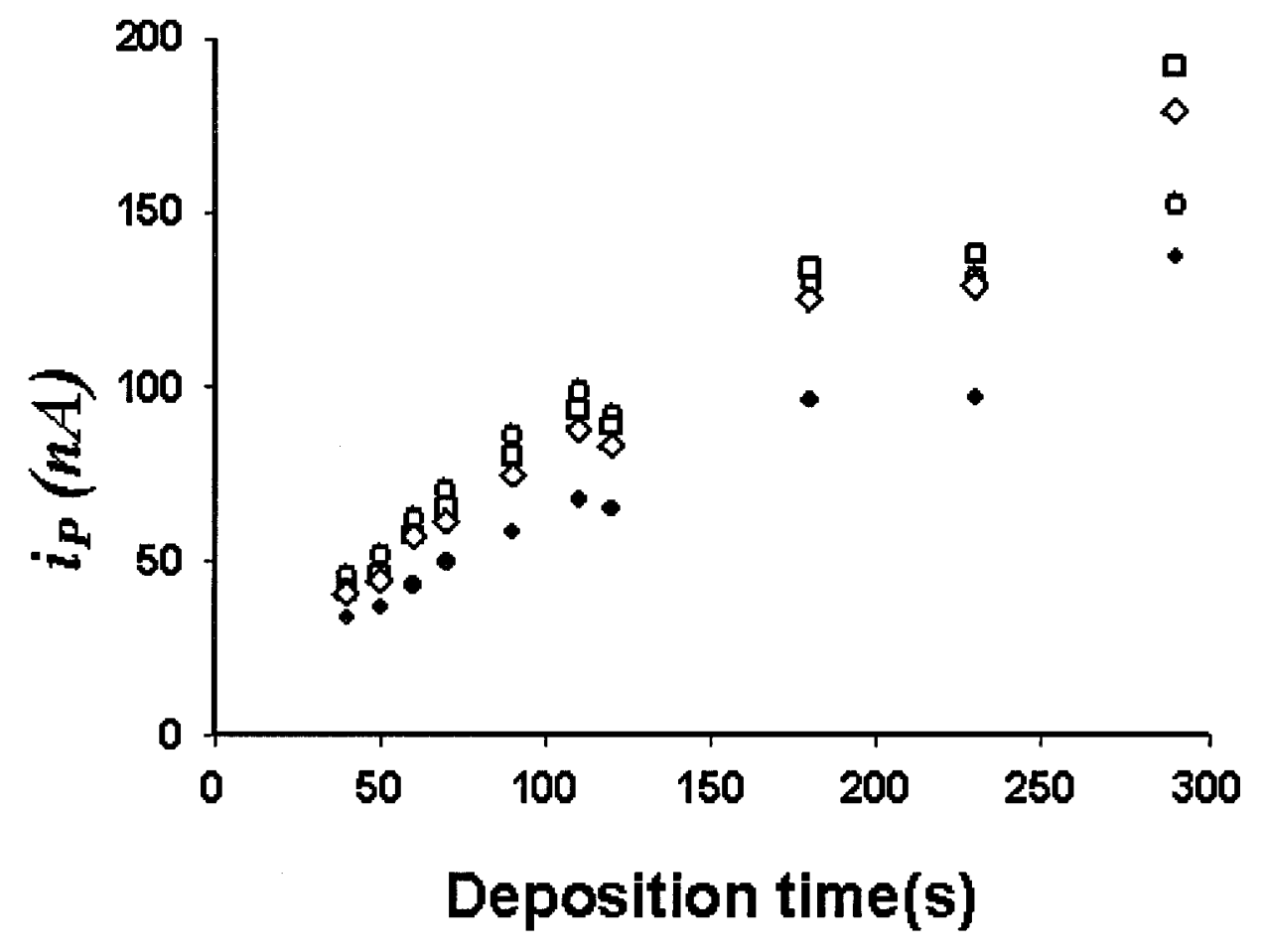

Figure 5.1. Effect of deposition time on peak currents $\left(i_{\mathrm{p}}\right)$ of M(II)-SRFA complexes in model solutions of SRFA. $C_{M, T}=5.0 \times 10^{-7} \mathrm{~mol} \mathrm{~L}^{-1} \cdot C_{S R F A}=1.0 \times 10^{-4}$ mol L ${ }^{-1}$. HOAc/NaOAc buffer, $\mathrm{pH} 5.0 \pm 0.1$, temperature $=23 \pm 2{ }^{\circ} \mathrm{C}$. $(\bullet), \mathrm{Cu}(\mathrm{II}) ;(0), \mathrm{Zn}(\mathrm{II}) ;(()), \mathrm{Pb}(\mathrm{II})$ and (( )), $\mathrm{Cd}(\mathrm{II})$. 


\subsubsection{Step potential:}

In simultaneous determination, the effect of step potential on the stripping peaks currents of $\mathrm{Cu}, \mathrm{Zn}, \mathrm{Cd}$ and $\mathrm{Pb}$ over the step potential range of $2 \mathrm{mV}$ s to $10 \mathrm{mV}$ was investigated. The plots of stripping peak current of all the metals as a function of step potential are shown in Fig. 5.2. Choice of smaller steps yields a finer resolution on the potential scale, but increases the measurement time. A step potential of $5 \mathrm{mV}$ was used throughout the experiment; it provided good sensitivities for all the four metals.

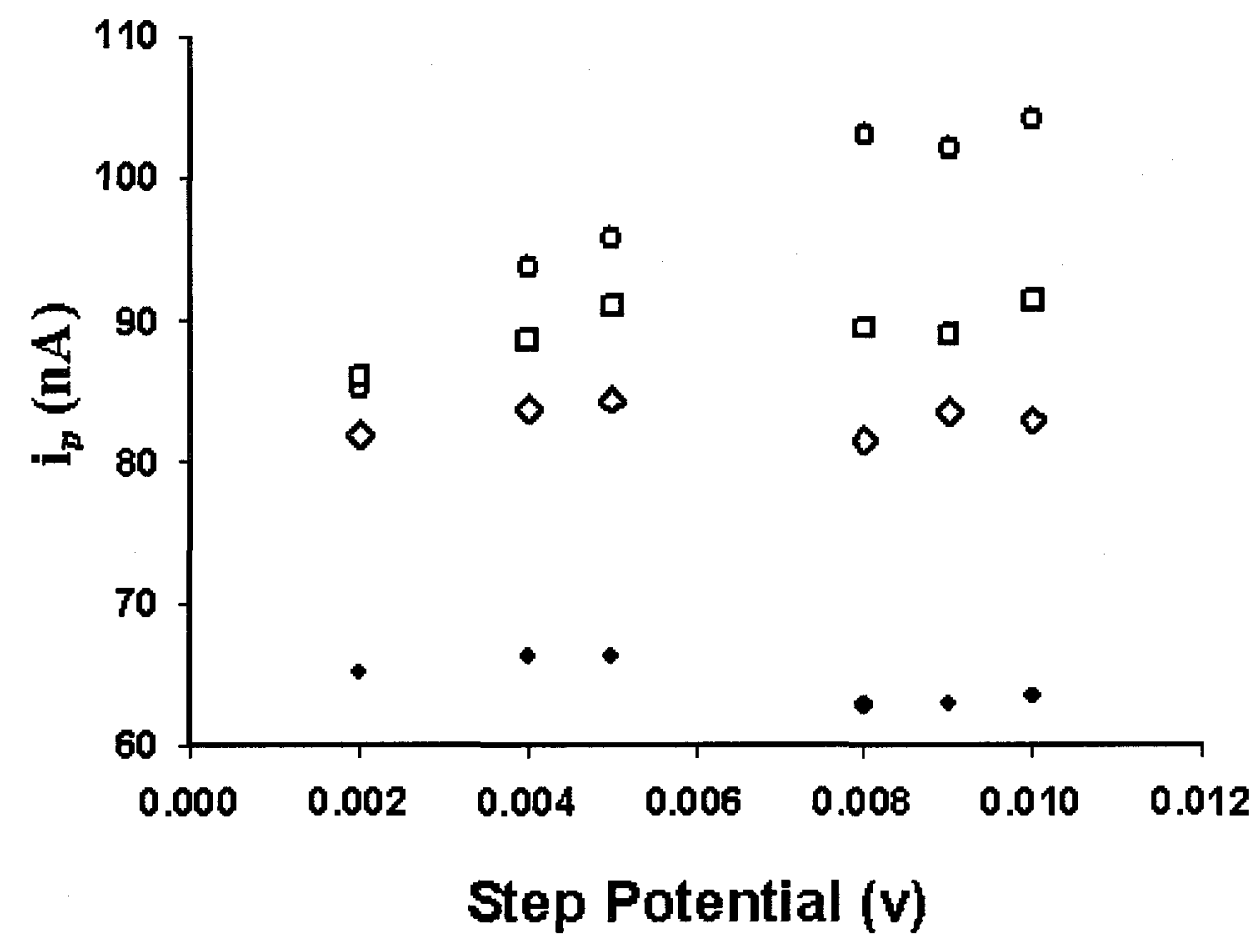

Figure 5.2. Effect of step potential on peak currents $\left(i_{\mathrm{p}}\right)$ of M(II)-SRFA complexes in model solutions of SRFA. $C_{M, T}=5.0 \times 10^{-7} \mathrm{~mol} \mathrm{~L}^{-1} \cdot C_{S R F A}=1.0 \times 10^{-4}$ mol L $\mathrm{L}^{-1}$. HOAc/NaOAc buffer, $\mathrm{pH} 5.0 \pm 0.1$, temperature $=23 \pm 2{ }^{\circ} \mathrm{C}$. $(\bullet), \mathrm{Cu}(\mathrm{II}) ;(0), \mathrm{Zn}(\mathrm{II}) ;(\diamond), \mathrm{Pb}(\mathrm{II})$ and $(\square), \mathrm{Cd}(\mathrm{II})$. 


\subsubsection{Modulation Amplitude:}

The modulation amplitude should preferably be in the range $5-100 \mathrm{mV}$. However, the sample matrix influences the modulation amplitude. Larger modulation amplitude yields a stronger response, but also broadens the peak, lowering the peak resolution. It has been found that above the modulation amplitude of $50 \mathrm{mV}$, the peak height becomes almost constant, probably as a result of distortion of the peak due to nonlinearity effects at larger modulation amplitudes. In simultaneous determination, the effect of modulation amplitude on the stripping peak current of copper, zinc, cadmium and lead over the modulation amplitude range of $15 \mathrm{mV}$ to $85 \mathrm{mV}$ was investigated. The plots of stripping peak current of all the metals as a function of modulation amplitude are shown in Fig. 5.3. Larger modulation amplitude yielded a larger peak current and a broadened peak, which resulted in a decrease in the resolution, and in a lower reproducibility. By trial and error (not reported) it was found that the best results were obtained with the use of the lowest modulation amplitude $(15 \mathrm{mV})$, which was therefore used. 


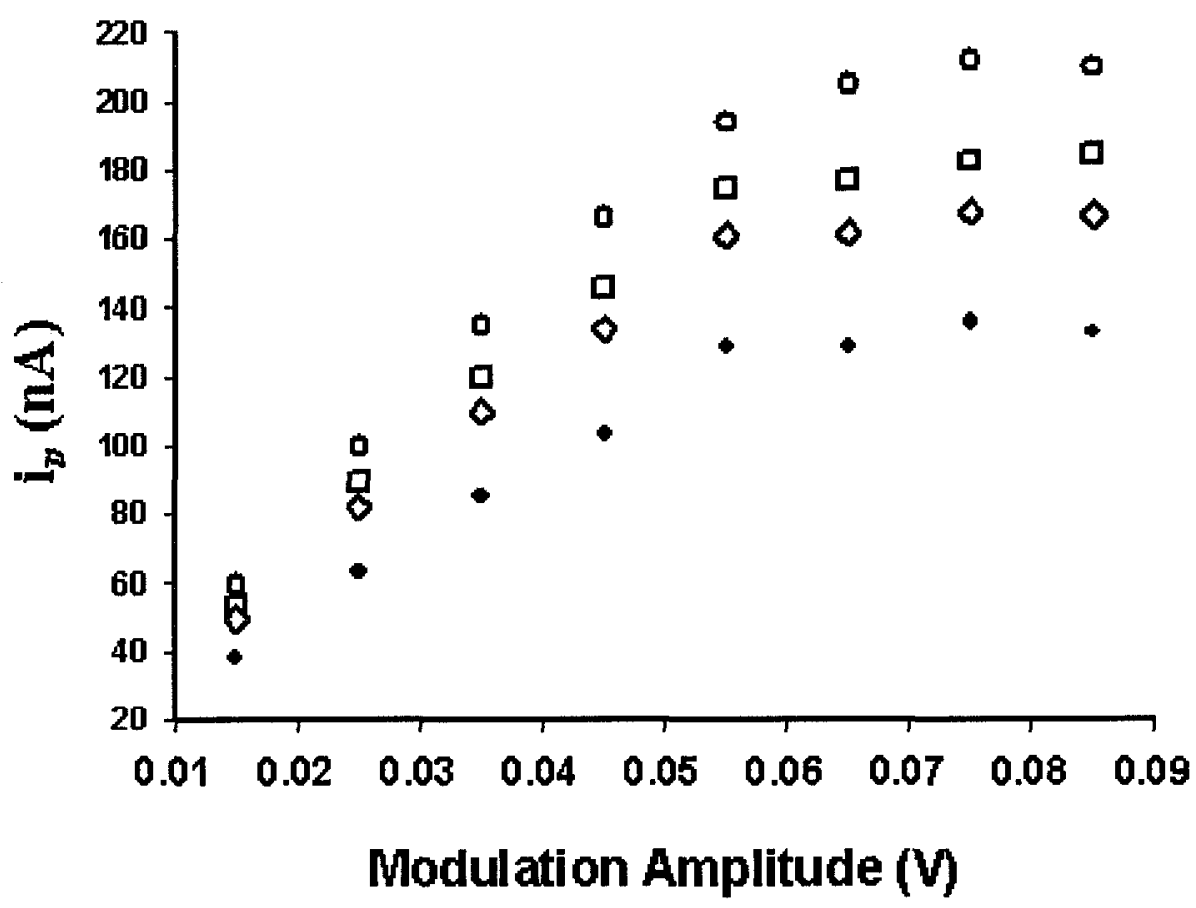

Figure 5.3. Effect of modulation amplitude on peak currents $\left(i_{\mathrm{p}}\right)$ of M(II)-SRFA complexes in model solutions of SRFA. $C_{M, T}=5.0 \times 10^{-7} \mathrm{~mol} \mathrm{~L}^{-1} \cdot C_{S R F A}=$ $1.0 \times 10^{-4} \mathrm{~mol} \mathrm{~L}^{-1} . \mathrm{HOAc} / \mathrm{NaOAc}$ buffer, $\mathrm{pH} 5.0 \pm 0.1$, temperature $=23 \pm$ $2{ }^{\circ} \mathrm{C} .(\bullet), \mathrm{Cu}(\mathrm{II}) ;(\mathrm{o}), \mathrm{Zn}(\mathrm{II}) ;(\diamond), \mathrm{Pb}(\mathrm{II})$ and ( $\left.\square\right), \mathrm{Cd}(\mathrm{II})$. 


\subsubsection{Effect of Formation of Intermetallic Compounds:}

The formation of intermetallic compounds can cause error in the analysis of metals by ASV. Shuman and Woodward [41] reported that several $\mathrm{Cu}-\mathrm{Zn}$ intermetallic compounds were formed during ASV analysis of solutions containing both copper and zinc. It has been reported [43] that there are three soluble intermetallic compounds, with copper to zinc ratios of $1: 1,1: 2$, and 1:3. The formation of these compounds decreases the ASV zinc current and increases the copper current since the mercury soluble $\mathrm{Cu}-\mathrm{Zn}$ intermetallic compounds are electroactive and are oxidized at a potential very close to $\mathrm{Cu}$ stripping potential. The effect of Intermetallic-compoundformation was investigated in this work.

Peak currents due to simultaneous oxidation of $\mathrm{Cu}, \mathrm{Zn}, \mathrm{Cd}$ and $\mathrm{Pb}$ over the deposition time range of $40 \mathrm{~s}$ to $300 \mathrm{~s}$ were also investigated. The plots of stripping peak current of $\mathrm{Cu}(\mathrm{II})$ and $\mathrm{Zn}(\mathrm{II})$ metals as a function of deposition time are presented in Figs. 5.4 and 5.5, respectively. The effect of deposition time on the peak current of copper in a test solution containing $\mathrm{Pb}(\mathrm{II}), \mathrm{Cd}(\mathrm{II})$, and $\mathrm{Zn}$ (II) shows a linear relationship between the peak current and the deposition time with a slope of 0.42 . However, the slope decreases to 0.34 when $\mathrm{Cu}(\mathrm{II})$ was alone in the solution. The increase in peak height, hence, in the slope was probably due to formation of electroactive $\mathrm{Cu}-\mathrm{Zn}$ alloy. The difference in peak heights for $\mathrm{Cu}(\mathrm{II})$ in the metal mixture, and for the $\mathrm{Cu}(\mathrm{II})$ alone, increases with increasing deposition time. Peak heights for zinc in the metal mixture solution start to decrease compared to the peak height of zinc alone after the deposition time of $120 \mathrm{~s}$ (Fig. 5.5). The slopes of $\mathrm{Pb}(\mathrm{II})$ and $\mathrm{Cd}(\mathrm{II})$ remain unchanged (data not presented). 


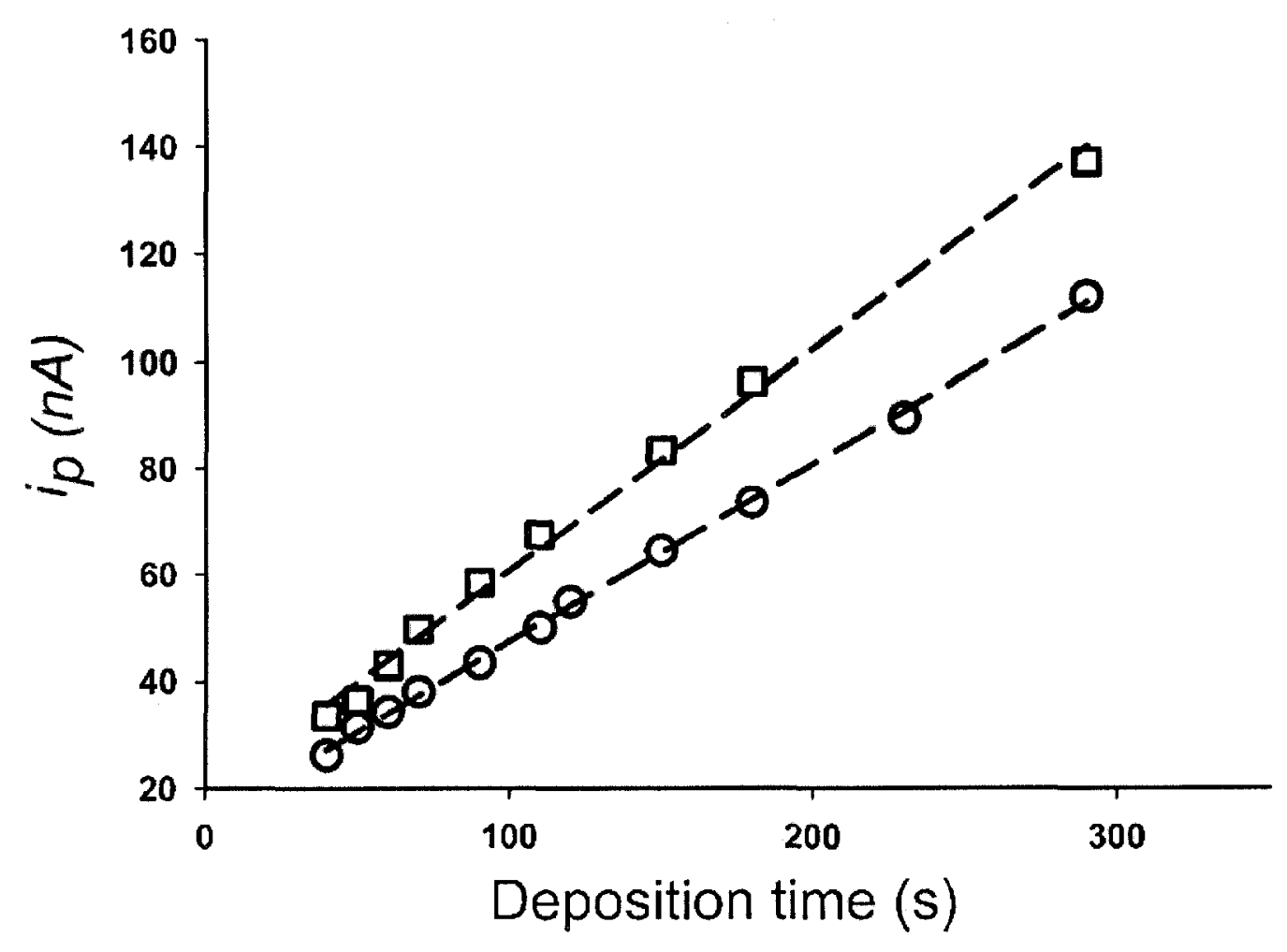

Figure 5.4. Effect of deposition time on peak currents $\left(i_{\mathrm{p}}\right)$ of $\mathrm{Cu}(\mathrm{II})$ when intermetallic compounds are formed in a solution of metal mixture containing $C_{M, T}=5.0 \times 10^{-7} \mathrm{~mol} \mathrm{~L}^{-1} \cdot C_{S R F A}=$ nil. $\mathrm{HOAc} / \mathrm{NaOAc}$ buffer, $\mathrm{pH}$ $5.0 \pm 0.1$, temperature $=23 \pm 2{ }^{\circ} \mathrm{C} .(\square), \mathrm{Cu}(\mathrm{II})$ in a metal mixture; (o), $\mathrm{Cu}(\mathrm{II})$ alone in a solution. 


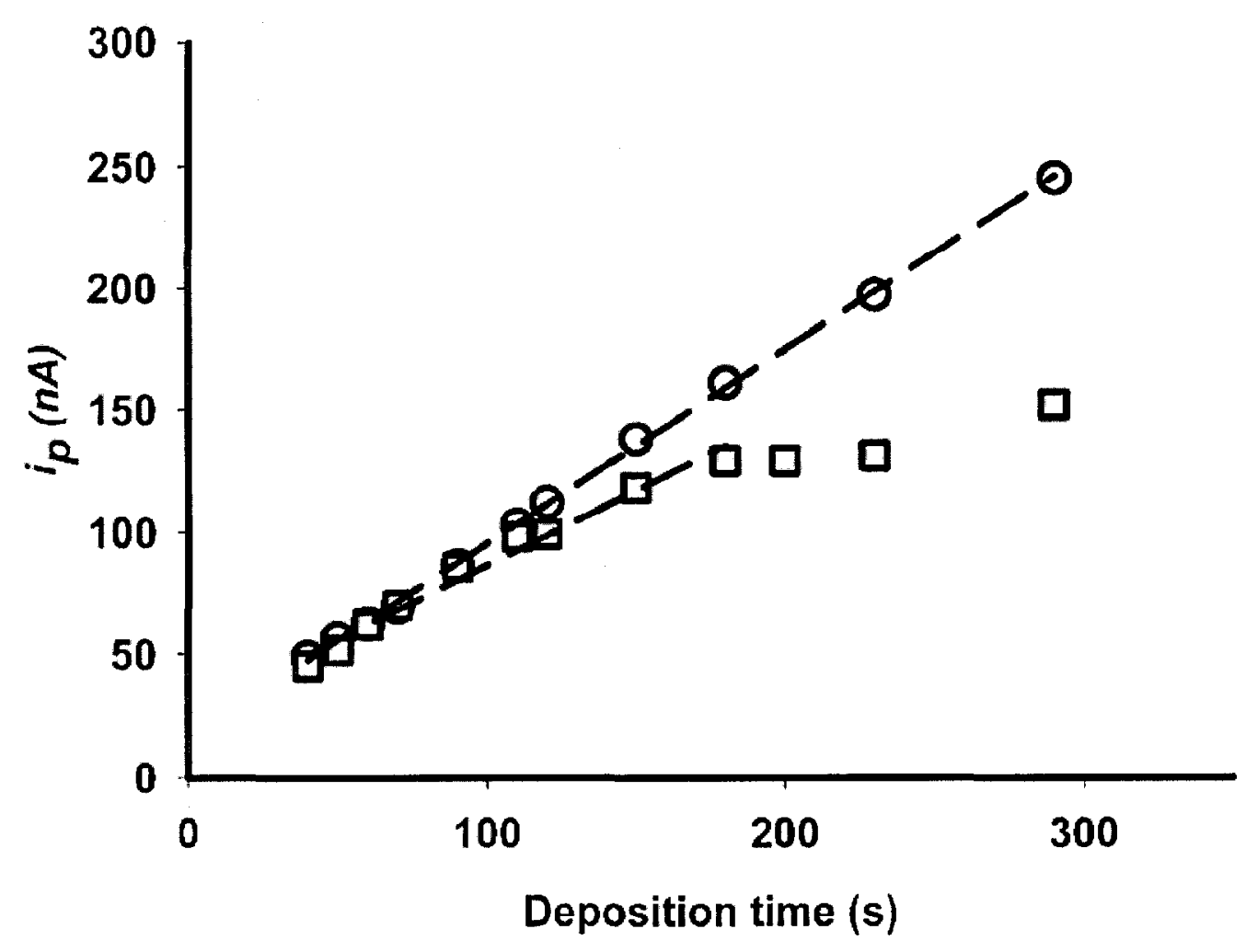

Figure 5.5. Effect of deposition time on peak currents $\left(i_{\mathrm{p}}\right)$ of $\mathrm{Zn}(\mathrm{II})$ intermetallic compounds are formed in a solution of metal mixture containing $C_{M, T}=$ $5.0 \times 10^{-7} \mathrm{~mol} \mathrm{~L}^{-1} \cdot C_{S R F A}=$ nil. $\mathrm{HOAc} / \mathrm{NaOAc}$ buffer, $\mathrm{pH} 5.0 \pm 0.1$, temperature $=23 \pm 2{ }^{\circ} \mathrm{C}$. (D), $\mathrm{Zn}$ (II) in a metal mixture; (o), $\mathrm{Zn}$ (II) alone in a solution. 
It is clear from the above studies that the effect of intermetallic-compounds which can cause error in the analysis of metals by ASV increases as the deposition time increases, and the effect can be reduced by decreasing the deposition time. It was found that minimum effect of intermetallic-compound was observed at a deposition time of $40 \mathrm{~s}$ (Figs. 5.4 and 5.5). Hence, $40 \mathrm{~s}$ was used as a deposition time for this work.

\subsubsection{Peak height versus peak area:}

It has been reported in the literature [42] that in ASV, peak height is the measure of the amount of the metal oxidized during the stripping step because the peak current is directly proportional to the stripping charge [42]. In this study, peak height was used as the analytical signal. It was also reported in the literature [43] that for a simpleligand system, the ratio between the signal in the absence and in the presence of ligand was the same irrespective of whether peak height or peak area was used. However, it was also reported [43] that in the presence of fulvic acid, a broadening of the stripping peak was observed because of chemical heterogeneity effects. For the test solutions of metals with SRFA, there may be a significant decrease in the peak height, whereas the peak area may decrease to a much lesser extent [44]. Figure 5.6 shows the plot of the ratio of peak area/ peak height for all these four metals show almost a zero slope over the range of $E_{d}$ values employed. The use of peak area in DPASV was proposed as being analytically superior to the use of peak height for determination of metal ions [45]. However, it has been reported by R.M. Town et al. [43] that in the more complex DP and SW modes, the peak area cannot be assumed to have a direct relationship with the bulk concentration. 

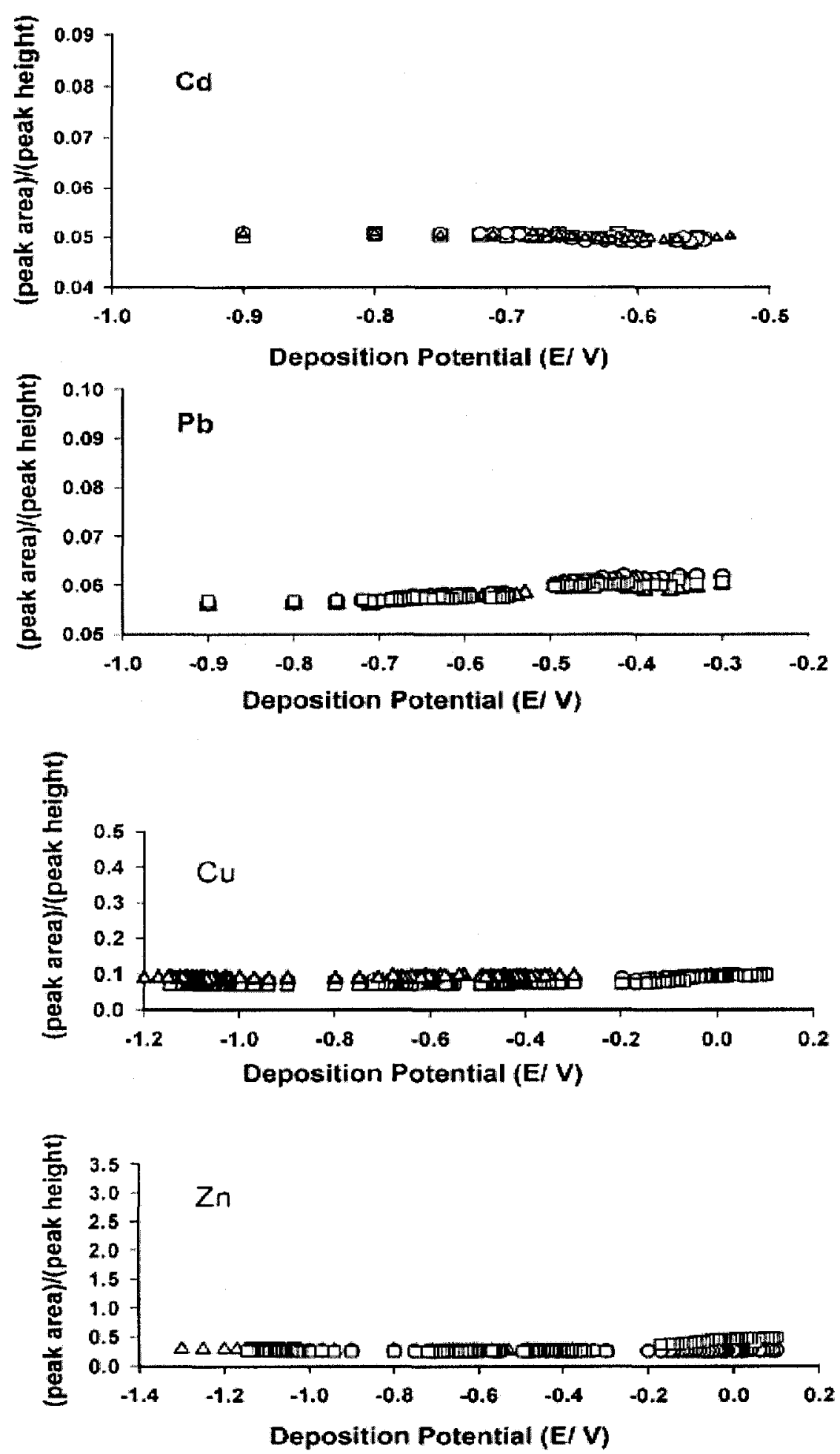

Figure 5.6. Effect of deposition potential on the ratio of peak area and peak height at various $C_{\mathrm{M}, \mathrm{T}} / C_{\mathrm{SRFA}}$ ratios. $C_{\mathrm{M}, \mathrm{T}} / C_{\mathrm{SRFA}}=0.01(\square) ; C_{\mathrm{M}, \mathrm{T}} / C_{\mathrm{SRFA}}=0.001(\mathrm{o})$; $C_{\mathrm{M}, \mathrm{T}} / C_{\mathrm{SRFA}}=0.0005(\Delta)$ 
In this work, peak height was used as the analytical signal in for the simultaneous determination of speciation parameters of these four metals. The voltammogram of $\mathrm{Cu}(\mathrm{II}), \mathrm{Zn}$ (II), $\mathrm{Cd}(\mathrm{II})$ and $\mathrm{Pb}$ (II) were recorded (Fig. 5.7) using the optimized experimental conditions.

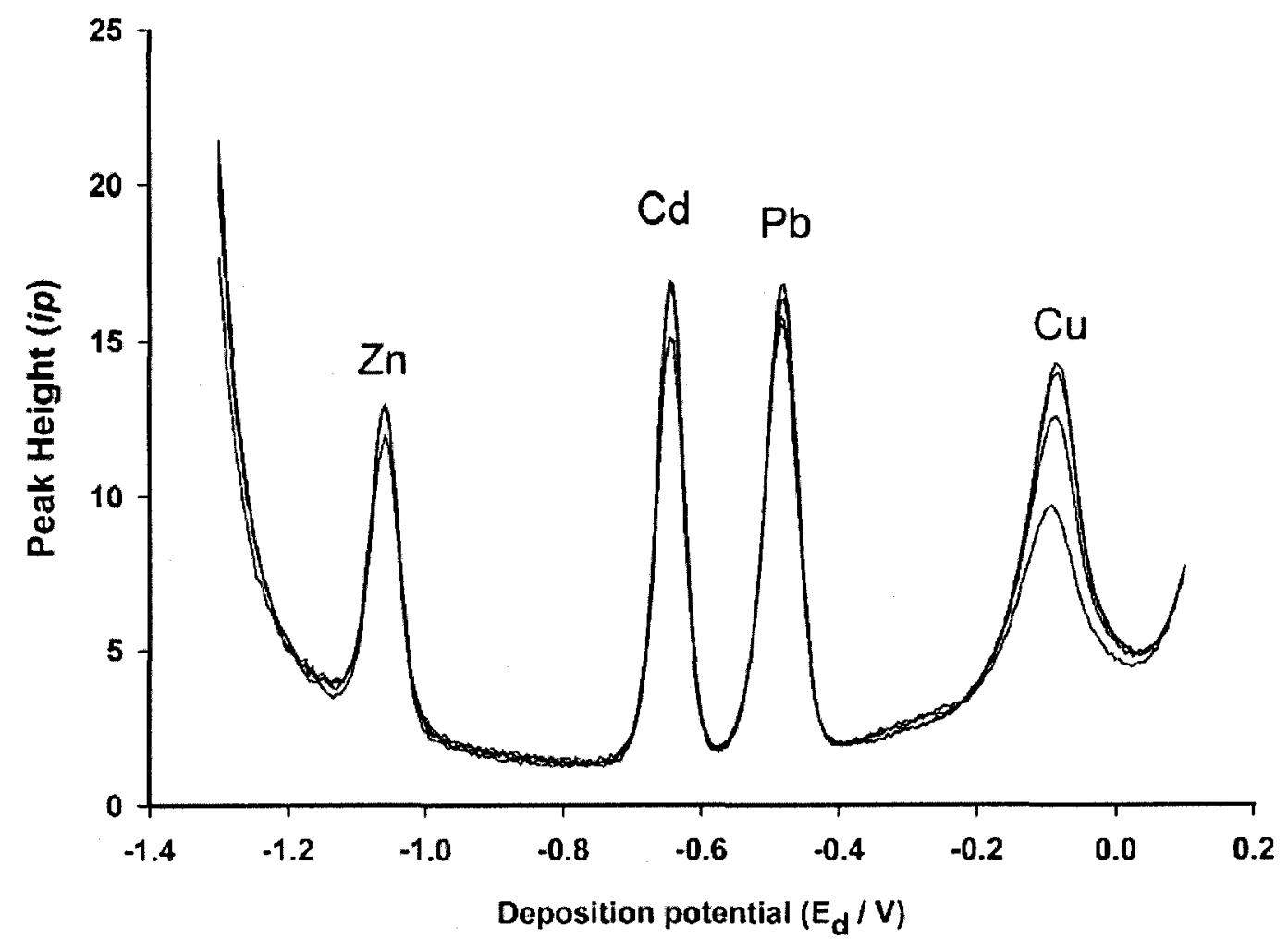

Figure 5.7. Voltammogram of $\mathrm{Cu}(\mathrm{II}), \mathrm{Zn}(\mathrm{II}), \mathrm{Cd}(\mathrm{II})$ and $\mathrm{Pb}(\mathrm{II})$ under the experimentally optimized conditions 


\subsection{Simultaneous determination of speciation parameters in -Suwannee River}

Fulvic Acid (SRFA) model solutions of these four metals:

Three model solutions, each containing $5 \times 10^{-7} \mathrm{M}$ of all the above mentioned four metals and $5 \times 10^{-5} \mathrm{M}, 5 \times 10^{-4} \mathrm{M}$ and $1 \times 10^{-3} \mathrm{M}$ of SRFA to provide a range of metal/SRFA mole ratios were used. The $\mathrm{pH}$ of all these solutions was adjusted to 5.00 \pm 0.05 by an acetic acid and sodium acetate buffer. The test solutions were kept in a dark place for 60 hours for equilibration, and were then used for simultaneous determination of speciation parameters. Pseudopolarograms are obtained by plotting normalized peak current $\left(i_{p} / i_{o}\right)$ vs corresponding reduction potential, where, $i_{P}$ and $i_{o}$ are the current for the complex system and the reference current under conditions of no complexation, respectively.

\subsubsection{Speciation parameters of $\mathrm{Cu}$ in model solutions:}

Typical pseudopolarograms for four test solutions of $\mathrm{Cu}(\mathrm{II})$ are presented in Figure 5.8. The top curve is that of copper spiked into a sample of ultrapure water containing the three other metals, buffered with the acetic acid-sodium acetate buffer solution, with no SRFA present. A sharp, well-defined, polarographic wave with a flat plateau and $\Gamma \approx 1$ was observed for $\mathrm{Cu}(\mathrm{II})$ aqua complex in the metal mixture, indicating a fully reversible electrode process.

The lower three pseudopolarograms were obtained for $\mathrm{Cu}(\mathrm{II})$-SRFAcomplexes of three metal mixtures containing the same concentration of the four metals with three different concentrations of SRFA. The observed reduction in the limiting currents of the $\mathrm{Cu}(\mathrm{II})-\mathrm{SRFA}$ complexes relative to that of the $\mathrm{Cu}$-aqua complex is probably a result of a decrease in the mean diffusion coefficient of $\mathrm{Cu}(\mathrm{II})-\mathrm{FA}$ complexes. 
Limiting current decreased with decreasing $\mathrm{C}_{\mathrm{M}(\mathrm{II})} / \mathrm{C}_{\mathrm{SRFA}}$ ratio. Table 5.1 presents the results for $\mathrm{Cu}(\mathrm{II})-\mathrm{SRFA}$ complexes in model solutions of SRFA. $\Gamma$ value for $\mathrm{Cu}(\mathrm{II})$ SRFA was found to be $\sim 0.50$ and independent of the SRFA concentration. $\log K^{*}$ value for $\mathrm{Cu}-\mathrm{SRFA}$ complexes decreased with increasing $\mathrm{C}_{\mathrm{Cu}(\mathrm{II})} / \mathrm{C}_{\mathrm{SRFA}}$ mole ratio (Table 5.1). The $\log \mathrm{K}^{*}$ value for $\mathrm{Cu}(\mathrm{II})-\mathrm{SRFA}$ complex with mole ratio of 0.0005 was found to be 7.41 , and it decreased to 6.38 in the test solution containing $\mathrm{C}_{\mathrm{Cu}(I)}$ / $\mathrm{C}_{\text {SRFA }}$ mole ratio of 0.01 . 


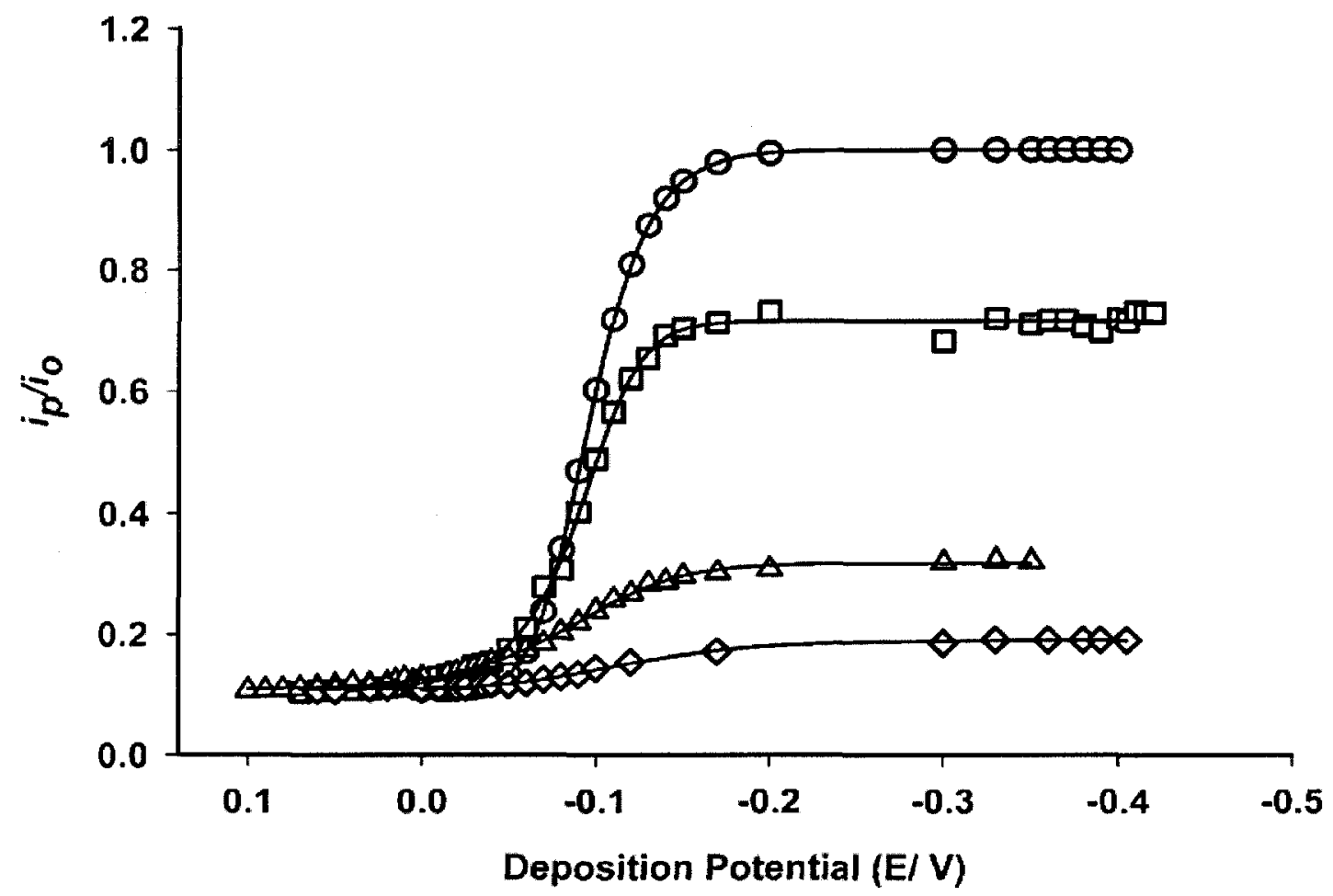

Figure 5. 8. Effect of deposition potential on the release (ip/io) of metal from the $\mathrm{Cu}(\mathrm{II})$-SRFA complex with the $\mathrm{Cu} / \mathrm{SRFA}$ mole ratio as a parameter. Each solution contained $\mathrm{C}_{C u, T}=C_{Z n, T}=C_{C d, T}=C_{P b, T}=5.0 \times 10^{-7} \mathrm{~mol} \mathrm{~L}^{-}$ 1. $C_{S R F A}$ was varied from, $0.0 \mathrm{~mol} . \mathrm{L}^{-1}(\mathbf{0}), 1 \times 10^{-3} \mathrm{~mol} . \mathrm{L}^{-1}\left(C_{\mathrm{M}, \mathrm{T}} / C_{\mathrm{SRFA}}=\right.$ $0.0005)(\diamond), 5 \times 10^{-4} \mathrm{~mol} . \mathrm{L}^{-1}\left(C_{\mathrm{M}, \mathrm{T}} / C_{\mathrm{SRFA}}=0.001\right)(\Delta)$ and $5 \times 10^{-5} \mathrm{~mol} . \mathrm{L}^{-}$ ${ }^{1}\left(C_{\mathrm{M}, \mathrm{T}} / C_{\mathrm{SRFA}}=0.01\right)(\square), \mathrm{HOAc} / \mathrm{NaOAc}$ buffer, $\mathrm{pH} 5.0 \pm 0.1$, temperature $=23 \pm 2{ }^{\circ} \mathrm{C}$. 
Table 5.1. Effect of decreasing mole ratios of $C_{\mathrm{M}, \mathrm{T}} / C_{\mathrm{SRFA}}$ on the Differential Equilibrium Functions, mean diffusion coefficients and heterogeneity of $\mathrm{Cu}$ (II)-SRFA complexes in model solutions of SRFA. Each solution contained $C_{\mathrm{Pb}, \mathrm{T}}=5.0 \times 10^{-7} \mathrm{~mol} \mathrm{~L}^{-1}, C_{\mathrm{Cu}, \mathrm{T}}=5.0 \times 10^{-7} \mathrm{~mol} \mathrm{~L}^{-1}, C_{\mathrm{Zn}, \mathrm{T}}=$ $5.0 \times 10^{-7} \mathrm{~mol} \mathrm{~L}^{-1}$, and $C_{\mathrm{Cd}, \mathrm{T}}=5.0 \times 10^{-7} \mathrm{~mol} \mathrm{~L}^{-1} \cdot C_{S R F A}$ was varied from $1 \times 10^{-3} \mathrm{~mol} . \mathrm{L}^{-1}\left(C_{\mathrm{M}, \mathrm{T}} / C_{\mathrm{SRFA}}=0.0005\right), 5 \times 10^{-4} \mathrm{~mol} . \mathrm{L}^{-1}\left(C_{\mathrm{M}, \mathrm{T}} / C_{\mathrm{SRFA}}=\right.$ $0.001)$ and $5 \times 10^{-5} \mathrm{~mol} . \mathrm{L}^{-1}\left(C_{\mathrm{M}, \mathrm{T}} / C_{\mathrm{SRFA}}=0.01\right), \mathrm{HOAc} / \mathrm{NaOAc}$ buffer, $\mathrm{pH} 5.0 \pm 0.1$, temperature $=23 \pm 2{ }^{\circ} \mathrm{C}$.

\begin{tabular}{cccc}
\hline $\begin{array}{c}\text { Chemical } \\
\text { speciation } \\
\text { parameters of } \\
\mathbf{C u}\end{array}$ & 0.01 & \multicolumn{3}{c}{ Mole Ratio of [Cu] /SRFA] } \\
\cline { 2 - 4 } & $0.54 \pm 0.04$ & $0.52 \pm 0.06$ & 0.0005 \\
\hline$\Gamma$ & $6.38 \pm 0.14$ & $6.93 \pm 0.12$ & $0.49 \pm 0.02$ \\
$\operatorname{Log~K}^{*}\left(\mathrm{~L} \mathrm{~mol}^{-1}\right)$ & & & $7.41 \pm 0.08$ \\
$\mathrm{D}_{\mathrm{ML}}\left(\mathrm{m}^{2} \mathrm{~s}^{-1}\right)$ & $(4.10 \pm 0.14) \times 10^{-10}$ & $(4.50 \pm 0.10) \times 10^{-11}$ & $(7.50 \pm 0.12) \times 10^{-12}$ \\
\hline
\end{tabular}




\subsubsection{Speciation parameters of $\mathrm{Zn}$ in model solution:}

Typical pseudopolarograms for four test solutions of $\mathrm{Zn}(\mathrm{II})$ are presented in Figure 5.9. The top curve is that for a solution of $\mathrm{Zn}(\mathrm{II})$ spiked into a sample of ultrapure water containing the other three metals, buffered with the acetic acid-sodium acetate buffer solution, with no SRFA present. A sharp, well-defined, polarographic wave with a flat plateau and $\Gamma=1$ was observed for $\mathrm{Zn}$ metal in the metal mixture, indicating a fully reversible electrode process. The lower three pseudopolarograms were obtained for $\mathrm{Zn}$ in samples of three metal mixtures containing the same concentrations of the four metals with three different concentration of SRFA. Equation 8 (along with 9) suggest that the observed reduction in the limiting currents of the $\mathrm{Zn}$ (II)-FA complexes relative to that of the $\mathrm{Zn}$-aqua complexe is probably due to decrease in the mean diffusion coefficient of $\mathrm{Zn}$ (II)-FA complexes. However, for the test solutions containing higher $\mathrm{C}_{\mathrm{Zn}(\mathrm{II})} / \mathrm{C}_{\mathrm{SRFA}}$ mole ratios, the limiting current was found to be about the same. Limiting current decreased as the metal to SRFA ratio decreased. Figure 5.9 and Table 5.2 show the results for $\mathrm{Zn}$ (II)-SRFA complexes in model solutions of the SRFA. For $\mathrm{Zn}(\mathrm{II})-\mathrm{SRFA}, \Gamma$ values were found to be $\sim 0.80$ and independent of SRFA concentrations. LogK* value for $\mathrm{Zn}(\mathrm{II})-\mathrm{SRFA}$ complexes decreased with increasing $\mathrm{C}_{\mathrm{Zn}(\mathrm{II})} / \mathrm{C}_{\mathrm{SRFA}}$ mole ratio (Table 5.2). 


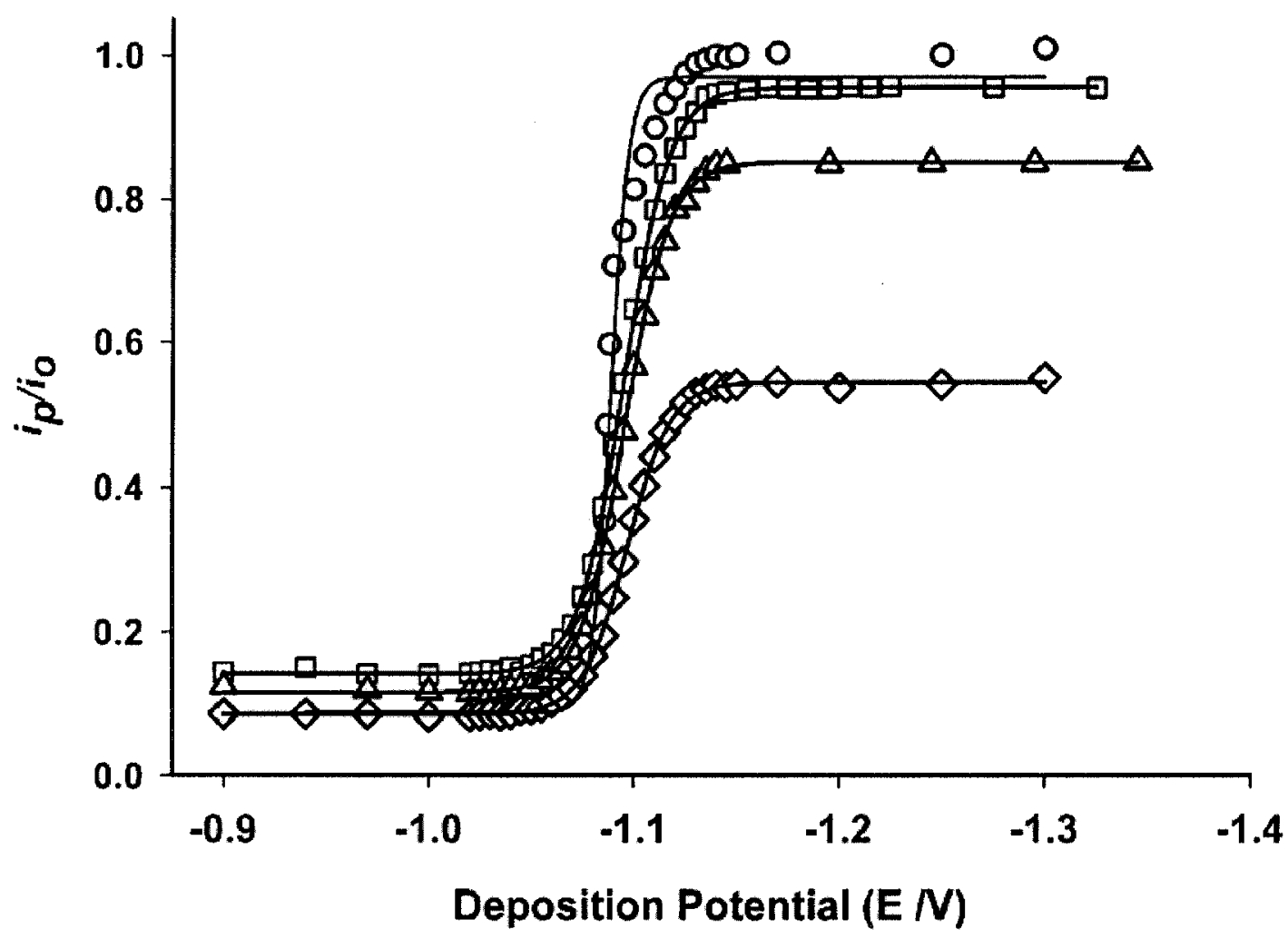

Figure 5.9. Effect of deposition potential on the release (ip/io) of metal from the $\mathrm{Zn}$ (II)-SRFA complex with the $\mathrm{Zn} / \mathrm{SRFA}$ mole ratio as a parameter.. Each solution contained $\mathrm{C}_{\mathrm{Cu}, T}=C_{\mathrm{Zn}, T}=C_{C d, T}=C_{P b, T}=5.0 \times 10^{-7} \mathrm{~mol} \mathrm{~L}^{-1} \cdot C_{S R F A}$ was varied from, 0.0 mol. $\mathrm{L}^{-1}(\mathbf{0}), 1 \times 10^{-3} \mathrm{~mol} . \mathrm{L}^{-1}\left(C_{\mathrm{M}, \mathrm{T}} / C_{\mathrm{SRFA}}=0.0005\right)$ $(\diamond), 5 \times 10^{-4} \mathrm{~mol} . \mathrm{L}^{-1}\left(C_{\mathrm{M}, \mathrm{T}} / C_{\mathrm{SRFA}}=0.001\right)(\Delta)$ and $5 \times 10^{-5} \mathrm{~mol} . \mathrm{L}^{-1}$ $\left(C_{\mathrm{M}, \mathrm{T}} / C_{\mathrm{SRFA}}=0.01\right)(\square), \mathrm{HOAc} / \mathrm{NaOAc}$ buffer, $\mathrm{pH} 5.0 \pm 0.1$, temperature $=23 \pm 2{ }^{\circ} \mathrm{C}$. 
Table 5.2. Effect of decreasing mole ratios of $C_{\mathrm{M}, \mathrm{T}} / C_{\mathrm{SRFA}}$ on the Differential Equilibrium Functions, mean diffusion coefficients and heterogeneity of Zn(II)-SRFA complexes in model solutions of SRFA. Each solution contained $C_{\mathrm{Pb}, \mathrm{T}}=5.0 \times 10^{-7}$ $\mathrm{mol} \mathrm{L}^{-1}, C_{\mathrm{Cu}, \mathrm{T}}=5.0 \times 10^{-7} \mathrm{~mol} \mathrm{~L}^{-1}, C_{\mathrm{Zn}, \mathrm{T}}=5.0 \times 10^{-7} \mathrm{~mol} \mathrm{~L}^{-1}$, and $C_{\mathrm{Cd}, \mathrm{T}}=5.0 \times 10^{-7}$ mol L ${ }^{-1} . C_{S R F A}$ was varied from $1 \times 10^{-3} \mathrm{~mol} . \mathrm{L}^{-1}\left(C_{\mathrm{M}, \mathrm{T}} / C_{\mathrm{SRFA}}=0.0005\right), 5 \times 10^{-4} \mathrm{~mol} . \mathrm{L}^{*}$ ${ }^{1}\left(C_{\mathrm{M}, \mathrm{T}} / C_{\mathrm{SRFA}}=0.001\right)$ and $5 \times 10^{-5} \mathrm{~mol} . \mathrm{L}^{-1}\left(C_{\mathrm{M}, \mathrm{T}} / C_{\mathrm{SRFA}}=0.01\right), \mathrm{HOAc} / \mathrm{NaOAc}$ buffer, $\mathrm{pH} 5.0 \pm 0.1$, temperature $=23 \pm 2{ }^{\circ} \mathrm{C}$.

\begin{tabular}{cccc}
\hline $\begin{array}{c}\text { Chemical } \\
\text { speciation } \\
\text { parameters of } \\
\mathbf{Z n}\end{array}$ & 0.01 & 0.001 & 0.0005 \\
\cline { 2 - 4 }$\Gamma$ & $0.87 \pm 0.02$ & $0.88 \pm 0.10$ & $0.85 \pm 0.05$ \\
\hline $\operatorname{Log~K}\left(\mathrm{L} \mathrm{mol}^{-1}\right)$ & $5.56 \pm 0.14$ & $5.58 \pm 0.06$ & $6.01 \pm 0.12$ \\
$\mathrm{D}_{\mathrm{ML}}\left(\mathrm{m}^{2} \mathrm{~s}^{-1}\right)$ & $(5.01 \pm 0.08) \times 10^{-10}$ & $(4.07 \pm 0.14) \times 10^{-10}$ & $(1.60 \pm 0.10) \times 10^{-10}$ \\
\hline
\end{tabular}




\subsubsection{Speciation parameters of Cd in model solution:}

Typical pseudopolarograms for four test solutions of Cd(II) are presented in Figure 5.10. The top curve is that for a solution of $\mathrm{Cd}(\mathrm{II})$ spiked into a sample of ultrapure water containing the other three metals, buffered with the acetic acid-sodium acetate buffer solution, with no SRFA present. A sharp, well-defined, polarographic wave with a flat plateau and $\Gamma=1$ was observed for $\mathrm{Cd}$ metal in the metal mixture, indicating a fully reversible electrode process. The other three pseudopolarograms obtained for $\mathrm{Cd}$ were identical to one another obtained from three metal mixtures containing the same concentrations of four metals with three different concentration of SRFA. The $\Gamma$ value obtained for Cd(II)-SRFA complexes were very close to 1 indicating that SRFA behaved almost as a homogeneous complexant. A very small change observed in the limiting current was probably due to a very small change in the diffusion coefficient of $\mathrm{Cd}(\mathrm{II})$-SRFA complexes compared to $\mathrm{Cd}(\mathrm{II})$-aqua complex. Figure 5.10, and Table 5.3 show the results for $\mathrm{Cd}(\mathrm{II})$-FA complexes in model solutions of SRFA. LogK* value for Cd-SRFA complexes decreased with increasing $\mathrm{C}_{\mathrm{Cd}(\mathrm{II} /} / \mathrm{C}_{\mathrm{SRFA}}$ mole ratio. 


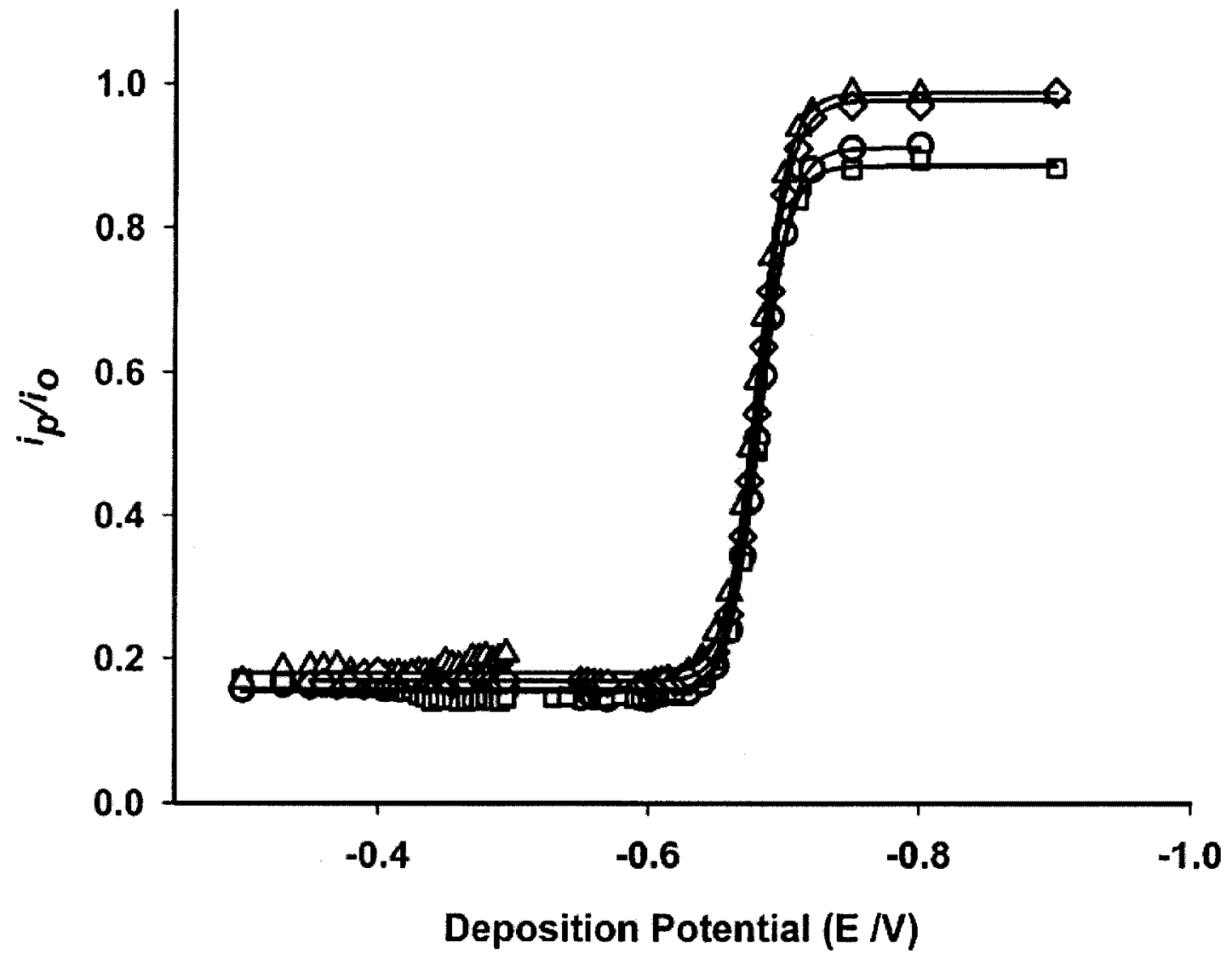

Figure 5.10. Effect of deposition potential on the release (ip/io) of metal from the $\mathrm{Cd}(\mathrm{II})-\mathrm{SRFA}$ complex with the Cd/SRFA mole ratio as a parameter. Each solution contained $\mathrm{C}_{C u, T}=C_{Z n, T}=C_{C d, T}=C_{P b, T}=5.0 \times 10^{-7} \mathrm{~mol} \mathrm{~L}^{-1} \cdot C_{S R F A}$ was varied from, 0.0 mol. $\mathrm{L}^{-1}(\Delta), 1 \times 10^{-3} \mathrm{~mol}^{-1} \mathrm{~L}^{-1}\left(C_{\mathrm{M}, \mathrm{T}} / C_{\mathrm{SRFA}}=0.0005\right)$ (口), $5 \times 10^{-4}$ mol. $\mathrm{L}^{-1}\left(C_{\mathrm{M}, \mathrm{T}} / C_{\mathrm{SRFA}}=0.001\right)(\mathbf{0})$ and $5 \times 10^{-5} \mathrm{~mol} . \mathrm{L}^{-1}$ $\left(C_{\mathrm{M}, \mathrm{T}} / C_{\mathrm{SRFA}}=0.01\right)(\vartheta), \mathrm{HOAc} / \mathrm{NaOAc}$ buffer, $\mathrm{pH} 5.0 \pm 0.1$, temperature $=$ $23 \pm 2{ }^{\circ} \mathrm{C}$ 
Table 5.3. Effect of decreasing mole ratios of $C_{\mathrm{M}, \mathrm{T}} / C_{\mathrm{SRFA}}$ on the Differential Equilibrium Functions, mean diffusion coefficients and heterogeneity of Cd(II)-SRFA complexes in model solutions of SRFA. Each solution contained $C_{\mathrm{Pb}, \mathrm{T}}=5.0 \times 10^{-7} \mathrm{~mol} \mathrm{~L}^{-1}, C_{\mathrm{Cu}, \mathrm{T}}=5.0 \times 10^{-7} \mathrm{~mol} \mathrm{~L}^{-1}, C_{\mathrm{Zn}, \mathrm{T}}=$ $5.0 \times 10^{-7} \mathrm{~mol} \mathrm{~L}^{-1}$, and $C_{\mathrm{Cd}, \mathrm{T}}=5.0 \times 10^{-7} \mathrm{~mol} \mathrm{~L}^{-1} . C_{S R F A}$ was varied from

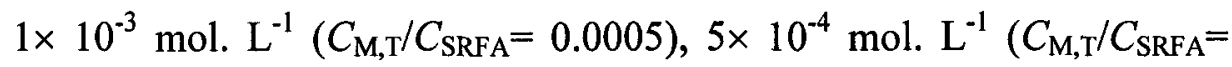
$0.001)$ and $5 \times 10^{-5} \mathrm{~mol} . \mathrm{L}^{-1}\left(C_{\mathrm{M}, \mathrm{T}} / C_{\mathrm{SRFA}}=0.01\right), \mathrm{HOAc} / \mathrm{NaOAc}$ buffer, pH $5.0 \pm 0.1$, temperature $=23 \pm 2{ }^{\circ} \mathrm{C}$.

\begin{tabular}{cccc}
\hline \multirow{2}{*}{$\begin{array}{c}\text { Chemical } \\
\text { speciation } \\
\text { parameters of Cd }\end{array}$} & $\mathbf{3}$ Mole Ratio of [Cd] / [SRFA] \\
\cline { 2 - 4 } & 0.01 & $\mathbf{0 . 0 0 1}$ & $\mathbf{0 . 0 0 0 5}$ \\
\hline$\Gamma$ & $0.93 \pm 0.08$ & $0.94 \pm 0.05$ & $0.95 \pm 0.10$ \\
$\log \mathrm{K}^{*}\left(\mathrm{~L} \mathrm{~mol}^{-1}\right)$ & $5.26 \pm 0.14$ & $5.41 \pm 0.04$ & $5.47 \pm 0.08$ \\
$\mathrm{D}_{\mathrm{ML}}\left(\mathrm{m}^{2} \mathrm{~s}^{-1}\right)$ & $(6.86 \pm 0.10) \times 10^{-10}$ & $(5.77 \pm 0.15) \times 10^{-10}$ & $(5.14 \pm 0.14) \times 10^{-10}$ \\
\hline
\end{tabular}




\subsubsection{Speciation parameters of $\mathrm{Pb}$ in model solutions:}

Typical pseudopolarograms for four test solutions of $\mathrm{Pb}(\mathrm{II})$ are presented in Figure 5.11. The top curve is that for a solution of lead spiked into a sample of ultrapure water containing the other three metals, buffered with the acetic acid-sodium acetate buffer solution, with no SRFA present. A sharp, well-defined, polarographic wave with a flat plateau and $\Gamma=1$ was observed for $\mathrm{Pb}$ metal in the metal mixture, indicating a fully reversible electrode process. The lower three pseudopolarograms were obtained for $\mathrm{Pb}$ from three metal mixtures containing the same concentrations of the four metals with three different concentrations of SRFA. Equation 8 suggests that the observed reduction in the limiting currents of the $\mathrm{Pb}$ (II)-SRFA complexes relative to that of the $\mathrm{Pb}$-aqua complexes was probably due to a decrease in the mean diffusion coefficient of $\mathrm{Pb}$ (II)-SRFA complexes. Limiting current decresed as the metal to SRFA ratio decreased. Figure 5.11 and Table 5.4 show the results for $\mathrm{Pb}(\mathrm{II})$ FA complexes in model solutions of SRFA. For $\mathrm{Pb}(\mathrm{II})$-SRFA, $\Gamma$ values were found to be 0.70 and independent of the SRFA concentrations. $\log \mathrm{K}^{*}$ value for Pb-SRFA complexes decreased with increasing $\mathrm{C}_{\mathrm{Pb}(\mathrm{II})} / \mathrm{C}_{\mathrm{SRFA}}$ mole ratio. 


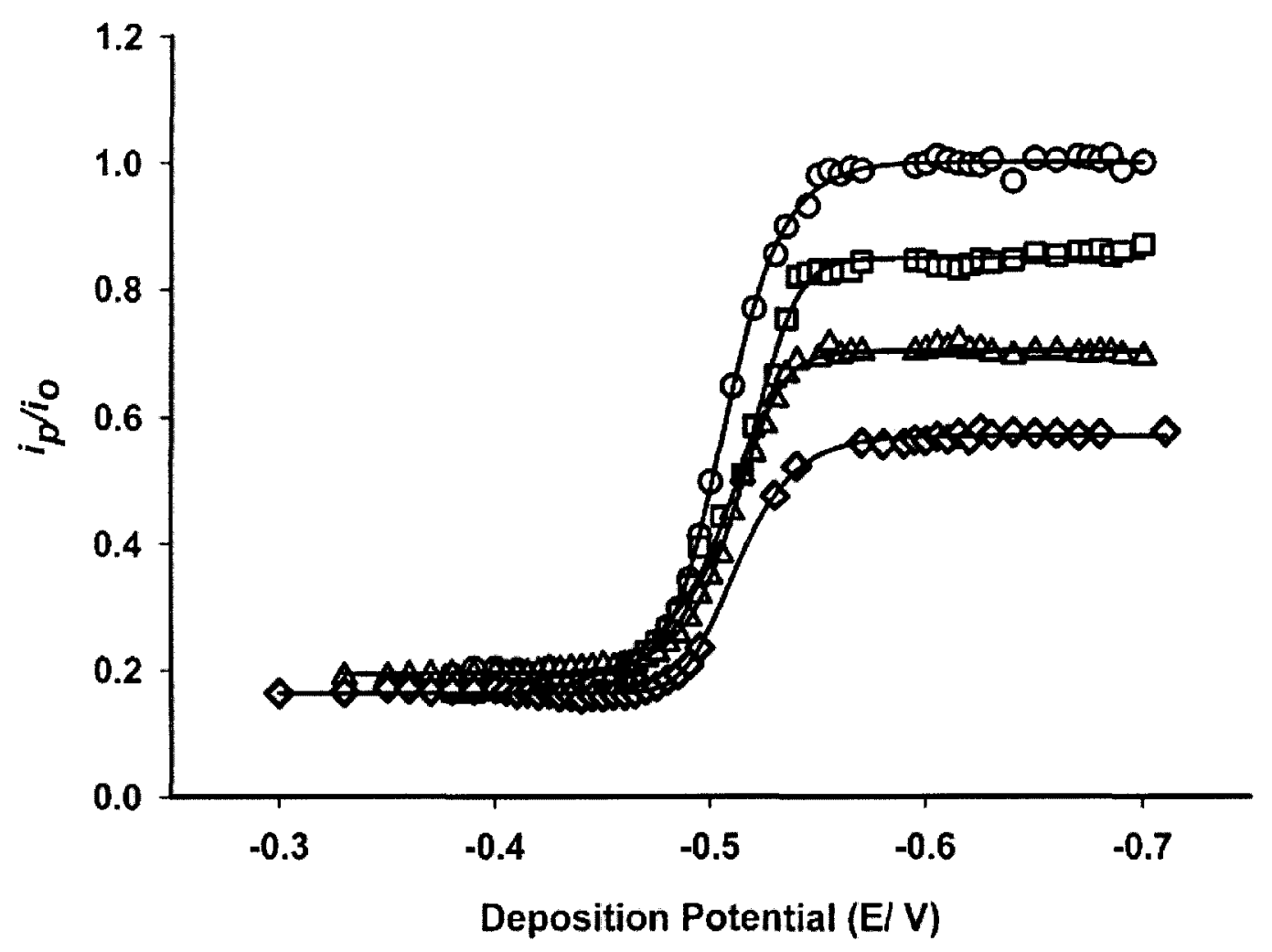

Figure 5.11. Effect of deposition potential on the release (ip/io) of metal from the $\mathrm{Pb}$ (II)-SRFA complex with the $\mathrm{Pb} / \mathrm{SRFA}$ mole ratio as a parameter. Each solution contained $\mathrm{C}_{C u, T}=C_{Z n, T}=C_{C d, T}=C_{P b, T}=5.0 \times 10^{-7} \mathrm{~mol} \mathrm{~L}^{-1} . C_{S R F A}$ was varied from, $0.0 \mathrm{~mol} . \mathrm{L}^{-1}(\mathbf{o}), 1 \times 10^{-3} \mathrm{~mol} . \mathrm{L}^{-1}\left(C_{\mathrm{M}, \mathrm{T}} / C_{\mathrm{SRFA}}=0.0005\right)$ $(\diamond), 5 \times 10^{-4}$ mol. $\mathrm{L}^{-1}\left(C_{\mathrm{M}, \mathrm{T}} / C_{\mathrm{SRFA}}=0.001\right)(\Delta)$ and $5 \times 10^{-5} \mathrm{~mol} . \mathrm{L}^{-1}$ $\left(C_{\mathrm{M}, \mathrm{T}} / C_{\mathrm{SRFA}}=0.01\right)(\square), \mathrm{HOAc} / \mathrm{NaOAc}$ buffer, $\mathrm{pH} 5.0 \pm 0.1$, temperature $=23 \pm 2{ }^{\circ} \mathrm{C}$. 
Table 5.4. Effect of decreasing mole ratios of $C_{\mathrm{M}, \mathrm{T}} / C_{\mathrm{SRFA}}$ on the Differential Equilibrium Functions, mean diffusion coefficients and heterogeneity of $\mathrm{Pb}(\mathrm{II})$-SRFA complexes in model solutions of SRFA. Each solution contained $C_{\mathrm{Pb}, \mathrm{T}}=5.0 \times 10^{-7}$ $\mathrm{mol} \mathrm{L}{ }^{-1}, C_{\mathrm{Cu}, \mathrm{T}}=5.0 \times 10^{-7} \mathrm{~mol} \mathrm{~L}^{-1}, C_{\mathrm{Zn}, \mathrm{T}}=5.0 \times 10^{-7} \mathrm{~mol} \mathrm{~L}^{-1}$, and $C_{\mathrm{Cd}, \mathrm{T}}=5.0 \times 10^{-7}$ mol L ${ }^{-1} \cdot C_{S R F A}$ was varied from $1 \times 10^{-3} \mathrm{~mol} . \mathrm{L}^{-1}\left(C_{\mathrm{M}, \mathrm{T}} / C_{\mathrm{SRFA}}=0.0005\right), 5 \times 10^{-4} \mathrm{~mol} . \mathrm{L}^{-}$ ${ }^{1}\left(C_{\mathrm{M}, \mathrm{T}} / C_{\mathrm{SRFA}}=0.001\right)$ and $5 \times 10^{-5} \mathrm{~mol} . \mathrm{L}^{-1}\left(C_{\mathrm{M}, \mathrm{T}} / C_{\mathrm{SRFA}}=0.01\right), \mathrm{HOAc} / \mathrm{NaOAc}$ buffer, pH $5.0 \pm 0.1$, temperature $=23 \pm 2{ }^{\circ} \mathrm{C}$.

\begin{tabular}{cccc}
\hline $\begin{array}{c}\text { Chemical } \\
\text { speciation } \\
\text { parameters of Pb }\end{array}$ & 0.01 & 0.001 & 0.0005 \\
\cline { 2 - 4 }$\Gamma$ & $0.72 \pm 0.04$ & $0.68 \pm 0.04$ & $0.70 \pm 0.06$ \\
\hline$\Gamma$ & $6.47 \pm 0.18$ & $6.52 \pm 0.25$ \\
$\operatorname{Log~K}{ }^{*}\left(\mathrm{~L} \mathrm{~mol}^{-1}\right)$ & $6.07 \pm 0.70$ & \multicolumn{3}{c}{ Mole Ratio of [Pb] / [SRFA] } \\
$\mathrm{D}_{\mathrm{ML}}\left(\mathrm{m}^{2} \mathrm{~s}^{-1}\right)$ & $(5.74 \pm 0.10) \times 10^{-10}$ & $(3.86 \pm 0.14) \times 10^{-10}$ & $(2.62 \pm 0.10) \times 10^{-10}$ \\
\hline
\end{tabular}




\subsection{Heterogeneity Parameter $(\Gamma)$}

At all the metal to SRFA mole ratios (i.e. $\mathrm{C}_{\mathrm{M}} / \mathrm{C}_{\mathrm{SRFA}}=0.01,0.001$ and 0.0005 ) used in this work, the value of $\Gamma$ remained about the same for a given metal (e.g. $\mathrm{Cu}$ ): the value of $\Gamma$ for $\mathrm{Cu}$ (II) was found to be $\sim 0.50$ in all solutions, suggesting that SRFA behaved as a heterogeneous complexant for $\mathrm{Cu}(\mathrm{II})$. The value of $\Gamma$ for $\mathrm{Pb}(\mathrm{II})$ was found to be $\sim 0.70$ in the three model solutions, suggesting that compared to $\mathrm{Cu}(\mathrm{II})$, for $\mathrm{Pb}$ (II) SRFA behaved as a less heterogeneous complexant. $\Gamma$ value obtained for $\mathrm{Cd}$ was found to be $\sim 0.94$, suggesting that SRFA behaved almost as a homogeneous complexant for $\mathrm{Cd}$, whereas, the $\Gamma$ value for $\mathrm{Zn}$ was found to be $\sim 0.86$, i.e. lower than the value obtained for $\mathrm{Cd}$, suggesting that SRFA was a little more heterogeneous for $\mathrm{Zn}$ than for $\mathrm{Cd}$.

A comparison of heterogeneity parameters for $\mathrm{Zn}(\mathrm{II}), \mathrm{Cd}(\mathrm{II}), \mathrm{Pb}(\mathrm{II})$ and $\mathrm{Cu}(\mathrm{II})$ complexes in the model solutions of SRFA (Tables 5.1-5.4) shows that $\Gamma_{\mathrm{Cd}}>\Gamma_{\mathrm{Zn}}>\Gamma_{\mathrm{Pb}}$ $>\Gamma_{\mathrm{Cu}}$, Similar observation was also reported in the literature [46].

The results are in good agreement with those of Town and Filella [43], who have reported that $\mathrm{Pb}(\mathrm{II})$ complexes with SRFA are less heterogeneous than $\mathrm{Cu}(\mathrm{II})-\mathrm{SRFA}$ complexes, and also with those of Pinehro et al [47], who reported that $\mathrm{Pb}$ (II) complexation by a peat-derived humic acid was more heterogeneous than the corresponding $\mathrm{Cd}(\mathrm{II})$ complexes. The above results suggest that the binding sites of SRFA for $\mathrm{Cd}(\mathrm{II})$ and $\mathrm{Zn}$ (II) are thermodynamically similar, whereas those for $\mathrm{Pb}$ (II) and $\mathrm{Cu}(\mathrm{II})$ are thermodynamically diverse.

Since the differential equilibrium function explicitly accounts for the degree of site occupation by the metals, $\theta$, it is relatively independent of the experimental 
conditions. However, in the determination of the experimental parameters by ASV, $\Gamma$ still may be influenced by the limitation of the ASV technique. $\Gamma$ values obtained for $\mathrm{Cu}(\mathrm{II}), \mathrm{Pb}$ (II), $\mathrm{Cd}(\mathrm{II})$ and $\mathrm{Zn}$ (II) by simultaneous determination in samples having various metal loadings are in good agreement with the theory; the very small deviations observed are probably due to uncertainties in the measurement.

The observed spreading of the polarographic wave was probably due to change in the metal to ligand mole ratio in the diffusion layer and was specific for heterogeneous complexants (SRFA).

\subsection{Differential Equilibrium Function $\left(\log K^{*}\right)$}

Tables 5.1-5.4 show increasing effects of trace metal competition on $\log \mathrm{K}^{*}$ values with decreasing SRFA concentrations of all the above metals. At a very low metal to SRFA mole ratio $\left(\mathrm{C}_{\mathrm{M}} / \mathrm{C}_{\mathrm{SRFA}}=0.0005\right)$, relatively higher values of $\log \mathrm{K}^{*}$ were observed for all the metals. However, $\log \mathrm{K}^{*}$ value decreased with increasing $\mathrm{C}_{\mathrm{M}}$ to $\mathrm{C}_{\mathrm{SRFA}}$ ratio, Since the stronger sites of the heterogeneous ligand (SRFA) are occupied first by the metal, as the degree of occupation of all sites types, $(\theta)$, increases, the averaging of the apparent equilibrium constants of the metal and the site-ligand, was carried out with an increasing number of weaker sites; hence, $\log \mathrm{K}^{*}$ decreased. In the lowest mole ratio $\left(\mathrm{C}_{\mathrm{M}} / \mathrm{C}_{\mathrm{SRFA}}=0.0005\right)$, the $\log \mathrm{K}^{*}$ for $\mathrm{Cu}$ was found to be 7.41 , followed by $\mathrm{Pb}\left(\log \mathrm{K}^{*}=6.52\right), \mathrm{Zn}\left(\log \mathrm{K}^{*}=6.01\right)$ and $\mathrm{Cd}\left(\log \mathrm{K}^{*}=5.47\right)$. i.e. $\log \mathrm{K}_{\mathrm{Cu}}{ }^{*}>\log \mathrm{K}_{\mathrm{Pb}} *>\log \mathrm{K}_{\mathrm{Zn}}{ }^{*}>\log \mathrm{K}_{\mathrm{Cd}}$. The same order was found for all three model solutions. This order of $\log \mathrm{K}^{*}$ suggests that at $\mathrm{pH} 5.0 \mathrm{Cu}$ (II) forms relatively thermodynamically stronger complexes with SRFA, followed by $\mathrm{Pb} . \log \mathrm{K}^{*}$ value for 
$\mathrm{Zn}$ (II)-SRFA complexes was higher than the $\log \mathrm{K}^{*}$ values for $\mathrm{Cd}(\mathrm{II})-\mathrm{SRFA}$ complexes. $\Gamma$ values also suggest that at $\mathrm{pH}=5.0$ SRFA behaves as a more heterogeneous complexant for $\mathrm{Zn}$ than for $\mathrm{Cd}$. This lower value of $\log \mathrm{K}^{*}$ for $\mathrm{Cd}(\mathrm{II})-$ SRFA complexes can be rationalized by considering the Hard Soft Acid Base (HSAB) Theory. According to HSAB Theory, $\mathrm{Cd}^{2+}$ ion (which is larger than $\mathrm{Zn}^{2+}$ ion) is a soft acid, whereas $\mathrm{Zn}^{2+}$ is a border-line acid, i.e. $\mathrm{Cd}^{2+}$ ion is softer acid than $\mathrm{Zn}^{2+}$ ion. Hence, $\mathrm{Cd}^{2+}$ ion would prefer softer base; $\mathrm{S}-$ and $\mathrm{N}$ - containing groups in humic substances, forming a more stable complexes with $\mathrm{Cd}^{2+}$ ion, i.e. with a higher $\log \mathrm{K}^{*}$ values. However, since the percentage of S- and $\mathrm{N}$ - containing groups are very small (minor sites) in humic substances, they cannot bind all the Cd; the remaining $\mathrm{Cd}$ bind with major sites, e.g. $-\mathrm{COOH},-\mathrm{OH}$ groups, giving a low value of $\log \mathrm{K}^{*}$. However, $\mathrm{Zn}$, which is relatively harder acid interacts more strongly with harder bases such as $-\mathrm{OH}$, $-\mathrm{COOH}$ groups, (major functional groups) and forms stable complexes with them. Our results show that $\mathrm{Cd}$ forms relatively weaker complexes probably because of the competition of stronger competing metals like $\mathrm{Cu}$ for the binding sites of SRFA. 


\subsection{Average Diffusion Coefficients $\left(\overline{\mathrm{D}}_{M L}\right)$}

Diffusion coefficients reflect the mobility of the metal species and hence, have important effect on the transport and bioavailability of the metals in the aquatic environment. As a rough approximation, the metal complexes of individual molecules of a given group of naturally-occuring, organic macromolecular heterogeneous complexants (e.g. SRFA) are often assumed to have similar sizes, and hence, assigned a single diffusion coefficient. Table 5.5, presents average diffusion coefficients of SRFA complexes of all the four metals, which were experimentally determined by using Eq. 8. The average diffusion coefficients $\left(\overline{\mathrm{D}}_{M L}\right)$ for all metal complexes were found to be much lower than the diffusion coefficient of free metal ion $\left(\overline{\mathrm{D}}_{M}\right)$ in aqueous media (Table 5.5). 
Table 5.5. Comparison of diffusion coefficients of free metal ions with the four different metals-SRFA complexes in model solutions of different mole ratios of $C_{\mathrm{M}, \mathrm{T}} / C_{\mathrm{SRFA}}$, determined simultaneously. Each solution contained $\mathrm{C}_{C u, T}=C_{Z n, T}=C_{C d, T}=C_{P b, T}=5.0$ $\times 10^{-7} \mathrm{~mol} \mathrm{~L}{ }^{-1} . C_{S R F A}$ was varied from $1 \times 10^{-3} \mathrm{~mol} . \mathrm{L}^{-1}\left(C_{\mathrm{M}, \mathrm{T}} / C_{\mathrm{SRFA}}=0.0005\right), 5 \times 10^{-4} \mathrm{~mol} . \mathrm{L}^{-1}\left(C_{\mathrm{M}, \mathrm{T}} / C_{\mathrm{SRFA}}=0.001\right)$ and $5 \times$ $10^{-5} \mathrm{~mol} . \mathrm{L}^{-1}\left(C_{\mathrm{M}, \mathrm{T}} / C_{\mathrm{SRFA}}=0.01\right), \mathrm{HOAc} / \mathrm{NaOAc}$ buffer, $\mathrm{pH} 5.0 \pm 0.1$, temperature $=23 \pm 2^{\circ} \mathrm{C}$.

\begin{tabular}{|c|c|c|c|c|}
\hline Elements & $\begin{array}{c}\overline{\mathrm{D}}_{\mathrm{M}(\mathrm{II})} \\
\mathrm{C}_{\mathrm{M}(\mathrm{II})}=\mathbf{5} \times \mathbf{1 0} \mathbf{0}^{-7} \mathrm{M} \\
\left(\mathbf{m}^{2} \mathbf{s}^{-1}\right)\end{array}$ & $\begin{array}{c}\overline{\mathrm{D}}_{\text {M(II)-SRFA }} \\
\mathrm{C}_{\mathrm{M}} / \mathrm{C}_{\text {SRFA }}=0.01 \\
\left(\mathrm{~m}^{2} \mathrm{~s}^{-1}\right) \\
\end{array}$ & $\begin{array}{c}\overline{\mathrm{D}}_{\mathrm{M}(\mathrm{II})-\mathrm{SRFA}} \\
\mathrm{C}_{\mathrm{M}} / \mathrm{C}_{\mathrm{SRFA}}=\mathbf{0 . 0 0 1} \\
\left(\mathbf{m}^{2} \mathbf{s}^{-1}\right) \\
\end{array}$ & $\begin{array}{c}\overline{\mathrm{D}}_{\mathrm{M(II)-SRFA}} \\
\mathrm{C}_{\mathrm{M}} / \mathrm{C}_{\mathrm{SRFA}}=\mathbf{0 . 0 0 0 5} \\
\left(\mathrm{m}^{2} \mathrm{~s}^{-1}\right)\end{array}$ \\
\hline $\mathrm{Cu}(\mathrm{II})$ & $7.33 \times 10^{-10}$ & $(4.10 \pm 0.14) \times 10^{-10}$ & $(4.50 \pm 0.10) \times 10^{-11}$ & $(7.50 \pm 0.12) \times 10^{-12}$ \\
\hline $\mathrm{Zn}(\mathrm{II})$ & $6.38 \times 10^{-10}$ & $(5.01 \pm 0.08) \times 10^{-10}$ & $(4.07 \pm 0.14) \times 10^{-10}$ & $(1.60 \pm 0.10) \times 10^{-10}$ \\
\hline Cd(II) & $6.90 \times 10^{-10}$ & $(6.86 \pm 0.10) \times 10^{-10}$ & $(5.77 \pm 0.15) \times 10^{-10}$ & $(5.14 \pm 0.14) \times 10^{-10}$ \\
\hline $\mathbf{P b}(\mathrm{II})$ & $8.28 \times 10^{-10}$ & $(5.74 \pm 0.10) \times 10^{-10}$ & $(3.86 \pm 0.14) \times 10^{-10}$ & $(2.62 \pm 0.10) \times 10^{-10}$ \\
\hline
\end{tabular}


The average diffusion coefficient $\left(\overline{\mathrm{D}}_{M L}\right)$ of all four metal complexes decreased as the $\mathrm{C}_{\mathrm{M}}$ to $\mathrm{C}_{\mathrm{SRFA}}$ ratio decreased (Table 5.5). It significantly decreased for Cu. However, a very small change was observed for $\mathrm{Cd}(\mathrm{II})$-SRFA complexes. As indicated above, the average diffusion coefficient $\overline{\mathrm{D}}_{M L}$, of M(II)-SRFA complexes is determined only by the properties of the complexant (SRFA). Molar volumes, and hence, diffusion coefficients are influenced by a number of factors, including polarity, conformation, molecular weight and other factors; for heterogeneous complexation, structure, shape, hydration and aggregation should be also considered. Generally, for a dilute aqueous solution at a given temperature, diffusion coefficient of an organic molecule is proportional to its hydrated molar volume. The $\overline{\mathrm{D}}_{M L}$ at lower $\mathrm{C}_{\mathrm{M}}$ to $\mathrm{C}_{\mathrm{SRFA}}$ ratio was significantly smaller than its value at higher ratios. This meant that for the same amount of metal, an increase in $\mathrm{C}_{\mathrm{SRFA}}$ by one order of magnitude produced a significant decrease in the mobility of M-SRFA molecule. Change in the SRFA concentration may cause aggregation and conformational changes and can reduce $\mathrm{D}_{\mathrm{ML}}$.

It is known that conformational rearrangements of the macromolecule may take place on complexation and that folding and coiling processes are time-dependent.

Depending on the amount of attack on metal ions and of their nature, there is more or less prefloculation folding; this will affect the diffusion of the macromolecule and their metal complexes.

However, with increasing amounts of SRFA, the diffusion coefficient of the $\mathrm{Cu}$ species decreases most, that of $\mathrm{Cd}$ changes least, and the other are similar in change. On the basis of diffusivity, a decrease in diffusion coefficient with increasing 
SRFA concentrations may suggest that there is an aggregation process between metal-free and metal-coordinated organic molecule.

It has been argued that strong binding sites may be strong in a kinetic sense, meaning that folding processes have moved them into the interior of the macromolecules. In view of the results given here, one may conjecture that attack on these specific binding sites causes conformational folding, thereby changing the outer appearance of the molecule, and hence, its mobility.

These experimental results show that ASV, which is a powerful and cost-effective technique, can be used satisfactorily for simultaneous determination of trace metal speciation in natural waters. The major advantage is the possibility of simultaneous determination of several metals in a sample in a single experiment, and hence, in a shorter time than taken by multiple experiments. 


\subsection{References}

1. Melaku S, Wondimu T, Dams R, Moens L, (2004), Canadian Journal of Analytical Sciences and Spectroscopy, 49(6), 374-384.

2. Sarmiento-Gonzalez, Alejandro M G, Juan M, Tejerina L, Jose M, Paz J J, Sanz M A, (2005), Anal. Bioanal. Chem. 382(4), 1001-1009.

3. Yin J, Jiang Z, Chang G, Hu B, (2005), Anal. Chim. Acta, 540(2), 333-339.

4. Lee Kyue-Hyung, Oshima M, Motomizu S, (2002), The Analyst 127(6), 769-74.

5. Huang, L S, Lin K C (2006), Analytical Sciences, 22(10), 1375-1378.

6. Kujirai O, Yamada K, (1996), Frese. J. of Anal. Chem., 354(4), 428-31.

7. Kujirai O, Yamada K, (1994), Frese. J. of Anal. Chem, 348(11), 719-23.

8. Cheng C J, Akagi T, Haraguchi H, Anal Chim Acta (1987), 198 173-81.

9. Berman, S S; McLaren, J W, Willie S N, (1980), Analytical Chemistry, 52(3), 488-92.

10. Mochizuki M, Hondo R, Ueda F, (2002), Biological Trace Element Research, $87(1-3), 211-223$.

11. Aiva de Oliveira A, de Moraes, M, Gomes N, Jose A, Lima E C., (2002), Atomic Spectroscopy 23(2), 39-43.

12. Chiu C, Sung Y H, Huang S D, (2003), Spectrochimica Acta, Part B: Atomic Spectroscopy 58B (3), 575-580.

13. Sen Gupta, J G (1993), Journal of Analytical Atomic Spectrometry 8(1), 93101.

14. Locatelli C, (2006), Anal. Chim. Acta 557(1-2), 70-77. 
15. Silva, P R M, E Khakani M A, Chaker M, Dufresne A, Courchesne F, (2001), Sensors and Actuators, B: Chemical B76 (1-3), 250-257.

16. Barbeira P J S, Stradiotto N R, (1998) Frese. J. of Anal. Chem., 361(5), 507509.

17. Izquierdo A, Luque de Castro M D, Valcarcel, M (1994), Electroanalysis $6(10), 894-902$.

18. Opydo J, (1989), Water Air and Soil Pollution 45(1-2), 43-8.

19 Vermeer A W P, McCulloch J K, Van Riemsdijk W H, Koopal L K (1999) Environ Sci Technol 33: 3892-3897.

20. Langsto W J, Bryan G W, in: Kramer C J M, Duinker J C (1984) (Eds), Complexation of Trace metals in Natural Waters; Martinus Nijhoff/Dr. W. Junk Publishers: the Hague, the Netherlands, p375.

21. Brown G K, Cabaniss S E, MacCarthy P, Leenheer J A (1999) Anal Chim Acta 402:183-193.

22. Woller A, Garraud H, Boisson J, Dorthe A M, Fodor P, Donard O F X, (1998), Journal of Analytical Atomic Spectrometry, 13(2), 141-149.

23. Winistoerfer D, (1995), Communications in Soil Science and Plant Analysis, $26(7 \& 8), 1073-93$

24. Agraz, R, Sevilla, M T, Hernandez, L, (1993), Anal Chim Acta 273(1-2), 205-12.

25. Haraldsson C, Lyven B, Pollak M, Skoog A (1993) Anal Chim Acta 284: 327336.

26. Ammann, Adrian A (2002) Anal Bioanal Chem 372:448-452. 
27. Heltai G, Percsich K, Fekete I, Barabas B, Jozsa T (2000) Microchemical Journal 67: 43-51.

28. Temminghoff E J M, Plette, A C C, Van Eck R, Van Riemsdijk W H (2000) Anal Chim Acta 417:149-157.

29. Sedykh E M, Starshinova N P, Bannykh L N, Ershova E Yu, Venitsianov E V (2000) Journal of Analytical Chemistry (Translation of Zhurnal Analiticheskoi Khimii) 55:344-349.

30. Wang J, (1985), Stripping Analysis: Principles, Instrumentation and Application (VCH Publishers, Deerfield Beach, Fla.,)

31. Copeland T R, Skogerboe R K, (1974), Anal Chem. 46, 1257A.

32. Filella M, Buffle J, van Leeuwen H P, (1990), Anal. Chim. Acta, 232, 209.

33. Gamble D S, Langford C H, (1988), Environ. Sci. Technol., 22, 1325.

34. Gamble D S, (1970) Can. J. Chem., 48, 2662.

35. DeFord D, Hume N, (1951), J. Am. Chem. Soc. 73, 5321.

36. Buffle J, Tercier-Waeber M L., (2000), In Situ Voltammetry: Concepts and Practices for Trace Analysis and Speciation, in: (Eds: J. Buffle, G. Horvai), In Situ Monitoring of Aquatic Systems: Chemical Analysis and Speciation, pp. 290-291 (John Wiley \& sons: New York).

37. Buffle J, (1988), Complexation Reactions in Aquatic Systems: An Analytical Approach, p.473 (Ellis Horwood: Chichester).

38. van Leeuwen H P, Buffle J, (1990), J. Electroanal. Chem. 296, 359.

39. Ritchie J D, Perdue, (2003), Geochim. Cosmochim. Acta, 6785. 
40. Sherrod P H, (2001), NLREG Reference Manual (Phillip H. Sherrod: Brentwood, Tennessee).

41. Shuman S S, Jr. Woodward G P, (1976), Anal. Chem., 48, 13.

42. Brown S D, Kowalski B R, (1997), Anal. Chem. 51, 2133.

43. Town R M, Filella M, (2000), J. Electroanal. Chem, 488, 1-16

44. Gregor J E, Powell H K J, (1998), Anal. Chim. Acta 211, 141.

45. Locatelli C, Torsi G, (1998) Electroanalysis 10, 904.

46. Murimboh J, (2002), PhD. Thesis, Carleton University.

47. Pinheiro J P, Mota A M, Simões Gonçalves M L, (1994), Anal. Chim. Acta, 284,525 


\section{6}

Complexation of Lead in Model Solutions of Suwannee River Fulvic Acid (SRFA): Heterogeneity of SRFA and Effects of Competition by Copper, Zinc and Cadmium on Target Metal Lead 


\subsection{Introduction}

It is well known that the chemical speciation of a metal (and not its total concentration) is a good indicator of toxicity, bioavailability, or reactivity $[1,2]$ of the metal in natural waters. The complexation of metal ions by naturally occurring humic substances attracts considerable attention because of its importance in regulating metal toxicity, bioavailability, and transport in natural waters. Humic substances present in natural waters are polyfunctional, heterogeneous, supramolecular association of small and large organic molecules. These heterogeneous substances contain both 'hard' (e.g., carboxylic, phenolic) and 'soft' (e.g., nitrogen and sulphur containing) complexing sites [3] for a wide range of metal ions and can be expected to buffer metal ion concentrations over a wide ranges of concentration. The same heterogeneous complexant like humic substance may have different heterogeneity to for different metal ion. Metal complexation in natural waters is strongly influenced by the heterogeneity of the humic substances. This paper investigated the complexation of $\mathrm{Pb}$ (II) with humic substances (SRFA). $\mathrm{Pb}$ (II) is one of the most extensively investigated heavy metals. Indeed $\mathrm{Pb}$, which has no physiological function and is potentially toxic, has been widely dispersed in the environment since the beginning of metallurgy [4]. One major dispersion pathway for $\mathrm{Pb}$ is atmospheric transport because $\mathrm{Pb}$-bearing aerosols are emitted from industrial activities, combustion of coal and leaded gasoline $[5,6]$. Its presence in aquatic systems results mostly from anthropogenic activities [7]. 
It is thus a great interest to know and understand the complexation reaction of lead with heterogeneous humic substances present in freshwaters. The significance of humic substances for complexation of $\mathrm{Pb}$ in freshwater has been reported in several studies. It has also been reported that $\mathrm{Pb}$ is strongly adsorbed by humic substances in sediments and in soil [8-10]. However, relatively few studies have considered the consequences of ligand heterogeneity for $\mathrm{Pb}^{2+}$ ion complexation by NOM. In natural waters, several studies have shown the importance of complexes with NOM in determining the speciation of $\mathrm{Pb}(\mathrm{II})[11,12]$.

However, it is extremely difficult to determine sound physiochemical properties to describe metal complexation by heterogeneous humic substances. One of the few approaches used to describe the stability of metal complexes formed by humic substances that takes the metal loading dependence into account is the differential equilibrium function (DEF). It is based on the differential intensity parameter, $\mathrm{K}^{*}$, which is a weighted average mean of the equilibrium constants $\mathrm{K}_{i}$, for all sites present in the humic substance [13-15]. The weighting factor depends on the mole fraction of [metal]/[HS], and degree of occupation of each site, $i$. The DEF is not equivalent to a molecular complexation model that describes complexation at each individual site. It is, however, most useful in making predictions of the complexation behaviour of the system as a whole. DEF was used to study the $\mathrm{Pb}$ complexation in this paper. This approach allows us to calculate the heterogeneity parameter $(\Gamma)$ of humic substances. Heterogeneity parameter, $\Gamma$, is very important parameter which is directly related to the buffer intensity of the complexing system, which might influence the capacity of natural waters to sustain life after metal pollution events [13]. The same complexing 
substance might have different heterogeneity for different metal ions [16-18] because of the following factors: 1) different complexing sites might be available to different metal ions, and 2) the stabilities of the strongest and weakest sites titrated with the same metal might vary from metal to metal. In addition, heterogeneity might be $\mathrm{pH}$ dependent, because of different ranges of binding sites being available at different pH's [19].

It was reported several times that humic substances behaves heterogeneously with $\mathrm{Cu}$ (II) and $\Gamma$ values for $\mathrm{Cu}$ was found to vary in between $0.3-0.5$, depending on the humic substances. The lower value of $\Gamma$ suggested that a wider distribution range of binding sites were available for $\mathrm{Cu}$ in humic substances.

Heterogeneity parameter $(\Gamma)$ for $\mathrm{Pb}(\mathrm{II})$ binding with humic substances from various sources was found to be $\sim 0.60$ by Filella et al [20]. Filella and R M Town [21] also reported that $\Gamma$ value was $\sim 0.70$ for $\mathrm{Pb}$ (II) binding with SRFA. However, in freshwater source, $\Gamma$ value for $\mathrm{Pb}(\mathrm{II})$ binding with $\mathrm{NOM}$ was reported to be lower than the $\Gamma$ value obtained from model solutions [22].

Binding of $\mathrm{Pb}$ (II) to different $\mathrm{HA}$ was reported [23] to be stronger than for $\mathrm{Cd}(\mathrm{II})$, with a greater heterogeneity of binding sites, so that the buffering action of different $\mathrm{HA}$ on the concentration of free $\mathrm{Pb}(\mathrm{II})$ is more effective than for $\mathrm{Cd}(\mathrm{II}) . \Gamma$ value of $\mathrm{Pb}$ (II) was reported to be $\sim 0.7$ and for $\mathrm{Cd}$ it was $\sim 0.9$.

It was reported by J H Ephraim [24] that $\mathrm{Zn}^{2+}$ zinc ion was appreciably bound to the sites where an $\mathrm{OH}$ is adjacent to another $\mathrm{OH}$ group and that site where an $\mathrm{OH}$ is adjacent to a $\mathrm{C}=\mathrm{O}$ groups and $\Gamma$ value for $\mathrm{Zn}$ (II) was reported to be $\sim 0.9$. The high value of $\Gamma$ suggested that the humic substance had a narrow distribution of binding 
sites for $\mathrm{Zn}$. RM Town and H P vanLeeuwen reported [25] that the extent of heterogeneity of metal binding by several humic substances followed the order $\mathrm{Cu}$ (II) $>\mathrm{Pb}(\mathrm{II})>\mathrm{Cd}(\mathrm{II})$.

It is well known that heterogeneous humic substances have widely differing affinity for binding various metal ions (which is responsible for different heterogeneity for different metals). This property allows competition between metal ions for strong binding sites on the above organic complexants (humic substances) in freshwaters, resulting in some metal ions binding to the weak binding sites, forming weak complexes which are labile, and hence, release free metal ions which are reported to be toxic.

The extents of competitions for binding depend on the relative concentrations of the metals (and ligands) and on their conditional stability constants under the given conditions. The $\Gamma$ is also relevant since it determines an effective range of sites at which binding occurs.

Xue et al. [26] investigated the competition of copper and zinc for highly selective, strong ligands in a eutrophic lake using cathodic and anodic stripping voltammetry and concluded that the release of zinc from electrochemically inert complexes upon addition of copper indicates that copper and zinc compete for the above strong organic complexants.

It was reported by Bizri et al. [27] that stability of the complexes followed the order $\mathrm{Cu}>\mathrm{Pb}>\mathrm{Cd}$. An increase in stability constant was observed with increase in $\mathrm{pH}$ and also with decrease in total metal ion concentration (at constant $\mathrm{pH}$ ). This order of stability constants suggested that $\mathrm{Cu}$ outcompeted $\mathrm{Pb}(\mathrm{II})$ and $\mathrm{Pb}$ (II) outcompeted $\mathrm{Zn}$ 
for the binding sites of humic substances in freshwater. It was reported in our recent study [28] that a comparison of the heterogeneity parameters $(\Gamma)$ for $\mathrm{Zn}(\mathrm{II}), \mathrm{Cd}(\mathrm{II})$, $\mathrm{Pb}(\mathrm{II})$ and $\mathrm{Cu}(\mathrm{II})$ complexes in the model solutions of SRFA showed that $\Gamma_{\mathrm{Cd}}>\Gamma_{\mathrm{Zn}}$ $>\Gamma_{\mathrm{Pb}}>\Gamma_{\mathrm{Cu}}$, suggesting that $\mathrm{SRFA}$ behaved as a relatively more homogeneous complexant for $\mathrm{Zn}(\mathrm{II})$ and $\mathrm{Cd}(\mathrm{II})$, whereas it behaved as a relatively more heterogeneous complexant for $\mathrm{Pb}(\mathrm{II})$.

It was also found [28] that the order of stability of M-SRFA complex is typically $\mathrm{K}_{\mathrm{Cu}}{ }^{*}>\mathrm{K}_{\mathrm{Pb}}{ }^{*}>\mathrm{K}_{\mathrm{Zn}}{ }^{*}>\mathrm{K}_{\mathrm{Cd}}{ }^{*}$

The objective of this paper is to check the hypothesis that the heterogeneity of humic substances determines the M(II)-DOC interactions and trace metal competition in freshwater.

To test the above hypothesis, heterogeneity of SRFA and its effect on $\mathrm{Pb}$ (II) complexation was studied. This study also investigated the effects of competition of the trace metals $\mathrm{Cu}(\mathrm{II}), \mathrm{Cd}(\mathrm{II})$, and $\mathrm{Zn}$ (II) on the $\mathrm{Pb}$ (II)-SRFA complexation in model solutions. In this study, psudopolarography was employed to study the complexation reaction of $\mathrm{Pb}(\mathrm{II})$ with $\mathrm{SRFA}$, using hanging mercury drop electrode (HMDE). 


\subsection{Experimental}

\subsubsection{Materials and Methodology}

Suwannee River Fulvic Acid (SRFA)

Suwannee River Fulvic Acid (SRFA, (Catalogue. No. 1S101F) was obtained from International Humic Substances Society (IHSS, USA) [29]. The concentration of carboxylic and phenolic groups in SRFA has been reported to be 11.44 and 2.91 mmol $\mathrm{g}^{-1}$, respectively [29]. The molar concentration of SRFA considered in this work is related to the concentration of carboxylic groups (at $\mathrm{pH}=5.0$ ).

\subsubsection{Model Solutions of Suwannee River Fulvic Acid}

Three model solutions (to be henceforth called 'test solutions') were prepared in ultrapure water containing various concentrations of SRFA $\left(1 \times 10^{-3}\right.$ mol. $\mathrm{L}^{-1}, 5 \times 10^{-4}$ mol. $\mathrm{L}^{-1}$ and $\left.5 \times 10^{-5} \mathrm{~mol} . \mathrm{L}^{-1}\right)$ and $5 \times 10^{-7} \mathrm{~mol} . \mathrm{L}^{-1}$ concentrations of $\mathrm{Pb}(\mathrm{II})$. The $\mathrm{pH}$ of the test solutions was adjusted to $5.0 \pm 0.1$ using $\mathrm{HAc} / \mathrm{NaAc}$ buffer. The test solutions were left for equilibration for 60 hours in a dark place before analysis. Metal competition in model solutions was investigated by adding the SRFA to an aqueous solution containing a fixed concentration of the $\mathrm{Pb}(\mathrm{II})\left(5 \times 10^{-7} \mathrm{~mol} \mathrm{~L}^{-1}\right)$ and equimolar concentrations of one of the competing $\mathrm{Cu}(\mathrm{II}), \mathrm{Cd}(\mathrm{II})$ and $\mathrm{Zn}$ (II) trace metals. A $15.00 \mathrm{~mL}$ aliquot of the model solution was weighed and used as the test solution. The $\mathrm{pH}$ of the model solution was checked again immediately before analysis and found to be the same.

\subsubsection{Reagents}

Standard solutions (1000 $\mathrm{mg} \mathrm{L}^{-1}$ ) of $\mathrm{Cu}(\mathrm{II}), \mathrm{Zn}(\mathrm{II}), \mathrm{Cd}(\mathrm{II})$ and $\mathrm{Pb}(\mathrm{II})$ were purchased from SCP Science, Montreal, Canada. Ultrapure water of resistivity $18.2 \mathrm{M} \Omega-\mathrm{cm}$ was 
obtained from a Milli-Q-Plus water purification system (Millipore Corporation). A 2 mol L $\mathrm{L}^{-1}$ stock solution of sodium acetate was prepared by dissolving an appropriate quantity of sodium acetate trihydrate (ACS grade/BDH) in ultrapure water. A stock solution of $2 \mathrm{~mol} \mathrm{~L}^{-1}$ potassium nitrate (supporting electrolyte) was prepared by dissolving potassium nitrate (Analar, BDH) in ultrapure water. The sodium acetate solution was then purified of metals by electrolysis at $-1.5 \mathrm{~V}$ vs. $\mathrm{Ag} / \mathrm{AgCl}$ electrode for a minimum of $48 \mathrm{~h}$. immediately prior to its use. While the electrolysis was continued the sodium acetate aqueous solution was drained from the electrolysis cell in order to make sure that the impurity metals removed by electrolysis did not go back into the sodium acetate aqueous solution on the termination of electrolysis. A 2 mol L ${ }^{-1}$ stock solution of acetic acid was prepared by diluting glacial acetic acid (ACS grade/Anachemia) with ultrapure water.

\subsubsection{Apparatus}

Voltammetric measurements were made with a computer-controlled Autolab PGSTAT30 potentiostat/galvanostat (Eco Chemie BV, The Netherlands), equipped with a Metrohm 663 VA stand (Metrohm, Switzerland). The working electrode was a static mercury drop electrode (Metrohm, Switzerland). The reference electrode was a $\mathrm{Ag} / \mathrm{AgCl}$ electrode in a glass tube filled with $3 \mathrm{~mol} \mathrm{~L}^{-1} \mathrm{KCl}$ and fitted with a porous Vycor tip (Bioanalytical Systems, Inc., USA). The counter electrode was made of a platinum rod (Metrohm, Switzerland). Analysis of voltammetric peaks was done using the General Purpose Electrochemical Software v4.8 (Eco Chemie BV, The Netherlands). The data were transferred to a Pentium computer and saved for processing. 


\subsection{Results and discussion}

Most research on metal complexation by heterogeneous complexants (e.g. SRFA) used pulse stripping techniques because of their high sensitivity of the method [30]. However, differential pulse anodic stripping voltammetry suffers from induced metal adsorption in the presence of HS.[30] Town and Filella[30] reported that in the presence of Suwannee River FA, peak height decreases to a much greater extent compared to peak area because of heterogeneity of SRFA and/or insufficient ligand are heterogeneous. Peak height and peak area were recorded in this work (data are not presented). The ratio of peak area-to-height for $\mathrm{Pb}(\mathrm{II})$-SRFA was relatively constant across the range of the deposition potentials used in our experiments as was reported in our recent publication [28]. However, in this work, peak heights were used in all calculations because they were more sensitive and more reproducible than the peak area.

\subsubsection{Effect of varying concentrations of SRFA on $\mathrm{Pb}$ (II) complexation}

The Differential Equilibrium Functions of $\mathrm{Pb}$ (II) were used for the interpretation of $\mathrm{Pb}$ complexation with SRFA in model solutions. This approach considers the binding intensity $\left(\log \mathrm{K}^{*}\right)$ as a function of metal ion loading $\theta(\theta=$ bound metal/binding site concentration). Typical pseudo-polarograms for the three test solutions of $\mathrm{Pb}(\mathrm{II})$ are presented in Fig. 6.1. The top curve is for a solution of $\mathrm{Pb}^{2+}$ buffered with $\mathrm{HOAc} / \mathrm{NaOAc}$, and is the pseudopolarogram for the $\mathrm{Pb}(\mathrm{II})$-aqua complex. It is a well defined curve with a plateau, indicating a fully reversible electrode process. 


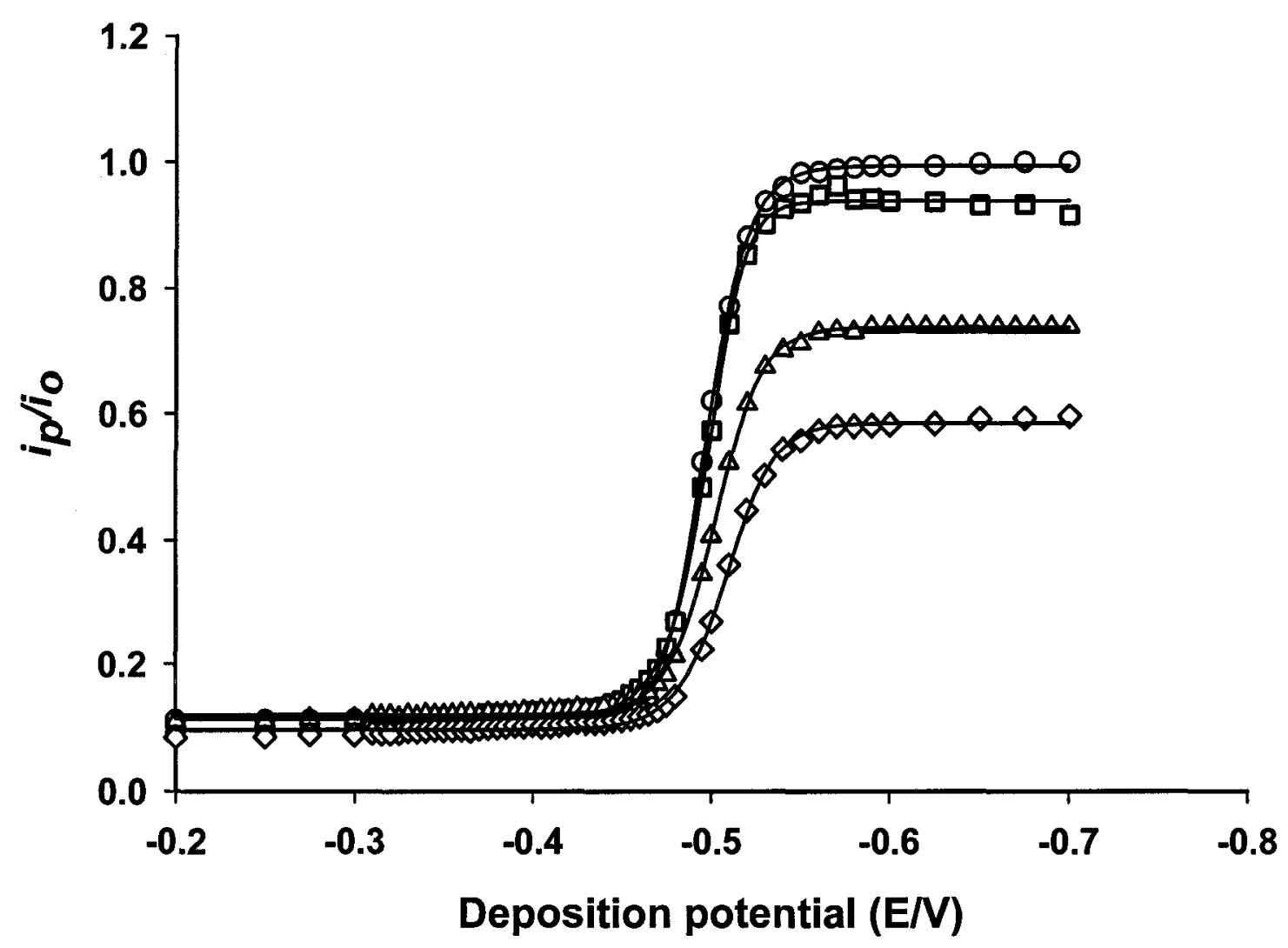

Figure 6.1. Typical pseudo-polarograms for $\mathrm{Pb}(\mathrm{II})-\mathrm{FA}$ complexes in model solutions of Fulvic acid. $c_{\mathrm{Pb}}=5.0 \times 10^{-7} \mathrm{~mol} \mathrm{~L}^{-1} ;(\mathrm{O}), \mathrm{Pb}(\mathrm{II})+$ nil FA; ( $\left.\square\right)$, $\mathrm{Pb}(\mathrm{II})+C_{\mathrm{FA}}\left(5 \times 10^{-5} \mathrm{~mol} \mathrm{~L}^{-1}\right),(\Delta), \mathrm{Pb}(\mathrm{II})+C_{\mathrm{FA}}\left(5 \times 10^{-4} \mathrm{~mol} \mathrm{~L}^{-1}\right)$, $(\diamond), \mathrm{Pb}(\mathrm{II})+C_{\mathrm{FA}}\left(1 \times 10^{-3} \mathrm{~mol} \mathrm{~L}^{-1}\right) ; \mathrm{HOAc} / \mathrm{NaOAc}$ buffer, $\mathrm{pH} 5.0 \pm 1.0$, ionic strength $=0.01 \mathrm{~mol} \mathrm{~L}^{-1}$, temperature $=23 \pm 2{ }^{\circ} \mathrm{C}$. 
The lower curves were for the same concentration of $\mathrm{Pb}(\mathrm{II})$, which had been equilibrated for $72 \mathrm{~h}$ in three model solutions of SRFA, containing different concentrations of SRFA. A decrease in the limiting current of the Pb(II)-SRFA complexes was observed relative to that for the $\mathrm{Pb}(\mathrm{II})$-aqua complex.

These experimental observations can be rationalized as follows. The pseudopolarograms of the $\mathrm{Pb}(\mathrm{II})$-SRFA systems present limiting current that are generated by reduction of $\mathrm{Pb}^{2+}$ ions (assuming at reduction potential $\mathrm{Pb}(\mathrm{II})-\mathrm{SRFA}$ is not directly reduced at the electrode). The observed decrease in the limiting current of the $\mathrm{Pb}(\mathrm{II})$ SRFA system relative to that of the $\mathrm{Pb}(\mathrm{II})$-aqua complex was probably due to the change in the diffusion coefficient of $\mathrm{Pb}$ (II)-SRFA complexes. The average diffusion coefficient $\left(\mathrm{D}_{\mathrm{ML}}\right)$ for $\mathrm{Pb}(\mathrm{II})-\mathrm{SRFA}$ complexes was found to be much lower than the diffusion coefficient of free $\mathrm{Pb}^{2+}$ ion $\left(\mathrm{D}_{\mathrm{M}}\right)$ in aqueous medium. The average diffusion coefficient $\left(\mathrm{D}_{\mathrm{ML}}\right)$ of all $\mathrm{Pb}$ (II)-SRFA complexes decreased as the Pb-to-SRFA mole ratio decreased (Table 6.1) and this decreased diffusion coefficient of $\mathrm{Pb}$ (II)-SRFA complexes was responsible for the lowering of limiting currents.

The polarographic waves are asymmetrical, and hence, shifts in the half-wave potential cannot be directly related to differences in stability constants as in the case of simple (homogenous) labile complexes. For heterogeneous complexants (e.g. SRFA), the site occupation by the metals at the electrode surface depends on the applied potential. Thus, the spreading of the polarographic wave is caused by a change in the metal/ligand mole ratio in the diffusion layer, and is specific for heterogeneous complexants. 
The breadth and flatness of the polarographic wave increased in the presence of heterogeneous complexants because stronger sites became free, and therefore, active in controlling the free metal ion concentration as the total metal concentration was depleted at the electrode surface. As a result, the metal complexes available at the electrode surface were thermodynamically more stable than those in the bulk solution. With increasing depletion of the metal at the electrode surface, this effect became progressively more pronounced, resulting in more flattening and elongation of the polarographic wave along the ordinate axis.

Complexation parameters calculated from the experimental pseudopolarographic waves obatained from the model solutions (containing different $\mathrm{C}_{\mathrm{Pb}} / \mathrm{C}_{\mathrm{SRFA}}$ mole ratios) systems are summarized in Table 6.1 .

Table 6.1 shows that the change in the mole ratio of $c_{\mathrm{Pb}, \mathrm{T}} / c_{\mathrm{SRFA}}$ did not appreciably affect the average heterogeneity of the system; $\Gamma$ remain almost unchanged. It is well known that in the presence of a sufficient excess of complexing ligand, the $\Gamma$ values are independent of the metal: ligand mole ratio. It must be noted that $\Gamma$ is a constant parameter that defines the Freundlich isotherm, and it should be independent of factors such as the metal-to-ligand ratio. However, different experimental conditions may look at different parts of the same distribution which may be more or less sensitive to $\Gamma$.

As expected, the stability of $\mathrm{Pb}(\mathrm{II})$ complexation by SRFA $\left(\mathrm{K}^{*}\right)$ depends on the metal loading, with stronger binding sites utilized at lower loadings. $\mathrm{K}^{*}$ increases with the increase of SRFA concentration (Table 6.1). There is a large decrease in $i / l_{\lim }$ because stronger sites form stronger $\mathrm{Pb}$ (II)-SRFA complexes. Thus, much fewer free $\mathrm{Pb}^{2+}$ 
ions were regenerated, resulting in a greatly decreased concentration of free $\mathrm{Pb}^{2+}$ ions at the electrode surface. As D is the weighted average diffusion coefficient, a decrease in its value down the last column of Table 6.1 reflects the same trend as seen in $i / i_{\mathrm{lim}}$. 
Table 6.1. Effect of increasing concentration of SRFA on the Differential Equilibrium Functions, mean diffusion coefficients and lability $\left(i / i_{\mathrm{lim}}\right)$ of $\mathrm{Pb}$ (II)-FA complexes in model solutions of Suwanee River Fulvic Acid. $c_{\mathrm{Pb}}=5.0 \times 10^{-7} \mathrm{~mol} \mathrm{~L}^{-1}$. HOAc/NaOAc buffer, $\mathrm{pH} 5.0 \pm 1.0$, ionic strength $=0.01 \mathrm{~mol} \mathrm{~L}^{-1}$, temperature $=23 \pm 2{ }^{\circ} \mathrm{C}$.

\begin{tabular}{ccccc}
\hline$C_{\mathrm{FA}}$ & $\Gamma$ & $\log \bar{K}\left[\mathrm{~L} \mathrm{~mol}{ }^{-1}\right]$ & $i / i_{\mathrm{lim}}$ & $\overline{\mathbf{D}}_{\mathrm{ML}}\left[\mathrm{m}^{2} \mathrm{~s}^{-1}\right]$ \\
\hline 0 & 0.99 & -- & 1 & $8.28 \times 10^{-10}$ \\
$5.0 \times 10^{-5}$ & 0.69 & 6.16 & 0.93 & $7.13 \times 10^{-10}$ \\
$5.0 \times 10^{-4}$ & 0.70 & 6.72 & 0.69 & $3.94 \times 10^{-10}$ \\
$1.0 \times 10^{-3}$ & 0.64 & 6.93 & 0.54 & $2.41 \times 10^{-10}$ \\
\hline
\end{tabular}


The average diffusion coefficient $\mathrm{D}_{\mathrm{ML}}$, of $\mathrm{Pb}$ (II)-SRFA complexes is determined only by the properties of the complexant. Molar volume and hence diffusion coefficients are influenced by a number of factors, including polarity, conformation, molecular weight; for heterogeneous complexation, structure, shape, hydration and aggregation should be also considered. Generally, for a dilute aqueous solution at a given temperature, diffusion coefficient of an organic molecule is proportional to its hydrated molar volume. The $\mathrm{D}_{\mathrm{ML}}$ at lower $[\mathrm{M}] /[\mathrm{SRFA}]$ ratio was significantly smaller than its value in higher ratio. This meant that for the same amount of $\mathrm{Pb}(\mathrm{II})$, an increase in [SRFA] by one order of magnitude produced a significant decrease in the mobility of $\mathrm{Pb}(\mathrm{II})$-SRFA molecule.

The lower concentration of free $\mathrm{Pb}^{2+}$ ions results in a smaller $i_{\text {lim }}$ value and a decrease in the weighted average diffusion coefficient.

A plot of the $\log \theta$ versus $\log \mathrm{K}^{*}$ (differential equilibrium parameter) gave a straight line as shown in Fig. 6.2. The correlation coefficient for $\mathrm{Pb}(\mathrm{II})-\mathrm{SRFA}$ system is $R^{2}$ $=0.99$. Since the strongest sites of the heterogeneous ligands are occupied first when they bind the metal, as the degree of occupation of all site types increases, the averaging of the apparent equilibrium between $\mathrm{M}$ and the complexing sites on $\mathrm{L}$ is carried out with an increasing number of weaker sites; hence, $\mathrm{K}^{*}$ decreases. 


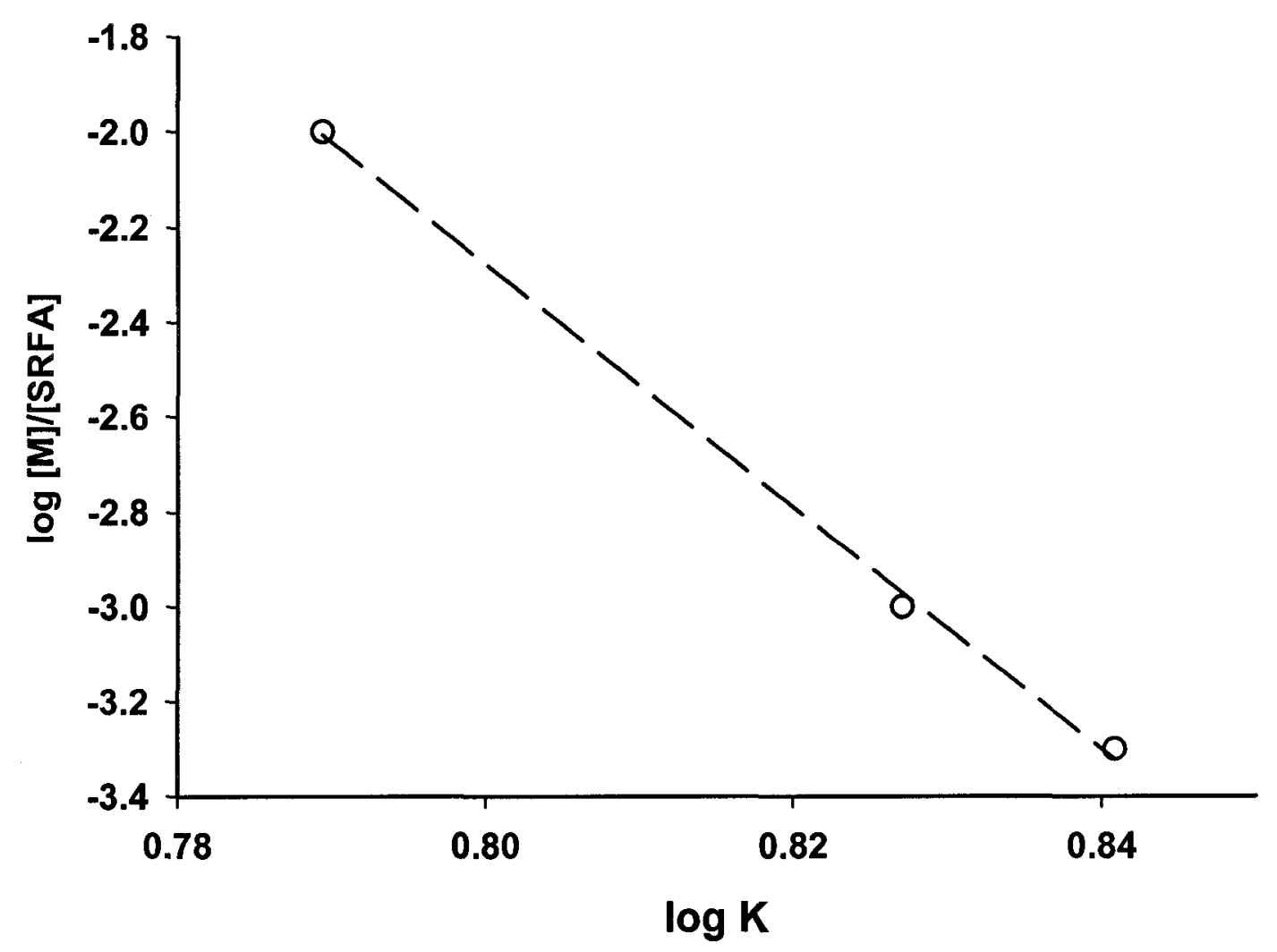

Figure 6.2. Differential equilibrium function of $\mathrm{Pb}(\mathrm{II})-\mathrm{SRFA}$ complexes in model solutions of SRFA. $c \mathrm{~Pb}, \mathrm{~T}=5.0 \times 10^{-7} \mathrm{~mol} \mathrm{~L}^{-1}$. HOAc/NaOAc buffer, $\mathrm{pH}$ $5.0 \pm 0.1$, ionic strength $=0.01 \mathrm{~mol} \mathrm{~L}^{-1}$, temperature $=23 \pm 2 \circ \mathrm{C}$. Correlation coefficient for $\mathrm{Pb}(\mathrm{II})-\mathrm{SRFA}$ system $R^{2}=0.99$. 


\subsubsection{Effect of $\mathrm{Cu}(\mathrm{II}), \mathrm{Cd}(\mathrm{II})$, and $\mathrm{Zn}$ (II) on $\mathrm{Pb}$ (II)-SRFA Complexation}

The DEFs of the $\mathrm{Pb}(\mathrm{II})-\mathrm{SRFA}$ complexes $\left(\mathrm{C}_{\mathrm{Pb}, \mathrm{T}}=5.0 \times 10^{-7} \mathrm{~mol} \mathrm{~L}^{-1}\right.$ and $\mathrm{C}_{\mathrm{SRFA}}=1.0 \times 10^{-3} \mathrm{~mol} \mathrm{~L}^{-1}$ ) were investigated at constant $\mathrm{pH}$ and fixed ionic strength in the presence of $\mathrm{Cu}(\mathrm{II}), \mathrm{Cd}(\mathrm{II})$, or $\mathrm{Zn}(\mathrm{II})$. Each metal was taken individually, one at a time. Figure 6.3 shows the pseudo-polarographic waves for the effect of the above mentioned metals on the $\mathrm{Pb}(\mathrm{II})-\mathrm{SRFA}$ complexes at $\mathrm{pH} 5.0$ (fixed with $\mathrm{HOAc} / \mathrm{NaOAc}$ buffer), and at ionic strength $0.01 \mathrm{~mol} \mathrm{~L}^{-1}$. One concentration of the competing trace metals was used which was the same as of $\mathrm{Pb}\left(1.0 \times 10^{-7} \mathrm{~mol} \mathrm{~L}^{-1}\right)$. At the fixed mole ratio of $c_{\mathrm{Pb}, \mathrm{T}} / c_{S R F A}=0.0005$, trace metal $\mathrm{Cu}(\mathrm{II})$ resulted in higher $i_{\text {lim }}$ values and shifted the half-wave potential towards a more positive direction, indicating an increase in the mean diffusion coefficient of $\mathrm{Pb}(\mathrm{II})-\mathrm{SRFA}$ complexes, and a decrease in the stability of the $\mathrm{Pb}(\mathrm{II})-\mathrm{SRFA}$ complexes (lower $\mathrm{K}^{*}$ ). This result suggests that trace metal $\mathrm{Cu}(\mathrm{II})$ competes with $\mathrm{Pb}$ (II) for SRFA binding sites.

The $\log \mathrm{K}^{*}$ values of the $\mathrm{Pb}(\mathrm{II})-\mathrm{SRFA}$ complexes decreased from 6.9 to 6.3 (Table 6.2) in the presence of increasing concentrations of $\mathrm{Cu}(\mathrm{II})$ from 0 to $1.0 \times 10^{-7} \mathrm{~mol}$ $\mathrm{L}^{-1}$. The results can be rationalized by hypothesizing progressive displacement of $\mathrm{Pb}(\mathrm{II})$ by $\mathrm{Cu}(\mathrm{II})$ from the binding sites of SRFA, resulting in the formation of more free $\mathrm{Pb}^{2+}$ ions, which enhanced the limiting currents, $i_{\text {lim }}$ and mean diffusion coefficient of $\mathrm{Pb}$ (II)-SRFA complexes (Table 6.2). If this hypothesis is true, then $\mathrm{Cu}(\mathrm{II})$ and $\mathrm{Pb}(\mathrm{II})$ compete for the same binding sites on the SRFA. 


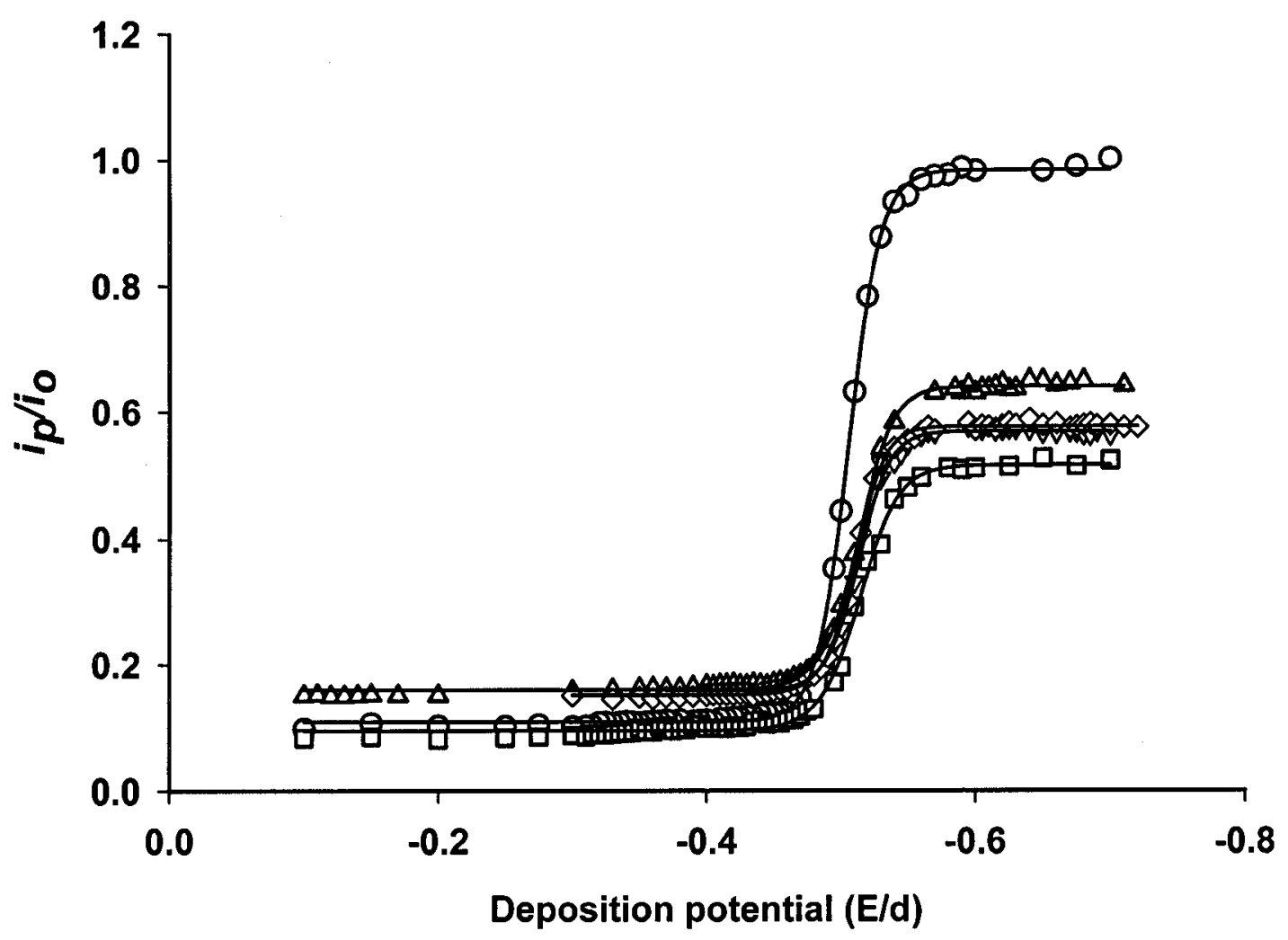

Figure 6. 3. Competition effect of trace metals on the pseudo-polarographic waves of $\mathrm{Pb}(\mathrm{II})-\mathrm{SRF} A$ complexes in model solutions of SRFA, using DPASV at a SMDE. $\quad c_{\mathrm{Pb}, \mathrm{T}}=5.0 \times 10^{-7} \mathrm{~mol} \mathrm{~L} \mathrm{~L}^{-1}, c \mathrm{HA}=1.0 \times 10^{-3} \mathrm{~mol} \mathrm{~L} \mathrm{~L}^{-1}$. $\mathrm{HOAc} / \mathrm{NaOAc}$ buffer, $\mathrm{pH} 5.0 \pm 0.1$, ionic strength $=0.01 \mathrm{~mol} \mathrm{~L}^{-1}$, temperature $=25 \pm 2{ }^{\circ} \mathrm{C}$. Concentration of $\mathrm{Pb}(\mathrm{II})$ is the same for all curves. (o) $\mathrm{Pb}$ (II)+nil SRFA, ( $\square$ ) $\mathrm{Pb}(\mathrm{II})-\mathrm{SRFA},(\Delta) \mathrm{Pb}$ (II)-SRFA+Cu(II) $\left(5.0 \times 10^{-7} \mathrm{~mol} \mathrm{~L}^{-1}\right),(\nabla) \mathrm{Pb}(\mathrm{II})-\mathrm{SRFA}+\mathrm{Zn}(\mathrm{II})\left(5.0 \times 10^{-7} \mathrm{~mol} \mathrm{~L}^{-1}\right)$, $(\diamond) \mathrm{Pb}(\mathrm{II})-\mathrm{SRFA}+\mathrm{Cd}(\mathrm{II})\left(5.0 \times 10^{-7} \mathrm{~mol} \mathrm{~L}^{-1}\right)$ 
Table 6.2. Differential equilibrium functions, mean diffusion coefficients, and normalized peak current $\left(i / i_{\text {lim }}\right)$ of $\mathrm{Pb}(\mathrm{II})-\mathrm{SRFA}$ complexes in model solutions of SRFA in the presence of various competing metals $\mathrm{Cu}(\mathrm{II})$, $\mathrm{Zn}(\mathrm{II})$, and $\mathrm{Cd}(\mathrm{II})$ The properties of the solutions were $c_{\mathrm{Pb}, \mathrm{T}}=5.0 \times 10^{-7} \mathrm{~mol}$ $\mathrm{L}^{-1}, c_{\mathrm{SRFA}}=1.0 \times 10^{-7} \mathrm{~mol} \mathrm{~L}^{-1}, \mathrm{CM}_{(\mathrm{II})}=5.0 \times 10^{-7} \mathrm{~mol} \mathrm{~L}^{-1}, \mathrm{HOAc} / \mathrm{NaOAc}$ buffer, $\mathrm{pH} 5.0 \pm 1.0$, ionic strength $=0.01 \mathrm{~mol} \mathrm{~L}-1$, temperature $=23 \pm 2{ }^{\circ} \mathrm{C}$

\begin{tabular}{ccccc}
\hline $\begin{array}{c}\text { Competing } \\
\text { metal, M(II) }\end{array}$ & $\Gamma$ & $\begin{array}{c}\text { logK } \\
\left(\mathbf{L ~ m o l}^{*}\right)\end{array}$ & $\mathbf{i} / \mathbf{i}_{\text {lim }}$ & $\begin{array}{c}\bar{D}_{\mathrm{ML}} \\
\left(\mathbf{m}^{2} \mathbf{s}^{-1}\right)\end{array}$ \\
\hline None & 0.68 & 6.9 & 0.49 & $1.95 \times 10^{-10}$ \\
$\mathbf{C u}(\mathrm{II})$ & 0.69 & 6.3 & 0.56 & $2.60 \times 10^{-10}$ \\
$\mathrm{Zn}(\mathrm{II})$ & 0.66 & 6.4 & 0.48 & $1.90 \times 10^{-10}$ \\
$\mathbf{C d}(\mathrm{II})$ & 0.69 & 6.5 & 0.49 & $1.97 \times 10^{-10}$ \\
\hline
\end{tabular}


This effect was not observed when similar concentrations of $\mathrm{Zn}$ (II) or $\mathrm{Cd}(\mathrm{II})$ were added to a fixed concentration of $\mathrm{Pb}(\mathrm{II})\left(1.0 \times 10^{-7} \mathrm{~mol} \mathrm{~L}^{-1}\right)$ as shown in Table 6.2. At a fixed mole ratio of ${ }_{c \mathrm{~Pb}, \mathrm{~T}} / c_{\mathrm{SRFA}}=0.0005$, addition of equimolar concentration of $\mathrm{Cd}(\mathrm{II})$ or $\mathrm{Zn}(\mathrm{II})$ did not change $i_{\text {lim }}$, contrary to what has been observed for $\mathrm{Cu}(\mathrm{II})$ (Table 6. 2).

The results suggest that $\mathrm{Cd}(\mathrm{II})$ and $\mathrm{Zn}(\mathrm{II})$ did not compete with $\mathrm{Pb}$ (II) for the strong SRFA binding sites under the experimental conditions used in this study. However, the $\log \mathrm{K}^{*}$ values of the $\mathrm{Pb}(\mathrm{II})$-SRFA complexes decreased from 6.9 to 6.5 and to 6.4 (Table 6.2) in the presence of increasing concentrations of $\mathrm{Cd}(\mathrm{II})$ and $\mathrm{Zn}(\mathrm{II})$, respectively, from 0 to $1.0 \times 10^{-7} \mathrm{~mol} \mathrm{~L}^{-1}$. These contradictory results are probably due to progressive displacement of $\mathrm{Pb}$ (II) either by $\mathrm{Cd}(\mathrm{II})$ or $\mathrm{Zn}$ (II) from the weaker binding sites of SRFA, resulting in the formation of free $\mathrm{Pb}^{2+}$ ions. However, weak $\mathrm{Pb}(\mathrm{II})$-SRFA complexes dissociate and generate $\mathrm{Pb}^{2+}$ ions on the electrode surface and contribute to the total current measured at different electrode potentials during the experiment. As a result, the limiting currents, $i_{\text {lim }}$ remain unchanged even in the presence of $\mathrm{Cd}(\mathrm{II})$ and $\mathrm{Zn}(\mathrm{II})$. The unaffected mean diffusion coefficient of $\mathrm{Pb}(\mathrm{II})$ SRFA in presence of $\mathrm{Cd}(\mathrm{II})$ and $\mathrm{Zn}$ (II) also support the above explanation.

$$
K^{*}=\frac{\sum_{i=1}^{n} K_{i} \theta_{i}\left(1-\theta_{i}\right) \Delta X_{i}}{\sum_{i=1}^{n} \theta_{i}\left(1-\theta_{i}\right) \Delta X_{i}}
$$

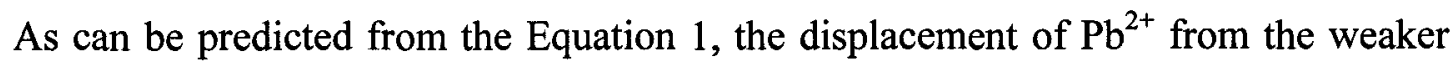
site of SRFA, either by $\mathrm{Cd}(\mathrm{II})$ or $\mathrm{Zn}(\mathrm{II})$ would decrease the total concentration of $\mathrm{Pb}(\mathrm{II})-\mathrm{SRFA}$ weaker complexes. Hence, the average equilibrium function $\left(\log \mathrm{K}^{*}\right)$, and so the DEF would decrease. 
Table 2 shows that the increasing order of effects of trace metal competition on the $K^{*}$ values, of the $\mathrm{Pb}(\mathrm{II})-$ SRFA complexes are: $\mathrm{Cu}$ (II) $>\mathrm{Zn}(\mathrm{II})>\mathrm{Cd}(\mathrm{II})$.

The average $\Gamma$ values of $\mathrm{Pb}(\mathrm{II})-\mathrm{SRFA}$ complexes in the presence of competing metals was $\sim 0.7$, which is typical of heterogeneous systems. This result suggests that average heterogeneity of $\mathrm{Pb}(\mathrm{II})-\mathrm{SRFA}$ complexes was constant in the presence of competing metals. Similar observation was reported by R. M Town and H. P. van Leeuwen for $\mathrm{Cu}$. They measured a significant displacement of $\mathrm{Cu}$ by $\mathrm{Pb}$ from $\mathrm{Cu}(\mathrm{II})-\mathrm{HS}$ complexes but no change in the $\Gamma$ value for $\mathrm{Cu}[38]$.

These results are expected for humic substances. Since the ligand (SRFA) is heterogeneous, the competing metal affects a range of sites (to different extents depending on it $\Gamma$ ), but does not specifically' block' a group of sites - so the conditional binding by metal appears slightly weaker, but its $\Gamma$ is not measurably affected.

These experimental findings on heterogeneity of SRFA and effects of trace metals competitions on $\mathrm{Pb}(\mathrm{II})-\mathrm{SRFA}$ complexation can be further supported by the data presented in Chapter 5. Data prresnted in previous chapter showed [28] that at different metals to SRFA mole ratios (i.e. $\mathrm{C}_{\mathrm{M}} / \mathrm{C}_{\mathrm{SRFA}}=0.01,0.001$ and 0.0005 ), the value of $\Gamma$ remained about the same for a given metal: the value of $\Gamma$ for $\mathrm{Cu}$ (II) was found to be $\sim 0.50$ in all solutions, suggesting that SRFA behaved as a heterogeneous complexant for $\mathrm{Cu}(\mathrm{II})$. The value of $\Gamma$ for $\mathrm{Pb}(\mathrm{II})$ was found to be $\sim 0.70$ in the three model solutions, suggesting that compared to $\mathrm{Cu}(\mathrm{II})$, for $\mathrm{Pb}(\mathrm{II}) \mathrm{SRFA}$ behaved as a less heterogeneous complexant. $\Gamma$ value obtained for $\mathrm{Cd}(\mathrm{II})$ was found to be $\sim 0.94$, suggesting that SRFA behaved almost as a homogeneous complexant for $\mathrm{Cd}(\mathrm{II})$; 
whereas, the $\Gamma$ value for $\mathrm{Zn}$ was found to be $\sim 0.86$, i.e. lower than the value obtained for Cd(II), suggesting that SRFA was slightly more heterogeneous for $\mathrm{Zn}(\mathrm{II})$ than for $\mathrm{Cd}(\mathrm{II})$.

A comparison of the heterogeneity parameters for $\mathrm{Zn}(\mathrm{II}), \mathrm{Cd}(\mathrm{II}), \mathrm{Pb}(\mathrm{II})$ and $\mathrm{Cu}(\mathrm{II})$ complexes in the model solutions of SRFA showed that $\Gamma_{\mathrm{Cd}}>\Gamma_{\mathrm{Zn}}>\Gamma_{\mathrm{Pb}}>\Gamma_{\mathrm{Cu}}$, suggesting that SRFA behaved as a relatively more homogeneous complexant for $\mathrm{Zn}(\mathrm{II})$ and $\mathrm{Cd}(\mathrm{II})$, whereas it behaved as a relatively more heterogeneous complexant for $\mathrm{Pb}(\mathrm{II})$. A similar experimental finding was reported [38] by $\mathrm{R} \mathrm{M}$ Town and $\mathrm{H} \mathrm{P}$ vanLeeuwen. The extent of heterogeneity of metal binding by several humic substances followed the order $\mathrm{Cu}(\mathrm{II})>>\mathrm{Pb}$ (II) $>\mathrm{Cd}$ (II). Experimental findings of Giberto et al [23] also support the above order of heterogeneity of SRFA for $\mathrm{Pb}$ (II) and $\mathrm{Cd}(\mathrm{II})$. Gilberto et al reported that the binding of $\mathrm{Pb}(\mathrm{II})$ to different $\mathrm{HA}$ was found to be stronger than for $\mathrm{Cd}(\mathrm{II})$, with a greater heterogeneity of binding sites so that the buffering action of different $\mathrm{HA}$ on the concentration of free $\mathrm{Pb}(\mathrm{II})$ is more effective than for $\mathrm{Cd}(\mathrm{II}) . \Gamma$ value of $\mathrm{Pb}(\mathrm{II})$ was reported to be $\sim 0.7$ and for $\mathrm{Cd}$ it was $\sim 0.9$.Ephraim et al.[24] reported that $\Gamma$ value for $\mathrm{Zn}$ (II) was found to be $\sim 0.9$. The high value of $\Gamma$ suggested that the humic substance had a narrow distribution of binding sites for $\mathrm{Zn}$.

It was also reported [28] that the order of stability of M-SRFA complex is typically $\mathrm{K}_{\mathrm{Cu}}{ }^{*}>\mathrm{K}_{\mathrm{Pb}} *>\mathrm{K}_{\mathrm{Zn}} *>\mathrm{K}_{\mathrm{Cd}} *$

Similar experimental finding was reported by Bizri et al. [27]. It was reported that the stability of the humate complexes followed the order $\mathrm{Cu}>\mathrm{Pb}>\mathrm{Cd}$. An increase in 
stability constant was observed with increase in $\mathrm{pH}$ and also with decrease in total metal ion concentration (at constant $\mathrm{pH}$ ).

It is well known that the extent of competition of different metals for binding with humic substances depends on the relative concentrations of the metals (and ligands) and on their conditional stability constants of $\mathrm{M}(\mathrm{II})$-Humate complex under the given conditions. In addition to these factors, $\Gamma$ (heterogeneity parameter) also has relevant significance in metal competition, since it determines an effective range of sites of humic substances at which binding occurs.

Considering the above points and literature data, it can be assumed that $\mathrm{Cd}$ (II) and $\mathrm{Zn}$ (II) should compete poorly with $\mathrm{Pb}(\mathrm{II})$ for the same binding sites in SRFA, whereas, $\mathrm{Cu}$ (II) should compete with $\mathrm{Pb}$ (II) and displace $\mathrm{Pb}$ (II) from $\mathrm{Pb}$ (II)-SRFA complexes because of low $\Gamma_{\mathrm{Cu}}$ (SRFA heterogeneous) value and relatively high $\log \mathrm{K}_{\mathrm{Cu}}{ }^{*}$ value (i.e. $\mathrm{Cu}(\mathrm{II})$ forms relatively strong complexes with SRFA than $\mathrm{Pb}(\mathrm{II})$ ). The competition by trace metals ( $\mathrm{Cu}(\mathrm{II}), \mathrm{Zn}$ (II) and $\mathrm{Cd}(\mathrm{II})$ ) with $\mathrm{Pb}(\mathrm{II})$ in model solutions of SRFA showed similar findings, which showed that $\mathrm{Cu}(\mathrm{II})$ competed with $\mathrm{Pb}$ (II) for the strong binding sites of SRFA when present at the same concentrations as that of $\mathrm{Pb}(\mathrm{II}) . \mathrm{Cd}(\mathrm{II})$ and $\mathrm{Zn}(\mathrm{II})$ ( having relatively higher $\Gamma$ values and relatively smaller $\log \mathrm{K}^{*}$ values than $\mathrm{Pb}(\mathrm{II})-\mathrm{SRFA}$ complexes) did not compete with $\mathrm{Pb}$ (II) for the strong binding sites of SRFA. However, they competed for the weaker binding sites of SRFA, resulting in a decrease of $\log \mathrm{K}^{*}$ value of $\mathrm{Pb}(\mathrm{II})-\mathrm{SRFA}$ complex, with a very little change in its limiting current. However, it is noteworthy to mention that Differential Pulse-Anodic Stripping Voltammetry wave sometime suffers from limitation on baseline shift. In this study, a higher baseline at the more positive 
potentials was observed in the presence of the competing metals under the experimental condition.

In summary, it can be concluded that the apparent stability and lability of $\mathrm{Pb}$ (II)-HS complexes depend on the $\mathrm{Pb}(\mathrm{II})$ loading and the competition of trace metal ions with the target metal for complexation with a heterogeneous complexant, e.g. SRFA. The relative stability $\left(\log \mathrm{K}^{*}\right)$ of $\mathrm{M}(\mathrm{II})$-HS complexes and the heterogeneity $(\Gamma)$ of the humic substance plays a crucial role in $\mathrm{Pb}$ (II)-DOC interactions in natural waters.

This study has shown that trace metal $\mathrm{Cu}$ (II) compete with trace $\mathrm{Pb}$ (II) for binding by SRFA in model solutions even when the competing trace metals are in the same concentrations as $\mathrm{Pb}(\mathrm{II})$. The environmental significance of this research for fresh water is that even at relatively low $\mathrm{Pb}$ (II) loadings, the metals associated with lead in minerals, e.g. copper, may successfully compete with $\mathrm{Pb}(\mathrm{II})$ for the same binding sites of the naturally occurring organic complexants (HS), with the result that some of the $\mathrm{Pb}$ (II) may exist as free $\mathrm{Pb}^{2+}$ ions, which has been reported to be one of the toxic forms of $\mathrm{Pb}$ in the aquatic environment [31]. 


\subsection{References}

1. Buffle J., Complexation Reaction in Aquatic Systems, An Analytical Approach, Ellis Horwood, Chichester, 1988.

2. Metal speciation and Bioavailability in Aquatic systems (Eds: A Tessier, D. R. Turner), IUPAC Series on Analytical and Physical Chemistry of Environmental systems, Vol 3, (Series Eds: J. Buffle, H. P. van Leeuwen), Wiley, Chichester, 1995.

3. Buffle J., Filella M., (1995) Anal Chim Acta, 313, 144-150.

4. Nriagu J. O., (1996), , Science, 272, 223-224.

5. Nriagu J.O., (1979), Nature, 279, 409-411.

6. Shotyk W., Le Roux G., Biogeochemistry and Cycling of Lead. In: A. Sigel, H. Sigel and R.K.O. Sigel, Editors, Bigeochemical Cycles of the elements Vol. 43, M. Dekker (2005).

7. Schaule B K, Paterson C C. (1981); Earth Planet Sci. Lett., 54: 97-116.

8. Waller P A , Pickering W F., (1993);Chem Spec. Bioavail., 18: 269-297.

9. Smith W H, Siccama T G., (1981); J. Environ. Qual, 10:323-332.

10. Bothelo C M S, Boaventura R A R, Goncalves M L S S, (1994), Sci. Tot. Environ. 149: 69-81

11. Filella M., Buffle J., van Leeuwen H. P., (1990), Anal. Chim. Acta, 232, 209.

12. Town R M, Fiella M., (2002), Sci. Tot. Environ, 300, 143-154

13. Gamble D S (1970) Can J Chem 48:2662-2669

14. Altmann R S, Buffle J (1988) Geochim Cosmochim Acta 52: 1505-1519 
15. Buffle J, Filella M (1995) Anal Chim Acta 313:144-150

16. Buffle J, Altmann RS, Filella M, Tessier A (1990) Geochim Cosmochim Acta $54: 1535-1553$

17. Pinheiro J P, Mota A M, Simoes-Gonçalves M L (1994) Anal Chim Acta $284: 525-537$

18. Filella M, Town R M (2000) J Electroanal Chem 485:21-33

19. Pinheiro J P, Mota A M, Gonçalves MLS, van der Weijde M, van Leeuwen H P (1996) J Electroanal Chem 410:61-68.

20. Filella M, Town R M (2000) J Electroanal Chem 485:21-33

21. Town R M, Filella M (2000) J Electroanal Chem 488:1-16

22. Botelho C M S, Boaventura R A R, Gonçalves M L S S (1994) Sci Total Environ 149:69-81

23. Abate G, Masini J C, (2002), Organic Geochemistry, 33(10), 1171-1182.

24. Ephraim J H, (1992), Anal Chim Acta, 267, 39-45

25. Town R M, vanLeeuwen H P, (2004), Australian Journal of Chemistry, $57,(10), 983-992$.

26. Xue H., Kistler D, Sigg L., (1995) Limnology and Oceanography, $40(6), 1142-1152$

27. Bizri H., 1st International Conference on Bioinorganic Chemistry-Session S, pp 236.

28. Chakraborty P, Fasfous I I, Murimboh J D, Chakrabarti C. L, (2007), Anal. Bioanal. Chem.388: 463-474.

29. Ritchie J D, Perdue (2003) Geochim Cosmochim Acta 67:85 
30. Town R M, Filella M (2000) J Electroanal Chem 488:1-16

31. Town R M., van Leeuwen H P, (2004), Aus. J. Chem., 57, 983-992. 


\section{Conclusions}




\subsection{Overall Conclusion}

Complexation of trace metals by humic substances is an important subject because it determines to a large extent their bioavailability, toxicity and mobility. In a complexing medium the supply of metal species towards an interface is determined by the combined flux of diffusion of $\mathrm{M}$ and $\mathrm{ML}$ to the consuming interface. For the metals that form amalgams with mercury (e.g. $\mathrm{Zn}, \mathrm{Cd}, \mathrm{Pb}$ and $\mathrm{Cu}$ ), voltammetry with a mercury electrode is a particularly useful technique for investigating metal bioavailability because the flux of reactive species towards an electrode surface are inherently similar to the reactions at a biological interface. The Competing Ligand Exchange Methods shows that the results obtained by Graphite Furnace Atomic Absorption Spectrometry (GFAAS) using Chelex 100 as the competing ligand are not able to measure sufficiently rapid kinetics to make their results directly relevant to bioavailability in the same way as voltammetry. The measurement timescale effectively define the measurement window, and hence, define the measurable chemical species.

The distribution of dissociation rate coefficients of M-DOC complexes determined by kinetic speciation provides qualitative information on chemical heterogeneity of humic substances. The heterogeneity of metal-NOM complexes extends to the distribution of kinetic dissociation rate constants. However, the inherent physicochemical complexity of humic substances makes it extremely difficult to determine sound physicochemical properties to describe metal complexation by humic substances. An important fact to be taken into account, and often neglected, is that the complexation of metals (i.e. complex stability and lability) of heterogeneous 
ligands (humic substances) is critically dependent on the metal loading, i.e. the [metal]/[HS] mole ratio, which becomes extremely important in pristine waters, where the extremely low [metal]/[HS] mole ratio produces very stable metal-HS complexes which are non-labile, and hence, do not produce free metal ions, that are widely reported to be bioavailable and toxic.

The heterogeneity of metal-NOM complexes which extends to the distribution of kinetic dissociation rate constants is reflected experimentally in their apparent lability under given conditions. The more stable complexes (those formed at low metal loadings) are expected to be the less labile. This, together with the time scale of the analytical technique employed, must be considered in the interpretation of metal ion binding data.

The Differential Kinetic and Differential Equilibrium Functions presented in this thesis assume that there is no upper or lower limit of $\log \mathrm{k}_{\mathrm{d}}$ or $\log \mathrm{K}$ for the binding sites of a complexant. However, real complexants (even extremely heterogeneous ones) are limited by a maximum $\log \mathrm{K}$ and $\log \mathrm{k}_{\mathrm{d}}$ value [1].

The cooperative action of the binding sites of naturally-occurring complexants means that there is always a suite of binding sites that actively complexes the metal, some beginning to be occupied, some near their half titration point, and some sites close to saturation. As a consequence, naturally-occurring complexants have closely spaced binding energies which enable them to buffer metals over a large concentration range (several orders of magnitude) with only a gradual increase in free metal ion concentration, resulting in chemostatics. 
The same complexant may have different heterogeneity for different metal ions because different complexing sites might be available to each metal ion, and stabilities of the strongest and weakest sites titrated with the same metal may vary from metal to metal.

The apparent stability and lability of any target metal-HS complexes was found to be dependent on the metal loading and heterogeneity of the humic substances. Heterogeneity of humic substances was found to play a crucial role in metal-DOC interactions and to control the trace metals competition for binding site on humic substances in freshwaters.

In addition, heterogeneity may be $\mathrm{pH}$ and ionic strength - dependent because of a different range of binding sites being available on humic substances at different $\mathrm{pHs}$ and ionic strengths. The apparent stability and lability of complexes determined by any given technique depend on the heterogeneity parameter $\Gamma$, the metal ion loading, the time-scale of the technique, and the water exchange rate for the metal ion. 